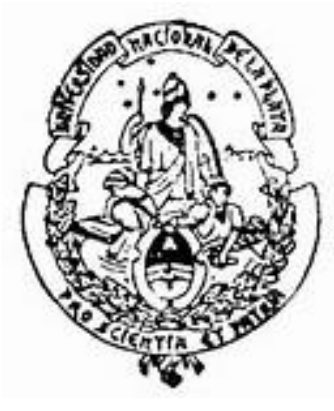

Facultad de Trabajo Social

Universidad Nacional de La Plata

Tesis de Maestría:

\title{
Hermosear y vigilar
}

Las Visitadoras de Higiene Social de la Universidad Nacional de La Plata en el proceso de institucionalización del Trabajo Social en la Argentina (1922 - 1948)

Alumna: Canela Constanza Gavrila

Director de tesis: Alfredo Carballeda

$12 / 07 / 2018$ 
Tribunal Docente:

Dr: Nestor Artiñano

Dra.: Paula Danel

Dra.: Daniela Testa 
La siguiente Tesis tiene por objetivo realizar un análisis histórico acerca del proceso de institucionalización del trabajo social durante la década de 1920 hasta fines de la década de 1940 en la ciudad de La Plata, atendiendo a la feminización como parte de la expansión de las actividades del Estado que al ampliar sus alcances requirió de mano de obra capacitada por las universidades que permitiera realizar una intervención económica mediante la conjugación de una serie de valores morales y científicos.

A través de la Escuela de Visitadoras de Higiene Social se sistematizaron y colocaron bajo el control de la mirada médica higienista una serie de prácticas e intervenciones que realizaban las mujeres para la sostenibilidad de la comunidad y de las familias, por lo cual esta tesis buscará establecer cartografías sobre las labores y espacios de atención social que realizaban las mujeres con antelación a la Escuela, para luego dar cuenta de las formas de articulación entre ordenanzas y planes de estudio desde la Universidad en sintonía con este abordaje. La riqueza de este proceso invita, entonces, al análisis de fuentes documentales de lo más variadas, como actas e informes de los espacios de atención social realizados por la sociedad de beneficencia y otras asociaciones, como así también los planes de estudio, ordenanzas y reformas curriculares, e incluso intercambios de cartas y publicaciones en revistas del ámbito de la medicina donde se exteriorizaron las pretensiones de los médicos por ordenar la atención sociosanitaria local y formar agentes dóciles.

El carácter feminizado de la profesión es entendido en la tesis como un espacio de negociación, disputa y resistencias respecto a la autoridad médica, del que emergen posibilidades de agenciamiento y renegociación de las jerarquías de género en el ámbito médico sanitario, como así también en el ordenamiento de sexo género de la primera mitad del siglo XX en Argentina. Por ello, otro grupo de fuentes documentales utilizadas serán las palabras de las visitadoras de higiene social, que a través de radioconferencias transcriptas e informes técnicos, dan cuenta de un conjunto de saberes y cuestionamientos a la profesión elaborados por ellas mismas.

Para este estudio me valdré de las herramientas de la historiografía de género y otras categorías feministas que permiten pensar las relaciones de poder establecidas en el ámbito sanitario y enriquecen el abordaje histórico, pero también posibilitan la crítica feminista respecto a cómo entender este importante periodo de la historia profesional, en una coyuntura particular para las féminas signada por una relación de inclusión / exclusión para sus posibilidades profesionales y políticas. 
The following thesis aims at developing a historical analysis about the process of institutionalization of social work during the 1920s until the end of the 1940s in the city of La Plata, focusing on the feminization as part of the expansion of the activities of the State which, by extending its scope, required skilled labor trained by the universities, allowing for economic intervention through the conjugation of a series of moral and scientific values.

Through the "Escuela de Visitadoras de Higiene Social" (In English, "School of Social Hygiene Workers"), a series of practices and interventions carried out by women for the sustainability of the community and families were systematized and placed under the control of the hygienist medical look. Therefore, this thesis will seek to establish cartographies on the tasks and spaces for social care performed by women prior to the School, and then to give an account of the forms of articulation between ordinances and plans of study from the University in tune with this approach. The richness of this process then prompts the analysis of varied documentary sources, such as records and reports of the spaces of social care carried out by the Benevolent Society and other associations, as well as the study plans, ordinances, and curricular reforms, and even exchanges of letters and publications in journals in the field of medicine, where the doctors' desires for ordering the local care and training docile agents were externalized. The feminized nature of the profession is understood in the thesis as a space for negotiation, dispute and resistance with respect to the medical authority, emerging possibilities of negotiation and renegotiation of gender hierarchies in the health care field, as well as in the management of gender sex in the first half of the 20th century in Argentina. For this reason, another group of documentary sources used will be the words of social hygiene workers who, through transcribed radio conferences and technical reports, account for a body of knowledge and questioning to the profession developed by themselves.

For this study, I will rely upon the tools of the historiography of gender and other feminist categories allowing me to reflect on the power relations established in the health field and to enrich the historical approach; but they also enable the feminist criticism regarding how to understand this important period of the professional history, in a particular situation for females marked by a relationship of inclusion/exclusion for their professional and political possibilities. 
Résumé

La Thèse suivante a pour objectif la réalisation d'une analyse historique concernant le processus d'institutionnalisation du travail social de la décennie de 1920à la fin de la décennie de 1940 à la ville de La Plata, visant la féminisation comme partie de l'expansion des activités de l'État qui, ayant élargi sa portée, a eu besoin d'une main d'œuvre capacitée par les universités permettant d'effectuer une intervention économique par le biais d'un ensemble de valeurs morales et scientifiques.

Par l'intermédiaire de l'École de Visiteuses d'Hygiène Sociale (Escuela de Visitadoras de Higiene Social en espagnol), une série de pratiques et d'interventions réalisées par les femmes visant la durabilité de la communauté et des familles ont été systématisées et placées sous le contrôle du regard médical hygiéniste. Pour cette raison, laprésentethèsecherchera à établir des cartographies sur les travaux et les espaces d'attention sociale produits par les femmes avant l'existence de l'École, pour rendre compte ensuite des formes d'articulation entre arrêtés et plans d'études de l'Université conformes à cette approche. La richesse de ce processus invite donc à l'analyse de sources documentaires très variées, comme des comptes rendus et des rapports des espaces d'attention sociale réalisés par l'association caritative et d'autres associations, ainsi que les plans d'études, arrêtés et réformes des programmes, mais également des échanges de lettres et des publications dans des revues du domaine de la médecine exposant les prétentions des médecins d'ordonner l'attention socio-sanitaire locale et former des agents dociles.

Le caractère féminisé de la profession est compris dans cette thèse comme un espace de négociation, dispute et résistances par rapport à l'autorité médicale, permettant l'émergence des possibilités d'agencement et de renégociation des hiérarchies de genre dans le domaine médical et sanitaire, ainsi que dans l'ordre du sexe genre de la première moitié du $\mathrm{XX}^{\mathrm{ème}}$ siècle en Argentine. Dès lors, un autre groupe de sources documentaires sera constitué par les paroles des visiteuses d'hygiène sociale qui, par le moyen de radio-conférences transcrites et des rapports techniques, rendent compte d'un ensemble de savoirs et questionnements sur la profession élaborés par elles-mêmes.

Pour cette étude, je m'appuierai sur les outils de l'historiographie de genre et autres catégories féministes qui permettent de concevoir les rapports de pouvoir établis au sein du domaine médical et enrichissent l'approche historique, mais qui rendent également possible la critique féministe sur la manière de comprendre cette importante période de l'histoire professionnelle, dans une conjoncture particulière pour les femmes,marquée par un rapport d'inclusion/exclusion quant à leurs possibilités professionnelles et politiques. 
a las que no se conforman

a las que luchan

a las que fugan

a las que construyen otros destinos 
Índice

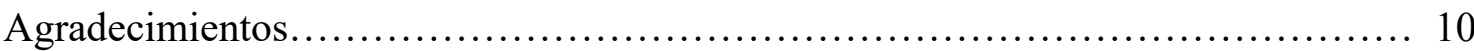

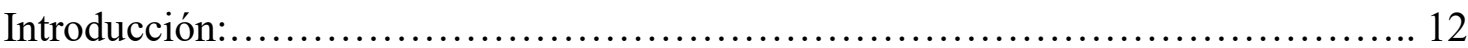

1. ¿De qué hablamos cuando decimos feminización?................................................... 14

2. Acerca de las miradas para el abordaje documental: Historia intelectual y feminismos................................................................. 19

3.1922- 1948: una temporalidad fértil para el estudio de la EVHS ...................25

4. ¿Por qué una docente en historia se desvela por las visitadoras de higiene y qué palabras la han despabilado?

PARTE I: Las Visitadoras de la Universidad. La configuración de la profesión a partir de las Escuelas de Visitadoras de Higiene Social. UBA- UNLP 1922- 1938

Capítulo 1: Antecedentes del Trabajo Social. La Escuela para Visitadoras de Higiene Social de la Universidad Nacional de Buenos Aires............................. 37

1.1. Abordar la cuestión social............................................... 37

1.1.1. Las mujeres en la cuestión social..................................... 42

1.2. La formación de las agentes para la intervención ........................44

1.2.1. El Instituto de Higiene UBA..........................................45

1.2.2. La Escuela para Visitadoras de Higiene Social UBA.........................46

1.2.3. La Escuela de Servicio Social del Museo Social Argentino....................49

1.3. La educación popular entre Buenos Aires y La Plata. La figura de Pilades

Dezeo para el desarrollo de la EVHS UNLP.............................52

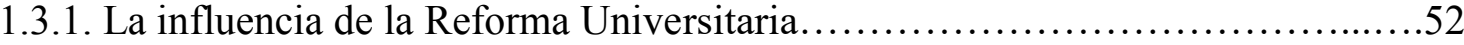

1.3.2. De artista plástico a médico higienista.....................................54

Capítulo 2: La Escuela para Visitadoras de Higiene UNLP. 1920- 1938 60

2.1. La ciudad higiénica y el ordenamiento de los cuerpos.......................61

2.1.1. Damas, señoras y visitadoras..........................................64

2.1.2 Médicos, burócratas, visitadoras y personal innominado.................... 70 
2.2. La crisis del treinta y el aumento de la demanda de atención en la asistencia social .73

2.2.1. La Conferencia Nacional de Asistencia Social ................................ 78

2.3. La ciencia en la ciudad higiénica. La Universidad Nacional de La Plata y su

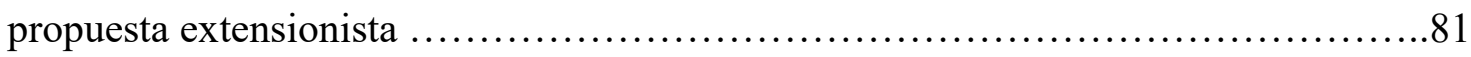

2.3.1. Los estudiantes de la Escuela Preparatoria de Medicina y la Reforma

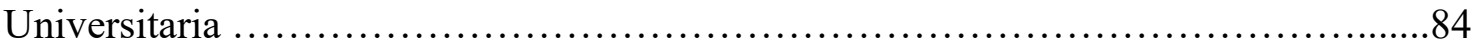

2.4. La Creación de la Escuela para Visitadoras de Higiene Social de la UNLP........88

PARTE II: Mujeres, Economía del cuidado y formación profesional. Entre deseos de libertad y posibilidades restringidas 1937-1948

Capítulo 3: Apuntes para comprender la construcción de una profesión feminizada....94

3.1. Feminización y profesionalización. .95

3.2. Mujeres y trabajos .98

3.2.1. El mercado de trabajo en la primera mitad del siglo XX.... 101

3.2.2. Las universitarias y las profesiones sociosanitarias 104

3.3. Entre ciencia, moral y género: planes de estudio y ordenanzas disciplinares......110

3.3.1. El currículo visible: Saberes del cuerpo, el hogar y la maternidad.

3.3.2. Formación profesional específica. .113

3.3.3. La reforma curricular de 1948 y la formación de profesionales polivalentes....123

3.4. El currículo oculto de la EVHS. 133

PARTE III: Las visitadoras de higiene social: entre el conservadurismo de la teoría y el reformismo de la práctica

Capítulo 4: Acciones de solidaridad, complicidad y agenciamiento. 136

4.1. El paisaje sonoro local. 138

4.1.1. Voces femeninas en el paisaje sonoro. .141

4.2. La persuasión del público como estrategia de intervención. 145

4.3. Interrupciones al discurso higienista: entre consejos domésticos e interpelaciones públicas. 152 
4.4. Entre tareas moralizadoras y reivindicaciones de demandas colectivas. La experiencia del Club de Madres................................................. 161

4.5. Acciones de agenciamiento y experiencias profesionales: persuasión, solidaridad y complicidad.

Conclusiones

173

Bibliografía.

178 


\section{Agradecimientos}

Esta tesis fue posible por el financiamiento de la Secretaria de Ciencia y Técnica de la Universidad Nacional de La Plata que me otorgó las becas tipo a y tipo b de investigación, localizando su lugar de ejecución en el Centro de Investigaciones en Trabajo Social y Sociedad de la Facultad de Trabajo Social. Agradezco a las autoridades de esta casa de altos estudios por la confianza en hacerme partícipe de su proyecto académico profesional. Esta tesis no podría haberse iniciado sin la confianza, el aliento e infinito espíritu de compañerismo del Dr. Alfredo Carballeda, quien aceptó gentilmente ser mi director durante este proceso y con quien mantuve interesantes intercambios para avanzar en la investigación.

También agradezco a las compañeras y colegas que han sido cómplices en este camino, en principio a Karina Ramacciotti por su dedicación y militancia silenciosa para hacer de los espacios de producción del conocimiento científico momentos de intercambio y aprendizaje, sobre todo por practicar la sororidad con compañeras que nos estamos iniciando, acciones ejemplares de las que deberían poblarse las universidades. También agradezco a Daniela Testa por su atención y escucha respecto al trabajo de investigación y escritura. A Ana Laura Martín por sus aportes y preguntas, por acercarme a bibliografía indispensable para entender el rol radiofónico de las visitadoras. Además, agradezco los comentarios y aportes realizados en distintos espacios de debate y exposición realizados por Carolina Biernat y Graciela Queirolo. Agradezco a todas ellas por compartir sus saberes y experiencias, y en especial por su pasión e interés en construir una historia de las mujeres en diálogo con el mundo del trabajo y la historia social de la salud y la enfermedad.

No hubiera sido posible este proceso de escritura sin mis amigas y colegas, las profesoras Inés Aprea, Yamila Balbuena, Astrid Bauman, Carla Cimino, Soledad Escudero, Rosana Gazaniga, Paula Satta y Feli Venero, por sus miradas, debates y aportes en la construcción de la historia y del conocimiento feminista. Agradezco infinitamente las lecturas, las correcciones y audaces comentarios de valeria flores. Una especial mención ameritan las bibliotecarias con quienes tuve la suerte de encontrarme en el largo camino de pesquisa. En principio, a las compañeras de la Biblioteca y archivo histórico de la Facultad de Trabajo Social, Gisela Venier y Mariana Ferrante, que me han facilitado materiales y con quienes compartimos el interés por nuevas búsquedas. También agradecer a Patricia Lischinski de la biblioteca Francisco Romero Delgado de la Universidad Popular Alejandro Korn, quien me ha permitido 
trabajar con depósitos aun no catalogados y por la gran contribución para encontrar otros documentos de la institución desperdigados por la ciudad, e incluso por su colaboración para el acercamiento a materiales de la Hemeroteca de la Biblioteca Pública de la Universidad Nacional de La Plata, donde también se desempeña como bibliotecaria. Vaya a su vez esta gratitud para las autoridades del Colegio Liceo Víctor Mercante de la UNLP y del Archivo Histórico de la UNLP que colaboraron en la búsqueda y el encuentro de documentos útiles. A todas ellas mi gratitud por ser partícipes estratégicas en la ardua tarea de desmontar archivos estructurados desde criterios androcéntricos.

A la maestría de Trabajo Social por su calidez y nivel académico, especialmente a las profesoras Alejandra Corbalán por compartir su creatividad metodológica y afectividad, también a Susana Cazzaniga por alentarme desde el primer momento y por confiar en la línea de investigación propuesta, de igual modo por compartir amorosamente información sobre el periodo estudiado.

No pueden faltar en estos agradecimientos mi abuela Irma, quien con sus historias de lucha y de organización en Berisso me mostró que podemos ser lo que anhelamos y con ello me alentó a pelear por mis deseos. A mi madre, por su trabajo cotidiano e insistencia en que nunca deje de hacer cosas que me hagan feliz, y por su atención y ayuda para que pudiera seguir mis estudios. A mis hermanas Rocío y Ayelén por ser compañeras de rutas, debates y abrazos.

Por las preguntas inquietantes y los cuestionamientos más íntimos de la escritura, por el amor y los cuidados a Paloma.

Y sobre todo, agradezco a quienes luchan cotidianamente por seguir sosteniendo la gratuidad y autonomía de la educación superior y universitaria. 
El Trabajo Social se caracteriza por ser una profesión que opera sobre las consecuencias sociales e ideológicas de los desajustes producidos en el mundo del trabajo a partir del crecimiento y transformación de las relaciones sociales de producción capitalista. El acceso a la vivienda, a la salud, la falta de trabajo, y sobre todo la incapacidad por parte de la sociedad de garantizar su reproducción social, fueron problemáticas que configuraron la cuestión social (Suriano, 2002). Los "desacoplados" al nuevo ritmo no solo fueron los obreros hombres, los desvalidos y niños; las mujeres y, en particular, las madres de los sectores populares y trabajadores, se volvieron una preocupación para los gobernantes en tanto de ellas dependía el futuro de la raza (Lobato, 2007; Biernat y Ramacciotti, 2013).

Desde fines del siglo XIX, el Estado y sus instituciones delinearon distintas estrategias para intervenir sobre la cuestión social, sobre todo a través de las sociedades de beneficencia, organizaciones de filantropía y otras vinculadas al catolicismo, para las cuales convocaron a las mujeres a participar en la intervención sobre las carencias de los sectores desamparados (Grau, 1954; Grassi, 1989; Oliva, 2007). Sin embargo, a partir de la década de 1920, con las exigencias sostenidas para el abordaje sobre la cuestión social, el temor por la expansión de diversas epidemias y las crecientes demandas obreras por garantizar mejores condiciones de vida, médicos vinculados al higienismo impulsaron la creación de soluciones organizadas y difundidas desde las Universidades nacionales. En principio, en 1924 desde la cátedra de Higiene Médica y Preventiva de la Facultad de Ciencias Médicas de la Universidad Nacional de Buenos Aires (UBA) y, luego, en 1938 su homónima platense, la Universidad Nacional de La Plata, seguirá el proyecto aunque con una serie de modificaciones. ${ }^{1}$

Las Escuelas para Visitadoras de Higiene Social (Buenos Aires 1924-La Plata 1938) constituyeron el primer antecedente universitario de la actual carrera de Trabajo Social (Alayón 1978; Carballeda 2006; Grassi 1987; Oliva 2007, Parra 1999; Rozas Pagaza 2001). Estas instituciones tuvieron a su cargo nuclear, ordenar y difundir los saberes y las prácticas de orden médico y social que se encontraban dispersos entre distintas

\footnotetext{
${ }^{1} \mathrm{Si}$ bien las inspecciones y visitas formaban parte de la intervención higienista sobre la vida cotidiana de los sectores populares, incluso desde distintas entidades como la Asistencia Pública de la Capital, la Liga Argentina contra la Tuberculosis y la Liga Popular contra la Tuberculosis de la Provincia de Buenos Aires y, desde 1927, también el Cuerpo Médico Escolar de la Provincia de Buenos Aires dio inicio al curso de Visitadora de Higiene Escolar, aquí repararemos exclusivamente en la formación universitaria de estas nuevas profesionales.
} 
instituciones abocadas a atender parte de las necesidades básicas para la reproducción social, tales como la Asistencia Pública y la Sociedad de Beneficencia. La UNLP, desde la Escuela para Visitadoras de Higiene Social (EVHS) intentó, de algún modo, reparar el déficit profesional de agentes auxiliares de la medicina preventiva requeridos por el Estado, a través de la formación universitaria para mujeres. Si bien en sus inicios mantuvo una relación de dependencia y de carácter auxiliar a la ciencia médica, con el paso del tiempo se produjo un acercamiento a las ciencias sociales que favoreció la autonomía disciplinar, la creación de escuelas y de facultades de Trabajo Social.

La Escuela buscó normalizar modalidades de intervención en la cuestión social bajo el control de la mirada higienista. Los vínculos entre higienismo y cuestión social se establecieron desde fines del siglo XIX, en principio fueron de carácter paliativo de las instalaciones urbanas (Recalde, 1988; Carballeda, 2006), aunque cobraron otro carácter entrado el siglo XX, momento en que el discurso médico científico se ligó íntimamente a la planificación de políticas sociales, y con ello a la creación de redes entre instituciones de asistencia, prevención y moralización (Armus, 2000). No obstante, la Escuela para Visitadoras de Higiene Social mantuvo como elemento común con las modalidades de intervención que la antecedieron, la convocatoria exclusiva a las mujeres para el desarrollo de estas actividades. Ese carácter feminizado de la profesión se mantiene hasta la actualidad, a pesar que la convocatoria se ha abierto también a varones. El hecho de que sean mujeres quienes son requeridas para la formación en el desarrollo de multiplicidad de funciones para la asistencia, educación, vigilancia y conservación individual y colectiva, sugiere razones políticas, económicas y sociales que son necesarias cuestionar y develar para avanzar en los sentidos críticos del quehacer profesional.

Mediante la construcción de una cartografía del espacio intelectual y profesional en que tuvo lugar la formación e intervención de las visitadoras de higiene podemos acercarnos a la resolución de estos interrogantes. Por eso mismo, esta tesis busca abordar desde la historia intelectual y la crítica feminista, las articulaciones entre los fundamentos teóricos políticos de la profesión, establecidos durante el primer período de la carrera por los médicos higienistas a cargo de la Escuela para Visitadoras de Higiene Social de la UNLP, y los procesos de feminización profesional durante el período de 1920 a 1948. El carácter amoroso, altruista, bondadoso y de entrega absoluta con el que fueron convocadas las primeras estudiantes (Dezeo, 1938) se validó en la asociación histórica que vincula a las mujeres con las tareas de caridad y beneficencia. Los trabajos de cuidar, educar, vigilar y asistir, son tareas que se asignaban a las visitadoras de higiene 
social y que formaban parte de ocupaciones que se han construido de manera exclusiva para el género femenino, al cual se intentaba convencer de la nobleza de semejantes tareas puesto que permitiría "hermosear la propia existencia" (Dezeo, 1938). De tal modo, la formación profesional de las visitadoras de higiene se presentaba como una extensión de las actividades que desarrollaban en el ámbito doméstico hacia el espacio público, de mayor contacto con la comunidad, y también como condición para la realización personal. Los conocimientos en que se instruía a las visitadoras formaban parte de un circuito de experiencias compartidas entre mujeres respecto del cuidado y la crianza, la economía doméstica, la proyección del presupuesto familiar, la asistencia, entre otros saberes, y se difundían para la reproducción de la familia y la comunidad, pero desde el fortalecimiento de la ciencia médica pasan a estar bajo su dominio (Ehreich y English, 1973).

En su función pedagogizante sobre los sectores populares, las visitadoras de higiene social apuntaron a la modificación de costumbres, a la corrección de hábitos y también a reproducir subrepticiamente normativas hegemónicas en relación a su género, desde una labor de carácter ideológico que garantizara el disciplinamiento social (Karsz, 2007).

1.¿De qué hablamos cuando decimos feminización?

La feminización es un término que designa el proceso de atribución de una serie de trabajos útiles a la reproducción de la vida -individual y colectiva - de manera exclusiva para las mujeres ${ }^{2}$, lo que permite abaratar los costos de reproducción del capital, puesto que con este trabajo se garantiza el orden y la sostenibilidad cotidiana dentro de los márgenes del "hogar" y, junto con ello, se exime de pagar por los cuidados de la población a través de la apropiación del trabajo de las féminas.

El hecho de que sean mujeres quienes se encargan de las acciones de reproducción social e ideológica es parte de la división sexual del trabajo que tradicionalmente asigna el espacio de la esfera productiva/pública a los hombres y de la esfera reproductiva/privada a las mujeres, supuesto que justifica su convocatoria para las tareas de reproducción del núcleo doméstico. Carol Pateman (1995) sostiene que la

\footnotetext{
${ }^{2}$ En esta tesis haremos alusión a la feminización de las mujeres de manera exclusiva, sin hacer de ambas palabras sinónimos. No abordaremos en esta exposición a otros cuerpos que también se encuentran sometidos a procesos de feminización y que no necesariamente se identifican con la categoría mujeres, nos referimos a maricas, trans, travestis y lesbianas. En este sentido, el lenguaje usado a lo largo del texto emplea el femenino y masculino para promover el uso de lenguaje no sexista y evitar el androcentrismo, aun entendiendo el binarismo que ello implica, pero es menester atender aquí a la producción de la diferencia sexual en el mismo proceso de academización e institucionalización de la carrera de las visitadoras de higiene.
} 
división en estas esferas es la síntesis del pacto social de la Revolución Francesa donde el pacto sexual fue invisibilizado. Éste refleja un derecho patriarcal o sexual del poder de los hombres sobre las mujeres, representando un pacto dual. El contrato social expresa la historia de la libertad y el contrato sexual la historia de la sujeción, puesto que el contrato original se constituye con ambos elementos. Es a través de este mecanismo político que el patriarcado moderno se constituye, legalizando las diferencias y la forma de ambas esferas: la pública, de orden, libertad civil y política, y la privada, considerada como poco relevante para la vida política del conjunto social.

Para garantizar la división sexual del trabajo de manera cotidiana y habitual, la ideología de la diferencia sexual instituye el régimen de la heterosexualidad obligatoria que construye como norma legal y científica a la familia hetero patriarcal, lo que favorece el establecimiento de jerarquías entre los sexos a partir de la apropiación de la fuerza productiva y creativa de las mujeres para el desarrollo del núcleo doméstico (Guillaumin, 1978; Wittig, 1992; Tabet, 1998). En esta dinámica se construye el pensamiento hetero y se fundan los roles de sexo (hombre y mujer) que actúan acordes a las necesidades exigidas para la reproducción de la especie y de la heterosexualidad en tanto régimen de dominación (Wittig, 1992). Este entramado exige la sujeción a las normas prescriptas a cada uno de los sexos-géneros, que deben ser aprendidas, difundidas y, sobre todo, efectuadas.

En este sentido, la invisibilidad de la apropiación del trabajo de las mujeres opera favorablemente sobre la base de la ideología de la diferencia sexual a través de distintos elementos, entre ellos, la censura que oculta la diferencia binaria, contradictoria y de poder que existe en el plano social entre hombres y mujeres, justificándola a través de la naturaleza (Wittig, 1992). Esta operación de naturalización y la imposibilidad de reconocer las acciones para la reproducción del núcleo doméstico como trabajo, permiten la apropiación del trabajo de las mujeres de un modo infravalorado, precarizado e invisibilizado. ${ }^{3}$

Al interior del ámbito doméstico las mujeres desarrollan multiplicidad de tareas: la asistencia, el cuidado, la protección, la educación, la difusión de saberes y valores morales asignados en la cultura, el control, el manejo de la economía doméstica, la alimentación, la lactancia, la higiene corporal, la higiene del vestido, el equilibrio del

\footnotetext{
${ }^{3}$ Para mayores referencias acerca de las características del trabajo flexibilizado de las mujeres, se sugieren las lecturas de Colectivo Precarias a la Deriva (2004) A la deriva por los circuitos de la precariedad femenina. Traficantes de Sueños, Madrid; y Federici, Silvia (2013) Revolución en punto cero. Trabajo Doméstico, reproducción y luchas feministas. Traficantes de Sueños, Madrid.
} 
presupuesto familiar, la comunicación afectiva, la producción de bienestar, entre otras acciones. ${ }^{4}$ Todas estas tareas son feminizadas en tanto se consideran exclusivas del orden femenino, y en contraposición con las acciones del mundo masculino, "no merecerían" mayor atención puesto que no generarían bienes intercambiables en el mercado y, por lo tanto, resultan incapaces de alcanzar el estatus de trabajo, por lo que pueden desarrollarse en condiciones de máxima precariedad y polivalencia. Tal como sostienen Federici y Cox (1971), el hecho de que estas tareas no sean intercambiables por un salario favoreció -y favorece- el desprestigio de la actividad, como también la falta de organización y proyección política de quienes la ejercen, elementos que propician la no organización de las féminas y desarticulan las potencialidades de lucha. Además de este efecto político, los argumentos que no reconocen estas labores como un trabajo vinculado a la producción de valor en el mercado resultan una falacia, puesto que mediante estas actividades se reproduce la fuerza de trabajo en términos ideológicos y biológicos, y se favorece la sostenibilidad de la vida de quienes participan del mercado de trabajo gracias a los servicios físicos, emocionales y sexuales que garantizan las mujeres en la familia y la comunidad (p. 51).

Por ello, si bien la división sexual del trabajo establece espacios y tareas diferenciales para hombres y mujeres, las fronteras que separan lo público de lo privado, lo doméstico de lo productivo, son permeables y porosas a los intercambios entre sí, aunque para mantener su estabilidad reproduzcan las marcas de género. Así, la posición de las mujeres en el trabajo se debe comprender como parte de las relaciones contradictorias y dinámicas en que se inscriben el capitalismo, el patriarcado (Kergoat, 1997, p. 19) y el régimen de la heterosexualidad.

En relación con el mercado laboral, la feminización se puede entender como un fenómeno producido por la confluencia de una mayor autonomía de las mujeres y la avanzada en derechos, junto con etapas particulares del capitalismo que hacen más precarias las condiciones laborales a través de justificativos ideológicos y económicos (Hirata y Kergoat, 1997).

Desde fines del siglo XIX y sobre todo desde comienzos del siglo XX, las mujeres fueron convocadas para el desarrollo de las áreas auxiliares de la medicina, como la enfermería, las visitas de higiene, la obstetricia y la puericultura, que pretendieron alejar a las féminas del monopolio masculino de los saberes médicos y vincularlas con

\footnotetext{
${ }^{4}$ Parte de estas acciones son identificadas por el Colectivo Precarias a la Deriva.
} 
actividades ligadas al cuidado y a la relación con otras mujeres. ${ }^{5}$ La posibilidad de que las mujeres se inclinaran hacia estas nuevas ocupaciones era posible en un contexto de avanzada de las luchas feministas por la adquisición de derechos políticos y jurídicos, como por ejemplo la ley $\mathrm{N}^{\mathrm{o}} 11.357$, normativa que removió la inferioridad consagrada por el ordenamiento civil para las féminas, esto significó una reforma a las exigencias más escandalosas de la unión heterosexual, entre ellas, el pedido de autorización de la mujer al hombre para poder estudiar, para profesionalizarse, comerciar, testimoniar o pleitar; la mujer también podía administrar los bienes que poseía previo al contrato matrimonial, pero si deseaba vender o comprar sus propiedades necesitaba autorización del hombre y, a pesar de cumplir con las tareas para el sostenimiento cotidiano del grupo familiar, no era reconocida la patria potestad sobre los y las hijas, por lo cual estas modificaciones se mantuvieron fieles al dictado patriarcal, reconociendo $\mathrm{y}$ legitimando el papel del varón productor y proveedor (Barrancos, 2007, p.139).

Particularmente, en el período que aborda esta tesis, desde el año 1922 a 1948, se desarrollaron múltiples estrategias desde el Estado que intentaron cooptar a las mujeres dentro de la "ideología de la domesticidad", es decir, un complejo entramado de discursos médicos, morales, científicos, y políticos que pretendían naturalizar la división sexual del trabajo, legitimando la separación entre el hogar y el trabajo, de modo que resultara eficiente a los fines de la acumulación capitalista (Scott, 2000, p. 429- 431). A su vez, la "ideología maternalista" intentó a través de la medicina la progresiva identificación entre mujer $\mathrm{y}$ madre, al igual que entre feminidad $\mathrm{y}$ maternidad (Nari, 2004). Así, la ciencia médica se construyó como uno de los soportes fundamentales del sistema patriarcal a través de la biología y diversas especialidades médicas como la sexología, la ginecología y la endocrinología, que legitimaron modelos sexuales y genéricos de varones y mujeres (Ledesma Prietto, 2016, p.51). La preocupación por mantener el binarismo de género fue puesto en evidencia por el establecimiento de comportamientos legitimados en función de una construcción anatómica binaria que definen ciertos rasgos como masculinos y otros como femeninos, hecho que produjo - produce- la exclusión de otras corporalidades, identidades sexuales y performances de género que exceden la "normalidad" de masculino-hombre/ femenino-mujer (Ben, 2000).

\footnotetext{
${ }^{5}$ Nari, Marcela (2004) Políticas de Maternidad y Maternalismo Politico, Biblos, Buenos Aires, pp. 101121; Martin, Ana Laura (2015) "Mujeres y enfermería. Un asociación temprana y estable, 1886-1940" en Biernat, Carolina, Cerdá, Juan Manuel, Ramacciotti, Karina (directores) La salud pública y la enfermería en Argentina, Universidad Nacional de Quilmes, Bernal, 2015, pp. 257-258.
} 
La medicina se encargó de producir discursos para definir, normalizar y patologizar a las sexualidades a través de la construcción de la heterosexualidad como norma (Salessi, 1995; Ben, 2000; Ramacciotti y Valobra, 2008). Sin embargo, no podemos considerar a los médicos como un cuerpo profesional homogéneo, ya que en su interior existieron negociaciones y diferencias, e incluso médicos ácratas que disputaron otros sentidos respecto a las experiencias de la sexualidad y la procreación (Ledesma Prietto, 2016).

Es preciso mantener las sospechas sobre el carácter subyugado de la profesión a la ciencia médica a través de estudios históricos que permitan cuestionar cómo mediante la voluntad de disciplinamiento de los sectores populares y de propagación de la ideología maternalista, el cuerpo de docentes de la EVHS legitimó una voluntad política y profesional por feminizar la nueva profesión. Sus funciones serán presentadas como parte de acciones de intervención desinteresada, natural y "amable" de las mujeres, que no disputan el status científico de los médicos hombres a cargo de la formación profesional, aceptan el rol auxiliar de la profesión y facilitan mediante su intervención el abaratamiento de los costos de reproducción social, haciendo extensible las prácticas del ámbito privado al ámbito público. Claro que destacar que la profesión ha sido feminizada puede resultar poco original puesto que generalmente se lee este hecho a partir de la elevada matrícula de mujeres en la profesión. No obstante, decir y estudiar las razones del porqué es una profesión feminizada pretende dar carnadura, nombre, acto y visibilidad a los intentos normalizadores por sujetar a las mujeres dentro de las relaciones heterocapitalistas; además de ser un interés compartido con las compañeras feministas por visibilizar y cuestionar el trabajo de las mujeres para la sostenibilidad de la vida. ${ }^{6}$

El interés por feminizar las prácticas y conocimientos promovidos en la formación de las primeras profesionales de la EVHS también pretendió trasladarse y proyectarse sobre las mujeres con quienes trabajaron. Es importante recordar que en el período de 1890 a 1940, las prácticas políticas de los médicos construyeron, tal como hemos dicho, un ideal de madre higiénica, amorosa y virginal que, presentado como universal, ahistórico y "natural”, reformuló la idea de mujer e intentó reducirla a la condición de madre (Nari, 2004). Con el fin de facilitar la sujeción de las mujeres, las visitadoras no solo debían "extender" los conocimientos universitarios sobre los sectores populares, sino también ostentar una debida "ejecutoria moral"7 que de alguna manera encarnara

\footnotetext{
${ }^{6}$ Vale destacar en este camino las obras realizadas por compañeras feministas como Florencia Partenio, Corina Rodríguez, Amaia Pérez Orozco, el colectivo anarquista "Precarias a la deriva" y, particularmente, en temas y estudios socio históricos, a Paula Lucia Aguilar.

${ }^{7}$ El Dr. Orestes Adorni, decano de la Facultad de Ciencias Médicas de UNLP, en una carta al Dr. Pilades
} 
el ideal del género femenino, trazando una matriz de ordenamiento e imitación de sus congéneres.

Las funciones de ejemplaridad que debían dar las visitadoras desde su inserción en la cotidianeidad familiar es parte de un proceso de feminización superior, no sólo profesional, en el que las mujeres eran instruidas desde la ideología de la domesticidad y la ideología de la maternidad. En este sentido, podríamos sugerir que la profesión no solo fue feminizada sino que también se sumó a un proceso de feminización y maternalizacion que se hacía desde el Estado sobre las mujeres con quienes trabajaban a través de las acciones educativas, de control y de vigilancia. Las visitadoras intentaron modificar costumbres y hábitos que facilitaran el desarrollo de las tareas domésticas de las mujeres para el bienestar de la comunidad.

Puesto que el espíritu feminista inscripto en el cuestionamiento al conocimiento androcéntrico anima esta investigación, no podría limitar el proceso de feminización a la voluntad de los médicos varones a cargo de la formación profesional y suponer con ello que sus acciones no tuvieron actos de resistencia y contestación. Por ello, me interesa en esta tesis dar cuenta de las sofisticadas e impredecibles redes de poder que hicieron de la asistencia social una profesión feminizada y feminizante donde no faltaron experiencias disruptivas al discurso disciplinante que aun exigen ser analizadas para complejizar las miradas de la profesión y de la historia de las mujeres en el proceso de institucionalización del Trabajo Social.

2. Acerca de las miradas para el abordaje documental: Historia intelectual y feminismos

"Pues mientras las oposiciones (las diferencias) sigan pareciendo datos, algo que ya está ahí, 'naturales', precediendo a cualquier pensamiento - sin conflicto ni lucha- no habrá dialéctica, ni cambio, ni movimiento. El pensamiento dominante se niega a analizarse a sí mismo para comprender aquello que lo pone en cuestión" Monique Wittig El pensamiento heterosexual y otros ensayos 
Son muchas las dudas e interrogantes que genera el estudio del momento inicial de la profesión en la ciudad de La Plata, sobre todo frente al precario y desarticulado archivo con que nos topamos quienes iniciamos la búsqueda de materiales referentes a la EVHS. Particularmente, considero relevante establecer una cartografía del espacio profesional e intelectual donde se iniciaron las primeras prácticas universitarias del quehacer profesional, mediante preguntas que busquen indagar con qué sectores sociales trabajaban las primeras visitadoras de higiene egresadas de la UNLP, qué tareas realizaban, en qué lugares se insertaron profesionalmente, quiénes eran ellas, en qué conocimientos fueron formadas, qué grupos de médicos y docentes fueron los encargados de idear la proyección de la EVHS, con qué sectores políticos se vincularon, y si esas vinculaciones políticas sugieren proyectos alternativos de sociedad. Además de organizar esta información de notable importancia, es interés de esta tesis poder acercarnos a la resolución de interrogantes que, a mi entender, son estructurantes de la profesión, a saber ¿qué elementos del proceso de institucionalización profesional se mantienen como un sustrato inicial para justificar la actual precariedad de las condiciones de trabajo en el campo de la intervención y en la investigación? Y sobre todo ¿cuál fue el alcance de la feminización profesional no solo para las mujeres visitadoras, sino también para las mujeres con quienes trabajaron? Es decir, cómo la construcción de la feminización se tradujo en las intervenciones profesionales y en el contacto con otras mujeres, madres u obreras. ¿Qué pretensiones económicas, ideológicas y políticas tenían los médicos a cargo de la profesión sobre las mujeres usuarias de los servicios asistenciales en que intervenían las visitadoras? ¿Qué discursos generaron las visitadoras? ¿Qué tensiones y acuerdos había entre ambas discursividades? ¿Qué elementos resultaron de la articulación entre las normativas de género sobre las profesionales y las acciones realizadas por ellas?

En estos primeros interrogantes se mantiene latente la pregunta acerca de cuáles son los elementos del proceso de institucionalización y feminización que podrían explicar por qué gran cantidad de mujeres instrumentan el trabajo social y no se ocupan con la misma intensidad del análisis de la práctica profesional, asimismo, por qué a pesar de ser una profesión que admite una matrícula sin distinciones de género siguen siendo las mujeres y las lesbianas quienes mayormente participan, e incluso reflexionar acerca de qué sucede con los hombres que ejecutan el trabajo social, qué masculinidades operan, qué diferencias y jerarquías se expresan, quiénes producen teoría, entre otras. Estos interrogantes son parte del problema que implica el mutismo -pero la sordina también- 
acerca del aporte teórico de las profesionales y la carencia de cuestionamientos sobre la práctica intelectual que realizan las y los agentes del servicio social.

El discurso de los médicos varones tuvo un peso gravitante a favor de la sujeción de las mujeres, por ello debemos tomar una serie de reparos metodológicos que nos posibiliten ver en las fuentes los intentos por disciplinar las acciones de las visitadoras y de las mujeres de los sectores trabajadores y populares, sin perder de vista los actos de resistencia y oposición a los deberes esperados de estas profesionales. Es en esta tensión entre las expectativas configuradas por los médicos a cargo de la disciplina, junto con la reapropiación y resistencias desde las visitadoras, que podemos delinear otros relatos acerca de las protoformas del Trabajo Social que trascienda el carácter moralizante y conservador con el que se considera a las profesionales durante este período (Parra, 2007).

Con el objetivo de identificar a las visitadoras en un entramado de relaciones sociales que cuestione la condición subalterna frente a los médicos, incluyéndolas como parte de proyectos políticos colectivos y profesionales, realizaremos un abordaje desde la historia intelectual con el objetivo de identificar la producción intelectual de los médicos docentes a cargo de la formación profesional, como así también de las prácticas intelectuales que las visitadoras delinearon en el desarrollo de sus tareas profesionales. Con esto último nos referimos a los informes, disertaciones, cuadros de observaciones, entre otros documentos, en los cuales las visitadoras establecieron referencias teóricas acerca de la intervención profesional.

El discurso médico, constituido por una voluntad de verdad sobre la intervención social, ha dado un soporte institucional y de distribución del conocimiento que ejerció un poder de coacción sobre otros discursos, del cual se deriva el sentido político de tales enunciados y el interés por anular otros sentidos (Foucault, 2008 [1969]). Por ello, nos proponemos realizar un abordaje arqueológico que trascienda el carácter superficial de los enunciados e indague sobre las condiciones de posibilidad para la emergencia de ciertos temas, objetos, preocupaciones, problemas y conceptos sobre los que se construyó el carácter feminizado de la profesión. Este modo de construcción del archivo inició su recorrido a partir de hurgar sobre los vestigios institucionales y los depósitos olvidados, y resulta, al menos momentáneamente, la única estrategia viable para materializar el deseo de destacar y privilegiar las opacidades e irrupciones al discurso médico dominante. ${ }^{8}$

\footnotetext{
${ }^{8}$ Parte de estas reflexiones fueron relatadas en el artículo "Para una arqueología del Trabajo Social. Reflexiones sobre la construcción del archivo de las Visitadoras de Higiene Social en la Universidad
} 
El trabajo de archivo reúne distintos artefactos como: disertaciones radiales realizadas por las visitadoras de higiene, correspondencia interna entre las instituciones a cargo de la formación profesional, recortes periodísticos y fotografías, informes de trabajo, balances anuales de las instituciones en que participaron, entre otros, todos útiles para desmontar sentidos anquilosados del trabajo femenino en la profesión y para cuestionar los acontecimientos destacables y monolíticos de la formación de la carrera.

También utilizaré como fuentes documentales los programas de estudio de la Escuela de Visitadoras de Higiene Social, puesto que en ellos se sintetizan elementos culturales (conocimientos, valores, costumbres, creencias, hábitos) que conforman una propuesta político educativa pensada e impulsada por diversos grupos y sectores sociales cuyos intereses son diversos y contradictorios, aunque algunos tiendan a ser dominantes o hegemónicos, y otros tiendan a oponerse y resistirse a tal dominación o hegemonía (De Alba, 1998, p.75). Al mismo tiempo, serán parte del estudio las radioconferencias de las visitadoras como los informes técnicos que realizaron en su desempeño profesional, donde dan cuenta de sus aportes y reflexiones sobre la intervención sociosanitaria.

Este rastreo, que toma nota de la historia intelectual, pretende analizar los procesos materiales de circulación de las ideas en diversos soportes, desde programas hasta correspondencias, para comprender las formas de intervención intelectual y las relaciones de poder que allí se establecen. En tanto campo de abordaje histórico, permitirá visibilizar los problemas políticos, sociales e ideológicos que atañen a la circulación de ideas.

Parto de un concepto amplio de intelectual, entendiendo tanto a docentes y a visitadoras como intelectuales del trabajo social -aunque con una diferencia jerárquica de poder en función de la división sexual del trabajo durante el período a trabajar-. Las visitadoras, en tanto educadoras y poseedoras de un capital cultural (Bourdieu, 2007), pueden ser entendidas como intelectuales por su papel reproductivo y productivo del conocimiento en esferas públicas y privadas, participando en la distribución de significaciones y bienes simbólicos (Altamirano, 2013).

En el caso particular de las visitadoras de higiene, y como veremos en el capítulo 4, tuvieron posibilidad de desplegar sus acciones como intelectuales a partir de la difusión ampliada de saberes, particularmente a partir de sus intervenciones radiales, que les posibilitó hacer audibles cuestiones que eran consideradas del ámbito individual/ privado, que favorecieron las condiciones para una presentación política de las problemáticas del desarrollo del núcleo doméstico. En este sentido, consideraremos 
también a las visitadoras como intermediarias sanitarias ${ }^{9}$, que no solo difundieron los preceptos impulsados por las instituciones de salud y de la EVHS, sino que también alentaron a la participación en otros espacios alternativos, como el caso del Club de Madres-UPAK, tal como mostraremos en el capítulo 4.

Ahora bien, ¿es suficiente mencionar a las visitadoras como intelectuales para realizar un trabajo acerca de la feminización en el proceso de institucionalización? Ubicarlas en una posición de autoridad profesional en el espacio público ¿basta para referirnos a las relaciones de poder sobre las que se construyó el carácter feminizado de la profesión? Rápidamente la respuesta es negativa, por esa razón tendremos que hacer un abordaje desde la historia intelectual así como complejizar nuestra mirada a partir de considerar categorías de análisis desprendidas del movimiento feminista y de la elaboración de feministas en la academia.

En principio, nuestro abordaje se alineará con la categoría género, puesto que esta "categoría útil para el análisis histórico", tal como la llamó Joan Scott (1986) en su texto fundamental para el campo disciplinar y del feminismo, presenta ciertas sistematizaciones que resultan útiles a los fines de esta investigación. Retomando el legado de Foucault, sostiene que el poder aparece como una constelación dispersa de relaciones desiguales, instituidas discursivamente en campos de fuerza. Para la autora, el género es un elemento constitutivo de las relaciones sociales, basado en las diferencias que se perciben entre los sexos; además, es un modo primordial de significar las relaciones de poder. Su propuesta metodológica consiste entonces, en rastrear los modos en que se construyen los géneros y las relaciones asimétricas y de poder entre ellos. Cuatro elementos resultan imprescindibles para este análisis: los símbolos culturalmente disponibles, los conceptos normativos, las instituciones y/o las organizaciones sociales que movilizan estos sentidos; y por último, la reapropiación subjetiva (Scott, 1996 [1986]). Desde esta propuesta orientaré lecturas y reflexiones para analizar las construcciones culturales e institucionales que intentaron normalizar las relaciones entre los géneros al interior del espacio profesional, y en las mismas intervenciones. $^{10}$

\footnotetext{
9 Tomamos este concepto de María Rosa Gudiño Cejudo, que parte de una reconceptualización de Michelle Vovelle (1985) sobre los intermediarios culturales. Estos intermediarios se caracterizan por ser agentes de circulación, que pueden ser desde guardianes de las ideologías dominantes hasta voceros de las revueltas populares. Esta posición ambigua es producto de su ubicación como representante del mundo dominante y partícipe del mundo de los dominados. Ver: Gudiño Cejudo, María Rosa (2016) Educación Higiénica y cine de salud en México, 1925- 1960. Colegio de México, México.

${ }^{10}$ Algunas de estas reflexiones fueron desarrolladas en un artículo de mi autoría, anticipando varias cuestiones que se desarrollarán en la tesis. Ver: Gavrila, Canela (2016) "División sexual del trabajo, régimen político de la heterosexualidad y género. Multiplicando las categorías útiles para el análisis
} 
Si bien el uso de género ha sustituido el uso de la categoría mujeres (Scott, 1996 [1986]2001 [1991]) e incluso se ha vuelto "un lugar común", hay una problemática que se mantiene respecto al empleo que se hace de la categoría puesto que en muchas ocasiones el género opera como una reiteración del sujeto que limita e imprime deberes sobre las corporalidades que describe, generando ficciones reguladoras sobre los cuerpos, incluso fijando un cuerpo descrito por la biología (macho-hembra) que confina las posibilidades de pensar en corporalidades y experiencias más allá de los biogéneros asignados y su función heteroreproductiva. Por ello, nos parece pertinente incorporar dos categorías más para comprender la complejización del entramado de poder en que se encuentran las mujeres.

Por una parte, la categoría de heterosexualidad obligatoria (Wittig, 1992) permite considerar la heterosexualidad como matriz fundadora de las relaciones sociales dentro de los análisis históricos, pone en evidencia las diferencias entre mujeres en razón de su elección sexual, así como también posibilita rastrear los mecanismos que sostienen a este régimen político que privilegia el "derecho masculino" en detrimento de las mujeres y de la unidad política entre éstas. De este modo, se establece la heterosexualidad como un régimen político y económico. Desde la perspectiva de Wittig, lesbiana materialista francesa, ${ }^{11}$ la categoría mujeres es pensada como clase, en tanto grupo oprimido por los hombres, es entonces esta opresión la que genera el sexo. Así la categoría mujer, hombre y sexo aparecen como una construcción social acorde a las necesidades económicas de reproducción de la sociedad heterosexual que antecede a las convenciones generadas por el discurso biologicista (Wittig, 2006 [1992]: 26).

Por otra parte, en el derrotero por construir una historia que analice la apropiación creativa y productiva de las mujeres fundamentada sobre una base material, la división sexual del trabajo es una categoría que iluminará elementos acerca de la apropiación del trabajo de las mujeres en la dinámica social de la diferencia sexual. Resulta útil para historiar las relaciones de dominación en función de los modos de producción en que las mujeres se encuentran -tanto en los espacios de reproducción, como los de producción y

histórico de las mujeres". En Arias, AC y López, MD (Editores) (2016) Indisciplinas. Reflexiones sobre la práctica metodológica en Ciencias Sociales. Diálogos entre investigadores/as en formación de la UNLP, EDULP- FILOSURFER, La Plata.

${ }^{11}$ Las feministas materialistas francesas reflexionaron en los tempranos 70 acerca de la naturalización del sexo, afirmando que ni varones ni mujeres son grupos biológicos puesto que no poseen una especificidad biológica o identitaria que los defina, sino que son definidos por una relación social antagónica que es material e histórica. Consideran que hombres y mujeres constituyen clases diferenciadas basadas en la apropiación el trabajo de las mujeres. Para mayores referencias sobre el feminismo materialista francés, se sugiere la lectura de: Curiel, Ochy; Falquet, Jules (comp) El patriarcado al desnudo. Tres feministas materialistas. Editorial Brecha Lésbica. BsAs. 2005. 
sus cruces-, potenciando las aristas desde las cuales comprender la situación de los sujetos en determinado tiempo. Esta propuesta permite realizar un análisis de la dinámica establecida entre las relaciones de sexo y las relaciones de clase de un modo crítico y no como una acumulación de las categorías sexo y clase (Dorlin, 2008, p. 75).

\section{1922- 1948: una temporalidad fértil para el estudio de la EVHS}

La intervención profesional en Argentina surgirá en el contexto posterior de instauración del estado capitalista que asume a la cuestión social como parte de su proyecto modernizante (Rozas Pagaza, 2001, p. 24). El temor producido por los conflictos sociales impulsó a los sectores de la elite gobernante a buscar una intervención educativa y sanitaria, no solo de orden técnico, sino también moral (Ramacciotti, 2009). Esta urgencia respondía a la necesidad del campo de la medicina preventiva de formar auxiliares de los médicos desde la impronta del higienismo social. Tal discurso versó sobre dos teorías sociales muy fuertes en Occidente desde fines del siglo XIX: por una parte, el darwinismo social, que presentó estructuras interpretativas de fenómenos sociales en función de categorías biológicas, lo que permitió realizar analogías entre la sociedad y organismos vivientes en tanto elementos pasibles de ser manipulados a fin de lograr la supervivencia del más apto. Por otra parte, la eugenesia, proclamada como la ciencia del cultivo de la raza, se dedicó al estudio de los agentes biológicos bajo control social que podían mejorar o empobrecer una raza.

La intervención en lo social surge también en relación con la detección de lo "anormal", su clasificación y en la aplicación de las formas de disciplinamiento (Carballeda, 2006, p. 24). Los sectores liberales de la burguesía encontraron en los discursos positivistas la posibilidad de "despejar a la sociedad de "desechos humanos"” que implicaban gastos de atención (Miranda y Vallejo, 2005, pp. 11-12). La medicina fue la ciencia elegida, considerada como la más apropiada para la resolución de estos problemas. Vinculada desde mediados del siglo XIX y principios del XX a la eugenesia, pudo otorgar un marco científico para la aplicación del darwinismo social en la lucha por "el más apto", alentando a la identificación, clasificación, jerarquización y exclusión de ciertas personas.

Si bien desde principios del siglo XX la concentración demográfica en las urbes favoreció la organización de los obreros y las obreras para sus reclamos, como contracara debieron soportar una serie de epidemias que azotaron a la población local y produjeron transformaciones institucionales, políticas y económicas (Armus, 2000). A 
esto se sumaba otro elemento alarmante para los sectores liberales conservadores: la disminución de la natalidad en los ámbitos urbanos, producto de la difusión de los métodos para la regulación de la maternidad, que ponía en riesgo la moral, rompía el vínculo entre madre e hijo como unidad de la familia nuclear patriarcal y atentaba contra la reproducción de la sociedad. Fue por esto que el Estado propuso una serie de políticas maternalistas que, focalizadas en la consolidación de la familia, tenían como fin limitar la mortalidad infantil (Nari, 2004; Biernat y Ramacciotti 2014).

Durante el período establecido entre las décadas de 1920 hasta avanzada la década de 1940, la estrategia del Estado fue hacer de la maternidad un asunto político. Marcela Nari definió este fenómeno como "politización de la maternidad", puesto que se pretendía modificar su organización privada, aislada y feminizada, lo cual conllevaba una fuerte tensión: por un lado, se consideraba que determinadas decisiones con respecto a la procreación y a la crianza de los niños eran "cuestiones de Estado" o “asuntos públicos" y, por lo tanto, no podían quedar al arbitrio de personas (es decir, en el orden privado), y por otro, debido a razones diversas, se prescindía casi totalmente de intervenir en las condiciones materiales y afectivas necesarias para realizar la maternidad. (Nari, 2004, p. 171). Con ello, el Estado hizo de la reproducción un asunto público y político pero no facilitó las condiciones materiales y afectivas para el desarrollo de la maternidad, sino que volvió a las mujeres objeto de políticas sociales y de discusiones públicas alrededor del futuro de la sociedad, de la nación y de la raza (Nari, 2004; Ramacciotti y Biernat, 2014).

La preocupación por la disminución de los nacimientos dio lugar al desarrollo de sistemas de servicios sociales y la creación de un personal idóneo (Nari, 2004). Las visitadoras de higiene social se inscriben como parte de este entramado. No solo para instruir a las mujeres madres, sino también para vigilar a los sectores considerados potencialmente peligrosos por la burguesía en la primera mitad del siglo XX. En este sentido, era fundamental el diálogo con las mujeres de sectores populares, consideradas las responsables de la reproducción doméstica, hecho que las ubicaba como las principales interlocutoras. De acuerdo al trabajo pionero de Estela Grassi (1989), la intervención de las visitadoras pretendía la normalización y disciplinamiento de la vida cotidiana, y con ello, el abaratamiento de los costos de reproducción social por parte del Estado (p.18-19).

Para ello, una de las estrategias principales tomadas por el trabajo social en sus inicios fue la transmisión de los preceptos de higiene a los pobres urbanos mediante una relación amistosa y familiar, cuyo objetivo era la modificación de patrones de conducta 
y prácticas cotidianas en los hogares (Di Liscia, 2004; Oliva, 2007), a través de un lenguaje ameno y visitas periódicas que vincularan a las mujeres madres y sus familias con el sistema de salud (Nari, 2004, p.172).

Mediante las intervenciones se trataba de construir los ideales sociales a los que se aspiraba: familia, padre, madre, hijos (Carballeda, 2006, p. 26). Específicamente, el diálogo que las visitadoras realizaban mayormente con las mujeres madres tenía como objetivo facilitar al Estado el abaratamiento de los costos de reproducción social de los sectores populares normativizando su vida cotidiana (Grassi, 1989, p.17). Las mujeres se encontraban presentes en la atención socio sanitario desde la formación del Estado Nacional, pero desde un lugar auxiliar. En la ciudad de La Plata participaban desde la Sociedad de Beneficencia, creada en 1887, y su intervención era en hospitales, asilos de niños y patronatos a fin de auxiliar y cuidar a huérfanos y desamparados, menesterosos, ciegos e inválidos, la infancia desvalida (Grau, 1954, p. 78). Además, se ocupaban de la administración de los Hospitales Misericordia (actual Hospital Policlínico San Martín), el Hospital de Niños, el Asilo de Huérfanos y la casa de la Maternidad (Censo municipal, 1910), para los que obtenían financiamiento del Estado nacional y provincial. La Sociedad de Beneficencia actuó conjuntamente en la ciudad con la Asistencia Pública (habilitada para su funcionamiento en 1885 y en dependencia del Consejo Superior de Higiene), dedicada al control y vigilancia del ejercicio de la medicina y demás artes de curar. Con la pérdida progresiva de los espacios de intervención de la Sociedad de Beneficencia, aumentaron las acciones de la Asistencia Pública (Grau, 1954), cuestión sobre la que ahondaremos en el capítulo 2.

Recordemos que la capital de la provincia de Buenos Aires contaba con un elevado índice de inmigrantes por lo cual también operaban organizaciones de socorros mutuos que procuraban no solo mantener la cultura de sus países de origen sino también atender a la salud y otras necesidades vitales de la comunidad (Lobato, 2004, p. 49; Vallejo, 2015, p. 39). El malestar económico de la década de 1930 se tradujo en un aumento de la demanda de servicios médicos y asistenciales a la Asistencia Pública local que superó el cincuenta por ciento del trabajo que previamente realizaba. ${ }^{12}$ Por esta razón, desde el año 1932 se reorganizaron los servicios que brindaba la Asistencia Pública, con la aprobación del Consejo General de Higiene y del Poder Ejecutivo, a fin de garantizar la

\footnotetext{
12 Según la Memoria Anual de la Asistencia Pública de la ciudad de La Plata, hasta el año 1932 se mantenía un promedio de atención de cien mil habitantes por año, mientras que para el año 1938 registran una atención que supera los ciento cincuenta mil habitantes. Ver: Memoria Anual de la Asistencia Pública. Taller de impresiones oficiales. La Plata, 1939.
} 
atención médica de urgencia todos los días para "toda persona sin distinción de clases ni categoría absolutamente gratuita". ${ }^{13}$

Sin embargo, el Estado municipal no se encargó de capacitar agentes especializados para la intervención en la vida cotidiana, ${ }^{14}$ sino que fue la Universidad y un grupo de médicos reformistas comandados por Pilades Dezeo quienes materializaron en 1938 un proyecto para la educación popular de los sectores más desprotegidos, a través de la creación de la Escuela para Visitadoras de Higiene Social. La EVHS es un hito en el proceso de institucionalización del Trabajo Social, e incluso se inscribe como parte de uno más amplio vinculado a las preocupaciones por la intervención profesional sobre la cuestión social. El clima reformista en las universidades de Buenos Aires y La Plata facilitó la difusión de la perspectiva social de la higiene en las carreras de Ciencias Médicas, y junto con ello, promovieron la creación y el desarrollo de cátedras específicas en las carreras de medicina, como también la organización de Institutos de higiene, proyectos de extensión, programas de radio, e incluso la necesidad de instalar otros espacios de formación de asistentes de los médicos en materia higiene y medicina preventiva, revistas para su difusión, ateneos a sectores trabajadores, entre otras acciones.

Ahora bien, es necesario reconocer que los recortes temporales suelen resultar una operación arbitraria, sobre todo si pretendemos no alinearnos con las fechas $\mathrm{y}$ acontecimientos históricos paradigmáticos de la historia profesional o de la historia política o económica, lo que nos exigen mayores justificaciones metodológicas en referencia a la importancia de ese tramo de tiempo. El período propuesto para este análisis no se corresponde con cronologías coincidentes a gobiernos en particular o a modelos económicos hegemónicos, ni al momento de inauguración de los cursos, sino que es un recorte realizado en función de la emergencia de la preocupación desde la Universidad por formar mujeres que operasen como agentes especializados en las tareas de asistencia social, la difusión de preceptos de higiene, que resultaran económicas a sus empleadores y que además pudieran conjugar saberes de orden técnico, moral y científico. En este sentido, el punto de partida de nuestra investigación se vincula al interés de los sectores reformistas de la Escuela Preparatoria de Ciencias Médicas de la Universidad Nacional de La Plata (que a partir de 1936 pasa a ser la Facultad de

\footnotetext{
${ }^{13}$ Memoria presentada a la Honorable Legislatura por el Ministro de Obras Públicas de la provincia de Buenos Aires Dr. Edgardo J. Miguez, Tomo I, 1932, pp. 154.

${ }^{14}$ Es preciso destacar que desde la Dirección de Educación y desde la Liga para la lucha contra la tuberculosis, se realizaban capacitaciones para la formación profesional de visitadoras, aunque estas escuelas no eran dependientes del Estado.
} 
Ciencias Médicas de UNLP) por establecer estrategias de difusión de la higiene para los sectores populares. Abarca los debates por la creación de la EVHS dentro de la UNLP, y se extiende hasta el año 1948, momento en que se creó por medio de la Ley N ${ }^{\circ} 13.341$ la Dirección Nacional de Asistencia Social bajo la órbita de la Secretaría de Trabajo y Previsión. Considero que ese hito histórico implica un momento de mayor complejización de las agencias del Estado, donde la asistencia social pasó a tener un ámbito de injerencia mayor dentro de un gobierno que amplió las políticas sociales, tanto dentro de la estructura formal del Estado como a través de las instancias informales, tal como las encaradas por la Fundación Eva Perón (1948).

Resulta interesante poder estudiar durante la coyuntura de 1922 a 1948, momento mayormente signado por la lucha en la adquisición de derechos políticos de las mujeres, las lógicas que producen la feminización de la profesión como así también analizar el entrecruzamiento de la intervención de estas mujeres Visitadoras de Higiene en la vida cotidiana, con el objetivo de rastrear qué tipo de conocimientos, saberes y/o datos se produce en ese encuentro. El estudio de las Visitadoras de Higiene nos permitirá echar luz sobre aquellos espacios grises de la historia del trabajo social donde se hallan estas agentes intermediarias entre el saber médico y la realidad social, generadoras de un saber sobre la cuestión social y capaces de formular nuevos conocimientos a través de los instrumentos de intervención.

4.¿Por qué una docente en historia se desvela por las visitadoras de higiene y qué palabras la han despabilado?

"El saber feminista es también una memoria de los combates" Elsa Dorlin (2006 [1992])

“¿Con la sangre de quién se crearon mis ojos?” Donna Haraway, Manifiesto Cyborg, 1995

Dona Haraway se preguntaba a fines de la década de 1980 con la sangre de quién fueron construidos sus ojos y desde esta pregunta desorbitante cuestionaba cómo nuestras miradas han sido disciplinadas por discursos androcéntricos, sexistas, racistas y clasistas a los fines de creer en una objetividad condicionada. Su pregunta me invita a 
pensarme desde la actualidad de mi condición como lesbiana feminista, historiadora y docente. ¿Con la sangre de quién fueron creados mis ojos? y resulta inevitable hilvanar una respuesta que al menos mencione los artefactos e invenciones que localizan mi mirada, como parte de una operación mayor por reconocerme situada, ubicada, en un punto como partícipe del proceso de producción del problema y del objeto de estudio, inmersa y afectada por los derroteros que asumo afrontar. Los conocimientos situados permiten la localización limitada sin el desdoblamiento entre sujeto y objeto, fortaleciendo el diálogo entre epistemologías, por fuera del relativismo y la totalización como trucos divinos que prometen discursos totalizadores desde ningún lugar (Haraway, 1995 [1991]). Es desde las perspectivas parciales que se encuentra la posibilidad de una búsqueda objetiva, de la enunciación como existencia.

Este deslizamiento permite formular el relato de una forma menos organizada por los ejes de dominación, desarrollándose desde un particular contexto de producción y de relaciones sociales en las que estamos inmersas, favoreciendo la multiplicidad de discursos para el desmembramiento de los grandes relatos y visiones únicas, posibilitando la emergencia de lo invisible. Por tanto, es una apuesta política que tiene como acción la contestación, la deconstrucción, las conexiones que apuestan a transformar los sistemas de conocimiento, sin negar otros relatos. Ensayar un conocimiento posicionado, contextualizado en determinadas redes políticas, sociales y culturales permitirá una proyección de la mirada a espacios y posibilidades inimaginadas, negadas históricamente.

Es por eso que necesito enunciarme: yo docente, lesbiana feminista, de una feminidad desobediente, perteneciente a una familia trabajadora conformada exclusivamente por mujeres en las dos generaciones que me anteceden, perteneciente a la primera generación que termina la escuela secundaria, y también a la primera generación que se gradúa en la Universidad. Como muchas otras, sé del trabajo que nos cabe para encontrar una trinchera en el mundo académico, de las batallas cotidianas por romper con la sujeción de la feminidad dominante y de la lucha por el reconocimiento de una sexualidad no hegemónica. Como muchas compañeras entreno los mil modos de resistir y contestar, y esta tesis lleva el impulso de esa fuerza deseante. Con todo ello, con toda esta parte constitutiva de mi existencia, ¿cómo podría evadir preguntarme acerca de las formas en que se construye la feminización de la sostenibilidad de la vida, o de las estrategias científicas que avalan el descrédito de la enunciación de las feminidades en distintos ámbitos laborales y de producción de saberes? 
La docencia al igual que el trabajo social, comparte una alta matrícula de mujeres y ciertos rasgos comunes atribuidos histórica y culturalmente, como las pesadas ideas de amor al prójimo, la vocación de servicio, la abnegación, la precariedad, entre otras. Estas características suponen una entrega total en el trabajo de corrección y enseñanza de nuevos hábitos a las personas con quienes se trabaja desmesuradamente. Pero a su vez, dado el carácter "natural" e "innato" que se adjudica a parte de estas acciones, no son consideradas un trabajo (citemos, por ejemplo, las actividades de preparación que se realizan en horas extras para ejecutar en la intervención, el tiempo empleado en la escucha y en la contención emocional de los y las usuarias, entre otras). Además, un fuerte descrédito recae sobre estas labores porque sus resultados no son inmediatamente intercambiables en la economía de mercado, hecho que esconde el carácter ideológico y político de estas actividades. Ambas profesiones son parte del círculo de precariedad laboral establecido por el Estado y justificado por la ideología de la diferencia sexual.

No sólo en la práctica laboral resultan tediosas las luchas por el reconocimiento del trabajo intelectual, como también por el reconocimiento del trabajo que implican las acciones afectivas, de cuidado y de creatividad, sino que incluso en la historia de muchas profesiones vinculadas a la educación y al cuidado, el silenciamiento y la invisibilidad de las voces de mujeres aparecen como susurros lejanos o se reproducen de manera automática para anular experiencias de agenciamiento, relatos alternativos de la misma práctica, disidencias al orden profesional y elaboraciones teóricas propias, entre otras cuestiones.

Como docente de la Cátedra A de Historia social de Argentina y Latinoamérica en la carrera de Trabajo Social ${ }^{15}$, no puedo dejar de preguntarme ¿por qué aun en el año 2018 más del ochenta por ciento de la matrícula de la carrera está conformada por mujeres y por qué dicha característica no resulta un interrogante para las futuras profesionales respecto de las funciones adjudicadas a su posterior desempeño profesional en función de su género? ¿Cuáles son las condiciones sociales, políticas, económicas y culturales que facilitan esta elevada matrícula? Pero sobre todo, y aunque parezca obvio, me pregunto ¿qué puede ofrecer una mujer al trabajo social que no pueda aportarlo otro sujeto? Acorde a mí vicio historizante elegí iniciar un camino de investigación sobre el

\footnotetext{
${ }^{15}$ Desde el año 2012 formo parte del equipo Docente de la Cátedra de Historia Social de Argentina y Latinoamérica. y hasta diciembre de 2017 formé parte del Proyecto de investigación "Aportes para una historia de los intelectuales argentinos y latinoamericanos del siglo XX. Un estudio de las revistas y publicaciones de los agrupamientos intelectuales, las agrupaciones estudiantiles y las instituciones universitarias (1917- 1979)", radicado en el Centro de Estudios de Trabajo Social y Sociedad de la Facultad de Trabajo Social, UNLP (CeTSyS).
} 
peso de la feminización en el proceso de institucionalización del trabajo social en la ciudad de La Plata, manteniendo algunos interrogantes como vertebradores de mi acción, a saber: ¿De qué manera las mujeres fueron funcionales a la legitimación de la nueva profesión universitaria? ¿Cuáles son las razones sociales, políticas, económicas y culturales que influyeron para que sean las mujeres las autorizadas para la intervención en nombre del Estado dentro de la vida privada de los sujetos? y sobre todo ¿qué contornos se establecieron en el inicio de la formación profesional que se mantienen como sedimentos de la actual condición de precariedad e infravaloración laboral?

Claro que muchas autoras y autores abordaron de distintas maneras interrogantes similares. Un corpus bibliográfico de gran importancia es impulsado por quienes ejercen la profesión de trabajo social (Alayon, 1978; Parra, 1999; Rozas Pagaza, 2001; Carballeda 2006; Oliva, 2007). Estos trabajos analizan la creación del curso de Visitadora de Higiene y la Escuela de Servicio Social como un hito transicional en la creación de la carrera de Trabajo Social, y los abordan como parte de la necesidad de la medicina preventiva de formar auxiliares de los médicos con el objetivo de ordenar los cuerpos desde el discurso higienista (Carballeda, 2006). Por su parte, Estela Grassi (1989) complejiza esta mirada desde la antropología e incluye la perspectiva de género, reconstruye el lugar de las mujeres en la formación de la disciplina desde la instrumentación de la asistencia, no obstante, no profundiza su análisis en las Escuelas de Visitadoras de Higiene Social y ubica su mirada exclusivamente en la Escuela de la Universidad Nacional de Buenos Aires. Asimismo, faltan estudios que analicen el surgimiento de estos cursos como parte de un proceso político y social más amplio. El acentuado énfasis en las ideas de control social en el surgimiento de la profesión obturó la comprensión de las acciones encaradas por las Visitadoras de Higiene como aporte al proceso de inclusión social. En este sentido, estudiar la presencia de las mujeres en la historia de los procesos de especialización y profesionalización sanitaria, también supone investigar los contenidos y los saberes que produjeron estas mujeres y analizar cómo éstos se articularon con las dimensiones científicas y sociales en distintos marcos temporales y espaciales. Los trabajos de las Visitadoras de Higiene y de las asistentes sociales aguardan ser leídos para comprender sus ideas en las diferentes temáticas que aportaron.

El trabajo de Andrea Oliva (2007) repara en las condiciones para el surgimiento del Trabajo Social en Argentina, se especifican los antecedentes en los que participaron las mujeres para la formación del campo profesional y cómo desde cada uno de ellos se intentó hacer frente a las demandas colectivas para saldar las necesidades insatisfechas 
por el salario. El peso de la organización colectiva y de las organizaciones de trabajadores para la exigencia de una mejora en sus condiciones de vida, junto con el peligro que acarreaban los potenciales conflictos que de ello se desprendería, permite pensar al trabajo social inmerso en la lucha de clases, sin embargo, no se reconocen los aportes de otros movimientos sociales de principios del siglo $\mathrm{XX}$, como el feminismo $\mathrm{y}$ tampoco ahonda en los elementos que hacen a la feminización profesional.

Otra apuesta muy interesante por visibilizar a las mujeres en la historia del Trabajo Social es realizada por Bibiana Travi (2006), quien establece un trabajo de recuperación de las primeras mujeres en el proceso de profesionalización, como han sido Mary Ellen Richmond, Gordon Hamilton y Hellen Perlman, agentes del servicio social anglófono que han influenciado la construcción de prácticas y herramientas interventivas actuales, pero queda vacante el estudio de figuras locales. Su interés pretende ponderar acciones de las mujeres que trabajaron en la asistencia social y recuperar sus acciones para desafiar con ella las visiones hegemónicas que obnubilan otros sentidos del quehacer profesional.

Los relatos a los que aludimos priorizan la experiencia de la ciudad de Buenos Aires para dar cuenta de la historia del Trabajo Social en Argentina, y en el caso de Trabi, de los Estados Unidos. En los últimos años han surgido otros relatos sobre historias regionales en el proceso de institucionalización profesional. Así encontramos a Olga Paéz, Mario Villarreal y Sergio Gianna (2012) con su trabajo sobre el surgimiento de la profesión del Trabajo Social en Córdoba, a Mariela Rubinzal (2014) que aborda el proceso de creación del Servicio Social en la Universidad del Litoral, mientras que Néstor Arrúa (2016) aporta un haz de luz a la reflexión sobre el proceso de modernización del Trabajo Social durante el período 1957- 1975 en la ciudad de La Plata. Estos estudios si bien ponderan los relatos regionales para configurar una cartografía más compleja del proceso de institucionalización a nivel nacional, no abordan la cuestión de la feminización en la configuración del campo profesional.

Sin embargo, estudios de otros países de Latinoamérica abordan la complejidad de la feminización profesional de la asistencia. Tal es el caso de Mirla Cisne (2012), quien estudió la división sexual del trabajo social en los inicios de la profesión en Brasil, o los aportes de Maricela González Moya (2010) quien realiza una lectura a contrapelo de la historia del trabajo social para ponderar las acciones y discursos de las visitadoras sociales en Chile.

No solo desde el Trabajo Social podemos reconstruir los antecedentes profesionales de la actual carrera. Su carácter "auxiliar" de la medicina nos invita a dialogar con la 
historiografía de la salud y la enfermedad, más específicamente con los aportes ligados a los procesos de profesionalización sanitaria (Armus, 2007; González Leandri, 1998; Di Liscia, 2014 y Soprano, 2014) y, sobre todo, con los trabajos que centralmente abordan los procesos de feminización de las actividades ligadas al cuidado de los otros (Grassi, 1987; Nari, 2004; Di liscia y Billorou, 2005; Ramacciotti y Valobra, 2015; Krmpotic, 2008; Testa, 2012; Martín, 2014). Las profesiones han sido concebidas por la sociología como un fenómeno de las sociedades modernas. El sociólogo norteamericano Eliot Freidson (1978) analizó la medicina como uno de los prototipos representativos de una profesión y destacó como elementos clave de la organización profesional la capacidad de acumular y usar conocimientos bajo sus propios estándares, sin estar sujetos al control de actores externos. Este autor considera que las pujas de poder, las relaciones con el Estado y con otros grupos ocupacionales son importantes en los procesos de profesionalización. La división del trabajo médico en otras ocupaciones y prácticas, útiles y necesarias a la medicina, generalmente dedicadas a brindar servicios relativos a la curación, reúne variados oficios especializados que podrían llegar a ser ocupaciones competitivas y a constituirse en una amenaza para el monopolio de la medicina. Por este motivo resulta interesante considerar las discusiones en torno a los desarrollos históricos de la profesionalización teniendo en cuenta las vinculaciones de poder y de autoridad, los sesgos de género y las jerarquías establecidas entre las distintas profesiones y al interior de cada una de ellas al momento de detener la mirada en las condiciones que posibilitaron su surgimiento. En este sentido, se impone repensar las relaciones de género y preguntarnos por la participación de las mujeres en estas profesiones y cómo se constituyeron los eslabones de subordinación y resistencia en la jerarquía médica.

Como señala Carole Pateman (1995, pp. 9-17), la subordinación ha sido un tema secundario entre los cientistas sociales. No obstante, esa cualidad muestra cómo la diferencia sexual da lugar a la división patriarcal del trabajo, no sólo en el hogar conyugal sino en los puestos de trabajo de la sociedad civil. El análisis de la profesionalización de ocupaciones feminizadas resulta un desafío para estudiar cómo la dominación sexual estructura los lugares de trabajo. El establecimiento del control, la autonomía y los límites de muchas profesiones respecto de la medicina y otras ocupaciones es un inacabado proceso histórico que se hace necesario desmenuzar a fin de ponderar acciones de agenciamiento de estas profesionales.

Puesto que no basta con la mención y visibilidad de un sujeto histórico para dar carnadura a los distintos procesos políticos, culturales e intelectuales de los que han 
participado, como tampoco es suficiente para problematizar las relaciones de poder en las cuales se inserta, intentaremos realizar una reflexión acerca de cómo operó la feminización en el proceso de institucionalización del Trabajo Social durante el período de 1922 a 1948. Con ello queremos polemizar con los supuestos que hacen de las prácticas asistencialistas una labor femenina y conservadora que desconoce el carácter orientado y asimétrico que produce la división sexual del trabajo, materializados en elementos objetivos, claros y definibles que operan junto a constantes ideológicas para generar una serie de obligaciones y prohibiciones vinculadas al trabajo, a las obligaciones familiares y a la creación de un identidad sociológica masculina y femenina (Tabet, 1998, pp. 62-63).

Del mismo modo, me propongo evidenciar las disidencias y relatos construidos por las propias profesionales como modo de reivindicar las acciones y propuestas realizadas por ellas mismas.

Para ello la tesis está estructurada en tres partes, la primera dedicada al estudio de la configuración profesional de las Escuelas de Visitadoras de Higiene Social de la Universidad Nacional de Buenos Aires y de la Universidad Nacional de la Plata, a cada una de ellas corresponde un capítulo en particular. El capítulo I aborda la configuración de la profesión desde la Cátedra y el Instituto de Higiene de la Facultad de Ciencias Médicas de la UBA donde se encuentran vínculos intelectuales entre médicos, sobre todo veremos en la trayectoria del Dr Pilades Dezeo el interés por expandir la educación popular e higiénica, pero sobre todo de la formación de una agente específica para tales funciones. Desde la figura de este médico higienista y reformista llegaremos al capítulo II donde trabajaré sobre los antecedentes para la creación de la Escuela de visitadoras en la UNLP. Para ello será presentada una cartografía de los modos en que se abordó la cuestión social en la ciudad de La Plata con antelación a la profesionalización de la asistencia. Puesto que será la década de 1930 donde se desarrolle la propuesta universitaria de abordaje a la cuestión social, veremos allí las propuestas realizadas por la I Conferencia Nacional de Asistencia Social y las demandas específicas surgidas del contexto de crisis económica. En suma, estos elementos aportaran mayores herramientas para pensar la profesionalización y feminización de la visita de higiene.

La segunda parte de la tesis esta dedicada a la reflexión sobre la construcción feminizada de la profesión en la ciudad de La Plata. para ello serán considerados los elementos específicos de la formación a través del análisis de las currículas, programas 
de estudio y ordenanzas donde se delinearon las expectativas sobre las estudiantes y graduadas de las escuela.

La última parte será compuesta por un capítulo específico. Estará dedicada a las acciones de agenciamiento de las profesionales entiendo la tensión entre las normativas ideadas por los médicos a cargo de la profesión, junto con las acciones específicas de las profesionales donde tensionaron las prescripciones de los galenos, e incluso logaron posicionarse como una voz autorizada y audible en el espacio público durante un período en el que aun no gozaban de derechos políticos. 


\section{PARTE I: Las Visitadoras de la Universidad. La configuración de la profesión a partir de las Escuelas de Visitadoras de Higiene Social. UBA-UNLP 1922- 1938}

\section{Capítulo 1: Antecedentes del Trabajo Social. La Escuela para Visitadoras de Higiene Social de la Universidad Nacional de Buenos Aires}

En este capítulo presentaré algunas de las principales características del contexto histórico en que se desarrolló la Escuela de Visitadoras de Higiene Social de la Universidad Nacional de Buenos Aires, antecedente inmediato de su homónima platense. Para ello resulta imprescindible dar cuenta de algunas de las principales problemáticas desprendidas del nuevo ritmo de trabajo de principios del siglo XX, como también de la preocupación de los sectores gobernantes por conducir armoniosamente el desenvolvimiento de la sociedad. Con este primer abordaje pretendo establecer una cartografía panorámica sobre las condiciones de posibilidad para la institucionalización del Trabajo Social en la ciudad de Buenos Aires. Éste nos brindará algunas pistas acerca de los vínculos intelectuales y académicos establecidos con la Escuela para Visitadoras de Higiene Social de la Universidad Nacional de La Plata, sobre todo alrededor de la figura de Pilades Dezeo.

\subsection{Abordar la cuestión social}

Con el crecimiento de los Estados modernos, los asuntos indispensables para el desarrollo colectivo como la previsión social, la vivienda, la salud y la educación, pasarán a ser cuestiones prioritarias para la integración de los individuos (Castel, 2008). Particularmente en Argentina, desde las últimas décadas del siglo XIX, se produjo un aumento de la conflictividad social producto de los desajustes vivenciados en el mundo del trabajo a partir del crecimiento y la transformación de las relaciones sociales de producción (Suriano, 2002).

La participación de la economía argentina en el mercado internacional en tanto proveedora de materias primas favoreció no solo el crecimiento de las industrias livianas vinculadas al área, sino también el desarrollo de las ciudades, como Buenos 
Aires, Rosario y La Plata, por citar solo algunas, que intentarían absorber a las poblaciones nativas y a las poblaciones inmigrantes que se acercaban a los nuevos centros urbanos en búsqueda de trabajo. Este escenario trajo consecuencias inmediatas al aparecer problemas más complejos vinculados a las carencias de estos sectores para garantizar sus condiciones básicas de reproducción, como la falta de viviendas para obreros y la incapacidad de acceder a servicios de salud y atención médica, entre otras. Los cambios producidos afectaron a la población en su totalidad, aunque la cuestión obrera centralizó este debate público puesto que los trabajadores, en condiciones de máxima precariedad y desprovistos de derechos, eran quienes padecían la mayoría de los desajustes producidos en el mundo del trabajo (Suriano, 2002; Lobato, 2007). Fueron variadas las voces que denunciaron las malas condiciones de vida y de trabajo, y la forma en que éstas repercutían en el mantenimiento del orden social. El movimiento obrero argentino, organizado polifónicamente, exigió respuestas para la cobertura de aquellas necesidades disociadas del salario y presentó nuevas demandas que constituyeron una ruptura con las formas organizativas existentes (Oliva, 2009. p. 15). Considero pertinente traer en este punto un debate de la historiografía argentina para iluminar cuáles fueron las iniciativas que hicieron posible el abordaje de la cuestión social a través de políticas sociales. Por una parte, nos encontramos con la postura presentada por Juan Suriano, quien considera que las múltiples expresiones del conflicto social -como acciones de huelgas, paros, asociaciones mutualistas, sindicatos, presencia de grupos socialistas y anarquistas- alarmaban al gobierno y dejaban en evidencia las falencias de su sistema organizativo. Por ello se desplegaron instituciones sociales y políticas tendientes a ordenar el desenvolvimiento de la sociedad y en esa táctica también lograr la inclusión de dichos sectores (Suriano, 2002). Otra mirada histórica al respecto considera que no es la movilización social la que impulsa la creación de políticas sociales, por el contrario, dicha estrategia no partiría del cuerpo de los sectores menos favorecidos de las relaciones sociales de producción, sino que, en diálogo con el clima de ideas positivistas reinante desde principios del siglo $\mathrm{XX}$, se introdujeron proyectos legislativos y debates parlamentarios a fin de impulsar una mayor intervención estatal para la resolución de los conflictos sociales (Zimmerman, 1995). Esta postura enaltece las acciones intelectuales de grupos de "reformistas" liberales que pretendía encauzar a los sectores descontentos a través de ciertas reformas sociales. En esta tesis utilizaré una noción polisémica de "cuestión social”, destacando las exigencias realizadas desde el movimiento obrero junto con las respuestas establecidas por los sectores reformistas liberales. 
Aun así, en el naciente Estado Nación argentino, desde principios del siglo XIX, la satisfacción de las necesidades básicas de subsistencia que estaban por fuera de la relación salarial era suplantado por la iglesia mediante la caridad. Junto con ella, a partir de 1823 con la creación de la Sociedad de Beneficencia, comenzaron a desplegarse una serie de acciones tendientes a establecer una beneficencia de carácter laico y filantrópico, en el cual el Estado tendría un rol institucional permanente (Moreno, 2009, p. 32) que, de un modo ortopédico, financiaba distintas acciones tendientes a dar respuestas a las necesidades de los grupos más desprotegidos.

Si bien la Sociedad de Beneficencia obtenía financiamiento del Estado nacional y provincial, se mantuvo mayormente de manera autónoma a cargo de las Damas de la Beneficencia, quienes debieron ocuparse de la atención y del cuidado (Cerda, 2015, p. 23). La asistencia social brindada por estas mujeres no fue necesariamente de carácter paliativo y tampoco operó meramente como instrumento de control social destinado a reducir la pobreza o ser un atenuante de las manifestaciones de la cuestión social, por el contrario, pretendía la rehabilitación, e incluso, la habilitación de los sujetos que estaban bajo su custodia (Eraso, 2009).

A pesar de que las tareas de las Damas de Beneficencia se vincularon a un proyecto de sociedad que no se identificaba con el de los sectores populares, es menester destacar que estas mujeres a cargo de la asistencia social en distintos lugares del país también establecieron relaciones de cuidado y defensa legal con otras mujeres madres solteras, e incluso con algunas casadas, sobre todo con antelación al reconocimiento de los derechos de la ciudadanía política en el año 1947, articulando de algún modo una pre política social (Guy, 2011).

Es importante recordar en el contexto de fines del siglo XIX y principios del XX, el ingreso del pensamiento positivista como parte de la racionalidad liberal, que pretendió explicar los efectos no deseados del proceso de modernización y, a la vez, asumir la responsabilidad de la invención de una nación a través de un modelo de país donde las instituciones trazaran el límite, encargando a los aparatos coercitivos que expulsaran a los sectores renuentes a incorporarse (Terán, 1987). A través del pensamiento filantrópico se coaguló el interés por la reproducción y conservación de la sociedad y se quitó a la iglesia los medios fundamentales para la reproducción ideológica: la educación y la asistencia a los miserables (Grassi, 1989, p. 12). Vale aclarar que el paso de la caridad a la filantropía no supuso un corte tajante entre una práctica y otra, de hecho la convivencia de ambas es palpable en los inicios de la creación de la profesión del Trabajo Social. Tal como señala Saúl Karsz, el asistencialismo y la toma a cargo 
serán constitutivas del primer período de la disciplina. ${ }^{16}$ En ambas formas de intervención se pretendió que las mujeres ocuparan el lugar de instrumentalizadoras y difusoras de valores morales al interior de las familias, en tanto transmisoras de las preocupaciones de la burguesía local por asegurar la reproducción de la fuerza de trabajo, pero veremos en el desarrollo de esta tesis cómo supieron lidiar con tal propuesta.

Durante 1880 se crea en Argentina el Departamento Nacional de Higiene que reemplazó al antiguo Consejo de Higiene. Con esta estrategia, el Estado ampliaba su base de incidencia sobre la sociedad y pretendía avanzar en el estudio de la salud pública, a la vez que establecía un mecanismo institucional para la asesoría en materia legal respecto de las medidas sanitarias que debía desplegar (Carballeda, 2006; Cerdá, 2015). Sin embargo, desde la creación del Departamento Nacional de Higiene, las tácticas de los médicos higienistas tuvieron un cambio en sus horizontes de intervención. Si en un principio este organismo tuvo una estrategia tendiente a evitar y prevenir epidemias recordemos que en 1870 la epidemia de fiebre amarilla diezmó a la ciudad de Buenos Aires ${ }^{17}$, para la década de 1920 con el aumento de los conflictos sociales generados por el vertiginoso aumento de la población, el crecimiento de las urbes y el despliegue de la industria vinculada al sector primario exportador, la estrategia de los médicos buscó no solo la prevención sino también la creación de organismos de asistencia social, prevención y moralización (Armus, 2007; Ramacciotti, 2009).

En este contexto de movilización obrera, como así también de preocupación de los sectores liberales y reformistas por encauzar a los sectores peligrosos, es que el Estado capitalista asume a la cuestión social como parte de su proyecto modernizante (Rozas Pagaza, 200, p. 24), puesto que el temor producido por los conflictos sociales impulsó a

\footnotetext{
${ }^{16}$ Saúl Karsz (2007) diferencia estos dos modelos basándose en la transformación política que vive Latinoamérica a principios del siglo XX, con el pasaje de una sociedad y cultura política conservadora, ligada a la Divina Providencia, hacia una sociedad liberal de corte positivista. El modelo asistencialista se liga al conservadorismo ilustrado y su principio organizador es la moral humanista. Los dispositivos institucionales que utiliza se enraízan en las obras filantrópicas, caritativas, humanitarias, correctivas, haciendo que las condiciones y objetivos de la intervención sean la buena convivencia y la paz social para la salvación divina. Distinto de este paradigma es la figura de la toma a cargo, ya que en ésta la concepción de sujeto implica un ser que demanda e incluso que desea (distinta del anterior que lo supone una criatura a quien debe ayudarse), y quienes trabajan con éstos son legisladores, funcionarios, empleados y no "voluntarios". La ética que acompaña esta práctica es humanista y se apoya en dispositivos institucionales vinculados a las instituciones públicas.

${ }^{17}$ Las epidemias de cólera, fiebre amarilla, peste bubónica, gripe, sarampión, fiebre tifoidea, tuberculosis, difteria y viruela se dispersaron rápidamente en las grandes ciudades de Argentina, América Latina y Europa. Ver: Armus, D. (2000) "El Descubrimiento de la Enfermedad como Problema Social". En Lobato, Mirta (2000) El Progreso, la modernización y sus límites (1880-1916). Sudamericana, Buenos Aires.
} 
los sectores de la elite gobernante a buscar una intervención educativa y sanitaria, no solo de orden técnico, sino también moral (Ramacciotti, 2009).

Esta urgencia respondía a la necesidad que existía desde el campo de la medicina preventiva de formar auxiliares de los médicos (Alayón, 1978). Tales discursos que propiciaban la gestación de una nueva carrera, formaban parte del pensamiento liberal positivista, ansiosos por organizar los cuerpos en función de un discurso higienista capaz de frenar posibles descontentos sociales (Carballeda, 2006). De algún modo, el higienismo buscaba regular el espacio urbano (Recalde, 1988) y, a su vez, transformar los hábitos cotidianos de las personas mediante la autoridad de la ciencia médica, lo cual posibilitaba también desterrar saberes populares del orden del curanderismo (Gonzalez Leandri, 2005). Para ello se debían instruir a los y las ciudadanas en los nuevos hábitos higiénicos que facilitarían el disciplinamiento y reproducción de rituales normalizados en la cotidianeidad (por citar algunos ejemplos, taparse la boca al toser, limpiar con trapos húmedos para no propagar el bacilo de koch, ventilar la casa durante los días soleados, entre otros).

Si bien, las políticas sanitarias y asistencialistas de las primeras décadas del siglo XX tuvieron como telón de fondo la preocupación por la cuestión social -evidente en la pobreza, la marginalidad y el desarrollo de enfermedades-, también estaba presente la cuestión de las madres y trabajadoras, ya que la difusión de los métodos anticonceptivos y la elevada tasa de mortalidad infantil alertaban sobre el riesgo de desmembramiento del núcleo doméstico y la necesidad por reformarlo (Suriano, 2002; Lobato, 2007; Aguilar, 2014).

La eugenesia dio sustento ideológico o pseudo científico al interés político de disciplinamiento social. Esta ciencia surgida en Inglaterra a fines del siglo XIX y consolidada en las primeras décadas del siglo XX tuvo como principal objetivo lograr el progreso de la "raza". Intelectuales y científicos locales seleccionaron y reformularon las teorías en boga en la Europa de la primera posguerra, dando lugar a una eugenesia local de carácter transformista que pretendía la modificación de los individuos y la "raza" a través de la corrección de hábitos como también de la ilustración de nuevas prácticas cotidianas (Nari, 2004). Médicos higienistas buscaban normalizar ciertas conductas que se consideraban inapropiadas y de esta forma crear una "raza fuerte". En este contexto, los médicos, en tanto grupo socio profesional, aparecen en interlocución con otros actores estatales y societales, producto de un imbricado vínculo entre profesión médica, Estado y sociedad que los posicionó como personajes notables del ámbito político (Soprano, 2014). El poder de los galenos y el acrecentamiento de su 
intervención en la asistencia social a través del control de instituciones y redes institucionales de atención en políticas sanitarias, fue apoyado por el Estado que avanzó en las atribuciones conferidas a este sector (González Leandri, 2005). No podemos olvidar que este privilegio profesional de intervención en la esfera pública era exclusivo de los varones, en cambio, las mujeres aún durante la década de 1930 no lograban acceder a cargos docentes dentro de la universidad, lo que motivó a muchas médicas mujeres, como Elvira Rawson, Julieta Lanteri, Cecilia Grierson y Alicia Moreau, a aliarse con el feminismo de principios de siglo para cuestionar, entre otros asuntos, las jerarquías de los ámbitos sanitarios y universitarios (Ramacciotti y Valobra, 2011, p. $37)$.

\subsubsection{Las mujeres en la cuestión social}

Juan Suriano (2002) comprende que dentro de las problemáticas constitutivas de la cuestión social no sólo están los obreros varones -y también los pueblos nativos que resistieron a la avanzada liberal de fines del siglo XIX-, sino que las mujeres madres y/o trabajadoras resultaron una parte constitutiva. Mirta Lobato (2000) destaca que al ser la familia el núcleo prioritario y "natural" de un ordenamiento moral colectivo, la mujer aparece como la responsable de la preservación y mejoramiento de las condiciones físicas y psíquicas de la comunidad. Para ello, las féminas debían permanecer en el ámbito del hogar, cuestión que resultaba problemática porque las mujeres de los sectores populares debían salir a trabajar para garantizar la reproducción de su familia, hecho que las constituía como un factor preocupante y perturbador para el cual se diseñaron distintas políticas sociales. ${ }^{18}$

Las mujeres en tanto garantes del orden doméstico y de la reproducción ideológica de la sociedad resultaban una preocupación para los sectores liberales conservadores, sobre todo desde principios del siglo XX en que disminuyó la tasa de natalidad en los ámbitos urbanos producto de la difusión de los métodos para la regulación de la maternidad,

\footnotetext{
${ }^{18}$ La legislación al respecto puede sintetizarse en: Ley No 5.291 (1908) de Reglamentación del trabajo de Mujeres y Niños; Ley N $\mathrm{N}^{\mathrm{o}} 11.933$ (1934) de creación de un régimen de protección de la maternidad para empleadas y obreras de empresas privadas, prohibición de trabajar 30 días antes del parto y 45 días después, se establecen cuidados gratuitos de un médico o de una partera y un subsidio por maternidad; Ley $\mathrm{N}^{\circ} 12.111$ (1934) de inclusión de empleadas y obreras del Estado en un régimen de protección a la maternidad, con licencia de seis semanas anteriores y posteriores al alumbramiento y recibiendo salario durante la licencia; Decreto $\mathrm{N}^{\mathrm{o}} 80.229$ (1936) de creación de la Caja de Maternidad como sección anexa de la Caja Nacional de Jubilaciones y Pensiones Civiles que administraba el seguro de maternidad; Ley $\mathrm{N}^{\circ} 12.339$ (1937) de disminución de los montos de multas; Ley $\mathrm{N}^{\circ} 12.339$ (1937) que exceptúa la retención para la Caja de Maternidad a las mujeres trabajadoras con salarios muy bajos debiendo los empleadores efectuar doble contribución; Ley $\mathrm{N}^{\circ} 12.568$ (1938) que establece dos descansos de media hora para amamantamiento.
} 
hecho que ponía en riesgo la moral, rompía el vínculo entre madre e hijo como unidad de la familia nuclear patriarcal y atentaba a la reproducción de la sociedad. Pero además de desestabilizar el desarrollo familiar, si nacían menor cantidad de niños y niñas disminuiría la cantidad de brazos disponibles para el mercado de trabajo, que en ese momento prometía un progreso indefinido. Fue por estas razones que el Estado propuso una serie de políticas maternalistas, focalizadas en la consolidación de la familia, que alentaban a limitar la mortalidad infantil (Nari, 2004; Biernat y Ramacciotti, 2013). Este interés por el desarrollo de la familia patriarcal se alineaba con la preocupación por las generaciones futuras, sobre todo por las mujeres madres y/o trabajadoras a fin de que no se sumaran a los desplazados del nuevo ritmo socio económico.

La preocupación estatal por el cuerpo de las mujeres para los fines de la reproducción biológica e ideológica de la sociedad tuvo como objetivo maternalizar a las mujeres a fin de que aceptaran su posibilidad reproductiva como un destino exclusivo (Nari 2004; Biernat y Ramacciotti, 2013; Ledesma Prieto, 2016). Para tal fin, la medicina social y la eugenesia produjeron tres especialidades que abarcaron científicamente las áreas del cuerpo de las mujeres destinadas a la reproducción: la ginecología, la obstetricia y la puericultura. Aun así, y dado que no todas las mujeres se acercaban a los controles periódicos para vigilar su salud reproductiva y planificación familiar, es que el Estado modifica su estrategia política sobre la maternidad a fin de construirla en un asunto público. Marcela Nari define este fenómeno como "politización de la maternidad", de la cual hablamos en la introducción. Esta operación consistió en que el Estado hizo de la maternidad un asunto político pero, sin embargo, no facilitó las condiciones materiales y afectivas para el desarrollo de la maternidad. Cabe destacar que, si bien la politización de la maternidad resultó estructurante del discurso médico eugenésico, también hubo otras intervenciones que tensionaron el carácter normativo del género femenino como las encarnadas por médicos anarquistas acerca del derecho a decidir sobre la capacidad de gestar de las mujeres (Ledesma Prietto, 2016). La condición maternal tenía un contenido político insoslayable del que muchas mujeres eran conscientes, para las trabajadoras resultó un argumento crucial en la lucha para la ciudadanía (Lobato, 2007; Queirolo, 2010) y para las feministas fue una plataforma desde la cual exigir derechos legales y civiles (Lavrin, 2005; Nari, 2004; Becerra, 2009).

Aun así, y como parte de la cadena de precariedad a la que eran empujadas las mujeres, el Estado promovió la formación de otras disciplinas auxiliares a la medicina que se encargaran de intensificar la conexión entre las instituciones sanitarias y las personas de los sectores populares, de modo que si las mujeres no concurrían a los dispensarios, las 
agentes del servicio social se acercaran a los domicilios a través de un vínculo amoroso y amigable, sobre todo con las mujeres madres, a quienes se consideraba como responsables de las tareas de reproducción biológica e ideológica de su familia y su comunidad inmediata, hecho que permitía el abaratamiento de los costos de reproducción social al hacer de las madres agentes garantes del núcleo domestico y de los problemas cotidianos (Grassi, 1989, p. 28).

\subsection{La formación de las agentes para la intervención}

“...al principio simples enfermeras de los pobres, ellas se transforman de más en más en mensajeras de la higiene, no limitando sus beneficios solo a los indigentes, sino concurriendo a prevenir el contagio, facilitar la marcha inteligente del tratamiento, señalar las enfermedades latentes o descuidadas, enseñar el orden, la limpieza, la higiene, la economía doméstica".

Manuel Carbonell (1924), Proyecto de creación del curso para Visitadoras de Higiene Social.

"Es la visitadora indispensable... y tiene todavía un mérito mayor: ¡Ejecutan su noble tarea sin percibir estipendio!”

Saul Betinotti (1925). Situación actual de la Visitadora de Higiene en Argentina.

En octubre de 1921, durante la Tercera Conferencia Nacional de Profilaxis Antituberculosa en La Plata, el Dr. Alberto Zwanck, delegado del Consejo Nacional de Educación, Médico asesor del Departamento Nacional de Higiene e integrante de la cuestionada Cátedra de Higiene de la Facultad de Medicina de la Universidad de Buenos Aires, ${ }^{19}$ destacó en su artículo La visitadora de Higiene en la escuela la importancia de enfrentar lo que era considerado una "lucha contra la pobreza y el hacinamiento" a través de la creación de un personal capacitado para tales cuestiones. De esta manera, propuso la formación del curso específico dentro de la Universidad. Esto no resultaba novedoso, desde hacía poco tiempo se formaban visitadoras desde instituciones como la Asistencia Pública de la Capital, el Hospital de Niños de la

\footnotetext{
${ }^{19}$ En el año 1917, Zacarías Strauss, estudiante de la carrera de Ciencias Médicas de la UBA, cuestiona a la cátedra de Higiene a cargo del Dr. Méndez, quien ocupaba la dirección desde el año 1905. Strauss considera que no proveen conocimientos útiles sobre economía, ciencias sociales y legislación que permitan un acercamiento a las ciencias modernas. La crítica apunta a la necesidad de que la ciencia médica comprenda los males de la higiene como males sociales y no solo individuales. Ver: "La cátedra de higiene" por Zacarías Strauss, Ideas $\mathrm{n}^{\circ}$ 15, septiembre de 1917, p.96-97.
} 
Sociedad de Beneficencia y la Liga Argentina contra la Tuberculosis, pero hasta el momento no existía un organismo universitario a cargo de tal formación (Alayón, 1978). Dos años más tarde, en agosto de 1924, comenzará el primer curso de Visitadoras de Higiene dependiente de la Cátedra de Higiene y del recientemente creado Instituto de Higiene de la Facultad de Medicina de la Universidad de Buenos Aires.

\subsubsection{EI Instituto de Higiene UBA}

El Dr. Manuel Carbonell, personaje activo de la política de la ciudad de Buenos Aires y Concejal de la misma en el año 1931, tuvo el mérito de ser el primer profesor elegido por unanimidad en el año 1920 como titular de la Cátedra de Higiene de la Facultad de Ciencias Médicas de la Universidad de Buenos Aires (FCM- UBA), de acuerdo a los postulados exigidos por los estudiantes reformistas. Carbonell también fue miembro de la Academia de Medicina, jefe de la sección de Higiene del Instituto Bacteriológico del Departamento Nacional de Higiene, y jefe del recientemente creado Instituto de Higiene de la FCM- UBA, todos indicios que avalan la relevancia e influencia de sus acciones. Este médico higienista propuso al Decano de la FCM, por ese entonces el Dr. Julio Iribarne, la concreción de la Escuela de Visitadoras de Higiene Social a fin de formar especialistas capaces de prever enfermedades infecciosas a partir de su capacidad de observar la higiene individual complementada por los saberes de la higiene pública. La "urgencia" que presentó el Director del Instituto de Higiene era tanta que, por única vez, el curso tuvo una duración de seis meses a fin de lograr que las primeras egresadas pudieran intervenir en los espacios educativos y sanitarios y ejercer sus funciones. Por otra parte, se pretendía "obtener mayor preparación de las candidatas" y "dar valor al título adquirido" realizando una sistematización modernizada de aquellas prácticas que efectuaban las mujeres desde las instituciones católicas y filantrópicas. Es destacable que esta será la primera escuela de Latinoamérica creada desde las universidades públicas y no desde las instituciones católicas, como sucedió en otros países (Oliva, 2009, p. 75).

El proyecto para la creación del curso coincide con el año en que la cátedra de Higiene de la Facultad de Medicina de la UBA contó con su propio Instituto de Higiene, reconocido por la FCM. Desde un primer momento, los objetivos del Instituto de Higiene se estructuraron sobre dos líneas: una de enseñanza, con cursos superiores dirigidos a médicos, otros cursos parciales para ingenieros, arquitectos y guardas sanitarios. También realizaban acciones de propaganda y educación higiénica del 
pueblo, e incluso contaban con un Museo de Higiene general y Servicio Social. La segunda línea de trabajo era dedicada a la investigación, con trabajos de higiene aplicada y legislación sanitaria (Carbonell, 1928, p. 6-7). Todas estas acciones se enmarcaban en el interés estatal por difundir la higiene pública y crear un acervo de conocimientos acerca de las problemáticas higiénicas.

\subsubsection{La Escuela para Visitadoras de Higiene Social UBA}

Respecto a la Escuela para Visitadoras de Higiene Social, Carbonell no dudó en ningún momento quién sería el sujeto de la intervención sobre las problemáticas de la salud y de la miseria: las mujeres, "mensajeras de la higiene", sobre quienes depositó la responsabilidad de la transmisión de los conocimientos generados desde el Instituto y la cátedra. La omisión de las razones justificatorias del porqué las mujeres se ocuparían de estas actividades es parte de la naturalización de la división sexual del trabajo que supone a las mujeres como naturalmente preparadas y dedicadas para la atención y cuidado de las personas, llevando la acción doméstica/familiar y de cuidado a la esfera pública. Carbonell incluso sostuvo que la intervención de las visitadoras sería más económica, pero no refirió específicamente a cuáles eran las tareas que realizarían, a pesar de que sabemos que en la figura de la visitadora se incluían labores médicas, sanitarias y de recolección de datos acerca de los afectados. Esto supone que en una sola trabajadora recaía una multiplicidad de actividades (sanitarias, educativas e informativas) que abarataban los gastos de las instituciones sanitarias, es más, esta explotación basada en la polivalencia funcional del trabajo de las visitadoras (Gavrila, 2016) a veces no era remunerada ni siquiera con un estipendio mínimo. ${ }^{20}$

De esta manera, las "mediadoras" del discurso higienista permitirían a sus empleadores una mayor acumulación de ganancias al realizar las siguientes labores: levantamiento de interrogatorios con una ficha clínico social, estudio de casos puntuales, derivación a instituciones capacitadas para la resolución de las problemáticas, documentación de las problemáticas y soluciones aplicadas, colaboración con la acción del médico a través del asesoramiento "sobre las causas sociales que obstaculizan la salud o bienestar del niño", atender y explicar "las prescripciones dadas por el facultativo", dar educación sanitaria a las madres, auspiciar obras de ayuda, inspeccionar la limpieza, fiscalizar los

\footnotetext{
${ }^{20}$ En el balance realizado en el año 1925 por el Instituto de Higiene, destacan la necesidad de que se generen puestos rentados para las jóvenes egresadas del curso que dictan. Ver: Bettinotti, Saul (1925) "Situación actual de la visitadora de higiene en la Argentina". Revista de la Sociedad de Higiene y Microbiología. Buenos Aires.
} 
alimentos que son para la ayuda, armar talleres de oficios para madres, examinar diariamente a los niños, su vestimenta y alimentación desde el control sobre la labor de las niñeras de la Sala cuna (Bustamante, 1935). A través de la fundamentación de "tareas naturales", estas mujeres tenían una multiplicidad de funciones que posibilitaba la no contratación de otros agentes, mientras se reforzaba la división sexual del trabajo y una explotación específica basada en discursos biologicistas. En la exposición de su proyecto, el director del Instituto de Higiene otorga algunas pistas sobre el rol de las nuevas asistentes. Así menciona Carbonell las tareas que les corresponderían:

\footnotetext{
Lazo de unión entre el enfermo y el médico, el problema social y el problema médico, la visitadora debe tener además de una cultura general, una especialización que se dirige hacia la tuberculosis, la protección de la infancia, el servicio escolar, el servicio industrial, la infancia anormal, las enfermedades mentales (Carbonell, 1924, p. 15).
}

Nuevamente, en el mismo comunicado Carbonell deja en claro el lugar instrumental de las mujeres, lugar de mediación entre una porción de la realidad y el conocimiento científico, dejando asentada la relación asimétrica de poder entre los poseedores del conocimiento y quienes lo replicaban. El dominio del conocimiento estaría en manos de los médicos, mientras que las visitadoras aparecen como un nexo, un puente, una suerte de polea que acríticamente transmite los saberes médicos a los distintos sujetos de la intervención. De esta manera, queda establecida una relación de poder en la cual los médicos hombres, poseedores de conocimiento, son quienes desde sus privilegios de grupo profesional forman a las visitadoras como instrumentos que garantizarán su capacidad de gestión sobre la cuestión social. Una lectura de este proyecto deja en evidencia que el curso no pretendía la formación de mujeres con capacidad autónoma de intervención sobre los distintos conflictos, aun así, esa prohibición de hecho y el silencio sobre la temática no implican que en su trabajo concreto las visitadoras no realizaran acciones acordes a lo que su experiencia les indicara, más allá de la prescripción de los profesionales jerarquizados, lo que veremos en los próximos capítulos.

La Escuela para Visitadoras de Higiene Social quedaría bajo la dirección inmediata del profesor titular de la Cátedra de Higiene y también estaría anexa al instituto. La carrera tendría una duración de dos años, el primero sería preparatorio, y el segundo de especialización en Visitadoras de Tuberculosis e Higiene Infantil o Visitadoras de Higiene Escolar. Durante el primer año contarían con una enseñanza teórica en las siguientes materias específicas: Anatomía y fisiología elementales, Elementos de 
microbiología y parasitología, Higiene general, Profilaxis de enfermedades infecciosas y parasitarias, Elementos de Patología Médica y Quirúrgica; y por último, Primeros Auxilios. Estos conocimientos serían puestos en práctica en salas de clínica y cirugía, según estipula el proyecto. En el segundo año de la carrera el apartado teórico se modificaba según la especialización que eligieran: en el caso de las Visitadoras para tuberculosis e higiene infantil, tendrían cuatro materias: Lecciones sobre la Tuberculosis, Lecciones sobre las enfermedades venéreas y las toxicomanías, Puericultura, Servicio Social de la visitadora y, por último, Economía Doméstica. Para las Visitadoras de Higiene Escolar las materias propuestas eran: Lecciones sobre la tuberculosis, Lecciones sobre las Enfermedades venéreas y las toxicomanías, Higiene escolar y Pedagogía médica infantil; Servicio social de la visitadora escolar y, por último, Economía Doméstica. Respecto a la enseñanza práctica, cada grupo de estudiantes trabajaría en los espacios acordes a su especialización, así, para las visitadoras escolares se ofrecían las escuelas y para las dedicadas a la lucha antituberculosa, dispensarios antituberculosos e institutos de puericultura. Dentro de la descripción de las mismas se menciona que serán los profesores del Instituto de Higiene quienes hagan gala del dictado de las clases, sin dejar lugar a ninguna mujer dentro del ámbito de la docencia, lo que refuerza la división sexual del trabajo entre hombres y mujeres al interior mismo de la planificación curricular.

Es interesante cómo en este proyecto se imponen los requisitos para el ingreso en la nueva disciplina: primero, tener entre 20 y 35 años de edad; segundo, certificado de buena conducta; tercero, certificado de buena salud y vacuna; y cuarto, certificado de sexto grado de las escuelas primarias o una instrucción general satisfactoria, pero con preferencia por el primero. Además, para la Visitadora de tuberculosis y de higiene infantil, se exigía un diploma de enfermera o servicios bien documentados de asistencia a enfermos, y para la visitadora de higiene escolar se requería el diploma de maestra normal. En este proyecto se esbozan los modelos de mujer que prefiere la institución sanitaria y educativa: joven, de buena conducta, saludable y formada; aquellas mujeres con posibilidades de haber tenido algún tipo de instrucción previa. Un elemento significativo que reafirmaba la división sexual del trabajo lo constituye la exigencia de un certificado de buena moral. Este lugar propuesto a un sector de jóvenes mujeres también cristaliza un modelo de mujer de clase media que es aceptado en la sociedad buena, saludable y asistencial- pero también podríamos pensar que hay un intento de formalizar dentro del sistema de salud esta feminidad, que resultaba menos peligrosa y 
poderosa que el de las mujeres médicas ${ }^{21}$, tal como el mismo Carbonell les dijo a las primeras visitadoras en su discurso de graduación:

No olvidéis nunca el gran lugar que ha tenido la mujer en las formas múltiples de la asistencia social. Manteneos siempre en vuestro dominio especial, procurando ser la eficaz colaboradora del médico, sin tratar nunca de ocupar un puesto que sólo a él corresponde ( Carbonell, 1925, p. $6)$.

La posición de subyugación a la que se invita a las primeras ciento cuarenta egresadas del Curso de Visitadoras de Higiene debía limitarse al lugar de colaboradora. Estas nuevas asistentes profesionales parecen ser la institucionalización académica de los trabajos no remunerados que realizaron las mujeres históricamente, aunque podríamos considerar a esta "capacitación" como un avance en sus posibilidades de acceso al conocimiento universitario, también implicó un intento por reforzar el lugar subalterno de las mujeres dentro de la intervención social.

\subsubsection{La Escuela de Servicio Social del Museo Social Argentino}

Frente a este lugar asistencial de las mujeres convocadas para la EVHS, surgirá la necesidad de parte de los sectores liberales que ya habían creado la carrera, de formar un nuevo agente con capacidad de comprender "los malestares globales de la sociedad, más allá de las partes que componen”. Así, la Escuela de Servicio Social (ESS) del Museo Social Argentino, creada en 1930, se proponía aunar los conocimientos que se encontraban separados dentro de la Universidad, como eran la economía, la medicina y el derecho con la integración curricular de estudios de estadística, antropología social, genética, higiene social y terapéutica social, es decir, articular una serie de saberes que posibilitará un mayor conocimiento para el abordaje de la cuestión social. Germinal Rodríguez, médico higienista y promotor de dicha carrera, integrante del cuerpo médico del Hospital Muñiz de enfermedades infecciosas y subjefe de Trabajos Prácticos en la cátedra de Higiene a cargo de Manuel Carbonell, integrante del Museo Social Argentino (MSA) y miembro activo del Partido Socialista (PS), menciona que las intervenciones que habían trabajado para "elevar la personalidad humana" y hacer prácticos sus

\footnotetext{
${ }^{21}$ Recordemos que, durante principios del siglo XX, mujeres del movimiento feminista y sufragista, como Cecilia Grierson y Julieta Lanteri, describieron las discriminaciones que debían pasar las mujeres dentro de las profesiones, como en medicina que se esperaba que ocuparan un lugar secundario y a la orden de los médicos. Ver: Ramacciotti, Karina y Valobra, Adriana (2011) en "Modernas esculapios: acción política e inserción profesional", en Lizzette, Jacinto y Scarzanella, Eugenia (eds.) Género y Ciencia en América Latina: mujeres en la academia y en la clínica. Madrid.
} 
dictados asistiendo al pobre, al desvalido, al enfermo, se habían guiado por "impulsos del corazón sin una inteligencia directriz ni una ciencia de la organización". ${ }^{22}$ No cita cuáles eran las personas que, guiadas por el corazón y sin inteligencia dirigida por la ciencia, se encargaban de asistir a los pobres, pero basta con revisar quiénes eran las empleadas en tales acciones y estereotipos para saber que hace alusión a las mujeres, aunque no distingue entre quienes estaban profesionalizadas -en la universidad o en otras instituciones sanitarias- y quienes no.

Es interesante considerar que en esta justificación para la creación de la ESS se excluye mencionar la tarea que realizaba en paralelo la EVHS, no se identifica a las graduadas como agentes de intervención, tampoco se las considera como parte del saber universitario aplicado a la problemática, sino que desde la omisión se las equipara como parte de las personas guiadas por el corazón y sin inteligencia. Seguramente este mutismo forme parte no solo de la invisibilidad de las mujeres en la historia, sino también de la ceguera a la que las mujeres son empujadas colectivamente por realizar "sus tareas naturales", elemento constitutivo del acaparamiento de la fuerza de trabajo de las féminas.

Guido Ruiz Moreno, director de la Escuela de Servicio Social y del curso de Visitadoras de Higiene en los años 50, destacó que si bien la Visitadora y las Asistentes Sociales eran parte del servicio social, la primera solo podía realizar acciones ligadas a la medicina, mientras que el asistente podía estar en otros espacios que no necesariamente tenían que estar ligados a la sanidad. ${ }^{23}$ Estas palabras fueron delineando una división de tareas entre las profesiones. Mientras que las primeras estarían ligadas a las actividades del ámbito médico, las segundas tendrían un campo de intervención más amplio y un mayor margen de autonomía profesional, cada una de ellas con marcas de género que imprimen un sentido respecto del poder y autoridad que tendrían.

Las Visitadoras de Higiene eran consideradas auxiliares de los médicos, pero a diferencia de otros auxiliares como las enfermeras y asistentes sociales, se ocupaban en términos teóricos de la educación sanitaria, el control de la higiene de la vivienda, el impulso de campañas educativas en fábricas, la readaptación social y médica, la realización de investigaciones y estadísticas médicas, la orientación social y médica; también, en caso de ausencia del médico o de la enfermera, la visitadora podría hacerse cargo de las inmunizaciones sanitarias, puesto que ante todo era considerada un agente

\footnotetext{
${ }^{22}$ Rodríguez, Germinal. La organización higiénica de la Republica. Diario La Prensa. 31/03/1927.

${ }^{23}$ Ruiz Moreno, Guido, Ruiz Ventue, Maria Luisa y Adam, Karma Elena (1948) "La Visitadora de Higiene como asistente médico social”. En La revista de Medicina y Ciencias Afines. Año X, No 8. Buenos Aires.
} 
de profilaxis. Germinal Rodríguez destacó el sexo como primera diferencia entre Visitadora de Higiene y Asistente Social (1959, p.16), aunque estas afirmaciones no se contrastaron con la realidad ya que ambas profesiones tendieron a estar feminizadas. La acción de las visitadoras se limitaba a la intervención en la vida cotidiana de los pobres, descargando la responsabilidad de la reproducción moral e ideológica de la sociedad sobre los mismos actores: trabajadores, mujeres madres y familias. Esta profesión se justificaba como un destino para las mujeres que eran convocadas al control de la vida cotidiana en tanto que, por sus buenas y desinteresadas intenciones, podían mantener la cohesión social de la familia popular (Grassi, 1989, p. 29).

La naturalización de la acción asistencial de las mujeres operó a favor de la apropiación colectiva de la mano de obra femenina, por ello resulta interesante poder reparar en la importancia de la profesionalización de la asistencia a través de la EVHS y ESS, en tanto cristalizaron el modelo de mujer aceptable para la asistencia social, pero además consolidaron en el cuerpo de estas féminas la obligación de la reproducción heterosexual de la sociedad, puesto que desde la formación profesional otorgada por las Universidades pretendían que se encargaran de transmitir valores, cuidar, asistir, dar educación sanitaria a las madres, auspiciar obras morales y materiales, fiscalizar a las mujeres/madres en sus domicilios, enseñar sobre la limpieza de los hogares y examinar incluso el alimento de las familias, pero sobre todo "empeñarse en su solución", tal como decía el Dr. Bustamante. Sus destinatarias, así como lo señalan Nari (2004) y Grassi (1989), eran mujeres, y de alguna manera con ello entretejían una enorme trama de saberes y conocimientos que lindaban con los roles esperables para las "damas", y con la preocupación de los sectores higienistas sobre la reproducción de la especie en un cuerpo femenino, sean madres o visitadoras.

Es interesante reparar en estas cuestiones acerca de la ESS del Museo Social Argentino para poder diferenciarlo de la EVHS, puesto que, conjuntamente, articularon una respuesta científica y universitaria a la cuestión social. Sin embargo, no nos detendremos en esta experiencia dado que en el caso de la Universidad Nacional de La Plata, durante la década de 1930, se optó por realizar un abordaje de las problemáticas sociosanitarias a través de la creación de una Escuela para Visitadoras de Higiene Social -que tendrá algunas características distintas a su homónima porteña- con el objetivo de formar una agente especializada para la profilaxis, educación y asistencia de los sectores desvalidos a través de la convocatoria exclusiva a mujeres, mientras que el modelo de abordaje de la cuestión social propuesto por la ESS MSA no será ejecutado en la ciudad 
de La Plata, aunque a partir de 1948 parte de sus intereses se materializarán en la reforma curricular que mantendrá la convocatoria exclusiva a las mujeres.

\subsection{La educación popular entre Buenos Aires y La Plata. La figura de Pilades Dezeo para el desarrollo de la EVHS UNLP}

\subsubsection{La influencia de la Reforma Universitaria}

El desarrollo del Instituto de Higiene de la Facultad de Ciencias Médicas UBA en 1924 contaba con multiplicidad de acciones tendientes a difundir nuevos y mejores hábitos para la sanidad de los sectores populares de las urbes. La principal estrategia para este acercamiento era la promoción de cursos de extensión universitaria para la educación en materia higiénica de los sectores más postergados. A través de la difusión de estos conocimientos se pretendía iniciar al pueblo en los principios y la práctica de la higiene. La difusión de la educación higiénica de los habitantes exigía tareas de propaganda que no solo realizarían los médicos, las visitadoras de higiene, enfermeras, parteras, etc. El Dr. Carbonell era claro con los objetivos que debía seguir la organización de esta educación sanitaria, al identificar como principal promotora a la Universidad, mientras que los departamentos de higiene, sanatorios, hospitales, fábricas, obras filantrópicas y mutualidades, entre otros espacios de reunión, serían los lugares para la difusión (Carbonell, 1928, pp. 18-19). Tal como he citado con antelación, la ciencia médica llevaba adelante desde fines del siglo XIX, una cruzada por establecer su voluntad de verdad como único discurso válido para el disciplinamiento corporal. Sin embargo, la obtención de recursos para efectuar la acción educativa aparecía postergada, y recién en 1921 desde el Centro de Estudiantes de Medicina de UBA pudieron ejecutar este proyecto sin financiamiento, garantizando veinte conferencias anuales en sus propias instalaciones (Carbonell, 1928, p. 19). Para el año 1923, el Dr. Iribarne otorgó una partida especial en el presupuesto anual destinado a la extensión universitaria para el desarrollo de tales actividades.

La idea de "extender la universidad" a los sectores populares que no tenían posibilidades de acceder a una educación superior pretendía la elevación cultural. Distintas universidades del país realizaban estas acciones desde finales del siglo XIX, aunque de una manera poco sistemática, y sobre todo voluntariamente (Biagini, 2001). No obstante, fue a partir de la Reforma Universitaria iniciada en 1918 en la ciudad de Córdoba, y propagada rápidamente en la Universidad Nacional de Buenos Aires y la 
Universidad Nacional de La Plata, en que la extensión universitaria pasará a ser uno de los pilares constitutivos del desarrollo profesional y académico de los graduados y graduadas universitarias.

El grito del cuerpo estudiantil iniciado en Córdoba en 1918, manifestó la incapacidad de las universidades por actualizar sus programas de estudio y su matrícula docente, pero sobre todo dejó al descubierto la negativa de incluir a los estudiantes en el gobierno de la universidad (Portantiero, 1978). La situación política nacional, tensada por las críticas al gobierno radical, además del clima de reforma y represión sobre los sectores trabajadores, favoreció el despliegue de reivindicaciones del movimiento estudiantil, que lo invitaba a inscribirse en un proceso de mayor alcance: el de la lucha por la democratización política y el acceso a la universidad de los sectores medios de la sociedad. Si bien es innegable el carácter institucional de la Reforma desde su crítica al sistema educativo, el pedido de democratización de la vida universitaria manifestó la dimensión política que situó a los estudiantes como sujetos políticos, nucleados por el interés de ganar espacio en la arena de disputa universitaria, hecho que será un hito en la formación de los jóvenes que se enfrentarán a la elite política y cultural (Portantiero 1978; Graciano, 1999).

Los estudiantes pedían no solo la actualización del plantel docente y de los programas de estudio, también incluían el debate acerca del carácter elitista de las universidades, a las cuales los sectores populares no tenían acceso. En este sentido, la extensión universitaria buscó saldar la brecha existente entre los conocimientos académicos producidos al interior de las casas de altos estudios y los sectores populares.

Como parte de este clima, la cátedra de Higiene FCM UBA concursó a sus docentes y resultó elegido por unanimidad el Dr. Manuel Carbonell, con quien se inicia un proceso de actualización de la cátedra y el surgimiento del Instituto. Entre los médicos que formaban parte del cuerpo docente se encontraban el Dr. Alberto Zwanck, quien ejercía como profesor suplente en tanto su cargo era Jefe de Trabajos Prácticos de la materia al mando de Carbonell. Zwanck era también médico asesor del Departamento Nacional de Higiene y del Consejo Nacional de Educación, lo que demuestra una red intelectual que excedía el ámbito universitario e incidía seguramente en el ámbito político. Otro de los médicos que formaba parte de la cátedra era Germinal Rodríguez, de quien ya hemos hablado. También fue parte de este selecto grupo de médicos varones Pilades Dezeo, quien estaba adscripto a la cátedra desde 1924. Su biografía nos exige una mayor atención porque resulta imprescindible para la formación de la EVHS platense, como 
también un maestro inspirador de los estudiantes reformistas de la Facultad de Ciencias Médicas de la UNLP.

\title{
1.3.2 De artista plástico a médico higienista
}

\author{
"Las ciencias médicas orientadas en el pasado, en ser puramente curativas de las múltiples \\ enfermedades individuales no han podido mantenerse en esa finalidad tan limitada y la influencia de los \\ tiempos nuevos, ha ensanchado sus horizontes hasta identificarlos al de los problemas sociales"
}

Pilades Dezeo. Tesis sobre educación sanitaria popular. 1927

Pilades Dezeo ha sido un hombre de ciencias y de artes que en el desarrollo de su vida ha mantenido múltiples curiosidades respecto de cómo acercarse con un lenguaje más ameno a la población, de modo que las múltiples enfermedades pudieran ser identificadas como problemas sociales. Quizás el arte no le bastó para demostrar a un público ampliado los peligros de los males sociosanitarios que empujaban a los trabajadores a la miseria, o quizás la medicina higienista por sí sola no le alcanzaba como estrategia para elevar a los pobres hacia una cultura de reforma social. Para comprender las estrategias educativas de este médico, realizaremos un análisis de su trayectoria profesional.

Son numerosas las obras recientes y clásicas que se han dedicado al análisis de las trayectorias profesionales (Ferrari, 2008). Mediante el análisis de figuras en particular ha sido posible conocer las tensiones, disidencias, alianzas y conflictos de poder desde los que se estructuraron las profesiones. De acuerdo con Bourdieu (2002), una trayectoria puede ser pensada como la suma de posiciones que un agente ha ocupado en uno o varios campos, y por otro lado, como un conjunto de acciones que un actor en particular lleva adelante para obtener una posición dominante (Bourdieu, 2005). De este modo, una biografía académico profesional se compone de la acumulación, inversión, estrategias y apuestas por el propio campo profesional, que nutren al mismo y al individuo.

Pilades Orestes Dezeo nació en 1891 en Capital Federal. Su primera formación de grado fue en artes plásticas. Durante esos años se vinculó a los jóvenes reformistas universitarios de la ciudad de Buenos Aires y compartía con ellos el ideal por "asumir la responsabilidad de extender los beneficios de la cultura a todos los que la organización social había desheredado", tal como cita el Dr. Loza Colomer (1966), 
quien también destaca que jamás quiso hacer carrera como político, tal como hacían otros médicos durante las primeras décadas del siglo XX.

En paralelo a su acercamiento a los grupos reformistas, Dezeo comenzó sus estudios en la Facultad de Ciencias Médicas UBA. Allí se vinculó tempranamente con Manuel Carbonell para desarrollar proyectos para la formación de estudiantes de medicina (Scelsio, 2016, p. 3). En el año 1923 rindió la última materia para graduarse como médico, y su amigo y referente en el ámbito del higienismo aceptó dirigirlo en la escritura de su Tesis titulada "Educación Sanitaria Popular", donde plasmó parte de sus desvelos sobre la difusión de los conocimientos higiénicos al pueblo en consonancia con el legado de la Reforma Universitaria. Entre sus líneas, Dezeo consideraba que las preocupaciones por la salud y la higiene no debían ser de interés exclusivo de los hombres de estudio, sino que era una condición básica de existencia para el progreso humano, a la que, según su idea, debían unirse todos los intelectuales, y aunque no lo mencione en su tesis de grado, también las mujeres se sumarían a ello.

La propuesta de Dezeo era extender la educación higiénica social sobre cualquier otro método administrativo o legislativo que resultara costoso e ineficiente. La operación que proponía colocaba a los médicos en el lugar de árbitros y articuladores del discurso higienista para el progreso social. Así lo planteó:

El valor de la educación higiénica del pueblo, no como complemento de las organizaciones sanitarias tal cual hoy es en nuestro país sino como fundamento esencial creemos contribuir a la realización de ese apostolado, señalando la obligación de la Universidad para encarar resueltamente el cumplimiento de ese deber ineludiblemente social (Dezeo, 1927, p.15).

La exigencia de carácter "obligatorio" que asigna a la Universidad en la formación y la divulgación de los conocimientos higienistas muestran el entramado político ideológico en que se inscribe el proyecto de "educación sanitaria popular" y, posteriormente, la EVHS, pero también un acuerdo tácito con su director de tesis y de cátedra, el Dr. Manuel Carbonell. Dezeo, en tanto reformista, promovió el diálogo con otros sectores sociales, ampliando la acción de la universidad no solo por su "apostolado" científico, sino para evitar otros males. Así lo dijo en su tesis: "los intelectuales extrauniversitarios, quienes las pocas verdades que enuncian las han aprendido viviéndolas, pero por falta de método y disciplina científica deforman las conclusiones creando sectarismos perniciosos al equilibrio social" (Dezeo, 1927, p. 21)

Esta preocupación por instruir al pueblo sin perder el carácter científico de la producción del conocimiento era una temática compartida con otros colegas coetáneos a 
Dezeo, tanto con quienes compartía la cátedra de Higiene FCM UBA, como también con otros que cuestionaban las acciones de difusión en materia de hábitos saludables encarnadas por las mujeres. Tal es el caso de Dr Gregorio Araoz Alfaro, ${ }^{24}$ quien destacó el trabajo educativo realizado por las mujeres en cantinas maternales, Institutos de Asistencia Pública de Capital Federal, la Sociedad de Beneficencia, el Patronato de la Infancia y otras instituciones benéficas que se encontraban en las principales ciudades y provincias, subrayando que si bien era una valiosa tarea también era insuficiente puesto que: "No basta decorar con el nombre de "inspectoras" o visitadoras a señoras de buena sociedad, frecuentemente ignorantes y que solo buscan un sueldo para remediar una situación difícil” (Araoz Alfaro, 1924, pp. 24-25). Es decir, que si bien se avanzaba en la difusión de los conocimientos de higiene sobre el pueblo, era imprescindible darles una valía científica a fin de garantizar "el equilibrio social” que solamente podían otorgar los espacios de producción del conocimiento académico científico, es decir, las universidades. Más adelante volveremos sobre este punto.

Ahora bien, la educación sanitaria popular que proyectaba Dezeo en su tesis y que aplicaba desde su acción como estudiante y graduado parece tener un amplio reconocimiento entre los sectores estudiantiles. Esto podemos deducirlo en función que fueron estos sectores que, en distintos momentos, publicaron su tesis; en principio fue publicada en el año 1927 por el Círculo Médico Argentino y Centro de Estudiantes de Medicina en la ciudad de Buenos Aires, y luego en el año 1938 el Centro de Estudiantes de Medicina de FCM UNLP decide reeditar esta tesis, pero modifica el título por "Educación Sanitaria Popular. La importancia de la extensión universitaria", indicando la valoración que daban a este escrito. En el capítulo 2 analizaremos este vínculo establecido con los estudiantes de la FCM UNLP y la relación con el temprano interés de los estudiantes reformistas platenses por abordar científicamente la cuestión social.

Las experiencias acumuladas en la intervención sobre la cuestión social se habían iniciado en su compromiso con los múltiples proyectos de extensión que había dictado desde el Instituto de Higiene de la Facultad de Medicina. ${ }^{25}$ Desde esta posición, propuso

\footnotetext{
${ }^{24}$ Profesor honorario de la Facultad de Medicina en las materias de Semiología y Clínica Propedéutica en la FMED- UBA durante los años 1904- 1928: médico en la sala de niños del Hospital San Roque (18931928); presidente del Departamento Nacional de Higiene en los períodos de 1923-1928 y 1930 a 1931. También fue Presidente de la Liga contra la Tuberculosis.

25 Entre las temáticas desarrolladas como parte de la Extensión Universitaria de la Cátedra de Higiene, Dezeo cita en su Tesis las siguientes temáticas: 1. el cuerpo humano y la salud, 2. profilaxis social de la tuberculosis, 3. el alcoholismo, sus peligros y profilaxis individual y social, 4 . insectos como transmisores de enfermedades, 5. principios generales de profilaxis, 6. elementos sobre inmunidad natural y adquirida, 7. las infecciones que se beben (tifoidea, difteria, cólera), 8. profilaxis de las fiebres eruptivas, 9. higiene
} 
en su tesis multiplicar las conferencias de una manera ejemplar para que sean imitadas por otras instituciones, e incluso por oyentes que potencialmente podrían convertirse en promotores de higiene; particularmente, debían ganar en la cruzada sanitaria a aquellos obreros que tenían mayor influencia en sus sindicatos y corporaciones, y con ello difundir la voz del higienismo en -y con- los sectores populares. Éstos aparecen en su relato como el sujeto a educar, casi como una metáfora de la relación padre-hijo, en la cual el médico poseedor del conocimiento higienista posibilita "desasnar" de las ideas "inmaduras" y perniciosas a la sociedad en su conjunto. El público obrero emerge en su análisis como:

los más necesitados de conocimientos, son los más preocupados por aprender, los más espontáneos en exteriorizar sus impresiones, los más desinteresados en escuchar [...] Ese público conserva muchas de las características de los niños: son preguntones, llenos de actividad y de inquietud, y sumamente apasionados (Dezeo, 1927, pp.).

En esta observación manifiesta el carácter redentor y civilizatorio que ejercerían los médicos higienistas sobre estos sujetos "aniñados" que carecían de los conocimientos sobre la higiene e incluso "se muestran hoscos" ante el conocimiento académico del cuál desconfían.

En el desarrollo de su trayectoria académica y profesional, Dezeo comprendió que no serían únicamente los médicos los encargados de educar e instruir al pueblo en materia de higiene. Por ello, no sólo estuvo a cargo de la extensión universitaria de la Cátedra y el Instituto de Higiene FCM UBA durante la década de 1920, sino que ocupó un lugar de mayor relevancia entrada la década de 1930, momento en que Alberto Zwanck ya ocupaba para ese entonces el lugar de director del Instituto de Higiene y también de la Cátedra de Higiene de FCM UBA, por lo cual Pilades Dezeo logró un voto de confianza de sus colegas y accedió al puesto de titular interino.

En paralelo, en el año 1934 en la ciudad de La Plata, la vieja Escuela Preparatoria de Medicina alcanzaba el estatuto de Facultad de Ciencias Médicas luego de más de una década de lucha encarnada por sus estudiantes reformistas. Su primer decano, el Dr Héctor Dasso, ${ }^{26}$ creó en agosto la cátedra de Higiene Médica y Preventiva, y para ello

social de la primera infancia, 10.principios generales de puericultura, 11. higiene escolar, 12. enfermedades venéreas: su profilaxis. Ver: Carbonell (1925) Balance del Instituto de Higiene.

${ }^{26}$ Dr Héctor Dasso. Profesor de Ciencias Naturales de la UBA en el año 1918 y secretario de la Facultad de Medicina en el mismo año. Desde 1922 fue profesor de la Cátedra de Microbiología de la Escuela de Ciencias Médicas UNLP. Durante 1923-1926 fue director de la Escuela de Ciencias Médicas de la UNLP y luego primer decano de la Facultad de Medicina UNLP durante el período 1934- 1938. 
convocó inmediatamente al Dr Pilades Dezeo para ocupar el puesto de profesor titular de la cátedra, quien concursa su cargo dos años más tarde.

Los estudiantes reformistas de la FCM UNLP admiraban al higienista y publicaban sus trabajos y desempeños. En relación a la participación en el ciclo de radioconferencias de LR11 -en el capítulo 4 detallaré este aspecto-, eran citadas cada una de las conferencias que organizaba Dezeo, siendo publicadas de manera completa aquellas que resultaban de mayor interés para los estudiantes. Así, los estudios socio sanitarios de Dezeo sobre las condiciones de hacinamiento y vivienda en que vivían las familias obreras fueron publicados en la revista. En su trabajo "Consideraciones sanitarias y económico sociales sobre los niños de la colonia marítima de Necochea", el autor sostuvo lo siguiente:

La relación desfavorable de la que disponen los padres para alimentar a sus hijos y luchar contra la debilidad de los mismos, revelando hasta para los más optimistas, que en el estudio de los antecedentes económico sociales se encontrarán las causas de muchos problemas sanitarios, cuyos agentes biológicos pueden ser meros huéspedes finales de un organismo empobrecido, deformado y aniquilado por el cortejo de factores que acompañan la miseria y a la ignorancia (Dezeo, 1937, pp. 25-26).

Con estas palabras Dezeo muestra su preocupación por instruir a las masas en la prevención de mayores males sanitarios. De algún modo, con esta trayectoria se vincula al interés por la educación higiénica del pueblo y reconoce que la labor de atención médica no bastaría para abordar la complejidad del malestar sanitario de la época. Al igual que otros higienistas coetáneos, la preocupación por la vivienda y el hacinamiento eran parte de una lucha mayor por regular el espacio urbano y transformar los hábitos cotidianos mediante la Ciencia, en detrimento del curanderismo y el naturalismo (Dezeo, 1927, pp. 37-38). La necesidad de intervenir en la modificación de los hábitos cotidianos de las personas, en especial de aquellas que se encontraban hacinadas en los centros urbanos, exigía una mayor difusión educativa y de personas que propagaran la voz.

Esta difusión la realizaban los estudiantes del Centro de FCM UNLP, pero con el correr de los años también se hizo necesario sumar nuevas agentes. Dezeo reconocía que la necesidad de realizar propaganda higiénica y educación sanitaria demandaba los esfuerzos de los estudiantes y graduados de la FCM, por ello serían otros agentes y personal técnico, como las visitadoras de higiene social, quienes: "entienden cumplir el deber universitario extendiendo más allá del aula parte del saber aprendido en ella. 
Creen que la democratización de la cultura es un ideal no cumplido sino en parte hasta hoy y hacia su plena realización" (Dezeo, 1939, pp. 17-18).

Sus antecedentes en la Escuela porteña seguramente lo impulsaron a replicar dicha experiencia en la UNLP. Así, en 1937 presentó el proyecto para la creación de la EVHS al Consejo Académico de la casa de altos estudios platense. Las razones y justificaciones para ello las abordaremos con detalle en el próximo capítulo. Una vez en la UNLP y como director de la EVHS, Dezeo será promotor de nuevas acciones de difusión de la higiene social, invitando a las estudiantes y graduadas de la EVHS-UNLP a disertar en la radio sobre distintas cuestiones, sobre todo alrededor de la maternidad y las enfermedades infectocontagiosas, lo que demuestra el interés porque estas profesionales dialoguen con las mujeres madres, en tanto encargadas de la reproducción del núcleo doméstico. A diferencia de las conferencias que realizó este maestro del higienismo en Buenos Aires, en la ciudad de La Plata se guardan algunas fuentes trascriptas de las radioconferencias realizadas por estas profesionales. Desarrollaremos con mayor especificidad cómo la experiencia, saberes y redes intelectuales establecidas se tradujeron y reformularon con la creación de la EVHS UNLP, el diálogo instaurado con los sectores reformistas y las áreas de incidencia de estas jóvenes profesionales. 
En el presente capítulo desarrollaré un panorama general de las condiciones que posibilitaron el surgimiento de la Escuela para Visitadoras de Higiene Social en la UNLP. Puesto que la ciudad de La Plata ha sido diseñada y planeada con el objetivo de conducir armoniosamente las contradicciones del crecimiento urbano e industrial, atenderé a los modos particulares en que se organizó la asistencia social de los sectores con dificultades para reproducir sus condiciones materiales de existencia.

Como mencionamos desde el capítulo 1, la asistencia social fue una de las preocupaciones centrales para el desarrollo de los Estados modernos. Durante fines del siglo XIX y principios del XX, se produjo en Argentina una crisis respecto a las modalidades de asistencia social promovidas desde las instituciones de caridad cristiana. A partir del despliegue de la racionalidad positivista, el gobierno nacional alentó el reconocimiento de nuevas instituciones filantrópicas, benéficas, de socorros mutuos, entre otras, capaces de dar respuesta y contener a los sectores más necesitados. En ese momento tuvo lugar un cambio en la fundamentación filosófica de la asistencia a los pobres que removió la tradicional noción de caridad para suplantarla por una propuesta positivista liberal de "solidaridad", fundamentada en una nueva responsabilidad del Estado encargado de organizar a las instituciones privadas abocadas a la beneficencia y recaudar impuestos para solventarla (Belmartino, 1996). Sin embargo, el Estado también sumaba sus propios esfuerzos a través de la creación de hospitales, dispensarios, oficinas de asistencia pública y otras dependencias de inspección de sanidad que, progresivamente y sobre todo a partir de la década de 1930, fueron creciendo conforme al aumento de la demanda.

Mediante la elaboración de esta compleja cartografía de la asistencia social en la ciudad de La Plata pretendo analizar los principios organizativos de la intervención, los dispositivos que utilizaron, cómo fue el trabajo de las mujeres en esos espacios, así como también el público a quien destinaban sus acciones; elementos que nos posibilitarán encontrar continuidades y rupturas con la formación profesional propuesta desde la Escuela para Visitadoras de Higiene Social (EVHS).

Tal como planteamos en la introducción, el Trabajo Social (TS) y sus protoformas, entre ellas la EVHS, se caracterizan por su indefinición, es decir, que la profesión no está definida a priori sino que es presupuesta y guiada por las acciones y constantes ideológicas de quienes ejercen la práctica (Karsz, 2007). Esto no quiere decir que sea 
imposible definir el TS, sino que en la dialéctica definicional del mismo es necesario presentar una problemática sobre la que van intervenir las agentes del servicio social e indagar las definiciones del TS que guían las acciones de los y las profesionales en función del marco teórico y conceptual del que parten y que atiende a intereses políticos e ideológicos (Karsz, 2007, p. 24). En este sentido, reparar en las modalidades que antecedieron a la profesión dará cuenta de cómo se priorizaron algunos saberes, prácticas profesionales, performances de intervención, entre otras cuestiones, sobre las que se estructuró la profesión en el período de 1920 a 1948 en la ciudad de La Plata.

Esta cartografía sobre las condiciones de la creación de la EVHS sería incompleta si no sumamos a otro agente crucial para la normalización, organización, difusión y exclusión de conocimientos: la universidad. La Universidad Nacional de La Plata, sus estudiantes reformistas y docentes, quienes compartían el anhelo por la exclaustración del conocimiento científico, tendrán un rol central en la promoción de respuestas científicas para el abordaje de la cuestión social.

\subsection{La ciudad higiénica y el ordenamiento de los cuerpos}

La ciudad de La Plata, capital de la provincia de Buenos Aires, fundada el 19 de noviembre de 1882, se distinguió de otras ciudades del moderno Estado nacional por ser proyectada desde la ciencia positivista. La unión entre medicina y urbanismo moderno que incluía las obras de provisión de agua y los precarios intentos de alumbrado eléctrico- manifestó, de algún modo, la preocupación del gobierno de La Plata por conducir las formas de convivencia dentro del moderno sistema institucional. El crecimiento urbano y poblacional hizo temer el despliegue de la llamada "cuestión social" y con ella, la expansión de las epidemias, hecho que permitió que la higiene como ciencia profiláctica y disciplina médica interviniera en el proceso institucional, suministrando un corpus normativo de orden prescriptivo y proscriptivo al Estado, haciendo de los médicos actores centrales en la proyección de las políticas sociales (Vallejos, 2007, pp. 53- 57).

El destacado médico higienista Emilio Coni ${ }^{27}$ había participado en el crecimiento de la ciudad. Su incidencia en los primeros años de urbanización lo invitó a llamarla "la

\footnotetext{
${ }^{27}$ Emilio Coni, médico higienista, egresó de la Facultad de Ciencias Médicas de la Universidad Nacional de Buenos Aires en el año 1878. Su trabajo se orientó hacia la práctica de la higiene pública y la medicina social sobre las cuales no solo estudió sino que también disertó, publicó y obtuvo reconocimiento internacional. Contribuyó a poner en marcha y reencauzar instituciones de abordaje infanto juvenil, como el Patronato de la Infancia, La Liga Argentina contra la Tuberculosis, la Oficina de Estadística municipal
} 
ciudad higiénica" dada su impronta positivista e higienista manifestada en el ordenamiento de las calles, el sistema cloacal, el alumbrado eléctrico público -primero en su tipo en Latinoamérica-, entre otras características de una urbe moderna. Esta planificación espacial también pretendía facilitar el ordenamiento de los cuerpos, en particular, de los trabajadores y las trabajadoras de los sectores populares, a quienes no solo se aisló del casco urbano trazado entre las diagonales y circunvalación, ${ }^{28}$ sino que también fueron ubicados para prestar su mano de obra en los lugares donde se desarrollaron actividades vinculadas a la última etapa de producción agroganadera, es decir, la faena y los saladeros en zonas cercanas al Río de La Plata. ${ }^{29}$ Esta separación era justificada desde el discurso biomédico, donde lo salubre y lo patológico tomaron protagonismo para definir como imprescindible el aislamiento de estas actividades que podían provocar distintas enfermedades entre los habitantes de la ciudad, sobre todo luego de la peste de fiebre amarilla suscitada en la ciudad de Buenos Aires en 1871 (Vallejos, 2015, pp.14-19).

Las enfermedades infecciosas constituían una preocupación para la salud, en especial luego de los brotes epidémicos en la ciudad de Buenos Aires que diezmaron la población. Así, distintas prácticas y costumbres que alteraban el orden público eran consideradas como perniciosas para la salud. La prostitución, el alcoholismo y las toxicomanías eran entendidos como "enfermedades sociales" en tanto resultaban "desviaciones" del orden pretendido. Las estrategias de intervención buscaban regular la conducta de los individuos para evitar la propagación de estas prácticas a través de un

(de la ciudad de Buenos Aires), la Maternidad del Hospital San Roque, entre otras. También fue presidente de la Primera Comisión Directiva de la Sociedad Médica Argentina (1891).

${ }^{28}$ La ciudad de La Plata fue planificada por el Jefe del Departamento de Ingenieros, Pedro Benoit, junto a un amplio grupo de ingenieros y urbanistas. El ordenamiento urbano de la ciudad se basó en un cuadrado de más de 900 cuadras y más de 20 plazas y parque recreativos, trazado por dos diagonales que cortan de lado a lado la ciudad y se unen en el centro de la misma (Plaza Moreno, donde está ubicada la catedral y el edificio municipal), teniendo como límite la circunvalación, que es la avenida que delimita el cuadrado constituido por la ciudad. Más allá de la circunvalación, hacia el sur, se encontraban (y mantienen la misma denominación actualmente) "Los Hornos", donde se hallaban los hornos encargados de hacer los ladrillos para la construcción de la ciudad. Del lado norte, estaba el barrio de Tolosa, el primer barrio de la región donde llegaba el tren desde la década de 1870. Otras comunas estaban más aisladas y no lindaban con la circunvalación, tal es el ejemplo de Ensenada y Berisso, ambas apostadas en la ribera del Río de La Plata.

${ }^{29}$ Ejemplo de ello es la ciudad de Berisso. Fundada en la década de 1870 por Juan Berisso, se destinó aquella zona cercana al río a la producción de un saladero de carne, puesto que en la ciudad de Buenos Aires donde se realizaban estos trabajos se presentaban serios problemas sanitarios. Surgió en principio como un villorio, aunque para la década de 1920 tuvo lugar un importante desarrollo industrial a partir de la radicación de dos importantes frigoríficos: Swift y Armour. La construcción del puerto de La Plata hacia fines del siglo XIX y la posterior ubicación de la destilería de YPF en 1924 o la hilandería Patent Knitting Company en 1925, no alcanzaron para diluir la fuerte vinculación entre el pueblo y la fábrica. Ver: Lobato, Mirta Zaida (2004)La vida en las fábricas. Trabajo, protesta y política en una comunidad obrera, Berisso (1904-1970). Prometeo, Buenos Aires. pp. 41- 43. 
abanico de medidas que iban desde ordenanzas municipales hasta planes de educación sanitaria (Belmartino, 1996, p. 214).

De este modo, la estrategia de planificación urbana pretendía no solo normalizar y disciplinar el espacio, sino también a estos cuerpos considerados "peligrosos" y su fuerza de trabajo. Claro que esto no hubiera sido posible sin el aval normativo y científico que brindaron los médicos. El poder de este grupo profesional se incrementó progresivamente desde la formación estatal, momento en que adquirieron una mayor gravitación sobre la asistencia social a través del control de instituciones y redes de instituciones de atención en políticas sanitarias en función de la legitimidad conferida a este sector por el Estado (González Leandri, 2005). El discurso médico constituido por una voluntad de verdad sobre la intervención social ha dado un soporte institucional y de distribución del conocimiento que ejerció un poder de coacción sobre otros discursos, tal es la dimensión política de estos enunciados y su interés por anular otros sentidos. ${ }^{30}$ Como parte de la división sexual del conocimiento científico, este lugar privilegiado era exclusivo de los hombres. A pesar de que muchas mujeres eran graduadas en medicina, no podían acceder a cargos de gestión pública, como tampoco al dictado de clases en la universidad, hecho que demuestra dos cuestiones importantes. En principio y de acuerdo a lo sostenido por Dora Barrancos (2002), esto es parte de la tensa relación de inclusión/exclusión que enfrentaron las mujeres en la primera mitad del siglo XX, que se encontraban en la contradicción entre avanzar en autonomía y organización feminista, y a su vez lidiar con la exclusión política y también profesional. Además, este hecho evidencia cómo la ciencia médica fue un soporte fundamental para el sistema heteropatriarcal y coadyuvó a la legitimación de modelos sexuales y genéricos hegemónicos de varones y mujeres (Ledesma Prieto, 2015, p.51), a la vez que también aisló a las mujeres de los espacios de difusión y producción de los discursos de poder, tal como era la universidad.

Aun así, las mujeres se encontraban presentes en la atención socio sanitario desde la formación del Estado Nacional. En la ciudad de La Plata participaban desde distintas asociaciones laicas y católicas que intentaban paliar las necesidades económicas de sectores sociales considerados incapaces de garantizar su reproducción cotidiana.

\footnotetext{
${ }^{30}$ Tomamos del análisis foucaultiano la noción de discurso de verdad ya que pone de manifiesto cómo el discurso está íntimamente vinculado con la materialización de las relaciones de poder. Puesto que las relaciones de poder son múltiples, atraviesan, permean y constituyen el cuerpo social, no pueden disociarse ni funcionar sin una producción, acumulación y circulación del discurso. En este sentido, todos los discursos de verdad, entre los que más se destaca el de orden legal y médico, resultan una práctica de ejercicio de poder. Ver: Foucault, Michel (1992 [1976]) Curso del catorce de enero de 1976, en Foucault, Michel, Microfisica del poder. Ediciones La Piqueta, Madrid.
} 
Grupos filantrópicos y católicos de mujeres sentaron las bases de políticas asistenciales que luego serían rearticuladas en la construcción del estado de bienestar (Guy, 2007, p . 27). Veamos a continuación cómo se configuraron los espacios de atención sociosanitaria en la ciudad de La Plata desde fines del siglo XIX hasta principios del siglo XX, y cómo fue la participación de las mujeres en este desarrollo.

\subsubsection{Damas, señoras y visitadoras}

El carácter moderno de la ciudad de La Plata estructuró sus modos de organización social a partir del ordenamiento urbano y también desde la precaria atención y organización de la asistencia social. Distintos agrupamientos de mujeres cristianas y/o de filántropas buscaron incidir en la esfera pública a través de acciones de cuidado no remunerado hacia mujeres y niños.

En 1887 se funda en la ciudad la Sociedad de Beneficencia (SB). Si bien desde el año 1823 el Presidente Bernardino Rivadavia había creado la primera de estas instituciones en la Ciudad de Buenos Aires, que en principio se conformaba solo de mujeres de la alta sociedad, esta composición se modificó con el crecimiento de la población extranjera y el acelerado desarrollo del mercado de trabajo. Como ya hemos dicho, a partir de 1880 se hizo necesario ensanchar la base de participación en la SB, fenómeno que invitó a mujeres de sectores medios y populares ascendentes -y no sólo a las damas de la elite porteña- a participar en esta institución benéfica. A partir de ese mismo año, la SB pasó a ser la Sociedad Nacional de Beneficencia y desde 1908 quedó bajo la dependencia del Ministerio de Relaciones Exteriores y Culto (Ciafardo, 1990; Ramacciotti, 2009).

La SB platense surgió casi en simultáneo con la ciudad para organizar la vigilancia y asistencia social. Fue "fundada a imagen y semejanza de la que funciona en Buenos Aires" 31 , ya que ambas compartían la realización de una ardua tarea política y económica: organizar el funcionamiento de las instituciones dedicadas a la atención sociosanitaria y con ello garantizar al Estado provincial las condiciones básicas de supervivencia de aquellos que por razones económicas y/o afectivas no podía valerse a sí mismos. Fundamentalmente, su trabajo era administrar e inspeccionar las instituciones dedicadas a gestionar la atención de mujeres madres, niños y niñas, como las casas de maternidad, los asilos de niños expósitos, huérfanos, desamparados e inválidos.

\footnotetext{
${ }^{31}$ Censo de la ciudad de La Plata 1910, pp. 336.
} 
Tal como lo menciona el Censo Municipal de 1910, esta organización de beneficencia se encargaba también de la administración de los Hospitales Misericordia (actual Hospital Policlínico San Martín), el Hospital de Niños, el Asilo de Huérfanos y la casa de la Maternidad, para lo cual obtenían financiamiento del Estado nacional y provincial. $\mathrm{Su}$ intervención en instituciones hospitalarias, asilos de niños y patronatos buscaba auxiliar y cuidar a huérfanos y desamparados, menesterosos, ciegos e inválidos, la infancia desvalida, con el fin de "mitigar el dolor de los pobres de solemnidad, de ayudar al enfermo sin recursos a curar sus males, y de llevar algún pequeño consuelo pecuniario al desamparado" (Grau, 1954, p. 78).

Si bien todas las mujeres socias de la SB podían visitar los establecimientos a su cargo, solo las inspectoras asignadas a cada uno de ellos podían realizar sugerencias acerca de qué acciones llevar adelante a través de la confección de informes mensuales para el Consejo $^{32}$ y para la Presidenta de la $\mathrm{SB}^{33}$. El puesto en este cargo tendría una duración de dos años y eran electas, en principio, por decisión de la Presidenta y posteriormente por votación del Consejo en su rol como "Consejeras Honorarias". 34 Este hecho es relevante porque, según la propia institución y el Gobierno de la Provincia -que estaba a cargo de su funcionamiento-, no era necesaria una formación para la intervención, hecho que, como veremos más adelante, se modificará junto con el desarrollo de las instituciones de asistencia social. Otra de las obligaciones de las inspectoras era visitar el establecimiento a su cargo al menos una vez a la semana, proveer las necesidades ordinarias de cada uno de ellos, velar porque el reglamento interno de cada una de esas instituciones se cumpla, entregar informes escritos de su actuación, visar órdenes y “cumplir las órdenes e instrucciones que se dicten por el Consejo o la Presidenta de la Sociedad"35.

El cargo de inspectora no otorgaba a estas mujeres capacidad de votar en las decisiones del Consejo, no obstante estaba revestido de cierta autoridad por ser quienes articulaban la relación de una tríada importante para el sostenimiento de la vida de parte de los sectores populares, a saber: las instituciones de asistencia (hospitales, maternidad, asilos), las damas de la sociedad de beneficencia, y mediante ellas, el gobierno de la provincia. El relevamiento de las condiciones en que se encontraban las instituciones,

\footnotetext{
${ }^{32}$ Las atribuciones del Consejo consistían en "aconsejar" a la Presidenta de la sociedad en la elección de las inspectoras de los establecimientos, nombrar a los empleados que estarán en las instituciones a su cargo y encargarse de los pagos, sueldos y otras actividades del desempeño financiero de la Sociedad de Beneficencia. Capítulo II, Art 24, 25, 26 y 27.

${ }^{33}$ Artículo 14 del Reglamento de la Sociedad de Beneficencia de La Plata, pág. 8. Año 1892. La Plata.

${ }^{34}$ Art. 52 y Art.54 del Reglamento de la Sociedad de Beneficencia La Plata, pág. 16. Año 1890. La Plata.

${ }^{35}$ Art. 57 del Reglamento de la Sociedad de Beneficencia La Plata, pág. 16. Año 1890. La Plata.
} 
las visitas a las niñas y niños al menos una vez a la semana, la provisión de necesidades específicas, el control del presupuesto, entre otras acciones, las constituía en un engranaje fundamental para el funcionamiento de la asistencia social, como también las reafirmaba en el desarrollo de las tareas feminizadas para la reproducción cotidiana de las condiciones de vida, aunque desde un espacio público que permitió a estas mujeres hacer de la "performance de la caridad" 36 un acto de reconocimiento político (Guy, 2011).

Dada la importancia de estas tareas, sobre todo por lo redituable que resultaban para el Estado, desde el Reglamento de la SB se pretendía garantizar la permanencia y discreción en los cargos mediante la exigencia escrita de un compromiso exclusivo, una suerte de consagración matrimonial con la institución, donde cualquier infidelidad institucional era penada con la expulsión de aquellas Inspectoras o Consejeras que formaran parte de otro directorio o de corporaciones de otras instituciones. ${ }^{37}$ Esta exigencia sugiere que, si bien estas inspectoras no eran formadas profesionalmente, constituían un capital importante de conocimientos sobre el funcionamiento interno de las instituciones, por lo cual se intentaba retenerlas en tanto eran poseedoras de saberes indispensables para la intervención y administración. Esta reglamentación sobre los espacios de participación encuentra también su fundamento en que las damas de la SB controlaban los principales hospitales de la zona -que aún siguen siendo de referencia para la provincia-, entonces, si alguna de estas mujeres partía a otra institución, se perderían "insumos" de la maquinaria de la atención social.

Estas tareas de las instituciones de beneficencia, en particular las de la SB, facilitaron al Estado contar con mano de obra que organizara la reproducción social de los sectores que no podían garantizar materialmente su supervivencia cotidiana. El Estado hizo uso de la fuerza de trabajo de las damas de la caridad de un modo polivalente que le permitía no solo abaratar los gastos de reproducción social de los habitantes del Estado y garantizar el control bajo su órbita a través de las múltiples funciones ejercidas por estas mujeres (inspección, educación, gestión de personal en las instituciones a su cargo,

\footnotetext{
${ }^{36}$ Donna Guy (2011) analiza a la SB porteña desde una multiplicidad de fuentes, entre ellas fotografías. A partir del análisis de las imágenes considera que las mujeres de la Sociedad de Beneficencia, si bien tuvieron un gran peso en indicar la proyección de las futuras políticas sociales que realizaría el peronismo en relación al binomio madre-hijo, ellas no manifestaban actos de solidaridad con la clase trabajadora, como considera la autora que sí sucederá posteriormente con el peronismo, sobre todo desde la figura de Eva Perón. Por su parte, las mujeres de la SB se mostraban como quienes auxiliaban a los necesitados pero desde una posición de jerarquía. Ver: Guy, Donna (2011) Las mujeres en la construcción del Estado de Bienestar. Caridad y creación de derechos. Cap. III "La performance de la asistencia infantil", pp. 99134. Prometeo, Buenos Aires.

${ }^{37}$ Art 26. del Reglamento de la Sociedad de Beneficencia La Plata. Año 1890. La Plata.
} 
etc.); sino también valerse de mano de obra experimentada sin intercambiar estipendio alguno.

Además de la SB había otras instituciones de carácter laico, como la Sociedad de Beneficencia Francesa "Dames Francaises Bienefaisance”, fundada en 1908. Contó con alrededor de cien socios y socias, y se dedicaba mayormente a dar amparo y ayuda económica a individuos pertenecientes a la colectividad, entregando ropas, alimentos e incluso juguetes. Una de las tareas destacadas era la atención a mujeres viudas y sus hijos, quienes eran beneficiarios de ciertas donaciones luego de la visita de las inspectoras de esta Sociedad. ${ }^{38}$ De manera similar funcionaba la Sociedad Italiana de Beneficencia Hospédale Umberto I -posteriormente Hospital Italiano-, creada en 1886. Nucleó a más de mil doscientos socios, hecho que no resulta llamativo dado el elevado número de residentes italianos que habitaban en la capital. ${ }^{39}$ Puesto que muchos italianos vivían y trabajaban en la ciudad, se organizaron como comunidad para garantizar el sustento de aquellos que dependían de una ayuda ${ }^{40}$ porque tenían inconvenientes causados por enfermedad, abandono o falta de trabajo.

Recordemos que la ciudad de La Plata contaba con un alto índice de inmigrantes que, a diferencia de los italianos y los españoles, eran menos en cantidad pero también se organizaban en sociedades de socorros mutuos que procuraban mantener la cultura de sus países de origen y atender a la salud y otras necesidades vitales de la comunidad (Vallejos, 2015, p. 39). También se desarrollaron distintas formas de mutualidades constituidas desde la fundación de la ciudad. En la organización de sociedades de socorros mutuos se identificaban "los paisanos", pero también se sumaban camaradas de trabajo. Así, desde finales del siglo XIX, se formaron más de veinte mutualidades en la ciudad que desplegaron su actividad hasta alrededor de 1920, cuando cesaron las inmigraciones masivas en el país. ${ }^{41}$ Estas prácticas de apoyo mutuo entre inmigrantes se

\footnotetext{
${ }^{38}$ Memoria correspondiente a tres años de ejercicio. Balance general correspondiente a 1921. Año 1922. La Plata. Talleres gráficos Alfredo Crespo.

${ }^{39}$ Censo 1910 La Plata.

${ }^{40}$ Hasta el año 1910 existían trece sociedades italianas de beneficencia y de socorros mutuos, a saber: Societá Unione e Fratellanza, Societá de M.S. Unione Operai Italiani, Societá Italiana di Beneficenza Hospédale Umberto I, Societá Femminile Italiana de M.S. Amore e Caritá, Societá Operai Italiani di M.S. de le Ensenada, Societa Italiana di M. S. Italia Unita de Melchor Romero, Societa Italiana de M. S. Nuevo Circolo Napolitano, Circolo Veterani e Militaria in Congedo, Societa Feminile Italiana M.S. princesa de Napoli, Societá Italiana di M. S. Fraternitá Cosentina y Societá di M.S. Italiana Unita. Ver: Censo 1910.

${ }^{41}$ Hasta la década de 1910 se contaba con más de veinte asociaciones de carácter mutual en la ciudad de La Plata. Entre ellas cabe mencionar: Sociedad Mutual entre Empleados de Provincia (1889); Sociedad Mutual Biblioteca de Policía (1894); Círculo Obrero La Plata (1896); Círculo Obrero Ensenada (1902); Círculo Femenil Cosmopolita de Socorros Mutuos (1896); Sociedad Tipográfica La Plata (1889); La Rial Sociedad Cosmopolita de Socorros Mutuos (1905); La Fraternal, Sociedad Cosmopolita de Socorros Mutuos Villa Elisa (1902); Asociación de Socorros Mutuos Fraternidad Española (1908); La Gauloise Societe Francaise (1889); Socours Mutuels (1884); Helvetia Sociedad Suiza de Socorros Mutuos (1886);
} 
hicieron extensivas entre compañeros de oficio, hecho que permitió fortalecer el temprano movimiento obrero argentino con las experiencias de sus inmigrantes. ${ }^{42}$

Otro grupo de mujeres que también se dedicó al abordaje de la niñez abandonada fue la Sociedad Protectora de la Infancia. Fundada en 1905 por iniciativa de la dirección y personal docente de la Escuela Superior Mixta No 3 de La Plata, pretendía convocar a "grupos de vecinos" que se organizarían de manera supuestamente autónoma para "llenar sus propósitos a favor de la niñez necesitada". ${ }^{43} \mathrm{Su}$ principal objetivo era cooperar con el éxito de la tarea educacional. Al igual que otros colectivos ya mencionados, éste tambien se ocupaba de proveer una atención de orden material y moral, aunque se diferenciaba por entregar una ayuda de orden intelectual. De esta manera, la Sociedad Protectora de la Primera Infancia se encargó tanto de entregar alimentos, asistencia médica, libros, útiles y medicamentos, a los y las niñas; como así también de garantizarles becas para estudiar en otras ciudades, incluso en el extranjero; a la vez que motorizaron la creación de colonias escolares, visitas vacacionales, organización de bibliotecas para los y las niñas, brindaron conferencias para la divulgación de temas relacionados a los estudios primarios, entre otros, e incluso cooperaron en la publicación de tesis y estudios que fueran utilizables por niñas y niños. ${ }^{44}$

Si bien en el estatuto no se menciona quiénes son las que se dedican a cada tarea, sí están mencionadas las más de treinta mujeres que eran parte de la comisión directiva y de la comisión auxiliar, como también las más de cincuenta socias protectoras. ${ }^{45} \mathrm{El}$ interés por la elevación intelectual de los niños y las niñas de los sectores populares distingue esta ayuda social de las otras que limitaban su acción a la entrega de paliativos alimentarios y de cuidado. Esta fuerte dedicación a la formación de los y las niñas es un elemento común con las acciones de asistencia social que realizaba el socialismo y el anarquismo, cuyo interés en la difusión educativa pretendía elevar culturalmente a los obreros para asegurar mejores condiciones de vida. ${ }^{46}$ Cabe aclarar que si bien el socialismo argentino no pretendía la transformación de condiciones materiales de

Sociedad de Socorros Mutuos Tolosa (1889); Sociedad Cosmopolita de Socorros Mutuos y Mejoramiento entre obreros (1895). Ver: Censo municipal año 1910. Ciudad de La Plata.

42 Ver: Lobato, Mirta Zaida, "Los trabajadores en la era del progreso", en Nueva Historia Argentina, t. 5. pp. 467-505.

${ }^{43}$ Estatutos de la Sociedad Protectora de la Infancia. 1905. La Plata. Talleres “La Popular”. La Plata. pp.3.

44 ídem pp.5-6

45 ídem pp.12- 13.

${ }^{46}$ Un ejemplo de ello fue la Sociedad Luz, encargada de instruir a obreros, trabajadores y artesanos, sin alcanzar una influencia destacable entre los sectores populares. Entre las temáticas a las que se abocaban en la enseñanza se encuentran: salud obrera e higiene industrial, higiene y profilaxis sexual, alcoholismo, higiene materno infantil, prostitución, hábitat, entre otras. 
existencia, procuró producir pequeñas reformas desde la instrucción cultural. Ejemplo de ello fue la promoción educativa en materia de higiene, salubridad y vivienda para el proletariado, hecho que los ligó a las primeras filas del reformismo sanitario (Barrancos, 1996, p. 177).

Otro agente importante en la intervención fue la iglesia católica. Mediante la encíclica Rerum Novarum ${ }^{47}$ fomentó la solidaridad y organización de los trabajadores, hecho que generó disputas con los sectores de izquierda respecto a quién capitalizaría tales luchas (Belmartino, 1996, p. 224). Sin embargo, la institución católica ya realizaba su intervención con antelación a la formación del Estado nacional teniendo bajo su dominio a gran parte de las instituciones encargadas de atender a los sectores empobrecidos, abandonados y/o carentes de atención a la salud, precediendo a la Sociedad de Beneficencia y a las organizaciones de socorros mutuos. Entre las principales congregaciones religiosas dedicadas a la beneficencia y a la caridad en la ciudad estaban las Damas de la Providencia, Instituto Sagrada Familia, Nuestra Señora de Luján y San Vicente de Paul. ${ }^{48}$ Las primeras se dedicaban a la recaudación de fondos para el sostenimiento de su obra caritativa y además educaban en la fe cristiana a niñas que carecían de medios para la instrucción. ${ }^{49}$

Las Damas de San Vicente de Paul realizaban obras de caridad, esgrimiendo una excusa que diera permiso a la visita. Una de las modalidades era ingresar al hogar de personas de los sectores populares y ofrecer "un ramillete de bonos espirituales" que consistían en un socorro material y moral. En este ramillete se incluían los bienes necesarios para la vida cotidiana, como alimentos, ropas, remedios, entre otros, además, entregaban instrucción moral y religiosa. En el "Manual del Socio de San Vicente de Paul para las Visitas a Domicilio" de 1888, se detalla el objetivo de las mismas: "Por el medio del bono y socorro material, nos introducimos en la casa del pobre y por consiguiente facilitamos la distribución del bono espiritual, cuyo valor es la santificación recíproca del visitador y de los visitados" (1888, pp. 7).

\footnotetext{
${ }^{47}$ La encíclica Rerum Novarum (1891) es la primera encíclica social de la Iglesia Católica. En ella la iglesia se posiciona a favor de los derechos laborales y de la organización de los trabajadores a través de sindicatos, aunque como contracara también se posiciona a favor de la defensa de la propiedad privada. Pretenden con ello encontrar un nuevo tipo de organización que pudiera conciliar intereses entre patrones y trabajadores a fin de realizar políticas económicas distributivistas, llamando al Estado a arbitrar las relaciones laborales. Ver: Caimari, Lila (1995) Perón y la Iglesia Católica. Religión, Estado y Sociedad en la Argentina (1943-1955), Buenos Aires, Ariel, en particular el capítulo I.

${ }^{48}$ Ricci, Sofía. Instituciones de protección materna infantil de la Ciudad de La Plata. En Hoja Médica de la Casa Cuna (Sociedad de Beneficencia de La Plata) Número 3. Marzo de 1945. La Plata.

${ }^{49}$ Sociedad Damas de la Providencia. Informe presentado por su asesor Monseñor Dr. Federico Rasore en ocasión del XXV aniversario de la fundación. La Plata. 1927.
} 
La propuesta de intervención de las mujeres de San Vicente de Paul era utilizar la visita para ingresar a la casa, ser partícipes de momentos de cotidianeidad que pudieran convertirse en ocasiones para habilitar un diálogo del cual obtener información sobre el grupo, y además, educar en la doctrina cristiana a las familias pobres. Como señala Oliva (2015), estas visitas no solo eran para la provisión de recursos indispensables para la reproducción social y la palabra cristiana, sino que también se hacían eco de las demandas colectivas y ofrecían ayuda para dar cuenta de una necesidad grupal y no de una exigencia individual (pp. 58-63).

Tantos las mujeres nucleadas en Sociedades de Beneficencia así como las mujeres que participaban en entidades religiosas, llevaron adelante acciones que facilitaron la intervención sobre las carencias que dificultaban la reproducción cotidiana de una manera sistemática y organizada. De este modo, le permitían al gobierno provincial tener conocimiento acerca de cuántas personas eran atendidas en los hospitales, dispensarios de salud, albergues de niños y casas de madres. A su vez, en estas prácticas aparecen modos de intervención que posteriormente serán constitutivos de la profesionalización de la disciplina, tal como la visita, la inspección, el relevamiento de información, el registro de su acción, el ingreso en la vida privada, la educación moral e higiénica, entre otros. Andrea Oliva refiere a que estas modalidades de intervención, como suministro de recursos, las visitas de control, de vigilancia de las condiciones de trabajo y también de profilaxis y control de las condiciones de vida, configuraron el campo profesional, sobre todo en la ciudad de Buenos Aires (2015, pp. 57-96). Para el caso de La Plata encontramos que hay modos similares de intervención, particularmente estas prácticas fueron realizadas por los grupos de mujeres de San Vicente de Paul que se dedicaban al suministro de recursos y también a inculcar educación moral y cristiana. En el caso de las Inspectoras de la SB, tomaron a su cargo las visitas de control a las instituciones dedicadas a la asistencia de personas hospitalizadas y de mujeres madres y niños. Es importante señalar que las acciones de estas mujeres resultaron imprescindibles para la posterior articulación de un sistema de sanitario y de atención infantil de la ciudad de La Plata (Colángelo, 2008, pp. 35-39).

\subsubsection{Médicos, burócratas, visitadoras y personal innominado}

Las acciones para paliar las necesidades de los sectores populares, de los niños y de las madres, no solo pretendían la elevación moral de quien obtenía la ayuda o de la misma inspectora o visitadora que entregaba la donación, eran también una estrategia 
interventiva que buscaba vigilar y controlar a los grupos imposibilitados de garantizar su reproducción material y afectiva de manera cotidiana, con el fin de evitar la alteración del ordenamiento pretendido por los sectores liberales y conservadores a cargo de las distintas esferas estatales. Por tal razón se trató de incidir, en principio, de manera desarticulada pero haciendo presente al Estado mediante distintas estrategias.

Desde el año 1885 existía una pequeña enfermería encargada de atender primeros auxilios. Ubicada en la zona céntrica por pedido de la policía, al poco tiempo y como consecuencia del elevado crecimiento poblacional de la ciudad, este primer servicio resultaba insuficiente. En 1890, con la Ley N² 2338 se crea la Asistencia Pública (AP) de la ciudad, encargada de la Dirección y Superintendencia de todos los establecimientos sanitarios, en dependencia del gobierno de la provincia. La obligación de la AP era brindar atención médica de urgencia y de manera gratuita, también realizaban placas radiográficas y entregaban medicamentos. Su radio de acción llegaba hasta los barrios periféricos, aunque por el crecimiento de la región entre las décadas de 1910 y 1920 las zonas de Ensenada, Berisso, Melchor Romero y Los Hornos lograron tener su sede con personal técnico y administrativo, junto a modernos medios de locomoción propios. Si bien dependía del Consejo de Higiene Provincial, materialmente fue el Poder Ejecutivo municipal quien se responsabilizó de su mantenimiento efectivo hasta 1911, cuando pasa a ser sección de la Salubridad Pública de la provincia de Buenos Aires por la Ley Nº 3.360 (Sempe, 1969, p. 23).

Quienes hacían uso de los servicios de la AP debían justificar la necesidad de acceder a ellos mediante su "libreta de pobre". Una vez en la institución se les confeccionaba una ficha de identificación (Sempe, 1969, p. 24) para tener mayor información acerca de quién se atendía, sus condiciones de vida y el grupo de convivencia, instrumento sumamente útil para el control social y sanitario de los sectores pobres. Esta práctica será retomada en la formación profesional de las visitadoras de higiene social, como veremos más adelante. Sin embargo, para el caso de la AP resulta curioso que no se mencione en las memorias anuales quiénes son las personas que hacen estas fichas, tampoco quiénes atendían en primera instancia a las personas recién llegadas a los consultorios, quién los derivaba y ordenaba en alguna instancia posterior de atención.

No sabemos con certeza quiénes eran las personas encargadas de realizar las tareas que facilitaban las labores de los médicos y de la burocracia sociosanitaria, quiénes comunicaban y tomaban nota de los datos que presentaban las personas que se acercaban, ni tampoco sabemos cómo confeccionaban los informes sobre su vida cotidiana. No obstante, sabiendo que la AP dependía de las acciones de inspección y 
control que realizaban las mujeres de la SB en las instituciones a su cargo (Grau, 1954, p. 71), podríamos suponer que la participación de las mujeres se extendía a la realización de estas tareas de auxilio y conexión entre "usuarios" de servicios socio sanitarios y trabajadores y trabajadoras, aunque no podría afirmar que eran las únicas en tal desempeño.

Además de la AP, el gobierno municipal también contaba con una oficina de atención sociosanitaria dependiente de la Inspección de Sanidad. ${ }^{50}$ Ésta brindaba servicios médicos básicos a quienes tenían la libreta de pobre y se encargaba de realizar acciones de inspección a clubes, bares, comercios y prostíbulos, como así también acciones de difusión para el cuidado sanitario. Realizaba inspecciones de orden corporal como exámenes médicos a conductores de vehículos, a aspirantes a ocupar puestos en la administración comunal y a obreros dependientes de la municipalidad, asimismo constataba enfermedades de empleados municipales y podía realizar informes periciales a los efectos de la Ley de Accidentes de Trabajo ante el Departamento Provincial del Trabajo y de los Tribunales. Pero además de ocuparse de pobres, inspeccionar las condiciones físicas de conductores, aspirantes y trabajadores del municipio, y ser partícipes en procesos judiciales acerca de la salubridad de los trabajadores, la Inspección se encargó con mucho énfasis del control de enfermedades venéreas a través de la realización de análisis a las trabajadoras sexuales y usuarios hombres que pudieran estar infectados por el consumo de sus servicios. ${ }^{51}$ El interés por el control de la salud de las trabajadoras sexuales era parte de una larga cruzada desde el municipio en contra de la reglamentación de la prostitución. Tal era la lucha emprendida desde la ciudad que logró abolir el trabajo sexual en el año 1935 mediante la ordenanza $\mathrm{N}^{\circ} 128^{52}$, la que se adelantó dos años a la Ley de Profilaxis Social. ${ }^{53}$

En este caso tampoco son mencionadas quiénes son las personas que se acercan a los y las afectadas, quiénes atienden, arman las fichas y recepcionan a los pacientes. Solo aparecen mencionados los médicos a cargo de los consultorios, mientras que las tareas auxiliares no son siquiera citadas.

\footnotetext{
${ }^{50}$ Durante un tiempo esta oficina compartió actividades con la asistencia pública. Sin embargo, una vez que la AP pasa a ser provincial, esta dependencia toma para sí las responsabilidades de atender, en principio, a pobres y al personal de la municipalidad.

${ }^{51}$ Memoria de la administración municipal. 1936. Ciudad de La Plata. pp. 119- 120.

${ }^{52}$ Labor comunal. Memoria. 1938- 1939. La Plata. Taller imprenta municipal. 1940.

${ }^{53} \mathrm{La}$ ciudad de La Plata era vanguardia en el ordenamiento urbano relacionado con la sexualidad, no solo en relación al control de quienes vendían y compraban los servicios de las trabajadoras sexuales, también sucedía lo mismo con el examen prenupcial, mediante el cual se pretendía garantizar un matrimonio eugénico capaz de dar a luz una prole saludable. Esto implicó la regulación de las uniones civiles y afectivas desde el Estado, con el fin de normalizar a los futuros ciudadanos y establecer una legalidad alrededor de la familia.
} 


\subsection{La crisis del treinta y el aumento de la demanda de atención en la asistencia social}

La intervención sobre la cuestión social que realizaban desde fines del siglo XIX, inspectoras, mujeres de órdenes religiosas, visitadoras, médicos, burócratas y "agentes sin nombre", muestra la pretensión por prestar un abordaje más completo de las problemáticas sociosanitarias. Las demandas colectivas por mejores condiciones de vida hicieron que el Estado interviniera para atenuar posibles conflictos, buscando al mismo tiempo educar y fortalecer la mano de obra activa y a los niños y niñas que engrosarían las filas del proletariado local.

Durante la década de 1920, se produce en la región un despliegue de nuevas instituciones de atención sociosanitarias que pretendían abordar dos problemáticas principales, por una parte, la intervención en las zonas aledañas al casco urbano para el combate contra la tuberculosis y, por otra, abordar en toda la región la higiene materno infantil. Es así que, en 1922, se creó el primer dispensario antituberculoso de la Liga Popular contra la Tuberculosis de La Plata y el dispensario para el tratamiento del tracoma en Tolosa. Con la apertura de estos espacios el gobierno municipal y provincial se hacía eco de las campañas y lucha contra la tuberculosis ${ }^{54}$, enfermedad que, si bien era foco de la medicina social, recién en la década de 1930 será objeto de políticas públicas. Esta enfermedad era vinculada a los sectores populares porque dadas sus precarias condiciones de vida podían infectarse con facilidad. Recordemos que el bacilo de Koch que trasmitía la enfermedad se encontraba en lugares hacinados y poco ventilados, por ello el principal sector que se buscaba controlar y educar estaba conformado por aquellos que vivían en condiciones paupérrimas, aunque toda la sociedad era susceptible de contagio. Durante las primeras décadas del siglo XX, esta enfermedad era un signo de degeneración y de decadencia material y espiritual de los individuos, aunque en ella también radicó una posibilidad de crear escenarios saludables alternativos. ${ }^{55}$ En el año 1935 se creó otro dispensario en la ciudad por intermedio de acciones llevadas adelante por la Cruzada Nacional contra la Tuberculosis.

\footnotetext{
${ }^{54}$ La institución más reconocida en la lucha contra la tuberculosis era la Liga Popular de Lucha contra la Tuberculosis. Formada en el año 1911, tenía como objetivo luchar contra la propagación de esta enfermedad a través de la creación de dispensarios y de la difusión educativa. Ver: Memoria correspondiente al año 1921- 1923 de la Liga Popular contra la Tuberculosis de la Provincia de Buenos Aires.

${ }^{55}$ Diego Armus evidencia cómo en función de esta enfermedad se proyectan espacios urbanos que resultaran más saludables y evitaran el contagio de la enfermedad. Sin embargo, a pesar del interés y
} 
Otra de las problemáticas sociosanitarias por abordar fue el vínculo madre-hijo. La ciudad capital contaba con una única maternidad provincial existente desde 1908, a la que se sumó el dispensario de lactantes Carlos Ferreira fundado en 1928. En paralelo, la SB proyectaba la creación de una Casa Cuna e Instituto de Puericultura ${ }^{56}$, contando en 1935 con la aprobación del Senado de la provincia de Buenos Aires, en tanto sus obras se iniciaron en 1938 y culminaron en 1942. Es importante señalar que este aumento en la cantidad de instituciones dedicadas a la atención materno infantil en la región de La Plata, Berisso y Ensenada se mantendrá durante el gobierno peronista, aunque con antelación a la llegada al poder de Juan Domingo Perón había en la zona más de cincuenta instituciones dedicadas a la cuestión. ${ }^{57}$

Si bien, como ya mencionamos, las políticas sanitarias y asistencialistas de las primeras décadas del siglo XX tuvieron como eje la preocupación por la cuestión social evidente en la pobreza, la marginalidad y el desarrollo de enfermedades-, también estaba presente la cuestión de las mujeres madres y trabajadoras (Suriano, 2002) en tanto el control de los métodos de regulación de la reproducción y la elevada tasa de mortalidad infantil colocó en el centro de la escena la preocupación por el desarrollo del núcleo doméstico. En este sentido, el discurso médico apeló a la búsqueda de multiplicidad de mecanismos para que las mujeres asuman la maternidad como único destino en la sociedad (Nari, 2004; Biernat y Ramacciotti, 2013).

La coyuntura de 1920 y 1940 guarda particularidades importantes de señalar. Durante la década de 1920 opera un cambio en la atención sociosanitaria, iniciándose un período de crisis en que algunas dificultades respecto a la atención se pretenden resolver con una mayor incidencia estatal. Al mismo tiempo, se pone en cuestionamiento la atención dedicada desde las instituciones de beneficencia, $\mathrm{la} \mathrm{SB}^{58}$ y las mutualidades de socorros

empeño que se puso en la planificación de ciudades ideales, dichos proyectos no fueron llevados adelante Ver Armus, Diego (2007) La ciudad Impura; pp. 31.

${ }^{56}$ María Adelaida Colángelo destaca en su libro que las "casa cuna" eran instituciones dedicadas a albergar y criar niños abandonados y huérfanos durante sus primeros años de vida, aunque también podían albergar a niños cuyas madres trabajaban durante todo el día. Ver: Colangelo, María Adelaida, "Un abordaje al abandono infantil: el Hospital zonal especializado "Dr Noel Sbarra" de La Plata". La Plata, Ediciones Casa Cuna.

${ }^{57}$ La visitadora de higiene social Sofia Ricci realizó un relevamiento en el año 1943 de las instituciones dedicadas a la atención materno infantil en la región. Destacó la existencia de más de cincuenta establecimientos, entre ellos la mayoría estaba regido por la Iglesia y la Sociedad de Beneficencia, aunque cuatro estaban bajo jurisdicción de la Dirección General de Higiene, tres eran de orden privado laico, tres municipales, dos dispensarios nacionales.

${ }^{58}$ Ejemplo de esta crisis es la situación que sucedió en enero del año 1924, cuando se suscita un debate en la Cámara de Diputados de la provincia de Buenos Aires, encabezado por el diputado socialista José Baliño. Éste solicita que la provincia reduzca el financiamiento de la Sociedad de Beneficencia a 10.000 pesos anuales, que dejen de estar en la administración del Hospital de la Misericordia (llamado desde 1950 Hospital San Martín), y además, exige que las propiedades a cargo de dicha sociedad sean reconocidas como patrimonio del fisco, puesto que no había documentación que probara lo contrario. 
mutuos, hecho que será evidente en la primera mitad de la década de 1940, pero será mayormente abordada por el peronismo (Belmartino, 2005, p. 76). Uno de los elementos a considerar es que, luego de la primera guerra mundial, se detuvo el flujo inmigratorio que ingresaba al país, lo que provocó fuertes debates sobre cómo formar una población nativa sana y fuerte que fuera útil para el desarrollo productivo nacional frente a la ausencia de los "blancos" proletarios llegados de Europa. Esto no solo era una preocupación de orden cuantitativo, sino también cualitativo, y dada la incidencia que tenía el poder médico en la definición de políticas sociales, se buscaron respuestas en esa tónica. Dos problemas centrales para el desarrollo cualitativo y cuantitativo de la población eran la mortalidad infantil y el descenso del número de nacimientos, problemas tanto de origen demográfico como social. Las inmigraciones masivas, las migraciones internas del campo a la ciudad producidas en la región por la crisis de $1930^{59}$, la rápida urbanización, el trabajo femenino, entre otras, eran consideradas causantes de las problemáticas del desarrollo familiar y debían ser corregidas. Los principales focos de este malestar recaían en las mujeres madres sin compañía masculina o que trabajaban fuera del espacio doméstico, en los hijos e hijas ilegítimas, en la infancia abandonada y en el descenso de la natalidad, hechos que impactaban en las nuevas costumbres y que desestabilizaron los patrones normativos de reproducción social (Biernat y Ramacciotti, 2013, p. 37).

Si bien estas problemáticas eran parte del acelerado ritmo de crecimiento urbano de la región, quienes aparecieron como responsables de los cambios en las costumbres fueron las mujeres madres, sobre todo de los sectores populares (Grassi, 1989; Lobato 2000; Nari, 2004; Biernat y Ramacciotti, 2014)

En la ciudad, el malestar económico de la década de 1930 no sólo se evidenció en el crecimiento de las instituciones de atención sociosanitaria, también se tradujo en un

Finalmente, en marzo del mismo año se permite que la Sociedad de Beneficencia mantenga su puesto directivo pero en carácter ad honorem. Ver: Grau, Carlos (1954) La Sanidad en las ciudades y pueblos de la provincia de Buenos Aires. La Plata. Dirección de impresiones oficiales. pp74- 79. En este sentido, desde fines del siglo XIX y principios del siglo XX, la disputa acerca de la distribución desigual de derechos y de poder en la Argentina fue un eje que el Partido Socialista tomó desde la racionalidad científica para cuestionar el escenario de diferencias sociales en los que se encontraba la sociedad. Prominentes militantes socialistas como del Valle Iberlucea y Alicia Moreau se destacaron en este combate, colocando el acento sobre la condición de las mujeres. Ver: Becerra, Marina (2009) Marxismo y feminismo en el primer socialismo argentino. Enrique del Valle Iberlucea. Rosario, Prohistoria Ediciones.

59 Particularmente en la zona de Berisso y Ensenada, que eran enclaves industriales, hubo una gran migración en búsqueda de trabajo desde las provincias de Santiago del Estero y Corrientes, la que se organizó mediante ligas de ayuda mutua, encargadas sobre todo de mantener viva la cultura folclórica de su región. Ver: Lobato, M. (2001). La vida en la fábrica. Trabajo, protesta y política en una comunidad obrera, Berisso (1904-1970.) Buenos Aires: Prometeo. 
aumento de la demanda de servicios médicos y asistenciales a la Asistencia Pública local que superó el cincuenta por ciento del trabajo que previamente realizaba. ${ }^{60}$ Por este motivo, desde el año 1932 se reorganizaron los servicios que brindaba la Asistencia Pública, con la aprobación del Consejo General de Higiene y del Poder Ejecutivo, a fin de garantizar la atención médica de urgencia todos los días para "toda persona sin distinción de clases ni categoría, absolutamente gratuita". ${ }^{1}$ Además, buscaron garantizar la asistencia a través de médicos a domicilio y en consultorios "para aquellas personas que posean certificado de pobreza, como así también para los que careciendo de dicho comprobante hagan presumir la necesidad de utilizar servicios de Asistencia Pública". ${ }^{62}$ El nuevo reglamento evidenció dos cuestiones: por una parte, la preocupación por el aumento de los sectores empobrecidos que necesitaban de la atención gratuita, y por otro, la extensión del servicio de visitas a los hogares de los sectores menos favorecidos y la incipiente necesidad de auxiliar estas acciones, para lo cual fueron convocados los practicantes no graduados en ciencias médicas.

Con este aumento en la demanda de los servicios de asistencia, se utilizó como estrategia la difusión educativa de la higiene a fin de lograr una mayor inserción en los sectores populares sobre los que reposaba el peligro de "degeneración" de la raza y desmoralización social. Dos leyes provinciales se proponían atacar la raíz de estos males socio sanitarios de la región: la Ley N 4.377 de "Profilaxis de la tuberculosis" sancionada el 9 de enero de 1936, que perseguía la prevención y educación de la población, sobre todo de los sectores trabajadores; y la Ley $N^{\circ} 4.547$ de "Protección a la infancia", con la que se creó una dirección con el mismo nombre a fin de controlar los establecimientos e instituciones que se encargaban de los menores de edad. ${ }^{63}$ En los debates para la sanción de cada una de estas legislaciones se reflejó la necesidad de realizar una asistencia social organizada con fines científicos, incluso se mencionó el interés por "crear un cuerpo de visitadoras", pero la idea no prosperó desde el Estado. ${ }^{64}$ La preocupación por la formación profesional de quienes intervendrían en la atención de las mujeres madres, niños, niñas, trabajadores y trabajadoras de sectores populares,

\footnotetext{
${ }^{60}$ Según la Memoria anual de la Asistencia Pública de la ciudad de La Plata, hasta el año 1932 se mantenía un promedio de atención de cien mil habitantes por año, mientras que para el año 1938 se registra una atención que supera los ciento cincuenta mil habitantes. Ver: Memoria anual de la Asistencia Pública. Taller de impresiones oficiales. La Plata.1939.

${ }^{61}$ Memoria presentada a la Honorable Legislatura por el Ministro de Obras Públicas de la provincia de Buenos Aires Dr Edgardo J. Miguez, Tomo I, 1932, pp. 154.

${ }^{62}$ Ibídem.

${ }^{63}$ Mediante la Ley orgánica de la "Protección a la infancia" quedan abolidas las cárceles de menores. Los tribunales de Menores buscarían entonces "no la represión sino la reforma y el amparo de los mismos" mediante el cuidado en Institutos de Protección a la Infancia, con el propósito de reeducar y reinsertar a los menores.

${ }^{64}$ Libro de cesiones del año 1937. Honorable Cámara de Diputados de Provincia de Buenos Aires.
} 
también se manifestó desde otras dos instituciones. Por un lado, la Liga Popular de Lucha contra la Tuberculosis de la Provincia de Buenos Aires, que atendía a infectados de tuberculosis y realizaba visitas domiciliarias, proponía que las visitadoras de la institución tuvieran un tiempo de tres meses de práctica en el desempeño de sus tareas: visitar domicilios para ver las condiciones de las familias afectadas y persuadirlos para que se acercaran a alguno de los dispensarios, asistir a quienes se allegaran al centro de salud y entregar alimentos a los enfermos. Con las exigencias de práctica y experiencia, se procuraba mejorar el servicio de atención que prestaba la Liga en un período en que aumentaba la demanda de 13.703 personas en 1936 a 14.373 en $1937 .{ }^{65}$ Tal era la petición de sus servicios que en 1938 se logró instalar otro preventorio donde se internaron a niños infectados, aislados de sus familias y con un tratamiento higiénico y dietético afín a las exigencias de atención.

Parece evidente que con el aumento de la demanda de la atención sociosanitaria de los sectores más carenciados se exigía una mayor especialización para el desarrollo de la tarea de asistencia social capaz de organizar y abaratar los costos de atención desde un ordenamiento científico.

Por su parte, el Cuerpo Médico Escolar de la provincia de Buenos Aires formaba visitadoras de higiene escolar desde 1927. Éstas se dedicaban a educar e instruir a los niños y a sus familias en hábitos higiénicos, también realizaban conferencias y propaganda en las escuelas, hecho que facilitó la promoción de la medicalización de los niños escolares. Las visitadoras encargadas de trabajar junto a los escolares confeccionaban las fichas antropométricas de los niños, estudiaban las psicopatologías de aquellos con algún tipo de retardo madurativo, e inculcaban hábitos de higiene en la lucha contra la tuberculosis. ${ }^{66}$

Este complejo abordaje de la atención social y la pretensión por profesionalizar la visita, la vigilancia, la difusión de conocimientos y el relevo de información, nos indican varias cuestiones. En principio, como ya hemos desarrollado, desde fines del siglo XIX hubo distintas estrategias de intervención en el control de la cuestión social a fin de evitar conflictos sociales por parte de los sectores imposibilitados de reproducir su existencia diaria debido a sus condiciones materiales. Por eso, desde la SB, obras de caridad, asistencia pública, dispensarios, entre otras instituciones, se intentó garantizar

\footnotetext{
${ }^{65}$ Memoria presentada a la asamblea anual por la comisión directiva respecto a la labor realizada desde el 1 de octubre de 1936 al 31 de diciembre de 1937.

${ }^{66}$ Ver: Oliva, A. (2009) Trabajo social y lucha de clases. pp. 107 y Camarotta, A. en "Saberes médicos y medicalización en el ámbito escolar (1920-1940). Revista Pilquen. Vol. 19. N³. ISSN 1851-3123.
} 
las condiciones básicas para la reproducción cotidiana de los habitantes (por ejemplo, a través de donaciones de ropa, alimentos, albergue, atención sanitaria gratuita, etc.). De estas prácticas se desprendieron distintos dispositivos que facilitaron el trabajo, como la inspección, la vigilancia, la observación, la realización de fichas e informes que, de alguna manera, fueron delineando los modos de intervención y los dispositivos para la obtención de información, que sostuvieron como constante la participación de las mujeres, a pesar de que en el caso de la inspección sanitaria municipal solo podemos suponerlo porque no aparecen mencionadas. No obstante, a partir de la década de 1930, con el aumento del malestar social producido por la crisis económica internacional, se hace necesario dar respuesta desde el Estado para abordar las problemáticas de reproducción social.

\subsubsection{La Conferencia Nacional de Asistencia Social}

La nueva década se iniciaba con un claro reclamo de los sectores populares y de los sectores dominantes exigiendo una mayor intervención del Estado. En una coyuntura de democracia restringida, iniciada por un período de intervencionismo militar conocido como "la restauración conservadora" que desplazó del poder ejecutivo a Hipólito Yrigoyen, líder de la UCR, para dar lugar al gobierno de la Concordancia (De Luque y Scaltritti, 2011), desde el Estado se buscaban soluciones al malestar económico afrontado por trabajadores rurales y urbanos con el objetivo de evitar conflictos sociales. En ese contexto, el Ministerio de Relaciones Exteriores y de Culto a cargo de Carlos Saavedra Lamas ${ }^{67}$ convocó a la Primera Conferencia Nacional de Asistencia Social a celebrarse en la ciudad de Buenos Aires durante el mes de noviembre de 1933. Tal como señala Claudia Krmpotic (2011), este evento constituye un antecedente significativo en el proceso de profesionalización de la ayuda social, como así también un nuevo punto de partida en la conformación de políticas sociales en función de la redefinición que establece el Estado en materia de intervención y que servirán de referencia para las que desarrolle el peronismo posteriormente (pp. 41-43).

\footnotetext{
67 Carlos Saavedra Lamas fue político, diplomático y jurista argentino. Su reconocimiento internacional se debe a que durante el año 1936 fue el primer latinoamericano en ser galardonado con el Premio Nobel de la Paz. Por la línea ascendente de su familia paterna era bisnieto del coronel Cornelio Saavedra, presidente de la Primera Junta de Gobierno de las Provincias Unidas del Río de la Plata establecida en 1810. Entre sus acciones como político se destaca su actividad como diputado y Ministro de Justicia e Instrucción Pública (1915) y de Relaciones Exteriores (1932 - 1938), durante la presidencia de Agustín P. Justo.
} 
Para la Conferencia fueron convocadas distintas instituciones públicas y privadas dedicadas a la asistencia social con el objetivo de debatir y proyectar estrategias para la centralización de acciones a fin de maximizar los esfuerzos de obras de asistencia social pública y privada. ${ }^{68} \mathrm{El}$ objetivo particular era poder desarticular posibles conflictos sociales desprendidos de la crisis y la miseria ${ }^{69}$ a través de la unidad de esfuerzos y la flexibilidad en las acciones de todas las organizaciones dedicadas a la asistencia social. ${ }^{70}$ Para ello resultaba imprescindible presentar las acciones que realizaban las obras de asistencia en todo el país, fueran de orden católico, científico, liberal o socialista, a fin de adaptar la asistencia a técnicas modernas y compartir las experiencias con el propósito de mejorar los métodos y sus resultados.

La jornada se dividió en más de treinta secciones dedicadas al tratamiento de problemas referidos a la organización y a la centralización de la asistencia, entre ellos: el financiamiento, la construcción de nuevos hospitales y asilos, la proyección de acciones de prevención, entre otras. Particularmente en las secciones dedicadas a los debates sobre los modos en que se realizaba la asistencia social se indicaron quiénes eran los sujetos con los que trabajaban las obras, así se destacan: Asistencia de la Madre y el Recién Nacido (Sección 14), Asistencia y Protección de la Primera y la Segunda Infancia (Secciones 16 y 17), Asistencia a Enfermos Comunes de hospitales (Sección 18), Coordinación de la Asistencia a Enfermos Comunes (Sección 19) y otra diez secciones de la número veinte a la número treinta dedicadas a la asistencia de enfermedades particulares: enfermos infectocontagiosos, tuberculosos, leprosos, alienados, frenasténicos, infectados de tracoma, pacientes con enfermedades tropicales, con paludismo, personas que padecían cáncer, con ceguera, sordera y mutismo. ${ }^{71}$

La séptima sección de la conferencia estuvo destinada exclusivamente a la formación del personal para las obras de Asistencia Social. Enfermeras, visitadoras de higiene social, asistentes sociales y superintendentes de usina ${ }^{72}$ eran los sujetos definidos en la

\footnotetext{
68 Entre las asistentes platenses a la conferencia se encontraban la Escuela Técnica del Hogar y Profesional de Mujeres, el Hospital San Juan de Dios, la Liga Popular contra la Tuberculosis, la Sociedad Protectora de la Infancia y la Sociedad de Beneficencia, hecho que demuestra la activa participación y diálogo de los distintos sectores de la región para la definición de políticas sociales. Actas de la Conferencia Nacional de Asistencia Social. Tomo I. pp. 57- 62.

${ }^{69}$ Conferencia Nacional de Asistencia Social. Tomo 1. p. 5.

70 ídem p. 70. (/ti 71-72).

71 ídem pp. 7 y 8.

${ }^{72}$ Germinal Rodríguez propuso la creación de una escuela técnica para superintendentes de usina, que a diferencia de las otras tres aun no funcionaba en Argentina. Se pretendía la formación de técnicos en administración y servicio social de industria. Éstos se encargarían de abordar especialmente las problemáticas de los trabajadores en las industrias. Para ello proponía una formación en servicios industriales, en legislación social y política, también en relación al régimen de salarios y la racionalización. ídem pp.51-52. tomo 2.
} 
conferencia como los encargados de intervenir en la asistencia social. A cada uno de ellos les corresponderían distintas funciones y acciones destinadas a remediar los efectos de la miseria o luchar contra las causas que generaban el malestar. Como ya hemos mencionado, durante este período la asistencia social era pensada como una estrategia integral en términos de asistencia socio sanitaria con un importante peso de la medicina para la definición de políticas de acción. De algún modo, en esta etapa de formación de la profesión se hace evidente el carácter indefinido del Trabajo Social, concibiéndose múltiples áreas de incumbencia profesional que finalmente confluirán en la misma disciplina ${ }^{73}$, aunque mantenían diferencias entre las funciones profesionales. El Dr Alberto Zwanck, médico participe de la creación de la EVHS UBA y de la Escuela de Servicio Social del Museo Social Argentino, fue relator en la sección respecto del personal que debía estar en las obras de asistencia social. Allí manifestó:

Que toda obra de Asistencia Social incorpore a su personal Visitadoras de Higiene Social o Asistentes Sociales -según sea la finalidad de la Obra- diplomados en institutos de capacidad docente reconocida oficialmente de manera que puedan desarrollar su programa de acción de acuerdo con los principios y procedimientos técnicos del Servicio Social, única forma científica de lograr un rendimiento social y económico que las convierta en organizaciones de utilidad pública (Zwanck, 1934, p. 48).

Es interesante la insistencia de Zwanck en la incorporación de visitadoras y asistentes diplomados y con conocimiento de las técnicas adecuadas para la intervención. El interés por profesionalizar a quienes se dedicarían a estas obras pretendía de algún modo garantizar un personal capaz de afrontar soluciones a las refracciones de la cuestión social desde un abordaje científico y no sólo voluntario como sucedía hasta el momento. Para ello proponían dos modelos de trabajadores para la asistencia: visitadoras y asistentes sociales que debían tener un aval institucional sobre su formación, aunque Zwanck no refiere cuál sería el organismo capaz de llevar adelante esa tarea.

Pilades Dezeo, quien también disertó en la misma sección que su compañero de Cátedra y del Instituto de Higiene Médica y Preventiva de la Facultad de Ciencias

73 En el caso de la EVHS UNLP, a partir del año 1963, siguiendo los postulados de la OMS (Organización Mundial de la Salud) comenzó a expedirse el titulo de "Visitador de Higiene Social y Enfermería". A partir de ese año la Escuela permitió el ingreso de varones. Para el año 1974 y haciendo caso de las modificaciones que vivía la profesión a nivel latinoamericano a partir del proceso de reconceptualización, la Escuela experimenta una serie de modificaciones, entre ellas, una duración de cinco años y un perfil más cercano al área de ciencias sociales, fenómenos que se expresaron en la creación del título de Licenciado en Servicio Social. Ver:

http://www.trabajosocial.unlp.edu.ar/resena historica 
Médicas UBA, y de la EVHS UBA Alberto Zwanck, tomó el guante para responder sobre quiénes formarían a las profesionales. En su exposición "Escuelas de Visitadoras de Higiene Social (Sus fines, organización, programas y métodos de enseñanza)”, propuso que:

Las Escuelas de Visitadoras de Higiene Social deben funcionar anexas a las cátedras o institutos de Higiene de las Facultades de Medicina de las Universidades, única forma de garantir la capacidad docente de la escuela, y por lo tanto la idoneidad de las egresadas (Dezeo, 1934, p.49).

Dezeo insistió en la centralidad de las universidades para la formación profesional de las visitadoras. Seguramente desde su espíritu reformista, este médico -a quien ya nos hemos referido en el capítulo 1- consideraba que las acciones educativas del nuevo grupo profesional animarían a la elevación intelectual de los sectores populares. Dezeo podía plantear esta propuesta porque desde 1924 era parte de la EVHS UBA, por lo cual entendía que la preparación técnica de agentes permitiría ayudar en la organización de las instituciones de medicina preventiva y asistencia.

En la ciudad de La Plata, como hemos visto, ya se desarrollaba la asistencia social y también estaban los cursos para visitadoras de higiene escolar. Sin embargo, al poco tiempo de la Conferencia Nacional de Asistencia Social, la UNLP se hará eco de esta demanda. Veremos a continuación cuál era el escenario universitario platense para que la propuesta de creación de la Escuela para Visitadoras de Higiene Social pudiera efectivizarse.

\subsection{La ciencia en la ciudad higiénica. La Universidad Nacional de La Plata y su propuesta extensionista}

Antes de referirnos a la UNLP es necesario historizar brevemente cómo se construyó esta casa de altos estudios en la ciudad higiénica. A partir de 1885, la administración del joven Estado argentino asume la responsabilidad de sostener una política educativa de mantenimiento y dirección de la educación superior a través de la Ley $\mathrm{N}^{\mathrm{o}} 1.597$ que delineó el marco jurídico para el despliegue del modelo científico educativo centrado en tres áreas: Medicina, Derecho y Ciencias Exactas, Físicas y Naturales. Esta ley no sugería el modo en que las casas de estudio debían desarrollar la promoción científica y profesional, vacío que fue capitalizado por los hombres de la elite política gobernante que se vieron posibilitados a desplegar su proyecto como dirigencia liberal. Las universidades existentes para fines del siglo XIX, como Buenos Aires y Córdoba, 
fueron nacionalizadas y quedaron bajo control estatal. Hombres de la elite que ocupaban cargos políticos también podían hacer uso de las cátedras y monopolizar la producción de saberes y conocimientos sobre la sociedad. No obstante, estos reductos eran insuficientes, generando que otras elites regionales exigieran la creación de universidades en sus provincias donde formar a su dirigencia local, ejemplo de ello son Santa Fe (1889-1890) y La Plata (1890-1897). Las universidades no solo se dedicaron al control de los saberes expertos -como a la expulsión de otros sistemas de conocimientos- y a la formación de la elite dirigente, asimismo se hicieron cargo de la formación de profesionales y recursos técnicos requeridos para las distintas dependencias de la burocracia estatal. ${ }^{74}$

Desde la capital de la provincia de Buenos Aires se impulsó la nacionalización de la Universidad provincial de La Plata en el año 1905 y desde allí se promovió un modelo de "universidad nueva" abocada a las tareas extensionistas con las que intentaba diferenciarse del profesionalismo de la UBA (Vallejo, 2007). A pesar de contar con un bajo presupuesto y reducido número de alumnos, Joaquín V. González ${ }^{75}$, ministro de Instrucción Pública del gobierno del Presidente Manuel Quintana, se proponía la construcción de una universidad capaz de continuar la construcción de conocimientos desde las ciencias naturales, especialmente agronomía y veterinaria (profesiones que resultaban útiles a la burguesía terrateniente de la provincia), y sumar la Facultad de Ciencias Jurídicas y Sociales orientada al estudio empírico de los problemas sociales y políticos. Con esta propuesta aspiraba a generar una educación liberal y moderna similar a las universidades anglosajonas por su sentido práctico y utilitario, donde la producción de conocimientos favoreciera el desarrollo de una clase dirigente regional capaz de conducir el proceso de modernización político y social (Buchbinder, 2005, pp. 81-84).

Durante la gestión de Joaquín V. González como presidente de la UNLP, se impulsó la investigación y experimentación, se crearon laboratorios, institutos de investigación, nuevas carreras y nuevas facultades, como la Facultad de Humanidades y Ciencias de la Educación. Un elemento destacado de su propuesta era la exclaustración del conocimiento científico, es decir, la difusión de los conocimientos producidos en la

\footnotetext{
74 Ver: Buchbinder, Pablo (2005) Historia de las universidades argentinas, Editorial Sudamericana, Buenos Aires; Graciano, Osvaldo (2008) Entre la torre de marfil y el compromiso político, Universidad Nacional de Quilmes Editorial, Bernal; Lorenzo, María Fernanda (2016) "Que sepa coser, que sepa bordar, que sepa abrir la puerta para ir a la universidad”. Las académicas de la Universidad de Buenos Aires en la primera mitad del siglo XX. Eudeba, Buenos Aires.

75 Joaquín V. González fue un destacado político, filósofo e historiador vinculado a la masonería. Fue gobernador de la provincia de La Rioja (1889-1891) y también senador y diputado nacional por la misma jurisdicción. En su gestión como ministro de instrucción pública promovió la nacionalización de la Universidad Provincial de La Plata.
} 
universidad a través de la extensión universitaria, planeando investigaciones enmarcadas en proyectos de reforma social fundados en la ciencia. De algún modo, mediante las prácticas de extensión la universidad delineó y construyó posibles respuestas a las preocupaciones de los sectores gobernantes respecto de los sectores trabajadores y populares.

La universidad moderna construida por González funcionó como centro de formación de recursos técnicos y profesionales que articularon redes intelectuales entre pares. Durante los años 1910-1930, distintos nucleamientos de sectores estudiantiles y docentes diseñaron proyectos y alternativas de construcción del conocimiento e inserción política en la sociedad. Entre ellos se destacan emprendimientos intelectuales como el del grupo Renovación, integrado por graduados y estudiantes que contaron entre sus acciones con la publicación de la revista Valoraciones. La acción de este grupo se basaba en la crítica al academicismo y formalismo en el saber, la participación en el gobierno de la universidad, la solidaridad obrero-estudiantil, la oposición al elitismo universitario y el afianzamiento de la identidad latinoamericana. Tal como señala Graciano (1999), este posicionamiento expresaba la impugnación a los valores culturales dominantes en la universidad y la sociedad argentina. Una de las figuras principales del período fue Alejandro Korn, médico psiquiatra y filósofo, también profesor en las universidades de Buenos Aires y de La Plata, que fue uno de los pilares para la formación intelectual de los jóvenes universitarios. Si bien desde fines del siglo XIX era parte del radicalismo e incluso fue diputado provincial, desde la década de 1920 se acercó progresivamente al pensamiento del socialismo a través de la figura de Juan B. Justo. La atracción por las ideas neokantianas orientadas a la crítica y superación del positivismo en amplios sectores de estudiantes y graduados, se hizo evidente en el seguimiento del grupo Renovación al Partido Socialista cuando el "maestro" decidió involucrarse íntimamente con estos sectores (Graciano, 1999, pp. 7576).

El interés por intervenir en la instrucción y elevación cultural de los sectores populares, sobre todo de los trabajadores, será una política temprana asumida por la UNLP, aunque quedará efectivizada con el triunfo del movimiento reformista. Aún resta indagar desde qué otras áreas del conocimiento asumieron el compromiso de involucrarse con los sectores populares. Veamos a continuación la experiencia realizada por los estudiantes de medicina, algunos que posteriormente influirán en la creación de la EVHS UNLP. 


\subsubsection{Los estudiantes de la Escuela Preparatoria de Medicina y la Reforma Universitaria}

La Reforma Universitaria, iniciada en Córdoba en el año 1918 y propagada rápidamente a las ciudades de Buenos Aires y de La Plata, se constituyó como un acontecimiento trascendental para la vida universitaria argentina. En esta exigencia del cuerpo estudiantil se manifestó la incapacidad de las universidades para actualizar sus programas de estudio y su matrícula docente, pero sobre todo, dejó al descubierto la negativa de incluir a los estudiantes en el gobierno de la universidad. La situación política nacional, tensada por las críticas al gobierno radical, además del clima de reforma y represión sobre los sectores trabajadores, favoreció el despliegue de reivindicaciones del movimiento estudiantil que invitaba a inscribirse en un proceso de mayor alcance: el de la lucha por la democratización política y el acceso a ella de los sectores medios de la sociedad (Portantiero, 1978).

Si bien hemos citado brevemente en el capítulo anterior algunas características del proceso reformista en las universidades, es de interés reparar en lo que sucedía en la ciudad de La Plata. El movimiento estudiantil platense manifestó su rechazo a la política universitaria un año después que sus compañeros de la Federación Universitaria Cordobesa. La Federación Universitaria de La Plata inició una secuencia político insurreccional entre octubre de 1919 y junio de 1920 con la "Huelga Grande". ${ }^{76}$ Las acciones del movimiento reformista platense abarcaron un amplio pliego de solicitudes para exigir una transformación de la cultura institucional universitaria. En principio, exigieron la renovación de su sistema de enseñanza y que se removieran los cargos directivos y docentes de las facultades de la UNLP, como así también demandaron la incorporación de egresados y estudiantes reformistas para que participen en distintas cátedras.

La crítica que el movimiento estudiantil realizó al ordenamiento de la UNLP, incluyó el cuestionamiento de las bases inglesas del modelo universitario al que se contraponía un modelo latinoamericanista. La intención por construir conocimientos que no estuvieran guiados por modelos extranjeros, como tampoco monopolizados por la burguesía,

\footnotetext{
${ }^{76}$ Esta huelga se había iniciado a causa del enfrentamiento de los estudiantes de Veterinaria con el decano y se extendió a toda la UNLP ante la negativa del conservador y liberal Rodolfo Rivarola, presidente de la Universidad, de otorgar voz y voto a los representantes estudiantiles en el Consejo Universitario. Sumado a ello, el Dr. Pedro Belou abrió una mesa de exámenes en la Escuela de Medicina y forzó a los alumnos a concurrir. La huelga continuó hasta la renuncia de Rivarola, quien fue suplantado posteriormente por Carlos Melo. Ver: Biagini, Hugo (comp.) (2001) La universidad de la Plata y el movimiento estudiantil. Desde sus orígenes hasta 1930, Edulp, La Plata.
} 
afirmaba la vieja posición de la UNLP en materia de extensión y trabajo social. Los estudiantes pedían el acceso del proletariado a la universidad con el fin de vincular sus luchas con el ideal político de la justicia social (De Lucía, 2001, p. 25).

Con la renuncia del entonces presidente Rodolfo Rivarola ${ }^{77}$ y con la llegada de Carlos Melo a la presidencia de la UNLP, los estudiantes lograron que se efectivizara su programa de lucha: participación en el gobierno universitario, asistencia libre y libertad de cátedra, participación estudiantil y de los egresados en el consejo académico, establecimiento de concursos para la designación de profesores, renovación del plantel docente, reforma de los planes de estudio a fin de promover la investigación científica y una educación humanista (Graciano, 2008, p. 63).

En la década de 1930, con la avanzada del gobierno de facto encabezado por el general Félix Uriburu, la intervención de la universidad y la pretensión de restaurar el orden jerárquico, autoritario y tradicionalista en las casas de altos estudios, se echaron atrás los sueños reformistas. Sin embargo, con la llegada de Agustín P. Justo al poder ejecutivo nacional en 1932, los estudiantes volvieron a tener participación en el gobierno universitario (Castiñeiras, 1938). De este modo, los años '30 se caracterizaron por ser el momento en que los estudiantes reformistas se incorporaron de manera decisiva a la vida política nacional mediante la participación en partidos políticos vinculados con las luchas de los sectores trabajadores y medios, hecho que los llevó a vincularse íntimamente con el Partido Socialista ${ }^{78}$ (Graciano, 1999, p. 85- 86).

En la primera mitad de la década de 1940, la relación de fuerzas al interior de la universidad parecía a favor de los estudiantes reformistas. En el año 1941 resultó electo presidente de la UNLP el Dr. Alfredo Palacios ${ }^{79}$ y con él se reanimó el proyecto de

\footnotetext{
${ }^{77}$ Rodolfo Rivarola estudió Ciencias Jurídicas en la Universidad Nacional de Buenos Aires, se recibió de Abogado y rápidamente inició su doctorado en Jurisprudencia. Se desarrolló como secretario de la Suprema Corte de Justicia de la provincia de Buenos Aires, también fue vocal en el Consejo de Educación de la misma provincia. Se desempeñó como docente en Derecho Civil en la UBA y como docente en Ciencia Penal en la UNLP donde acompañó al presidente de esa misma universidad que lo antecedió, el Dr. Joaquín V. González.

78 El Partido Socialista articulaba proyectos de extensión cultural desde fines del siglo XIX. Desde su extremada fe en la ciencia como medio para mejorar la calidad de vida de los trabajadores, produjo conferencias a través de la Sociedad Luz, a partir de las cuales pretendían irradiar saberes relacionados con la profilaxis, higiene, alcoholismo, prostitución y hábitat, con el objetivo de elevar cultural y materialmente al proletariado. Ver: Barrancos, Dora( 1996) La escena iluminada. Plus ultra. Buenos Aires. En la ciudad de La Plata, el acercamiento entre los socialistas y reformistas se materializó también a través de la creación de la Universidad Popular Alejandro Korn (UPAK) en el año 1937. Ésta funcionaba -y aun lo hace- en las instalaciones del PS. Los propósitos de esta universidad no consistían en saldar el déficit de la UNLP, sino proponer otro modelo que estableciera lazos de "solidaridad" con el movimiento trabajador. En el capítulo 4 retomaremos esta experiencia.

${ }^{79}$ Alfredo Palacios, abogado, político y profesor universitario, fue militante del Partido Socialista. En 1906 se consagró como primer diputado por el socialismo en toda América. Fue inspirador de la Reforma Universitaria a través de su obra Nuevo Derecho y resultó designado por el Congreso de Estudiantes Latinoamericanos como Maestro de América. En sus acciones como diputado se encuentran la
} 
plasmar un programa orgánico de Universidad capaz de gestar alternativas políticas que demandaba la realidad (Vallejos, 2007, pp. 409- 411). Con las fuerzas políticas universitarias de su lado, los estudiantes y, posteriormente, graduados reformistas, promovieron la creación de cursos y espacios de formación profesional que dieran respuesta a las necesidades político económicas de su contexto particular, propuestas que veremos a continuación y también en el capítulo 4 .

En este contexto de disputa político académica, los estudiantes no solo hicieron uso de las estrategias de acción directa como la huelga o toma de facultades, sino que también difundieron sus debates respecto de la formación profesional al interior de la universidad como parte de sus preocupaciones. Muestra de ello es La Revista del Centro de Estudiantes de Medicina ${ }^{80}$, publicada entre los años 1921 y 1925. En la primera época establecida entre 1921-1922, publicaron tres números en los que se identificaron como parte de la vanguardia reformista. En esas publicaciones exigieron cortar con la dependencia que la Escuela Preparatoria de Medicina mantenía con la Facultad porteña, donde los estudiantes cursaban los últimos dos años de su formación profesional, mientras los primeros tres eran realizados en la ciudad de La Plata. En sus páginas reflexionaron acerca de las competencias que les cabían en tanto universitarios reformistas, en especial sobre la extensión universitaria de los conocimientos a los sectores populares.

La necesidad de difundir conocimientos sobre higiene entre los obreros era una preocupación compartida con los y las militantes del PS, quienes eran invitados a su casa de estudios para dictar conferencias en pos de la formación crítica de los futuros profesionales. Muestra de ello fue la publicación de una conferencia acerca de la higiene obrera dictada por la feminista Alicia Moreau de Justo. En esa ocasión, la referente del partido socialista y reconocida fundadora de la Unión Feminista Argentina subrayó el

promulgación de leyes a favor de las mujeres trabajadoras, como la Ley N 5.291 de Reglamentación del trabajo de mujeres y niños (1908); la Ley $\mathrm{N}^{\circ} 11933$ de Protección a la madre obrera (1934); la Ley $\mathrm{N}^{\circ}$ 12.111 de Licencia a empleadas y obreras antes y después del parto (1934); y la Ley $\mathrm{N}^{\circ} 12.341$ de Creación de la Dirección de Maternidad e Infancia (1936), entre otras.

80 Esta revista tuvo origen en el año 1921 como parte de la avanzada organizativa de los estudiantes de Medicina vinculados a la Reforma. En ella se destacan tres períodos: el primero que va desde el año 1921 al 1922, en que se cierra la revista como parte del repliegue grupal de estos jóvenes en el contexto de avanzada de los sectores más conservadores del radicalismo con Marcelo T. de Alvear. Sin embargo, en 1925, obtenido el reconocimiento como Escuela de Ciencias Médicas, se reedita la revista pero con una gran participación de los profesores y financiamiento externo, hecho que muestra una reducción en la participación estudiantil. La revista tuvo una tercera etapa iniciada en enero de 1937, luego de un año de haber obtenido el pase a Facultad. La nueva revista mantendrá la llama reformista como una declaración escrita, aunque no será encendida exclusivamente por los estudiantes, sino por algunos reformistas graduados, como Alberto Zambosco. 
carácter social de la tuberculosis y la peligrosidad que implicaba para los sectores pobres que vivían en la miseria. ${ }^{81}$

La lucha iniciada por estos grupos estudiantiles para conseguir el reconocimiento como Facultad de Ciencias Médicas debió esperar hasta el año 1936. Este hito institucional posibilitó la creación y el desarrollo de cátedras encargadas de la formación y de la producción de conocimientos en el ámbito académico, como fueron las cátedras de Higiene Médica y Preventiva en 1936 a cargo del Dr. Pilades Dezeo y también la cátedra de Clínica Obstétrica creada en 1937, cuyo docente titular concursado fue el Dr. Victorio Monteverde. ${ }^{82}$ Ambas cátedras se abocarían a problemáticas específicas de la cuestión social, por una parte, a la problemática de la higiene y la prevención de las enfermedades sociales, y por otra, a la relación madre-hijo desde la obstetricia. Incluso ambas compartirían proyectos de extensión para la difusión de sus conocimientos. Vale destacar que no es casual el encuentro de estas dos cátedras puesto que la preocupación por la atención de las mujeres madres y los niños parecían reunir a estas dos áreas de conocimiento. En el mismo año en que estas cátedras son concursadas también se llevaba adelante la aprobación de la Ley Nacional $\mathrm{N}^{\mathrm{o}} 12.341$, mediante la que se estableció la creación de la Dirección de Maternidad e Infancia, instaurada sobre la base del Departamento Nacional de Higiene y la Sección de Asistencia y Protección a la Infancia. El objetivo principal de esta nueva dirección sería combatir la morbimortalidad infantil y amparar a la mujer en su condición de madre "o futura madre". Además, la creación de esta dirección pretendía estudiar la higiene social de la infancia, llevar adelante la inspección de las instituciones oficiales y privadas que se ocuparan de la protección y asistencia a madres e hijos, realizar propaganda de los postulados de higiene social y eugenesia, sobre todo en puericultura e higiene infantil. Tal como hemos citado con antelación, esta mayor intervención estatal sobre el binomio madre-hijo exigió una modificación de los servicios de salud, como también la formación de agentes que llevaran adelante campañas y controles. Si bien no aparecen

\footnotetext{
81“"Tercer Congreso de Profilaxis Antituberculosa". Conferencia de la Dra. Alicia Moreau de Justo, en Revista del Centro de Estudiantes de Medicina La Plata, nº 1 , diciembre de 1921, pp. 44-46.

${ }^{82}$ El Dr. Victorio Monteverde ejerció como docente de obstetricia desde el año 1917 en la UBA. Dos años después comenzó su ejercicio como Director de la Maternidad Piñeiro. Su destacada labor fue reconocida por la Facultad de Medicina de la UBA que le otorgó el título de profesor extraordinario de Clínica Obstétrica en 1934. Su inquietud por los problemas gremiales lo llevó a organizar, en octubre de 1936, el Primer Congreso de Medicina Gremial y Social. Desde su compromiso profesional y gremial formó la Casa del Médico en la ciudad de Buenos Aires, institución tendiente a realizar la unión del gremio en su afán de solidaridad entre todos los profesionales del país y como instrucción permanente para la construcción de una cultura profesional. Durante el período de 1942 a 1945 se desempeñó como Decano de la Facultad de Ciencias Médicas UNLP.
} 
citadas quiénes podrían ser las encargadas de tales tareas, de acuerdo al funcionamiento de la asistencia social y la beneficencia, eran féminas quienes se encargaban de la atención a las mujeres madres y a la infancia desvalida.

La nueva Dirección planeaba la creación de una Escuela de Servicio Social de la Infancia y también la creación de una Escuela de Puericultura ${ }^{83}$ a fin de garantizar una intervención organizada según patrones comunes. Más allá de los alcances que hayan tenido estas escuelas, -y que no serán abordados en esta tesis por la amplitud que sugieren-, es interesante considerar que esta ley promueve la profesionalización de la asistencia, en especial de quienes trabajaban con niños y madres, mediante un abordaje que conjugue el Servicio Social con la Puericultura y Obstetricia. Esta novedosa propuesta no había sido parte de las currículas disponible en los años '30 por la EVHS UBA y tampoco por la Escuela de Servicio Social del Museo Social Argentino en la ciudad de Buenos Aires. En cambio, para los médicos de la UNLP resultarán de importancia cardinal e incluso serán dos de las cuatro especializaciones sugeridas por la EVHS local.

No obstante el encuentro de ambas cátedras, y la participación del Jefe de la Cátedra de Obstetricia en la EVHS como también en los ciclos de radioconferencias que veremos en el Capítulo 4, será Pilades Dezeo quien, un año después de iniciado su cargo, impulsará el proyecto de creación de una Escuela para Visitadoras de Higiene Social con el fin de ampliar la acción de asistencia social que se llevaba adelante en todo el país, prestando especial atención a la cuestión de las mujeres madres y niños.

\subsection{La Creación de la Escuela para Visitadoras de Higiene Social de la UNLP}

En el año 1937, el reciente profesor titular de Higiene médica y preventiva Pilades Dezeo junto con Alberto Zambosco llevarán adelante la presentación al Consejo Académico del proyecto para la creación de la Escuela para Visitadoras de Higiene. El proyecto titulado "Escuela de Visitadoras de Higiene Medica y Preventiva" -que luego es mencionado como Escuela para Visitadoras de Higiene Social- se presentó como parte del avance alcanzado por las ciencias médicas, en particular la higiene preventiva, pero también como parte de un movimiento mayor a nivel internacional iniciado por la Liga Internacional de las Naciones y la Cruz Roja, contando a nivel regional con el antecedente de la EVHS UBA, y también con la I Conferencia Nacional de Asistencia Social. La justificación del proyecto se basó en que era imprescindible la formación de

\footnotetext{
${ }^{83}$ Ver: Artículo 57 y Articulo 58 de la Ley Nº12.341, pp. 581-582.
} 
un agente auxiliar de la medicina preventiva para el avance mismo de la ciencia, en tanto estas profesionales podrían "enfocar los factores sociales que acompañan a los netamente médicos". 84

El objetivo de la formación de este personal sanitario auxiliar era permitir a las organizaciones de medicina preventiva un mayor rendimiento económico social a través de la ejecución de las siguientes funciones: realizar propaganda y educación popular en materia de higiene y medicina preventiva con el objetivo de modificar hábitos y atraer al individuo y la familia hacia las organizaciones sanitarias; presentar al médico los antecedentes sociales y económicos involucrados en el malestar de los individuos, educar a quienes estuvieran afectados a fin de garantizar el cumplimiento de las prescripciones médicas y, por último, "ser un agente del servicio social, contribuyendo a la mejor organización de las instituciones de medicina preventiva" (Dezeo, 1938, p.1). Reparemos por un momento en lo que implica el concepto economizar, muy citado por los médicos a cargo de la formación profesional. La posibilidad de economizar permite aumentar las reservas mediante la reducción de la inversión para la realización de un determinado producto elaborado o la entrega de un servicio a terceros, hecho que facilita una mayor ganancia a partir de invertir exiguos recursos para tal fin. Es decir, que si el objetivo era abaratar los costos de la intervención sobre la cuestión social mediante una intervención educativa y de carácter preventivo para facilitar a las instituciones sanitarias la reducción de gastos en la atención de personas afectadas por tuberculosis, embarazos complejos, enfermedades congénitas, entre otros, no podemos pasar por alto que la estrategia preventiva también se valía del uso de la fuerza de trabajo de las mujeres, que mediante labores sin límites de tiempo y no reguladas formalmente facilitaban la desvalorización de su trabajo.

Históricamente las mujeres habían facilitado la atención de los sectores desvalidos para reproducir sus condiciones cotidianas de vida (niños, ancianos, enfermos, entre otros), pero a partir de la década del '30 ya había un mercado de trabajo claramente delineado (educación a madres y niños, inspección a posibles afectados por las enfermedades venéreas, atención y prevención de la tuberculosis, etc.) en el que el Estado y sus agentes pretendían involucrarse a través de una mano de obra que no pusiera en peligro los privilegios de los médicos varones. Pero además de ser trabajadoras supuestamente dóciles, también debían ser instruidas. Así lo sostiene Dezeo en el Discurso Inaugural de la EVHS UNLP:

\footnotetext{
${ }^{84}$ Fundamentos del Proyecto de Creación de la Escuela para Visitadoras de Higiene. 1937. pp. 7.
} 
Es menester también poseer el conocimiento de una técnica adecuada para el estudio y solución de cada problema que la realidad social ofrece a fin de acrecentar la eficacia del esfuerzo no malgastando energías en soluciones intuitivas, incompletas, a veces hasta contraproducentes, por falta de la guía que da la experiencia y la ciencia del servicio social (Dezeo, 1938, p. 7).

Es decir, que más allá de las buenas intenciones de las mujeres que realizaban la asistencia social de manera privada o publica, la UNLP apeló a garantizar una formación técnica bajo el auspicio de la ciencia que evitara el malgasto de energías, y también de dinero, en soluciones que no resultaran definitivas.

El derrotero burocrático para la aprobación del proyecto de creación de la EVHS implicó el debate en distintas comisiones del Rectorado de la UNLP, donde se podría dirimir la utilidad y sostenibilidad de la nueva profesión. En su tratamiento, la Comisión de Enseñanza aconsejó la aprobación de dicho proyecto por formar parte del "gran" movimiento de asistencia social que se está realizando en el país, cuya primera referencia era la I Conferencia de Asistencia Social sucedida cuatro años antes. A pesar de este primer sostén, la Comisión de Economía y Finanzas se negó a dar el total apoyo pecuniario y sugirió que lo soliciten en los próximos años. A fin de que funcionara ofrecía un plan de pagos para docentes en función del arancel que pagarían las estudiantes. ${ }^{85}$ Esto demuestra el carácter subalterno al que se expulsaba a la nueva carrera, pero también la decisión desde la Universidad de reforzar el circuito económico de precariedad e infravaloración que la división sexual del trabajo establecía para las mujeres.

El llamamiento exclusivo a las féminas para la formación en la EVHS no tuvo explicitaciones. Incluso dentro de las comisiones que trataron el proyecto no mencionaron, y menos aun cuestionaron, la convocatoria feminizada, lo que demuestra el poder de la ideología de la diferencia sexual. No solo las autoridades de la Universidad alentaban la subordinación de la EVHS, incluso los estudiantes de la Facultad de Medicina, reconocidos por su trayectoria reformista y combativa en la ciudad de La Plata, celebraron la presentación del proyecto de creación de la EVHS puesto que estaría "subordinado a las necesidades de una organización sanitaria eficiente" ${ }^{86}$ En especial, porque esa posición subordinada suponía, entre otras cosas, no comprometer los recursos asignados en el presupuesto para la Facultad de Ciencias Médicas.

\footnotetext{
${ }^{85}$ Sesión del día 10/1937 Consejo Académico UNLP. Tomo I. pp. 226- 228.

${ }^{86}$ Revista de la Facultad de Ciencias Médicas. Centro de Estudiantes de Medicina, año 1, no 3, abril/mayo 1937, p. 105.
} 
El espacio de cursada destinado fue la Escuela de Señoritas Liceo Víctor Mercante, a cargo de la Dra. en Biología Juana Cortelezzi, a quien Pilades Dezeo llamó en el discurso inaugural de la escuela "la colaboradora invisible" (1938, p.2), a pesar de los importantes aportes materiales que hizo al desarrollo de la EVHS. La Escuela de Señoritas era un espacio propicio para el desarrollo de tareas educativas puesto que contaba con aulas y laboratorios libres durante el horario vespertino que podían suplir las carencias edilicias de la Facultad de Ciencias Médicas. La Escuela de Señoritas Liceo Víctor Mercante es una de las escuelas que forma el sistema pre-universitario de la UNLP. Su matrícula era exclusivamente de mujeres y daba una formación de seis años a sus estudiantes. Allí también se brindaban distintos cursos para las jóvenes en el nivel secundario y para graduadas, buscando formar una comunidad educativa intergeneracional de mujeres. Entre los cursos estaba la enseñanza de la cultura e idioma alemán dictado por el Instituto Cultural Argentino Germano. ${ }^{87}$ Un mes después de iniciados los cursos para la Escuela de Visitadoras de Higiene Social, comenzaron a funcionar Cursos de Cocina de corta duración ${ }^{88}$ y también Cursos de Economía doméstica destinados a las estudiantes de años superiores. ${ }^{89}$ El Liceo prestaría sus instalaciones también a las reuniones de la Comisión Femenina del Club Universitario, quienes también celebraron allí la constitución de la Sección Femenina del Club. ${ }^{90}$

En el discurso inaugural de la EVHS, Dezeo (1938) destacó que la amplitud del campo de la medicina preventiva no podía ser colmada por los esfuerzos de los médicos, y por ello, su carácter social reclamaba la incorporación de nuevos elementos a fin de completar la obra médica con la social que, "día a día, la realidad exige". La preocupación del médico higienista versó sobre las distintas fases del círculo de la miseria, que unida con la enfermedad y la muerte precoz, impedían el reajuste social de una parte importante de la población. La necesidad de intervención sobre los conflictos y las enfermedades sociales, como la tuberculosis, el alcoholismo, la sífilis, pretendía remediar la degeneración de la raza, temor en boga por los sectores eugenésicos que encontraban en estos males la pérdida de la nación. Si bien estas cuestiones interesaron a médicos, jueces, educadores, sacerdotes, entre otros, las mujeres aparecen como las indicadas para esta función, ya que por sus "sentimientos altruistas" y ser fuente inagotable de "perseverancia, resignación y paciencia”, resultaron "insustituibles".

\footnotetext{
${ }^{87}$ Diario El día, 7 de abril de 1937.

${ }^{88}$ Diario El día, 14 de mayo 1938.

${ }^{89}$ Diario El día, 15 de mayo de 1938.

${ }^{90}$ Diario El día, 3 de marzo de 1937.
} 
Las características amorosas y altruistas adjudicadas a las mujeres no eran suficientes para la intervención sobre la cuestión social, de hecho las obras realizadas por la caridad y la beneficencia ya no podían auxiliar las necesidades de "los nuevos desplazados". Era necesaria una formación en salud pública, profilaxis y prevención social, que permitiría a las visitadoras "luchar con eficacia contra la intemperancia de las costumbres, contra la morbimortalidad materna e infantil, contra las enfermedades que desgastan al individuo, abrevian la vida o taran la descendencia, degenerando la raza" (Dezeo, 1938, pp.10-11). La EVHS establecía una formación de dos años, el primero de orden preparatorio y común a todas, y el segundo dedicado a alguna de las especializaciones ofrecidas: visitadora de higiene escolar, visitadora para la profilaxis de la tuberculosis, visitadora en puericultura, y por último, visitadora para puericultura y obstetricia. Cada una de ellas requería distintos antecedentes, por ejemplo, las estudiantes que se especializaran en Profilaxis de Tuberculosis o Puericultura se les demandaba comprobar el cursado de estudios secundarios, normales o especiales, incluso siendo parciales, y en caso de no ser así deberían rendir un examen de ingreso. A las interesadas en el tratamiento de la Higiene Escolar se les pedía la presentación del título de maestra; mientras que a las dedicadas a la especialización en Obstetricia y Puericultura se les solicitaba ser parteras diplomadas de la UNLP o alumnas de tercer año de dicha escuela, a condición de seguir el segundo año de la EVHS, luego de finalizado el tercero como obstetras. Este recorrido previo exigido a las jóvenes interesadas, como también el hecho de que pagaran sus estudios, sugiere que las estudiantes pertenecían a una clase media ascendente, y que en su interés por participar como agentes del servicio social laico podían solventar los gastos de su formación como profesionales universitarias (Di Liscia, 2014; Gavrila, 2016).

Prescriptivamente, las labores que a ellas correspondían eran: trabajar junto al médico para la conservación o restablecimiento de la salud individual o colectiva, realizar propaganda $^{91}$ para atraer al individuo o a la familia a la institución preventiva o curativa, presentar los antecedentes mórbidos o económicos sociales de la situación que debían remediar, entre otros trabajos.

Resulta destacable que en estas acciones de las visitadoras también hubo un trabajo de orden intelectual a través del estudio sistemático de las condiciones de vida de las

\footnotetext{
${ }^{91}$ Entre las acciones de propaganda de las visitadoras encontramos: conferencias en clubes, en sociedades de socorros mutuos, en escuelas, y hasta disertaciones radiales. Esta última acción resulta destacable porque colocó a las nuevas profesionales en un espacio de difusión pública y enunciación compartida con médicos higienistas que eran parte de la Liga Provincial de Lucha contra la Tuberculosis y de la Facultad de Ciencias Médicas de la UNLP. Ver: Gavrila, Canela (2016) "Prevenir y persuadir. Las acciones de difusión radial de las Visitadoras de Higiene en la primera mitad del siglo XX". Avances del Cesor.
} 
personas afectadas junto con la presentación de dichos informes. Sin embargo, estas tareas no son reconocidas como parte del quehacer profesional, lo que refuerza su lugar subalterno. Se esperaba, además, que las visitadoras interpretaran la opinión técnica del médico para que educaran a los sujetos en las causas sociales de sus males. Esta multiplicidad de acciones era el complemento de la acción social médica que los mismos galenos dejaban de cumplir para dar paso a una nueva profesional que auxiliara la totalidad del tratamiento, a pesar de que el diagnóstico final fuera privilegio de este grupo de poder en el ámbito sanitario. La multiplicidad de tareas que debían cubrir las visitadoras suponía una innata capacidad de contención, ayuda en la resolución de problemas y una disponibilidad sin límites que se asocia con los roles atribuidos socialmente a las mujeres. Con esta situación, el Estado como principal empleador se favorecería de la polivalencia funcional de estas profesionales que educaban, curaban, prevenían, hacían informes, vigilaban, vulgarizaban los saberes médicos, etc.

Para ahondar aun más en los objetivos de los médicos para la formación profesional de las visitadoras de higiene social, analizaremos en el siguiente capítulo el programa de estudios de la profesión, dado que la malla curricular muestra los intereses, conocimientos, valores, costumbres y hábitos que conformaron esta propuesta educativa, en la que se manifiestan los intereses políticos de los sectores hegemónicos para la formación profesional (De Alba, 1998, p.75). 


\title{
PARTE II: Mujeres, Economía del cuidado y formación profesional. Entre deseos de libertad y posibilidades restringidas 1937-1948
}

\section{Capítulo 3: Apuntes para comprender la construcción de una profesión feminizada}

\author{
"La Visitadora de Higiene Social es una de las tantas mujeres que trabajan. \\ No se maquiniza en el esfuerzo de una acción monótona, \\ sino que eleva constantemente \\ su "Yo" en pro del mejoramiento de los demás. \\ Los que no conocíais esta nueva función de la mujer, \\ aquí la tenéis esbozada: es un trabajo noble y grande, \\ que requiere inteligencia cultivada y corazón magnánimo.” \\ Revista Viva Cien Años (1939)
}

Un año después de abiertas las puertas de la EVHS platense, la Revista "Viva Cien Años", destacada publicación eugenésica ${ }^{92}$ para la "divulgación popular de la ciencia", presentó un número especial dedicado a las visitadoras de higiene social. En la tapa de la revista se mostraba a una visitadora con una libreta en la mano y detrás de ella, en un plano más reducido, las siluetas de tres parejas heterosexuales. Los hombres estaban de esmoquin y las mujeres llevaban vestido blanco y largo, vestimentas claramente alusivas al compromiso matrimonial del que no caben dudas puesto que el título de la publicación dictaba "Hacemos de 6 a 8 casamientos por mes, dice la visitadora de higiene" ${ }^{\circ 3}$. Como afirmamos en el capítulo anterior, parte del trabajo de las visitadoras era realizar el examen prematrimonial a fin de constatar que el hombre y la mujer que deseaban unirse civilmente fueran capaces de garantizar una familia saludable para la reproducción sana y fuerte de acuerdo a los parámetros establecidos por la eugenesia. ${ }^{94}$ A pesar de que las visitadoras tenían multiplicidad de tareas por cubrir, ésta aparece presentada en la tapa de la revista de divulgación popular sobre medicina y eugenesia como la más importante de su desempeño profesional.

\footnotetext{
92 Creada en 1934.

${ }^{93}$ Revista Viva Cien Años. Volumen VIII, Nº4. 15 de Noviembre de 1939.

${ }^{94}$ Para una mayor información acerca de la revista se sugiere la lectura de Linares, Luciana (2016) "Matrimonios y algo más. Discurso eugénico en torno al proceso de selección de pareja. El caso de la revista Viva Cien Años. 1935-1947”. Avances del Cesor, V. XIII, No 14, Primer semestre 2016, pp. 89109. ISSN 1514-3899/ISSN 2422-6580. Recuperado de:

http://web2.rosario-conicet.gov.ar/ojs/index.php/AvancesCesor/index
} 
En el siguiente capítulo analizaré las condiciones laborales y educativas que posibilitaron el proceso de feminización de la profesión de las visitadoras de higiene social en la ciudad de La Plata. En principio serán expuestas algunas características de las profesiones feminizadas, luego presentaré someramente cuál era el mercado de trabajo y las condiciones de ingreso para las mujeres en Argentina durante la primera mitad del siglo XX, considerando como elemento común el trabajo de sostenibilidad de la vida que ellas realizaron, tanto en la esfera productiva como en la reproductiva. En una tercera instancia, y de manera particular dado el interés de esta tesis, trabajaré sobre los planes de estudio de la carrera donde se hallan las pistas acerca de cómo se feminizó la profesión, desde la elección de los contenidos curriculares y los espacios de prácticas profesionales. Por último, daremos cuenta de parte de los elementos de la malla curricular que operaron de manera normativa y excluyente en la formación de la profesión.

\subsection{Feminización y profesionalización}

Tal como mencioné en la introducción de esta tesis, las profesiones han sido concebidas por la sociología como un fenómeno de las sociedades modernas. El sociólogo norteamericano Eliot Freidson (1978) analizó la medicina como uno de los prototipos representativos de una profesión y destacó como elementos clave de la organización profesional la capacidad de acumular y usar conocimientos bajo sus propios estándares, sin estar sujetos al control de actores externos. Este autor considera que las pujas de poder, las relaciones con el Estado y con otros grupos ocupacionales son importantes en los procesos de profesionalización. La división del trabajo médico en otras ocupaciones y prácticas, útiles y necesarias a la medicina, generalmente dedicadas a brindar servicios relativos a la curación, reúne variados oficios especializados que podrían llegar a ser ocupaciones competitivas y a constituirse en una amenaza para el monopolio de la medicina.

Dentro de la historiografía argentina, el estudio de las profesiones sanitarias fue abordado por una multiplicidad de voces. Susana Belmartino (2005), desde un enfoque de orden institucionalista, reparó en la necesidad de identificar a los actores estatales, grupos de poder económico y político que intervienen en el proceso de profesionalización y mercantilización, para evidenciar que la jerarquía e importancia de una profesión no depende solo de la formación y técnicas adquiridas, sino también de cuestiones políticas, sociales y económicas. En este sentido, Frederic, Graciano y 
Soprano (2010) consideran que el análisis sobre las relaciones que establecen las profesiones con el Estado resulta necesario e imprescindible para comprender la dinámica de las agencias estatales y la sociabilidad de sus funcionarios.

Con antelación, Ricardo González Leandri (1999) identificó que los procesos de profesionalización debían ser comprendidos en el marco de una puja de intereses entre factores políticos, económicos, científicos y académicos que se mantienen como procesos conflictivos (pp. 25-26). Un registro clave para analizar cómo se manifiestan esas tensiones y pujas de interés se encuentra en las relaciones de poder entre los grupos profesionales más encumbrados, como es el caso de los médicos, frente a los grupos considerados auxiliares y subordinados, como por ejemplo las enfermeras (Martin, 2015; Ramacciotti y Valobra, 2015) y las terapistas ocupacionales (Testa, 2012).

Desde los estudios de género se han iniciado cuestionamientos sobre el carácter sexuado de los procesos de profesionalización. Como señala Pozzio (2012), los incipientes puentes que tienden entre sí se caracterizan por reflexionar acerca de las condiciones en que el mercado de trabajo y el acceso diferencial a la educación se construyeron como instancias elementales en la constitución de las identidades e imaginarios de género que han moldeado subjetividades para la elección de las profesiones (p. 113). En el caso particular de las profesiones sociosanitarias, como es el caso del trabajo social y sus antecedentes como la visita de higiene, pero también en los casos como la enfermería, la obstetricia, la nutrición, la terapia ocupacional, entre otras, mantienen marcas de género desde sus inicios puesto que estas actividades de "cuidados" se asociaban a los roles domésticos. Embarazos, partos y alimentación eran consideradas como actividades privativas de las mujeres, por lo que fueron utilizadas por la ciencia y la burocracia estatal para alejar a las féminas de los espacios de participación política y científica (Pateman, 1995) como asi también para ampliar el dominio de la ciencia médica sobre el Estado y el mercado (Buschini, 2016).

Alrededor de las profesiones feminizadas se establece el debate acerca de si son o no "semiprofesiones", designadas de tal modo por ser una formación de corto tiempo, tener menor estatus, conocimientos menos especializados y una menor autonomía (Finkel, 1999). Sin embargo, tal como señala Pozzio (2012), el hecho de que se consideren semi profesiones se vincula íntimamente con la feminización, sobre todo con la caída del prestigio y la precarización de sus condiciones de trabajo.

La profesionalización de la visita de higiene puede inscribirse como parte de un entramado más amplio suscitado en Argentina durante la primera mitad del siglo XX. Por una parte, el crecimiento y expansión de los alcances de la profesión médica sobre 
multiplicidad de esferas políticas y sociales, con un destacado predominio del género masculino que detentaba las posiciones de poder, junto con la exclusión de las mujeres médicas. ${ }^{95}$ Por otra parte, la incorporación femenina en el mercado de trabajo estaba cargada de fuertes contradicciones por las problemáticas que acarreaba la mujer obrera para la moralidad femenina y su condición maternal (Lobato, 2007, p. 66). El peso de la ideología de la domesticidad ${ }^{96}$ y las voces que denunciaban el peligro de desintegración del orden doméstico y familiar hicieron que actividades como la enfermería, la educación y la asistencia resultaran más apropiadas con los "deberes femeninos", construyéndolas como profesiones atajo (Martín, 2015, pp. 257-258). Sin embargo, el hecho de que las mujeres participaran en trabajos que eran considerados "naturales" de su condición facilitaba también la desvalorización de su desempeño y, por ende, su feminización (Ramacciotti y Valobra, 2014).

En particular, el proceso de profesionalización y feminización de la carrera de visitadoras de higiene resultó similar a la de dietistas en tanto son resultado de la proyección de grupos de médicos varones - y no de las propias agentes- que, en su afán de expandir los alcances de su ocupación en el ámbito estatal y en el mercado, fundaron espacios profesionales sobre los cuales pretendían mantener el control (Buschini, 2016, pp. 137-138).

En esa misma línea se inscribió la EVHS UNLP. Su fundador y primer director, el Dr. Pilades Dezeo (1938), les proponía a las jóvenes que ingresaban a la escuela ser "cual ángeles de piedad fuertes en vuestra propia debilidad o como la rumorosa ola que con su constante caricia modela la dura roca" (p.7). Al igual que sus colegas médicos acordaba con los criterios de época acerca de la "debilidad" femenina y su utilidad para la reproducción cotidiana, por ello sabía que podía exigir esfuerzos constantes y persistentes a las féminas en pos de modificar hábitos o modelar conductas ajenas, puesto que los trabajos de cuidados, asistencia y auxilio al prójimo ya formaban parte de las tareas que las mujeres realizaban en el espacio doméstico y también en el espacio

\footnotetext{
${ }^{95}$ Ver: Armus, Diego (2000) "El descubrimiento de la enfermedad como problema social", en LOBATO, Mirta (directora) El progreso, la modernización y sus limites, colección Nueva Historia Argentina, T. V, Sudamericana, Buenos Aires; Belmartino, Susana (2005) La atención médica argentina en el siglo XX. Instituciones y procesos, Siglo Veintiuno Editores, Buenos Aires; Biernat, Carolina (2015) "El proceso de centralización del Departamento Nacional de Higiene (1890-1944)", en Biernat, Carolina, Cerdá, Juan Manuel y Ramacciotti, Karina (directores) La salud pública y la enfermería en la Argentina, Universidad Nacional de Quilmes Editorial, Bernal.

96 Joan Scott llama ideología de la domesticidad al entramado de discursos médicos, morales, científicos y políticos tendientes a naturalizar la división sexual del trabajo, legitimando la separación entre el hogar y el trabajo, de modo que resultara eficiente a los fines de acumulación capitalista. Ver: Scott, Joan(1993)“La mujer trabajadora en el siglo XX”. En Duby y Perrot. Historia de las mujeres. El siglo XIX. Ed Taurus. Madrid. pp.427- 461.
} 
público. La EVHS permitiría a estas mujeres tender puentes entre aquellos conocimientos privativos del orden doméstico (como la limpieza de la casa, la ventilación, el amantamiento, entre otros) junto con los conocimientos producidos por los médicos higienistas a cargo de la escuela.

El peso de la división sexual del trabajo en el ámbito sanitario influyó para que las mujeres ocuparan las áreas auxiliares como la enfermería, las visitas de higiene, la obstetricia y la puericultura, hecho que pretendió alejar a las féminas de la competencia del monopolio masculino de los saberes médicos y vincularlas con actividades ligadas al cuidado y a la relación con otras mujeres (Nari, 2004; Ramacciotti y Valobra, 2011; Testa, 2013; Martín, 2014). El carácter feminizado se tradujo en una posición subordinada dentro del ámbito sanitario, justificada en las prescripciones de los médicos varones, quienes predefinieron una matriz de formación para la expansión del discurso científico que, si bien pretendía mantener a las profesionales como "auxiliares" de los médicos, abrió intersticios de acción para las visitadoras en su comunicación con los y las usuarios de los servicios de asistencia social, cuestión que desarrollaré en el próximo capítulo.

\subsection{Mujeres y trabajos}

"El ritmo acelerado de la existencia actual ha requerido la cooperación de las mujeres en todos los órdenes de la vida, y ellas han respondido ampliamente" Revista Viva Cien Años

Las mujeres han trabajado históricamente en diversas tareas, con o sin remuneración, con o sin derechos, dentro y fuera de su casa e incluso en algunos casos sin reconocerse que sus acciones constituían un trabajo. Una ocupación que históricamente han realizado las mujeres y que ha invitado a ricos debates entre economistas neoclásicos y economistas feministas ${ }^{97}$ son las tareas para la reproducción del núcleo doméstico como el cuidado, la atención a niños y ancianos de la familia, la preparación de alimentos,

\footnotetext{
${ }^{97}$ Amaia Pérez Orozco denuncia que el paradigma neoclásico adolece de profundos sesgos androcéntricos al construirse sobre la negación de la participación de las mujeres en la economía y, por lo tanto, no considerar la relevancia económica de las esferas que se asocian a la feminidad como el ámbito privado doméstico, el hogar y los trabajos no remunerados, haciendo que sea la experiencia masculina de intervención en el mercado la única válida para el estudio de la economía. Esto no es casual ya que estos discursos se instalaron junto con la consolidación de un sistema económico basado en la escisión de la división sexual del trabajo. Pérez Orozco, Amaia (2014) Subversión feminista de la economía. Aportes para un debate sobre el conflicto capital- vida. Traficantes de sueños, Madrid. pp. 36-37.
} 
entre otras. La economista feminista Corina Rodríguez Enríquez (2015) destaca que dentro del orden capitalista y de la división sexual del trabajo, las mujeres son el sostén fundamental de la reproducción social en cuanto sobre ellas recaen actividades y prácticas necesarias para la vida cotidiana, como por ejemplo, el auto cuidado, el cuidado de otras personas, la provisión de las precondiciones en que se realizan los cuidados (como la limpieza de la casa, la compra de alimentos, la preparación de los mismos, entre otras labores) y su gestión, es decir, la organización de horarios y traslados de las personas que forman el grupo doméstico. Es por ello que el trabajo doméstico y las prácticas de cuidado resultan constitutivas de la economía capitalista. Estas labores contribuyen a producir valor económico en tanto facilitan las condiciones para la reproducción cotidiana de la fuerza de trabajo. Sobre todo, el cuidado permite atender las necesidades de las personas que son dependientes por sus capacidades, edad y/o condiciones, como también de aquellas que podrían autoproveerse (Rodríguez Enríquez, 2015, pp.15-16).

Los trabajos de cuidado resultan imprescindibles para el funcionamiento del sistema económico a fin de organizar la reproducción de las personas. Shahra Razavi (2007) considera que la organización social del cuidado puede pensarse como la representación arquitectónica de un "diamante de cuidado". Cada uno de sus vértices indicaría la presencia de cuatro actores interventores para la provisión de cuidados: las familias, el Estado, el mercado y las organizaciones sociales que organizarían y distribuirían el cuidado de manera dinámica. ${ }^{98}$ Las redes de cuidado que se establecen para el funcionamiento socio económico constituyen lazos que se conforman entre quienes son cuidados y quienes cuidan, pero también entre los y las agentes de las instituciones, los marcos normativos, la participación mercantil y comunitaria (Rodríguez Enríquez, 2015, p. 41). En un contexto ideal, estas redes estarían distribuidas equitativamente, sin embargo, la mayor responsabilidad cae sobre las familias, que en los casos de poseer menores recursos, con un Estado ausente y sin capacidad de pagar por los servicios de cuidado, son las mujeres quienes se ven obligadas a ocuparse de tales trabajos.

Es importante reparar en que las reflexiones respecto a la organización social del cuidado corresponden a una serie de estudios abordados por la economía feminista que retoma debates de la década de 1970 acerca del carácter político y económico del trabajo doméstico y de la reproducción social, por lo que si bien estos análisis sirven

\footnotetext{
98 Shahra Razavi (2007) The Political and Social Economy of Care in a Development Context: Conceptual Issues, Research Questions and Policy Options. Ginebra: Instituto de Investigaciones de las Naciones Unidas para el Desarrollo Social (unrisd).
} 
para iluminar problemáticas del pasado no podemos equipararlos con preocupaciones de principios del siglo XX. La categoría de cuidado es polisémica y se encuentra en construcción, nos desafía a las cientistas sociales a repensar de manera interdisciplinaria cuáles son los alcances y las limitaciones de la misma, sobre todo para un abordaje histórico puesto que la preocupación por la reproducción cotidiana y doméstica emergió de distinto modo en cada organización económico social, pero adquirió mayor visibilidad y difusión con el cuestionamiento de las feministas estadounidenses e italianas. ${ }^{99}$ Aún así consideraremos una serie de trabajos adjudicados a las mujeres para la reproducción del núcleo doméstico, entre ellas el mantenimiento familiar y comunitario como parte de la economía del cuidado y de las tareas subalternas asociadas a la organización social del mismo. ${ }^{100}$

Sin lugar a dudas estos trabajos no hubieran sido posible sin el entrenamiento cotidiano que han vivido las mujeres, generalmente enseñadas por otra mujer que realiza su trabajo de manera no remunerada (Federicci, 1975, p. 37). Dado el carácter subalterno de estas tareas, ha sido mayoritariamente emprendido por mujeres que podían ser parte del núcleo doméstico (pensemos, por ejemplo, en la enseñanza de tareas "del hogar" entre generaciones de una misma familia, como cocinar, limpiar, entre otras, o las enseñanzas acordes a patrones morales de cada época que se trasmiten entre mujeres respecto al cuidado de la sexualidad), o también ser parte de algún organismo estatal o para estatal. Hemos visto en capítulos anteriores cómo monjas, inspectoras de la Sociedad de Beneficencia y de distintos agrupamientos y colectividades se encargaban de difundir preceptos higiénicos y de economía doméstica a otras féminas. A su vez hubo mujeres asalariadas y/o profesionales que buscaban enseñar las acciones de cuidado, entre ellas, maestras, enfermeras, puericultoras, obstetras y agentes del servicio social, como las visitadoras de higiene social.

En Argentina, desde principios del siglo XX y sobre todo durante la década de 1930, tal como desarrollamos en el capítulo anterior, el Estado asumió un rol de mayor intervención a través de distintas políticas sociales con las que pretendía intervenir en la cuestión social para evitar conflictos de los sectores incapacitados de reproducirse

\footnotetext{
${ }^{99}$ Durante la década de 1970, las feministas estadounidenses e italianas lanzaron la campaña "Salario por el trabajo Doméstico" en la que pusieron de manifiesto el carácter político y económico de las tareas de reproducción del ámbito privado, las implicancias para la sexualidad, para la reproducción social e ideológica y el carácter político de las relaciones familiares. Ver: Federicci, Silvia; Cox, Nicole (2012 [1975]) "Contraatacando desde la cocina", En Federicci, Silvia (2012) Revolución en punto cero. trabajo doméstico, reproducción y luchas feministas. (pp. 51-69). Madrid: Traficantes de sueños.

${ }^{100}$ Parte de estas reflexiones se desprenden del trabajo presentado por Graciela Queirolo y la conferencia de cierre a cargo de Paula Lucia Aguilar en la I Jornada de Cuidados realizada en la Universidad Nacional de Quilmes, en diciembre de 2017.
} 
cotidianamente, pero también para garantizar un mayor control y vigilancia sobre ellos (Suriano, 2002; Rozas Pagaza, 2001). En esa lógica, resultó imprescindible una formación profesional que facilitara el control y construcción del espacio doméstico, que desde fines del siglo XIX intentaba ser reformulado (Aguilar, 2014) ${ }^{101}$, y al mismo tiempo mantener la cruzada por la maternalizacion de las mujeres (Nari, 2004; Biernat y Ramacciotti, 2013).

Para muchas mujeres la entrada al mercado laboral no era una opción sino una necesidad para la reproducción individual y del grupo familiar, a pesar de ello, se las consideró problemáticas para el orden familiar, por lo cual el Estado intentó regular y normalizar esta situación -en el próximo apartado abordaremos esta cuestión-.

Resulta interesante pensar la creación de la EVHS como parte de las estrategias de distribución de la economía del cuidado en tanto las jóvenes profesionales serán formadas para incluirse como agentes estatales que ingresarán al ámbito privado avaladas por su condición de género para educar a mujeres madres trabajadoras en las tareas domésticas y maternales (como amamantar, asear la casa, cuidar a enfermos, cuidar a niños, entre otras), garantizar la vigilancia y el control social, y a su vez difundir las políticas sociales favorables a las mujeres y al grupo familiar.

\subsubsection{El mercado de trabajo en la primera mitad del siglo $\mathrm{XX}$}

Mirta Lobato (2007) indica que desde el primer censo nacional realizado en 1869 se reconocían como "profesiones de mujeres" a las tareas de costureras, lavanderas, tejedoras, planchadoras, cigarreras, amasadoras, etc., en su mayoría realizadas por solteras, viudas y huérfanas (p. 39). Excepto las cigarreras y amasadoras, el otro grupo de mujeres se encargaba de facilitar tareas para la reproducción cotidiana de los sectores que podían pagar por sus servicios domésticos y de tal modo eximirse de realizarlos. Será en el contexto de fines del siglo XIX y principios del siglo XX cuando el crecimiento del modelo agroexportador junto con el desarrollo de la industria dependiente del agro, el crecimiento urbano, las inmigraciones masivas, la expansión del consumo y la producción de servicios, permita la masificación del ingreso de las mujeres al mercado de trabajo en Argentina (Lobato, 2002). Paralelamente, los avances del movimiento de mujeres y el movimiento feminista propiciaban la búsqueda de

101 De acuerdo con Paula Lucía Aguilar (2014), el espacio doméstico no puede ser definido como un a priori, sino que desde un abordaje histórico es posible entenderlo como formas históricamente cambiantes de domesticidad a partir de las cuales se pueden captar resignificaciones y/o transformaciones y líneas de continuidad de los núcleos de valores, funciones, tareas, relaciones de poder y de los propios sujetos. 
autonomía de las féminas, lo que invitaba a muchas a salir del espacio doméstico. ${ }^{102}$ Sin embargo, otro grupo de mujeres perteneciente mayormente a sectores de bajos recursos, empujadas por las necesidades económicas, encontró la posibilidad de ingresar a las nuevas fábricas.

Si bien las mujeres se encontraban presentes en el mercado de trabajo industrial, desde la década de 1910 las hallamos dispersas y en un porcentaje reducido en las industrias de alimentación, tocador, construcción, muebles y anexos, artísticas y ornatos, metalurgia, gráfica y productos químico, entre otras (Lobato, 2007). Otro puesto que ofrecía el mercado de trabajo a las mujeres era el de costureras, que les permitía realizar gran parte del trabajo en su domicilio aunque hacía más precarias sus condiciones laborales, como era el caso de las costureras (Pascucci, 2007, pp.29-31; Aguilar, 2014, pp. 55-57). Durante la década de 1930 ya había un notable número de mujeres empleadas en las industrias textiles y de confección, también un número considerable en las industrias de cartón y papel, aunque no alcanzaban ni la mitad de la proporción de hombres ocupados. Esta feminización del mercado de trabajo, comprendida por el elevado ingreso de féminas, suele explicarse por el hecho de que las mujeres aceptaban salarios menores que los varones, como así también por la noción que une a éstas con la atención de los otros, supuesto que naturaliza el lugar de la mujer para el cuidado de los enfermos (Lobato, 2007, p. 66).

Aun así se mantenía la preocupación por el incumplimiento de los trabajos de cuidado familiar y de reproducción biológica, hecho que propició la creación de un escenario privilegiado para la intervención médica y estatal. El trabajo femenino era considerado una amenaza a la capacidad física de las mujeres en tanto podía retrasar su desarrollo, deformar el organismo y disminuir las posibilidades de gestar y llevar a cabo un embarazo (Biernat y Ramacciotti, 2011, p.154), incluso atentaba contra los objetivos pro-maternalistas del amamantamiento en un escenario de explotación laboral sin reglamentación horaria y de labores. A pesar de las opiniones encontradas respecto a la participación de las mujeres en el mercado de trabajo, su presencia era un hecho sobre el que, en todo caso, podían intervenir para mejorar las condiciones de desarrollo.

La necesidad por legislar y reglamentar el trabajo asalariado para que no resultase un impedimento a la productividad pudo conjugarse, sin mayores tensiones, con los reclamos de organizaciones obreras e incluso de sus vertientes femeninas (Recalde, 1988; Lobato, 2004; Nari, 2004; Ramacciotti, 2005). Los proyectos de socialistas y

${ }^{102}$ En la primera mitad del siglo XX, el movimiento feminista y sufragista hizo su aparición en Argentina, exigiendo participación política en aquellos espacios que eran vedados a las mujeres. Ver Barrancos, Dora (2001) Inclusión/ Exclusión. Historia con mujeres. Fondo de Cultura Económica. Buenos Aires. 
católicos pretendían reforzar la familia nuclear heterosexual mediante el otorgamiento de un "salario familiar" a los padres varones, hecho que además de robustecer la dominación conyugal y aislar a las mujeres del mercado de trabajo, las dejaba en condiciones más precarias de participación en la economía familiar. Otro de los proyectos promovía el cuidado de los niños mediante la madre, a través de garantizar la atención a las mujeres madres trabajadoras desde los servicios de asistencia sanitaria y social materno infantil, a partir de la multiplicación de instituciones para el control de los y las cónyuges (los llamados exámenes prenupciales), el amparo a las madres solteras y la educación de las mujeres madres o "potencialmente" madres (Nari, 2004; Barrancos, 2007; Biernat y Ramacciotti, 2012).

En este sentido, es destacable la reforma del Código Civil en 1926 que removió la condición de inferioridad civil de las mujeres, lo que permitió a muchas de ellas ingresar al mercado profesional y ocupacional sin pedir permiso a ningún hombre.

La feminización del mercado de trabajo a principios del siglo XX mostró una naturalización de la división sexual del trabajo cargada de contradicciones: la mujer obrera desafiaba y corrompía el modelo de feminidad y maternidad esperable, pero a la vez resultaba mano de obra barata para los empresarios. El temor por la corrupción de la feminidad y los deberes reproductivos plagaron los discursos médicos. Jorge Salessi (1995) destacó cómo en los informes del Dr. Juan Bialet Massé ${ }^{103}$ sobre la clase obrera, las trabajadoras solteras eran consideradas como un "tercer sexo" en tanto eran mujeres que sin compañía de un hombre renunciaban a casarse y hasta tenían "delirios de castración". Esta visión médica confundía lo "femenino" del sexo biológico de la mujer con el rol masculino, y a pesar del proceso de modernización y liberalismo de la sociedad, Bialet Massé exigió que las mujeres fueran inculcadas en principios de orden religioso que las obligaran a servir al hombre en el matrimonio y, mediante esa tarea, servir a la patria. Es decir, unificaron discursos de orden clerical y liberal en pos de acotar las libertades de las mujeres (pp. 208-212).

Esta desconfianza sobre la autonomía de las mujeres era parte la propagación de un "pánico homosexual" promovido por el higienismo, esto se tradujo en una ansiedad cultural producida y utilizada para controlar a la población, siendo las prácticas lésbicas

\footnotetext{
${ }^{103}$ Juan Bialet Massé fue una destacada personalidad de la cultura hispanoamericana por sus tareas como médico, abogado y constructor. Además de las obras hidráulicas llevadas adelante por éste en la ciudad de Córdoba, también se destacó por sus investigaciones en medicina. Una de las más destacadas fue la realizada durante el gobierno de Julio A. Roca en 1904, titulada "Informe sobre el Estado de las Clases Obreras Argentinas", en el cual Bialet Massé realizó un detallado estudio de las condiciones de vida y trabajo de los proletarios en el interior del país.
} 
-o epidemia de uranismo- consideradas como peligrosas por la cultura patriarcal y burguesa hegemónica. Si las trabajadoras podían considerarse un tercer sexo por su independencia económica por fuera del dominio patriarcal; las estudiosas, las intelectuales y las artistas se consideraban peligrosas por su autonomía intelectual, puesto que también desafiaban el orden patriarcal, hecho que hacía temer por la posibilidad de que se transformaran en "invertidas sexuales" (Salessi, 1995).

El ingreso de las mujeres al mercado de trabajo fue producto no solo de la búsqueda de autonomía, también estuvo motivado por necesidades económicas, generalmente asociadas a la complementariedad del salario masculino pues, en muchos casos, era una salida de lo doméstico al espacio público tras el armazón de "la naturaleza femenina" que posibilitó salarios menores e incluso trabajos ad honorem con la esperanza de lograr un ascenso social. En el caso particular de las mujeres dedicadas a la asistencia y a las visitas de higiene, pertenecían a una clase media en ascenso, esto lo podemos suponer por el tiempo libre que disponían para el cursado de una carrera que exigía además de clases teóricas diarias el cumplimiento de clases prácticas. El interés primordial no era de orden salarial, sino que podríamos considerar que buscaban a través de esta intervención una forma de participación social, política e incluso religiosa que hasta ese momento les estaba vedada, a pesar de los avances del movimiento feminista de la época (Parra, 2007; Di Liscia, 2014 ).

Frente al peligro que representaban las trabajadoras industriales y/ o domésticas para el orden heterocapitalista, aparecía como contracara el ejercicio de otras labores como la enfermería, la educación, la asistencia y la caridad, consideradas más apropiadas para el ordenamiento de género que se pretendía.

\subsubsection{Las universitarias y las profesiones sociosanitarias}

En Latinoamérica, a partir de la década de 1880, las mujeres pudieron acceder a los estudios universitarios. Alicia Palermo señala que esta década se caracterizó por un cambio en la idea de educación, que ya no sólo resultaba constitutiva para el progreso social, económico y político de las naciones, sino que para tales fines se reconocía la obligatoriedad, gratuidad y la inclusión de distintos niveles sociales y sexos, a pesar de que en los hechos los grados de aceptación variaran según las disciplinas (2006, p. 27). Sin lugar a dudas, las mujeres participaban en espacios públicos y políticos desde la creación del Estado nacional y el reclamo por el acceso a la educación era vertebrador de sus acciones (Nari, 2000; Barrancos, 2001, 2007). Lavrin (2005) consideró que el 
acceso de las mujeres a la educación, sobre todo las de clase media, favoreció un cambio en la situación del conjunto de las mujeres, e incluso Palermo (2006) suma a esta observación que serán las universitarias argentinas de fines del siglo XIX y principios del siglo XX quienes mediante sus reclamos y producciones escritas realicen un primer antecedente en los estudios de educación y género (p. 28).

Con la eclosión del movimiento feminista y sufragista durante la primera mitad del siglo $\mathrm{XX}$ en Argentina, las universidades nacionales se transformaron en ámbitos privilegiados para el despliegue personal y político de muchas mujeres (Nari, 2002; Lorenzo, 2016; Barrancos, 2007; Ramacciotti y Valobra, 2011). Una de las ramas profesionales en la cual más se sumaron fue en la medicina, sobre todo en especialidades referentes al cuidado del cuerpo femenino (Barrancos, 2000; 2007), lo que les permitía ostentar un destacado posicionamiento político en función de ejercer una profesión de gran prestigio político social (Nari, 2002). La asociación entre feministas y profesión médica se dio tempranamente. La primera médica graduada en Latinoamérica fue Cecilia Grierson en 1889 y luego, Elvira Rawson, segunda médica graduada en Argentina graduada en 1892, quien defendió en su tesis la necesidad de la igualdad de derechos entre hombres y mujeres. La llegada de las mujeres universitarias al ámbito de la medicina era temida por los médicos varones, que alertaban sobre el retroceso que ellas producían sobre los valores maternales y morales propios de la feminidad hegemónica. ${ }^{104}$

No obstante, las mujeres continuaron su formación académica a pesar de los escollos que debían atravesar, sobre todo de sus propios colegas varones que durante largas décadas las mantuvieron alejadas del privilegio de la docencia universitaria. Como demuestran Ramacciotti y Valobra (2014) en el estudio sobre la inserción de las mujeres en sus áreas profesionales, los médicos varones consideraban que ellas debían dedicarse a tareas de asistencia, puesto que sostenían que las labores médicas no podían ser emprendidas por el "sexo débil". ${ }^{105}$ Como expresé con antelación, los médicos y el aparato sanitario del país eran una parte fundamental del Estado en formación, por lo

\footnotetext{
104 Bravo, Celia y Landaburu, Alejandra (2000) "Maternidad, cuestión social y perspectiva católica. Tucumán, fines del siglo XIX”, en Gil Lozano, Fernanda et al., Historia de las mujeres en Argentina, Taurus, Buenos Aires; Ramacciotti, Karina (2004) "El Museo Social Argentino y el Primer Congreso de Población de 1940", en Sociohistórica. Cuadernos del Centro de Investigaciones Sociohistórica, La Plata, $\mathrm{N}^{\circ} 13$ y 14.

${ }^{105}$ Las autoras citan los textos de los médicos Gregorio Marañon y Pedro Baliña que justificaban desde las diferencias biológicas la incapacidad de las mujeres para afrontar su destino en la ciencia médica. Ver: Ramacciotti, Karina y Valobra, Adriana (2011) "Modernas esculapios: acción política e inserción profesional" en Lizette, Jacinto y Scarzanella, Eugenia. Género y Ciencia en América Latina: mujeres en la academia y en la clínica. Madrid.
} 
que pudieron consolidarse como una corporación intelectual de gran prestigio y poder, con capacidad de influir socialmente. Los acuerdos entre el Estado y médicos facilitó la persecución de las mujeres que practicaban curaciones, asistencia de partos, comadronas y curanderas, hecho que permitió la masculinización del campo profesional de la medicina (Nari, 2004; di Liscia 1997).

María Fernanda Lorenzo (2016), en su estudio sobre las mujeres universitarias de la primera mitad del siglo XX en la Universidad Nacional de Buenos Aires, destaca que la marginación de las mujeres del campo científico y académico era justificado desde la diferencia sexual, pero también porque se restaba valor cognitivo a ciertos atributos femeninos como podrían ser la emoción y la sensibilidad (p. 15). Desde el lugar como auxiliares de la medicina tuvieron que lidiar con un campo tempranamente profesionalizado y fuertemente jerarquizado que pretendió alejar a las féminas de la competencia del monopolio masculino de los saberes médicos y vincularlas con actividades ligadas al cuidado y a la relación con otras mujeres.

Ana Laura Martín (2015) realizó un detallado estudio sobre la feminización profesional de la enfermería. Considera que el género se constituyó en un elemento de segmentación sobre el que se estructuró la profesión haciendo caso a la división sexual del trabajo en el ámbito sanitario, donde los médicos manejaban el campo científico y las mujeres el empírico (p.257). Esta estructuración en función de la diferencia sexual también sucedía en el caso de la formación para visitadoras de higiene social.

Podemos arriesgar, entonces, que el mercado de trabajo para las mujeres a principios del siglo XX configuró dos demandas específicas acordes a proyectos de feminidad distintos. Por una parte, una demanda de obreras en tanto mano de obra barata que ingresaba a las fábricas, donde eran remuneradas con un bajo salario tras la justificación del "salario complementario"106, pero, contradictoriamente y según los deseos de la elite gobernante, ponían en riesgo la moral femenina vinculada a la maternidad. Por otro lado, hallamos una demanda de mujeres a fin de potenciar y ejercer sus "dotes naturales" por fuera de la esfera doméstica a través de una formación específica que les permitiera intervenir socialmente. Esta demanda planteada en función de las necesidades de asistencia, sanidad y educación que sugieren los sectores gobernantes, aparece como una suerte de extensión de las tareas realizadas en el ámbito privado hacia

\footnotetext{
${ }^{106}$ Mirta Lobato (2007) destaca que esta diferencia salarial se justificaba como parte de una valoración desigual de habilidades y destrezas de las mujeres y los hombres, donde los trabajos especializados con mayor remuneración eran aquellos que tendrían distintas especializaciones y calificaciones basadas en la diferencia sexual. Esta inequidad se traducía no solo en los salarios y en los puestos de trabajo, a nivel ideológico se justificaba mediante la noción de "complementariedad" que reafirmaba el lugar secundario del aporte económico de las mujeres dentro de la estructura familiar. (pp. 86- 94).
} 
el ámbito público, consolidando un estereotipo de mujer vinculado a los cuidados, la asistencia, la salud y la educación, como así también a las tareas más específicas que suponen un contacto con otras mujeres, como la labor realizada por enfermeras, parteras y visitadoras (Di Liscia y Billorou,2005; Testa, 2012; Martin, 2014; Ramacciotti y Valobra, 2014). Esta demanda se configura dentro de la división sexual del trabajo, en tanto las mujeres son convocadas para la realización de tareas vinculadas al desarrollo del núcleo familiar, desde las cuales se consolida el rol femenino, se acapara ilimitadamente su fuerza de trabajo y se garantiza la reproducción del orden familiar y de la sociedad heterosexual.

Es importante destacar que los discursos higienista y positivista esgrimieron una serie de argumentos y alegorías desde la cual la heterosexualidad representaba a la nación saludable, y por contrapartida, la homosexualidad, el uranismo y los maricones representaban la insalubridad y peligro de corrupción moral y sanitaria del país. Por ello, podríamos arriesgarnos a pensar que el peso de la heterosexualidad obligatoria no resultó menor en la visita de higiene, ya que al ingresar en la vida privada de las personas podía controlar, malear e incluso denunciar hábitos que fueran considerados perniciosos para el conjunto de la población. Si bien aun es un campo poco explorado, cabe considerar a esta profesión como parte integral del proyecto heterosexualizante que estableció el higienismo para el control y disciplinamiento de las posibles interrupciones al modelo económico y sexual reproductivo.

En el caso de las visitadoras de higiene social sucedía algo muy similar a la enfermería, e incluso a las terapistas ocupacionales, puesto que una de las condiciones excluyentes era pertenecer al sexo-género femenino. Mediante la unión de ciertos atributos asignados al sexo-género femenino, como la buena voluntad, el anhelo por una comunidad más feliz y ser bálsamo y consuelo para todo dolor (Dezeo, 1938, p. 7), junto con una serie de conocimientos técnicos vinculados a la salud pública, profilaxis, previsión social, economía doméstica, entre otros, se pretendía garantizar una mujer profesional capaz de "llevar la cultura universitaria y sus verdades más allá de las instituciones técnicas, inaccesibles para el público, realizando de forma fácil y continuada educación sanitaria popular" (Dezeo, 1938, p. 5). Es decir, garantizar una agente formada en la cultura científica que brindaba la universidad durante la década de 1930, que contaría con la capacidad de sostener continuadamente su actividad para facilitar la transmisión de valores morales. Este conjunto de potencialidades y condiciones atribuidas a las mujeres se presentaba útil en tanto eran parte de los valores, las costumbres y los hábitos presentes a principios del siglo XX. La utilidad económica 
de las características amorosas y altruistas fue incorporada como parte de la ordenanza de creación de la EVHS y se conjugaron como parte de un proyecto político hegemónico.

Estos objetivos se plasmaron de distintas maneras en el Plan de Estudios y la Ordenanza de Creación de la EVHS en 1938, donde también se explicitan las funciones que se asignarían a las graduadas y las estrategias que permitirían garantizar lo que estimamos fueron dos objetivos: por un lado, iniciar el desarrollo del carácter feminizado de la profesión; y, por otro, en función de su vínculo estrecho con mujeres dentro del ámbito privado, fomentar la difusión de estereotipos de género que facilitaran la reproducción del núcleo doméstico. Entendemos que este carácter feminizado de la profesión no actuó de manera independiente de las relaciones de género, sino que se integró en la reproducción de desigualdades entre hombres profesores y estudiantes mujeres. Relación orientada a producir conocimiento sobre un objeto (tuberculoso, infantil, escolar, obstétrico) atravesado por la división sexual del trabajo y por los múltiples conflictos y acuerdos que permearon a la universidad platense.

En este sentido, la amplitud del programa de primer año muestra en cierta medida la totalidad de tareas que se esperaba pudieran cubrir las Visitadoras. Las cuatro primeras materias eran: I. Anatomía y Fisiología Elementales, II. Higiene, III. Elementos de Microbiología y Parasitología, IV. Elementos de Patología Médica y Quirúrgica. Mientras que para el segundo año solo compartían cuatro materias: I. Higiene social, II. Nociones de Tisiología, III. Nociones de puericultura y IV. Servicio Social. Por último, vale aclarar que las estudiantes dedicadas a la Higiene Escolar tendrían una materia específica con el mismo nombre y las dedicadas a la Visita de Puericultura o Puericultura y obstetricia cursarían una materia específica de Puericultura.

En la EVHS UBA también se realizaba un primer año preparatorio y otro de especialización, aunque tuvo algunas diferencias con la escuela platense, sin embargo, en ambas primaba la idea de nociones generales, es decir, de un abordaje superficial de una serie de cuestiones médicas sobre las que debían poseer conocimientos limitados, pero hubo diferencias entre ambas currículas. Veamos sucintamente algunas diferencias:

\begin{tabular}{|l|c|c|}
\hline & \multicolumn{1}{|c|}{ EVHS UBA } & \multicolumn{1}{c|}{ EVHS UNLP } \\
\hline 1er año & $\bullet \quad$ Anatomía y fisiología. & $\bullet$ Anatomía y fisiología \\
& $\bullet \begin{array}{l}\text { Profilaxis de enfermedades } \\
\text { infecciosas y parasitarias. }\end{array}$ & $\bullet \quad$ Higiene general y especial \\
\hline
\end{tabular}




\begin{tabular}{|c|c|c|}
\hline & $\begin{array}{l}\text { Elementos de patología } \\
\text { médica y quirúrgica. } \\
\text { - Primeros auxilios. }\end{array}$ & $\begin{array}{l}\text { - } \begin{array}{l}\text { Elementos de microbiología } \\
\text { y parasitología }\end{array} \\
\text { - Elementos de patología } \\
\text { médica } \\
\text { - } \begin{array}{l}\text { Elementos de patología } \\
\text { quirúrgica }\end{array}\end{array}$ \\
\hline 2do año & $\begin{array}{l}\text { Tuberculosis e higiene infantil: } \\
\text { - } \quad \text { Lecciones sobre tuberculosis } \\
\text { - } \begin{array}{l}\text { Lecciones sobre } \\
\text { enfermedades venéreas y } \\
\text { toxicomanías }\end{array} \\
\text { - Puericultura } \\
\text { - Servicio Social de la } \\
\text { Visitadora } \\
\text { Higiene escolar: } \\
\text { - Lecciones sobre tuberculosis } \\
\text { - Lecciones sobre } \\
\text { enfermedades venéreas y } \\
\text { toxicomanías } \\
\text { - Higiene escolar y Pedagogía } \\
\text { médica infantil } \\
\text { - Servicio social de la } \\
\text { visitadora escolar } \\
\text { Economía Doméstica }\end{array}$ & $\begin{array}{l}\text { Común a todas las } \\
\text { especializaciones: } \\
\text { - Higiene social } \\
\text { - } \quad \text { Elementos de tisiología } \\
\text { - Servicio Social } \\
\text { Especialización en Visitadora } \\
\text { Escolar: } \\
\text { - Higiene Escolar. } \\
\text { Especialización en puericultura y } \\
\text { en Puericultura y Obstetricia: } \\
\text { - Puericultura }\end{array}$ \\
\hline
\end{tabular}

Estas diferencias de contenidos pueden ser pensadas a la luz de una selección específica en función de las problemáticas socio sanitarias que cada una de las escuelas consideraba imprescindible atender. No obstante, algunos elementos resultaron idénticos, como Anatomía y fisiología elementales y Elementos de patología médica y quirúrgica, aunque la división de contenidos que se hacía para cada una de las especializaciones también resultaron diferentes, e incluso en la ciudad de La Plata hubo una mayor gravitación sobre las cuestiones relacionadas a la maternidad y el cuidado infantil. 
Veamos a continuación los elementos más destacados de la formación curricular para las estudiantes de la EVHS UNLP durante el período inicial establecido entre los dos primeros planes de estudio de los años 1938 y 1948.

\subsection{Entre ciencia, moral y género: planes de estudio y ordenanzas disciplinares}

Una estrategia para conocer los proyectos políticos en pugna en la educación e instrucción es a través del análisis de los curriculums y planes de estudio de una carrera y de las materias que componen cada tramo formativo. Dar una definición respecto al currículo no sería acertado puesto que es un concepto polisémico y en permanente construcción, por eso me limitaré a considerarlo para este análisis como una propuesta formativa que una sociedad elige en determinado momento histórico para el desarrollo de generaciones futuras (de Alba, 1995; Salinas Fernández, 1997; Gimeno Sacristán, 1998).

De acuerdo con lo planteado por De Alba (1995), el currículo puede ser entendido como una síntesis de elementos culturales (conocimientos, valores, costumbres, creencias, hábitos) que conforman una propuesta político educativa donde hay distintos intereses, algunos que tienden a ser dominantes o hegemónicos, y otros que pretenden resistirse a tal dominación, hecho que se resuelve mediante mecanismos de negociación e imposición social (pp.75- 76). Para construir los currículos hay claramente un proceso de selección de contenidos que procuran realizar una traducción sintética del orden cultural. En ellos no están solo las prescripciones formales acerca de los contenidos, también se incluyen otras experiencias de aprendizaje no intencionales o no planificadas por los docentes, consideradas como el currículo oculto en tanto no fue explicitado con anticipación. Este puede ser considerado de dos modos: de un modo positivo o útil se entiende al aprendizaje de conductas y normas mediante el proceso educativo puesto que ello facilitaría su integración social futura. $\mathrm{O}$, en cambio, puede considerarse negativo al currículo oculto en tanto facilita la reproducción de la dominación y la disciplina, encubierto en otro conjunto de saberes referidos a la conducta y hábitos que serían pertinentes de las estudiantes. En resumidas cuentas, este currículo oculto facilita la reproducción de una serie de constantes ideológicas por las que se mantiene el statu quo, pero también abre un intersticio para posibles cambios desde propuestas alternativas (Giroux, 1997). Esta reproducción ideológica opera mediante el control de conductas y de actitudes que pueden ser opuestas al currículo oficial, e incluso hay un carácter oculto de género conformado por elementos no formales que contribuyen a la 
reproducción de los roles e identidades del sistema de sexo género hegemónico (Altable, 1995). Más adelante veremos algunos ejemplos de la EVHS.

\subsubsection{El currículo visible: Saberes del cuerpo, el hogar y la maternidad}

Tal como mencionamos anteriormente, el primer año de la Escuela resultaba preparatorio y común a todas las estudiantes. Las materias que componían el currículo abordaban conocimientos elementales de Anatomía y Fisiología, de Higiene, Microbiología, Parasitología, Clínica Médica y Quirúrgica. En todas ellas primó la idea de "nociones generales" para el abordaje de cuestiones específicas como podían ser, por ejemplo, los tejidos y las células. La primera de las materias, Anatomía y Fisiología, compuesta por un total de catorce unidades, priorizaba una descripción de los organismos vivientes, descompuestos en unidades específicas. Ocupaba dos bolillas particulares el aparato digestivo y su funcionamiento para la alimentación, reparando en la sed, el apetito, la insalivación, la formación del bolo alimenticio, absorción intestinal y defecación. ${ }^{107}$ Como ya hemos dicho, una de las preocupaciones centrales de la época fue el desarrollo de los niños y las niñas, razón por la cual la alimentación era central y se hacía evidente en la proyección de políticas públicas (Buschini, 2015), pero a su vez, esta insistencia en conocer el aparato digestivo sobre el resto de la anatomía y fisiología humana reiteraba la importancia de la transmisión de estos saberes a otras mujeres que, en tanto garantes de la reproducción del núcleo doméstico y como responsables de la unidad familiar, tenían que ser instruidas detalladamente en los modos de alimentación correctos.

La segunda materia de este diseño curricular era Higiene, que resultó la más extensa de todas las materias por componerse de diecinueve unidades, hecho que resulta más que coherente en función de los intereses que perseguía la formación disciplinar. Fueron dos los focos específicos que se pretendía alumbrar desde esta área de conocimiento, en principio lo que podríamos llamar una higiene individual o privada, considerada de este modo por encargarse de los conocimientos alrededor de la higiene corporal, de los órganos, aparatos y mucosas, como también de la higiene del vestido, "propiedades de los tejidos, limpieza y desinfección de los vestidos". En este conjunto de cuestiones de higiene de orden "privado" también podríamos situar la correspondiente a la alimentación, puesto que es una parte importante de la reproducción cotidiana de la que

107 Universidad Nacional de La Plata, Facultad de Ciencias Médicas. Escuela de Visitadoras de Higiene Social. Ordenanza de creación. Reglamentación y programa para el examen de ingreso. Programas de Estudio. La Plata, 1938. pp.8-9. 
se han encargado las mujeres. Las principales preocupaciones eran dos, por una parte, enseñar a clasificar, definir y entender la composición de los alimentos y, por otra, en relación a ello, establecer las raciones alimenticias según el tipo de régimen que se pretendía llevar adelante. Una bolilla especial se dedicaba a la cuestión de la leche, las enfermedades y alteraciones que podían contener, e incluso se cierra ese apartado con la enseñanza de la "vigilancia sanitaria de la alimentación". ${ }^{108}$ Es interesante que en este punto se aclara el objetivo que perseguían estos conocimientos impartidos por los médicos, es decir, la finalidad de dar a entender los detalles acerca de que mantener un régimen alimentario y/o de lactancia tenía por intención hacer de la visitadora una monitora de las prácticas y costumbres en que se llevaba adelante esta actividad básica para la reproducción cotidiana, pero además, porque de la vigilancia y observación de estas prácticas tomarían nota para informar a los médicos.

Otro conjunto de conocimientos por abordar lo constituía lo que podríamos llamar la higiene del medio, es decir, el suelo, agua, residuos, eliminación de materias excrementicias, los crematorios, los cementerios, los residuos sólidos y domiciliarios, la habitación junto a la preocupación por la iluminación y la ventilación y, por último, las ciudades y servicios de higiene pública. ${ }^{109}$ Esta preocupación infraestructuralarquitectónica del medio en que habitaban los sujetos formaba parte de las principales preocupaciones de los higienistas que consideraban la resolución de tales problemáticas como un paso prioritario para evitar enfermedades (Recalde, 1988; Armus, 2007).

Un tercer grupo de unidades de la materia Higiene conjugaba los otros dos elementos de higiene individual privada con los de orden público. Apuntaba específicamente a la profilaxis de epidemias, pandemias, endemias y otras enfermedades como viruela, escarlatina, varicela, rubéola, parotiditis y difteria. Estas enfermedades requerían de cuidados privados e individuales pero también de ciertas atenciones sobre el medio en que se encontraban para evitar contagios o un empeoramiento general, por lo tanto, demandaban no solo cuidados privados, sino también la atención de instituciones públicas o privadas.

Nuevamente se explicita desde el currículo la voluntad de que estas profesionales se dediquen a la vigilancia, y para ello se describen los modos en que podrían ejercer el control mediante el conocimiento de leyes sobre la profilaxis internacional, nacional y comunal, como también a través de técnicas de desinfección. ${ }^{110} \mathrm{El}$ programa de higiene sintetizaba de algún modo acciones de control y prevención que resultaban útiles para el

\footnotetext{
108 ídem p. 11.

109 ídem pp. 11-12.

110 ídem p.13.
} 
disciplinamiento de la población, sobre todo en su vida cotidiana, para ello no escatima la reproducción de saberes de orden médico, sino que incluye las normativas que avalarían las acciones de las futuras profesionales.

La tercera materia Elementos de Microbiología y Parasitología, compuesta de diez unidades, refuerza el carácter superficial del acercamiento a los conocimientos del cuerpo al igual que la primera materia del programa, pero a diferencia de ella propone un rol más activo de la visitadora a través de la toma de muestras para exámenes diagnósticos, por ejemplo. Este llamado a la recolección de datos aparece también en la cuarta materia llamada Elementos de Patología Médica y Quirúrgica, compuesta por veintidós unidades, donde se detalla especialmente el relevamiento de interrogatorios personales, cuidado y transporte de heridos, como asimismo los signos para detectar los síntomas de enfermedad y vigilar enfermos y operados. Me interesa señalar el carácter polivalente al que fueron convocadas las auxiliares de salud, hecho que las emparentó con otras profesionales, como las enfermeras en tanto agentes subalternas frente a los médicos y otros agentes estatales.

\subsubsection{Formación profesional específica}

Tal como mencioné anteriormente, el segundo año de la carrera se destinaría a la capacitación en alguna de las especialidades ofrecidas por la EVHS. Sin embargo, todas las estudiantes tendrían cuatro materias comunes a cursar: Higiene Social, Nociones de Tisiología, Nociones de Puericultura, y por último, Servicio Social. Las únicas materias agregadas fueron Higiene Escolar y Puericultura, destinadas a las estudiantes que intervendrían en los servicios sociales escolares, los de obstetricia y puericultura. No hay mención a las materias específicas que tendrían las estudiantes de la especialización en tuberculosis.

La materia Higiene Social era la más extensa. Aparece con especial desarrollo la preocupación por la protección del binomio madre-hijo, problema al que dedican siete unidades para el estudio de las siguientes temáticas: mortinatalidad, mortalidad infantil, la defensa del niño débil, protección de niños ciegos, sordomudos, abandonados, indigentes y delincuentes. Por una parte, desde el programa buscaban enseñar las causas económicas y sociales de la mortinalidad y la mortalidad infantil, junto con la protección de la futura madre y las instituciones sociosanitarias dedicadas a la asistencia social del lactante, todos conocimientos que de algún modo intentarían situar a las visitadoras en un marco político institucional de defensa de la reproducción como 
responsabilidad de las féminas. Por otro lado, hay un conjunto de conocimientos dedicados nuevamente a la enseñanza de la alimentación de los infantes, conservación de la leche, lucha contra la lactancia mercenaria, entre otros. ${ }^{111}$

Mediante este currículo los médicos a cargo de la formación pretendían que las visitadoras pudieran dar respuesta a las preocupaciones planteadas en el I Congreso Nacional de Asistencia Social de 1933 respecto de la instrucción de auxiliares de la medicina preventiva, pero también tomaba nota de las exigencias de la Ley Nacional $\mathrm{N}^{\mathrm{o}}$ 12.341, por la que se estableció la creación de la Dirección de Maternidad e Infancia, cuyo interés principal era combatir la morbimortalidad infantil y amparar a la mujer en su condición de madre "o futura madre". Las visitadoras serán de gran utilidad para la difusión de los beneficios de esta ley y para la promoción de los avances en función de los conocimientos desprendidos de su práctica profesional, como veremos en el próximo capítulo.

Entre los sujetos que serían destinatarios de las acciones de las visitadoras se encontraban grupos cuya vulnerabilidad no provenía de su corta edad o su condición de progenitora, sino por ser considerados como incapacitados de reproducir sus condiciones materiales de existencia. Así aparecen mencionados cada uno en una unidad particular: los obreros, los enfermos y los convalecientes, los ancianos, los inválidos, los psicópatas y los alienados. El eje común que ubicaba a estos sujetos en la mirilla de los médicos higienistas era la necesidad de controlar a los sectores subalternos, garantizar y abaratar los costos de la reproducción de sus condiciones de existencia, y además evitar posibles conflictos.

De acuerdo a estos intereses, las tareas que se asignan a las visitadoras eran de defensa y protección de los sectores desprotegidos -hartamente vinculado a las tareas asignadas a las mujeres-, de profilaxis y detección de las enfermedades trasmisibles junto con la denuncia y aislamiento. Resulta interesante en este punto que las mujeres visitadoras no solo serán parte del engranaje del poder médico a través del uso de sus "cualidades" maternales de cuidado y protección asignadas en la lógica heteronormativa, sino que, además, tendrán un rol disciplinador en tanto se encargarán de vigilar, denunciar, certificar y corregir o aislar a los sectores peligrosos, seguramente avaladas por la “ejecutoria moral" -como veremos más adelante les exigía el Decano de la Facultad de Ciencias Médicas, Dr. Adorni- que guiaba sus acciones en nombre de la Universidad. La preocupación por los niños también aparece en la segunda materia, Nociones de Tisiología. En las diez unidades que la componen se abordan las acciones de las

\footnotetext{
111 ídem pp. 25-26.
} 
visitadoras: diagnósticos de presunción, probabilidad y certeza, inmunizaciones, propaganda sanitaria antituberculosa y, por último, la colocación familiar del recién nacido. Es interesante reparar en este lugar de vigilancia de las visitadoras donde se resquebraja la visión unívoca de ángel de piedad y, por el contrario, aparece como la representante estatal sanitaria con autoridad para denunciar si un niño o niña debía ser retirada del núcleo doméstico. A pesar de que esta materia se abocaba específicamente al conocimiento de la tuberculosis, los espacios de atención, los modos de detección, el armado de historias clínicas, la toma de antecedentes, entre otras cuestiones, presenta como únicos sujetos beneficiarios de la potencial atención de las visitadoras a las madres e hijos. Si bien se pretendía cuidar de este binomio, en caso de que el menor pudiera estar en un ambiente de posible contagio, permitía la separación de éste o de la madre del núcleo doméstico. ${ }^{112}$

Si bien la preocupación por los niños y las madres fue transversal a todas las materias comunes del segundo año, en Nociones de Puericultura las estudiantes contarían con catorce unidades destinadas a comprender las problemáticas específicas. La Puericultura era un campo de saber autónomo encargado del arte de educar y cuidar a los niños, si bien había surgido en el siglo XIX, fue en el siglo XX con la preocupación por la mortalidad infantil y con la pretensión de evitar una descendencia "degenerada" de los sectores populares, que la puericultura se alió tempranamente con la eugenesia y ambas facilitaron la intromisión en las prácticas cotidianas y habituales de la población. Tal como señala Marcela Nari (2004), la puericultura resultó un área de desarrollo académico para muchos médicos varones que se encargaron de escribir manuales para la educación de las madres donde no se pretendía la instrucción de las mujeres madres, sino que eran una serie de órdenes a seguir que sistematizaban hábitos, prácticas y valores respecto a la gestación, cuidados durante el embarazo y al momento del nacimiento. ${ }^{113} \mathrm{La}$ atención sobre la madre era mayor aun puesto que era considerada el recipiente de la gestación de los o las niñas, por lo cual debía cuidarse y realizar puericultura desde ese momento (pp. 114-119). A pesar de la voluntad médica masculina por intervenir sobre el cuerpo de las mujeres madres, los saberes eugenésicos y de puericultura que se arrogaba este gremio no llegaban a las mujeres trabajadoras que no se acercaban a los dispensarios, razón por la cual se requería de una agente

\footnotetext{
112 ídem pp. 29-30.

${ }^{113}$ Uno de los títulos más conocidos fue "El libro de las Madres", del Dr. Gregorio Araoz Alfaro, médico destacado, tisiólogo y reconocido como uno de los fundadores de la pediatría en Argentina. También fue profesor universitario y mantuvo contactos internacionales que le valieron un máximo reconocimiento entre sus colegas.
} 
especializada capaz de ingresar a inspeccionar la intimidad de la población y revisar las condiciones en que se desarrollaban los embarazos (Nari, 2004; Biernat y Ramacciotti ,2013; Aguilar, 2014).

Así, en la materia Nociones de Puericultura del segundo año de formación de la EVHS UNLP, las primeras doce unidades detallaban el interés e inquietud por conocer e intervenir en el desarrollo, crecimiento, alimentación, posibles enfermedades y cuidados de los recién nacidos y niños. La principal preocupación correspondía a la alimentación y la lactancia, por ello se describen en el programa gran cantidad de elementos que estudiarían las visitadoras, a saber:

Bolilla VI: Alimentación natural. Su importancia. Secreción láctea. Calostro. Composición química de la leche de la mujer; comparación con la leche de la vaca. Causas que modifican la cantidad y la calidad de la secreción. El análisis de la leche.

Técnica de alimentación natural. La succión. Cantidades. Horarios. Alimentación por sonda y por cucharaditas. Sobre alimentación e hipo alimentación.

Bolilla VII: Dificultad de la lactancia natural. Dificultades dependientes de la madre: malformaciones del pezón, hiperestesia del pezón, grietas, galactoforitis, linfagitis y absceso de la mama, infartos dolorosos, hipogalactia. Dificultades dependientes del niño: osbtruccion nasal, labio leporino y fisura del paladar, lesiones de boca y garganta, muguet, anorexia y perturbaciones de la succión.

Bolilla VIII: Lactancia mercenaria. Indicaciones según la edad y el estado del niño. Elección de la nodriza. Condiciones locales y generales. Salud del niño dado a criar a la nodriza. Sífilis y tuberculosis. La "buena leche" y la "mala leche". Régimen de vida y alimentación de la nodriza. El reposo y el ejercicio. Los alimentos. Influencia de la psiquis, del embarazo, de la menstruación y de la enfermedad en general sobre la secreción láctea. El destete. Destete precoz injustificado. Destete paulatino: edad en que debe iniciarse. Destete brusco.

Cito esta detallada explicación acerca de los conocimientos que debían aprender las visitadoras para dar cuenta del peso que tuvo la enseñanza de la lactancia materna, que junto con la búsqueda por controlar y garantizar la vida de los recién nacidos como responsabilidad única de las madres, operaron como una negativa ante la posibilidad de abandono o infanticidio. Por otro lado, funcionaban como un reforzamiento de la medicalización de la maternidad y de las prácticas cotidianas desprendidas de este acto (como por ejemplo, la alimentación), que resultaban de saberes ya conocidos por las mujeres madres pero que aun así pasaron a estar bajo la normativa de la ciencia médica. En este diseño curricular aparecieron como sujetos de intervención las madres afectadas por sífilis o tuberculosis, sobre quienes reposaba el riesgo de una descendencia "degenerada" contraria a la que pretendían desde la eugenesia transformista, es decir, 
una eugenesia que tuviera en cuenta la fusión entre el carácter heredado y la influencia del medio ambiente. En los trabajos prácticos asignados se proponía la enseñanza a las madres puérparas, destacando los consejos que debían darles -lamentablemente no aparecen consignados en el programa- como también la enseñanza "práctica" de la lactancia materna vinculadas a la extracción y administración de la leche, incluso se sugería en los trabajos prácticos la difusión de cuidados específicos que debían realizarse con el recién nacido, a saber: baño y limpieza del vestido y de la habitación; régimen de vida, régimen de sueño, vacunación, chupeta, cuna y los cantos. ${ }^{114}$ Es decir, se intentaba ordenar y disciplinar una práctica habitual de cuidado, pero además normalizarla en función de los parámetros médicos de control social.

Las actividades propuestas por esta materia se encargaron también de representar la Ley No 12.341 sancionada en 1936 y reglamentada en 1938. Como mencioné anteriormente, mediante esta ley se creó la Dirección de Maternidad e Infancia bajo la dependencia del Departamento Nacional de Higiene. Su finalidad era "propender al perfeccionamiento de las generaciones futuras por el cultivo armónico de la personalidad del niño en todos sus aspectos, combatiendo la morbimortalidad infantil en todas sus causas y amparando a la mujer en su condición de madre o futura madre". Entre sus objetivos se encontraban la asistencia pre concepcional, del embarazo y del parto, la vigilancia del niño desde el momento de su nacimiento a través de la confección de fichas sanitarias individuales, el control de la lactancia materna, la alimentación racional y la protección social de niños necesitados.

El interés por disciplinar la vida cotidiana de los sectores populares fue trasversal a la currícula de la EVHS, aunque aparece abordado desde un carácter social y económico en la última materia común del segundo año: Servicio Social. Esta contenía ocho unidades que establecían un panorama del espacio socio profesional que ocuparían las visitadoras, como también una serie de definiciones y límites acerca del accionar de las mismas. Este segmento presentaba al Servicio Social (SS) como la respuesta científica al abordaje de la cuestión social mediante la conjugación de elementos sociales, económicos, morales, físicos, entre otros, que podían aislarse de distintas disciplinas (como la economía, la abogacía, la medicina) y formar un conjunto de conocimientos específicos (Rodríguez, 1927).

El primer punto de la materia presentaba una historización de la atención social partiendo del concepto de caridad hasta el concepto "moderno" de SS. El Dr. Germinal Rodríguez, uno de los ideólogos y mentores de la Escuela de Servicio Social en el

\footnotetext{
114 ídem. p. 34.
} 
Museo Social Argentino, del que ya hemos hablado en el capítulo 1, consideraba que el SS establecía obras de solidaridad guiadas por la razón y no por la buena voluntad como lo hacían las obras de beneficencia, razón por la que la nueva ciencia resultaba útil a la "pacificación de las masas" (Rodríguez, 1952, pp. 14-22), es decir, era el abordaje científico afín al pensamiento positivista el que supuestamente garantizaría la efectividad en el disciplinamiento de las multitudes.

De acuerdo con este objetivo por mantener el control sobre los sectores potencialmente peligrosos, es que una de las bolillas de la materia era sobre "las causas del pauperismo y las posibles resoluciones a la miseria”. Entre ellas, algunas aparecen consideradas como directas en tanto serían consecuencia de "enfermedad, invalidez, vejez o muerte del jefe de la familia". Es interesante destacar que nuevamente el currículo manifiesta una situación presente en la organización familiar y en el mercado donde la mujer aparece en dependencia del salario masculino, puesto que la fuerza de trabajo de los hombres era mejor remunerada que la de las mujeres. Las otras causas eran consideradas indirectas, entre ellas se encontraban "el alcoholismo, el juego y las apuestas, la ignorancia, la indiferencia y la imprevisión", todos hábitos que el SS pretendía modificar para evitar que los sujetos afectados sean parte del círculo vicioso de la miseria.

Mediante la asignatura SS se sistematizaban una serie de discusiones acerca del abordaje sobre la cuestión social y la "evolución técnica" que habían tenido las obras públicas y privadas de atención sociosanitaria. ${ }^{115}$ También se presentaban los

\footnotetext{
${ }^{115}$ El entrecomillado en el concepto evolución pretende dar cuenta del debate alrededor del mismo. El trabajador social Carlos Montaño (1998) cuestiona la posibilidad de que las obras de asistencia social decimonónicas fueran antecedentes del Servicio Social. En función de ello se plantean dos posturas político ideológicas. La tesis de carácter endogenista, que quienes suscriben a esta teoría presentan la beneficencia, la asistencia social y el servicio social como etapas que se inscriben dentro de un proceso histórico que no tiene vinculación con el contexto más que como telón de fondo a este despliegue. Consideran que en estas etapas de "evolución" de la profesión se ha definido un objeto de intervención que le otorga especificidad y la distancia de otras profesiones. Así, lo específico sería la intervención sobre los sectores más desvalidos de la sociedad, a través de un método particular de intervención cuya originalidad daría legitimidad a la profesión por distinción con otras. La otra tesis presentada por Montaño que explica el origen y legitimidad de la carrera es la de la perspectiva histórico crítica. Ésta comprende el surgimiento de la profesión de Servicio Social como producto de los proyectos políticos económicos que operan en el desarrollo histórico del capitalismo monopólico donde se reproduce material e ideológicamente la fracción de la clase hegemónica, haciendo que el estado tome para sí la "cuestión social". La profesión obtiene legitimación al ponerse al servicio del orden burgués - en tanto contribuye en la reproducción de la fuerza de trabajo y de la reproducción ideológica- como ejecutor de políticas sociales, en función de las demandas sectoriales y de la existencia de instituciones con interés y capacidad de contratar a los y las profesionales. Por lo tanto, resulta de este servicio una vinculación entre el carácter de empleado, funcionario y trabajador. Este estudio sistemático de Montaño resulta una referencia indudable, aunque el autor pierde de vista quiénes son las encargadas de la intervención y el valor económico que ello implicó en las distintas formas de intervención sobre la cuestión social. Ver: Montaño, Carlos (1998) La naturaleza del Servicio Social. Un ensayo sobre su génesis, su especificidad, su reproducción, Cortez Editora, San Pablo. Una crítica al carácter androcéntrico de este estudio se encuentra en un artículo de mi autoría, Ver: Gavrila, Canela Constanza (2014) Algunas consideraciones
} 
dispositivos de intervención existentes a nivel nacional, como lo eran el Fichero Central de la Asistencia Social ${ }^{116}$ junto con una cartografía del SS en las escuelas, en las industrias y en las organizaciones de medicina preventiva. Entre los avances legales que se presentan para el conocimiento de las estudiantes de la EVHS se mencionaba la ya citada Ley $\mathrm{N}^{\mathrm{o}} 12.341$, hecho que da cuenta de su peso en la formación común de todas sus estudiantes.

Esta ley tardó dos años en ponerse en vigencia por una serie de diferencias con el Patronato de la Infancia ${ }^{117}$, y una vez reglamentada no logró alcanzar los objetivos previstos puesto que su radio de acción era muy reducido en función del bajo presupuesto asignado (Biernat y Ramacciotti, 2007). La necesidad de efectivizar el control sobre el proceso reproductivo en el período gestacional y de los primeros años de vida del infante exigía también la capacitación de profesionales que pudieran dar respuesta a las exigencias de la ley, entre ellas realizar las tareas de atención inmediata, vigilancia e incluso en la confección de las fichas sanitarias. Acciones que ya aparecen mencionadas en otros puntos del diseño curricular para ser aprendidas por las visitadoras.

Si bien esta materia poseía pocas bolillas en comparación con otras, en ella se sintetizaron y nuclearon los acuerdos político legislativos que operarían como marco de intervención de las profesionales del servicio sociosanitario. Esta mayor incidencia del Estado en la intervención sociosanitaria, sobre todo en relación a las madres y los niños, se profundizará en los años subsiguientes con el triunfo del peronismo y la ampliación de políticas sociales e instituciones abocadas al desarrollo de la infancia (Guy, 2008; Biernat y Ramacciotti , 2007, 2014).

sobre las implicancias del trabajo femenino en la génesis y legitimación del trabajo social (19241938) (En línea). Trabajo presentado en VIII Jornadas de Sociología de la UNLP, 3 al 5 de diciembre de 2014, Ensenada, Argentina. Disponible en: http://www.memoria.fahce.unlp.edu.ar/trab eventos/ev.4773/ev.4773.pdf

${ }^{116}$ El Fichero Central de Asistencia Social junto con el Registro de Asistencia Central fueron creados durante el gobierno del Gral. Agustín P. Justo, a fin de coordinar los servicios de asistencia social que se prestaban a nivel nacional, provincial o municipal. Todas las instituciones que tenían personería jurídica debían inscribirse en dicho registro, del mismo modo en el fichero se debían registrar quienes fueran asistidos. Para el año 1940 se nacionalizó este registro y fichero en pos de atender a una mayor centralidad que se verá plasmada en la creación de la Dirección Nacional de Salud Pública y Asistencia Social y la Dirección Nacional de Asistencia Social en 1948.

${ }^{117}$ Una de las problemáticas entre el Patronato Nacional de Menores y la nueva Dirección resultaba de que la primera consideraba que la nueva ley avanzaba sobre atribuciones de la infancia abandonada y la delincuencia que eran propias del Patronato. Finalmente intervino el director del Departamento Nacional de Higiene, Miguel Sussini, quien consideró que cada uno de los organismos atendía cuestiones diferentes en función de que el primero abordaría la problemática sanitaria mientras que el segundo se ocuparía de la tutela de los niños cuyos padres biológicos no tuvieran la tutela. Ver: Biernat, Carolina, Ramacciotti, Karina (2008) "La tutela estatal de la madre y el niño en la Argentina: estructuras administrativas, legislación y cuadros técnicos (1936-1955)". Història, Ciencias, Saúde-Manguinhos, Rio de Janeiro, v. 15, n2, p. 331-351. abr- jun 2008. 
Otra de las unidades se encargaba de presentar los métodos de abordaje y de vigilancia, de la sistematización y de relevamiento de los y las usuarias de los servicios sociales. Así, la séptima unidad presentaba los nuevos métodos norteamericanos del Servicio Social. En principio, el SS en los casos individuales ${ }^{118}$, método organizado y sistematizado por la trabajadora social norteamericana Mary Ellen Richmond a principios del siglo XX, era considerado como "el conjunto de métodos que desarrolla la personalidad, reajustando consciente e individualmente al hombre a su medio social" (Richmond, 1962 [1922] p. 67). Para ello se exigía la investigación individual y del grupo de pertenencia de la persona afectada junto con un tratamiento prolongado en función de las posibilidades que ofreciera el medio social circundante $\mathrm{y}$, a partir de esta información, se suponía que deberían lograr una mejor intervención.

Para el estudio social de casos individuales resultaba imprescindible el uso de una serie de técnicas ya realizadas en las obras asistenciales, a saber: la entrevista necesaria para conocer las condiciones y posibilidades de cambio individual, e incluso como parte de una intervención en sí misma. En segunda instancia, el registro y, en tercera, el informe social. El segundo dispositivo resultaba central para la investigación y para la posterior intervención, en él se debían plasmar descripciones y reflexiones individuales acerca de las modificaciones que producían los sujetos y su entorno, como también del propio hacer profesional. Por su parte, mediante el informe se pretendía establecer una herramienta de comunicación que operase como fundamento de la toma de decisiones de la profesional y que además sirviera para posteriores intervenciones e investigaciones (Travi, 2006; pp. 73-77).

El Dr. Germinal Rodríguez (1952) consideraba a las visitadoras como "hermanas de la caridad civil”, razón por la cual con sus métodos ya no debían ser “inspectoras que van en tren de curiosear, delatar, castigar; es si se me permite, una buena vecina que va a ser confidente y a dar los consejos apropiados" (p.166). Para que estas acciones fueran precisas era necesario que hicieran relevamientos de encuestas, tal como lo cita el Plan de Estudios de 1938. Y para que estas encuestas fueran "profundas y completas", se delinearon una serie de elementos imprescindibles en los cuestionarios. Rodríguez destaca siete líneas generales de toda encuesta: Datos de identificación: nombre, apellido y domicilio; Antecedentes civiles: estado social, número de hijos, muertos, etc.; Antecedentes sociales: vivienda, salario, presupuesto obrero; Antecedentes morales: conducta, sentido del honor, etc.; Antecedentes intelectuales: capacidad de trabajo,

\footnotetext{
${ }^{118}$ En el año 1922, Richmond publica un libro donde explicita su experiencia y propuesta de abordaje de la cuestión social titulado Caso Social Individual.
} 
oficios, etc.; Antecedentes personales: enfermedad, prisión, etc. y por último, Derechos Adquiridos: seguros. ${ }^{119}$

En la unidad en cuestión se señalan tres tipos de encuestas en particular: encuestas en puericultura pre y post natal, encuesta en profilaxis de la tuberculosis y encuesta en medicina escolar. Es decir, se enseñaba a interrogar e investigar sobre las condiciones en que se encontraban los tres sujetos designados para la atención: madres, niños escolares y tísicos, si bien éstos no eran los únicos beneficiarios de ayudas sociales, sí aparecen en el programa de 1938 como los sujetos sobre quienes las estudiantes debían aprender a investigar y vigilar, e incluso, logar ser reconocidas como la íntima confidente para relevar información y con ello, posteriormente, poder "aconsejar".

La última unidad de la materia SS se dedicaba a la economía doméstica, el presupuesto familiar, el equilibrio del mismo, el ahorro, los gastos en alimentos, créditos, y también al concepto social del salario. La economía doméstica interpeló mayoritariamente a las mujeres y estaba destinada a la organización y administración del hogar. Tal como señala Paula Lucía Aguilar (2014), el discurso de la economía doméstica establecía un detallado decálogo de tareas, prioridades, modos de abordarlas y sujetos que las ejecutaría. El “gobierno del hogar" aparecía como responsabilidad asignada primordialmente a las mujeres, quienes fueron destinatarias de los discursos que pretendían ordenar y optimizar las labores domésticas. Fue el discurso científico médico relacionado con la higiene y la prevención de contagios el que otorgó legitimidad a la economía doméstica (pp. 156- 158). Es interesante que en este punto se vuelve nuevamente a consolidar el lugar de la mujer en la estructura de la familia heterosexual como espacio productivo y reproductivo, donde las tareas de reproducción material e ideológica aparecen como responsabilidad única de las mujeres, las madres y/o trabajadoras, pero también de las mujeres visitadoras que, de algún modo, a través de sus controles y consejos influirían sobre las otras en la ideología de la domesticidad, hecho que permitía el abaratamiento de los costos de reproducción social al hacer de las madres agentes responsables del núcleo doméstico y responsables últimas de los problemas cotidianos (Grassi, 1989, p. 28).

En este análisis del Plan de Estudios de la EVHS de 1938, el primero de esta institución, resulta evidente el objetivo de los docentes por imprimir una feminidad hegemónica, acorde al sistema sanitario: joven, de buena moral, con estudios básicos y con disponibilidad horaria, tal como lo exigía la ordenanza. Los contenidos del currículo

\footnotetext{
119 Ver: Rodríguez, Germinal (1952) La encuesta Social, en Principios Generales de Asistencia Social.
} Editorial Universitaria. Buenos Aires. Cap. VIII, pp. 165-185. 
dialogaron con el proyecto de politizar la maternidad y fijar los contornos del espacio doméstico como así también definir las acciones que debían aprender las visitadoras y luego transmitir a otras mujeres. Entre los distintos saberes mencionados en cada materia cobraron un lugar de mayor relevancia la difusión de enseñanzas tendientes a la modificación de hábitos de la vida cotidiana, como por ejemplo, las detalladas enseñanzas sobre la higiene corporal o del vestido, los modos de alimentación, los cuidados sobre enfermos, ancianos y discapacitados, entre otros. También aparecen con interés la aplicación de métodos del SS como la encuesta y el informe mediante los cuales los médicos podían obtener información sobre las personas con quienes trabajaban las visitadoras.

La gama de saberes que se describe en el programa indica las acciones a llevar adelante por las mujeres visitadoras tales como la vigilancia, toma de muestras médicas, cuidados, diagnósticos, la enseñanza en el tratamiento de las madres puérperas como asimismo la transmisión de consejos para la lactancia, la alimentación de niños, saberes del orden de la economía doméstica, obtener la "confesión" de las personas con quienes trabajarían, entre otros, que buscaban consolidar un estereotipo femenino maternal y ordenado desde el campo médico. Con ello se pretendía reforzar la situación de las mujeres dentro de la familia en su rol como madres, y reactualizar su posición dentro de la sociedad heterosexual en tanto garantes del desarrollo del núcleo familiar. Las prácticas para el sostenimiento del núcleo doméstico aparecen como dominio exclusivo de las mujeres, así la preparación de alimentos, los consejos para las madres que daban de amamantar, cantos para el bebé, entre otros, aparecen como tareas de dominio de las gestantes. La enseñanza específica de saberes que ya existían en las comunidades intergeneracionales de mujeres (abuelas, madres e hijas) respecto de la elaboración de alimentos o de la cría de niños se reinscribe en el proceso de medicalizacion de la maternidad e infancia. Resulta importante considerar para trabajos futuros qué cambios produce el discurso gestado desde las profesionales de la asistencia social respecto de la maternidad e infancia a medida que la profesión adquiere un mayor contacto con las ciencias sociales y esboza un relato propio.

La incidencia de la Ley $\mathrm{N}^{\mathrm{o}} 12.341$ parece ser transversal a los dos años de estudio propuestos, donde se evidencia la insistencia por cuidar y garantizar una futura población fuerte y sana acorde al proyecto de la eugenesia. Para responder con éxito a esta tarea se necesitaba la dedicación y participación de la madre, hecho que podía lograrse mediante las acciones de acercamiento, control y vigilancia de las visitadoras educadas en materia médico sanitaria. Para esta misión evangelizadora por maternalizar 
a las mujeres y medicalizar las costumbres de reproducción social, los médicos proyectaron a trabajadoras que representaran la buena moral y las buenas costumbres, las que debían imprimir sobre las familias y personas beneficiarias de la asistencia. Por ello, las figuras alusivas que citaba Pilades Dezeo, “ángeles de piedad”, "seres de buena voluntad con el anhelo de una comunidad más justa y feliz", "ser bálsamo y consuelo para todo el dolor, fuente inagotable de perseverancia, resignación y paciencia", reforzaban un carácter servicial y disciplinado por parte de las estudiantes que luego tendría que trasladarse a las mujeres con quienes trabajaban. Si bien dentro del desarrollo del currículo oficial o visible esto no aparece mencionado, la moral fue parte de un currículo oculto que operaba sobre las estudiantes aunque no era parte explícita de los programas -más adelante desarrollare este punto-.

Para que las visitadoras lograran ser "la buena vecina" que escucha y aconseja, como planteaba Germinal Rodríguez, era necesario que asumieran sus acciones en los márgenes establecidos para las mujeres en la primera mitad del siglo XX. Es decir, que se valieran de su carácter supuestamente amoroso, pero que los conjugaran con conocimientos técnicos y científicos a fin de que pudieran extraer una confesión a partir de la cual los médicos avanzarían en el conocimiento de estos sujetos.

Insisto, las visitadoras resultaron agentes importantes para la reproducción del orden ideológico imperante a través de la transmisión de valores y conocimientos que favorecieron la reducción de los costos para la intervención en la cuestión social a través de la difusión de los valores morales e higiénicos al interior de los sectores populares. Mediante estas labores, las visitadoras, las mujeres y las madres resultaron ser una suerte de agentes para la garantía de la reproducción social. Estas nuevas asistentes profesionales parecen ser la institucionalización académica de aquello que realizaron las mujeres históricamente. Si bien podríamos considerar esta "capacitación” como un avance en sus posibilidades de acceso al conocimiento universitario, también implicó un intento por reforzar el lugar secundario de las mujeres dentro de las instituciones sociosanitarias en un contexto de avanzada feminista.

\subsubsection{La reforma curricular de 1948 y la formación de profesionales polivalentes}

En el año 1941 falleció el Dr Pilades Dezeo y uno de sus colegas asumió las funciones de dirección interina de la EVHS, el Dr. Carlos Carreño, profesor adjunto de la Cátedra 
de Higiene Médica y Preventiva de la Facultad de Ciencias Médicas. ${ }^{120}$ Durante ese año otros cambios se sucedían en la ciudad de La Plata, uno de ellos resultaba de la apertura de la Casa Cuna e Instituto de Puericultura. Esta institución -de la que ya hemos hablado en el capítulo anterior- resultaba una obra magnánima para el cuidado de la infancia abandonada y de niños que integraban familias que no podían satisfacer sus necesidades básicas. La construcción de este edificio se había iniciado en el esplendor del gobierno provincial a cargo del conservador Manuel Fresco y culminó durante un largo período de intervenciones federales y militares al gobierno provincial.

El golpe militar producido por el Grupo de Oficiales Unidos (GOU) en 1943 trajo cambios aparejados en relación a la organización burocrática administrativa y facilitó la construcción de un nuevo Estado acorde a las condiciones sociales y económicas de la época. La puja entre los sectores terratenientes y la burguesía industrial se había acomodado en favor de estos últimos, que buscaron afianzar y garantizar las condiciones materiales para el desenvolvimiento del proceso industrializador (Murmis y Portantiero, 1971, p.113). Esto implicó una acción directa del Estado en el área económica, con un mayor rol social que permitiera avanzar en su consenso y legitimidad entre los sectores trabajadores (Grassi, 1989, p.79).

En este escenario es que el 21 de octubre de 1943, mediante el decreto $N^{0} 12.311$, se creó la Dirección Nacional de Salud Pública y Asistencia Social bajo la tutela del Ministerio del Interior, con el fin de coordinar los servicios sanitarios y los asistenciales, y además romper los subsidios estatales a instituciones privadas (Ramacciotti, 2009, p. 36). Sin embargo, esta intención centralizadora duró solo diez meses ya que fue desarmada en dos direcciones, por un lado, la Dirección General de Asistencia Social que se encargaría de las cuestiones relativas a la beneficencia, hogares y asistencia social y la administración de los subsidios que recibían las instituciones, estando bajo el ala de la recientemente creada Secretaría de Trabajo y Previsión Social, al mando de Juan D. Perón. Por otra parte, se creó la Dirección Nacional de Salud Pública dependiente del Ministerio del Interior. Estas idas y vueltas formaron parte de lo que Daniel Campione (1996) considera la improvisación y no racionalidad de este periodo (p.30). Esta mayor atención sobre los sectores populares tomaba nota de la avanzada de los trabajadores y nuevos migrantes internos como también de la necesidad por parte de los empresarios de controlar a esta fuerza de trabajo imprescindible para el modelo de acumulación basado en la industrialización por sustitución de importaciones.

\footnotetext{
${ }^{120}$ En la Ordenanza de Creación de la EVHS UNLP se explicitaba que el titular a cargo de la Cátedra de Higiene Médica y Preventiva era quien tenía los méritos para ocupar la Dirección de la EVHS UNLP. Como era Carreño quien lo seguía en jerarquía, pasó a ser el sucesor de ambos cargos.
} 
Las pujas entre facciones del Grupo de Oficiales Unidos resultaban difíciles de dirimir, sobre todo frente a la presencia de Juan Domingo Perón, quien desde la Secretaría de Trabajo y Previsión Social acaparaba el centro de la escena como producto de las concesiones que realizaba al movimiento trabajador, solo por citar algunas de ellas: expansión de beneficios jubilatorios, mejores indemnizaciones por accidentes de trabajo, aguinaldos, mayor cantidad de días de vacaciones pagos, cláusulas de estabilidad para varios gremios, creación de un fuero judicial, reglamentación de convenios colectivos por actividad (Adamovsky, 2012, p.173). Sin dudas, estas políticas desafiaban las jerarquías de clase establecidas por empresarios industriales y ganaderos, pero a pesar de que estas reformas redistributivas fueron beneficiosas para los trabajadores durante el primer gobierno, no atentaron contra la propiedad de los patrones y, por lo tanto, no modificaron la estructura productiva del país. No obstante, la incomodidad que producía la figura de Perón dentro de las fuerzas militares se tradujeron en su exilio a la Isla Martín García con el posterior apoyo y movilización masiva del 17 de octubre de 1945, contando con el respaldo masivo de gran parte de los trabajadores (con excepción de socialistas y comunistas, quienes debieron soportar la persecución política) y los sectores populares que se habían beneficiado de las políticas sociales, lo que garantizó una movilización histórica y la posterior liberación del líder.

El primer gobierno de Perón iniciado en 1946 se destacó por una mayor inversión destinada a reformas sociales que duró hasta 1950, momento en que comenzó un período de crisis económica e inflación por lo que dejaron de estar disponibles los recursos del primer momento. Entre las políticas más destacadas del período se encuentra la aprobación parlamentaria del voto para las mujeres en el año 1947, reconociendo una larga lucha de feministas y sufragistas. Otro de los avances legales del primer gobierno peronista fue la promulgación de una nueva constitución destinada a promover derechos sociales y políticos como muestra de la mayor intervención estatal. Con el objetivo de ampliar las políticas sociales y optimizar el funcionamiento de los servicios sociosanitarios, que como ya hemos mencionado en el capítulo anterior constituían parte de las políticas intervencionistas de la década anterior, en el año 1944 se crea la Dirección Nacional de Salud Pública que entendería solo en lo relativo a la asistencia hospitalaria, a la sanidad y a la higiene. Los centros que quedaron bajo su administración eran los que dependían del Departamento Nacional de Higiene y aquellos bajo la comisión Asesora de Asilos y Hospitales regionales (Ramacciotti, 2009, p. 36). En 1947 se creó la Secretaría de Salud Pública, lo que representó el traspaso del área de la salud pública al Ministerio del Interior del que había dependido durante más 
de sesenta años para estar en relación directa con el poder ejecutivo, e inició un camino en búsqueda de mayores facultades en la administración de la gestión y de las partidas presupuestarias (Ramacciotti, 2015, p.85). Las instituciones bajo dominio de la Sociedad de Beneficencia mantuvieron su autonomía hasta que en el año 1948, mediante la Ley $\mathrm{N}^{\mathrm{o}}$ 13.341, se creó la Dirección Nacional de Asistencia Social dependiente de la Secretaría de Trabajo y Previsión. En el artículo $N^{o} 1$ de la misma se aclaraban parte de sus funciones:

\footnotetext{
Destinada a ejercitar en todo el territorio de la Nación el amparo por el Estado de las personas que por causas fortuitas o accidentales se vean privadas de los medios indispensables de vida y de las que, careciendo de ellos se encuentren incapacitados en forma definitiva (Art ${ }^{\circ} 1$. Ley $n^{\circ} 13.341$ ).
}

Si bien no es parte de esta tesis analizar la continuidad de las políticas asistenciales y la intervención profesional posterior a 1948, me interesa destacar que estos cambios en la política pretendían expandir la "democratización del bienestar", tal como Torre y Pastoriza (2002) llamaron a este período, para lo cual fue necesario generar consensos entre la población afines a las nuevas políticas sociales y al reordenamiento administrativo que proponía el peronismo. Este hecho repercutió en la formación de profesionales encargados de transmitir y traducir entre el pueblo la palabra del Estado. La modernización en las instituciones estatales resultó una novedad del período. En el área asistencial fue parte de una mayor racionalidad en la atención a través de la centralización y unificación de las instituciones dedicadas a ello, hecho que también llevó a que se modificara la formación profesional que se dictaba hasta el momento. Rozas Pagaza (2001) considera que la constitución de la Dirección de Asistencia Social centralizó las políticas públicas y motorizó una intervención tecnificada de los y las profesionales en dicha materia; sin embargo, esto no sería exclusivo del peronismo sino resultado de un proceso iniciado en la I Conferencia Nacional de Asistencia Social donde ya se habían acordado quiénes podrían ser agentes de intervención sobre dichas políticas (p.117).

En este mismo año se crea la Fundación Eva Perón (FEP) que actuó como un mecanismo informal para el consenso pasivo de los sectores populares (Plotkin, 1993). Procedió con subsidios del gobierno, contribuciones voluntarias de sindicatos y empleadores. Las obras de la Fundación sustituían a la vieja caridad por la justicia social peronista (Guy, 2007, p. 245), intentado mitigar las diferencias sociales y brindar herramientas de apoyo a los sectores más humildes. Por otra parte, la FEP también absorbía el control de hospitales, escuelas y orfanatos que, luego de disuelta la Sociedad 
de Beneficencia en el año 1947 por el decreto $N^{\circ} 28.752$, habían quedado acéfalas o no habían sido absorbidas por la estructura administrativa de la Secretaría de Salud Pública. Además de las tareas de asistencia, la FEP también se ocupó de formar profesionales sanitarias dedicadas a la enfermería y la divulgación sanitaria (Ramacciotti y Valobra, 2015, p. 294).

En el caso particular de la EVHS se iniciaron una serie de cambios previos a la creación de la Dirección que de algún modo registraban los sucesos nacionales y la necesidad por incidir en los espacios asistenciales que comenzaban a acrecentarse durante el período peronista. Puesto que las visitadoras en tanto agentes del servicio social trabajarían sobre las refracciones de la cuestión social y eran las mensajeras de la cultura higiénica en los hogares e instituciones de atención sociosanitaria, con la transformación de estas instancias y de las direcciones a su cargo también comenzaron a reformularse los planes de estudio de la carrera. Desde la presentación del proyecto para la EVHS de la UNLP en el año 1937, Dezeo consideraba que el programa propuesto para la creación de la Escuela solo formaría profesionales monovalentes capaces de intervenir en una sola área del vasto campo de atención sociosanitaria (escolaridad, tisis, puericultura y obstetricia, y puericultura), y que en caso de querer formar visitadoras polivalentes se debía ampliar un año más la carrera. Así sucedió en el año 1948, en el cual la carrera se amplió a tres años de cursada y se daba por finalizado el período de formación monovalente. Aun sin especializaciones, se hacía mención a las tareas específicas que cumplirían las visitadoras según su función en el mercado de trabajo, agregándose a las que anteriormente aparecían mencionadas -escuelas y hospitales- la industria y las instituciones destinadas a la atención de la infancia abandonada, a fin de dar respuesta y ejercer una mayor vigilancia sobre dos de los sujetos privilegiados de las políticas sociales del peronismo: los trabajadores y los niños.

La reforma curricular de 1948 incluía gran parte del programa anterior. El primer año no tuvo ninguna diferencia en relación al programa de 1938, se mantuvieron las mismas materias y contenidos. El segundo año sí tuvo una serie de cambios, ya no estaba dedicado a la formación específica pero aun así abordaba todas las áreas anteriores, excepto la Higiene Escolar que dejó de ser una materia exclusiva del programa y sus contenidos pasaron a estar distribuidos en las nuevas áreas.

\begin{tabular}{|l|l|l|}
\hline & \multicolumn{1}{|c|}{1938} & 1948 \\
\hline 1er año & Anatomía y fisiología & Anatomía y fisiología \\
\hline
\end{tabular}




\begin{tabular}{|c|c|c|}
\hline & elementales & $\begin{array}{l}\text { (se separan en dos materias } \\
\text { con programas propios) }\end{array}$ \\
\hline & Higiene general y especial & Higiene \\
\hline & $\begin{array}{l}\text { Elementos de } \\
\text { microbiología y } \\
\text { parasitología }\end{array}$ & $\begin{array}{l}\text { Microbiología y } \\
\text { parasitología }\end{array}$ \\
\hline & $\begin{array}{l}\text { Elementos de patología } \\
\text { médica }\end{array}$ & $\begin{array}{l}\text { Elementos de patología } \\
\text { médica }\end{array}$ \\
\hline & $\begin{array}{l}\text { Elementos de patología } \\
\text { quirúrgica }\end{array}$ & $\begin{array}{l}\text { Elementos de patología } \\
\text { quirúrgica }\end{array}$ \\
\hline \multirow[t]{5}{*}{2 do año } & Higiene social* & Higiene y medicina social \\
\hline & $\begin{array}{l}\text { Elementos de } \\
\text { tisiología* }\end{array}$ & Tisiología \\
\hline & Servicio social* & Servicio social (Parte 1) \\
\hline & Higiene escolar (VHE) & $\begin{array}{l}\text { Elementos de psicología e } \\
\text { higiene }\end{array}$ \\
\hline & Elementos de puericultura & $\begin{array}{l}\text { Puericultura y protección } \\
\text { materno infantil }\end{array}$ \\
\hline
\end{tabular}




\begin{tabular}{|l|l|l|}
\hline 3er año & & Elementos de nutrición \\
\hline & & Administración sanitaria \\
\hline & & $\begin{array}{l}\text { Sociología y legislación } \\
\text { social }\end{array}$ \\
\hline & & Servicio social (II parte) \\
\hline
\end{tabular}

El cambio del plan de estudios incluía los nuevos avances nacionales e internacionales en relación a la higiene. Así, para el segundo año estaba la nueva materia Higiene mental y psicología. El movimiento de higiene mental surgido en la primera década del siglo XX en Estados Unidos pretendió declinar las bases de la psiquiatría organicista asentada en la tesis de la herencia y degeneración. El peso de esta crítica quedó de manifiesto en la creación de un comité internacional para la higiene mental que en 1930 realizó el Primer Congreso Internacional en Washington. Sin embargo, en Argentina la higiene mental estuvo íntimamente ligada a la tradición eugenésica con un fuerte peso de la herencia para la transmisión de las anomalías. En este marco se pretendía un avance en materia de diagnóstico precoz y aislamiento de los y las alienadas, a quienes además debían impedirles la reproducción puesto que su peligrosidad no radicaba en un delito contra las normativas y legalidades, como sucedía con otros sujetos en la mirilla de la eugenesia, sino que constituían un "delito natural contra la especie" (Talak, 2005, pp. 570- 576). En el año 1930 se formó en el país la Liga Argentina de Higiene Mental, su foco primordial era ocuparse de cuestiones de interés público, e incluía entre sus preocupaciones la higiene social e individual de la infancia, como los estudios relativos a su educación e instrucción.

En la formación de las visitadoras los contenidos se diferenciaban en dos apartados. El primero se refería a la psicología y estaba compuesto por trece unidades que se encargaban de presentar la definición de psicología y las utilidades que brindaba este conocimiento para la intervención de las agentes del servicio social. En este punto se definían los métodos de abordaje que podían usar las profesionales: observación, escritura, encuesta y estadística. Luego de estas dos primeras unidades nos encontramos con un decálogo de componentes de la psicología a los que deberían atender las visitadoras, a saber: la vida intelectual, la vida afectiva, la voluntad, la imaginación, el 
temperamento, entre otras, es decir, una serie de elementos subjetivos que hacían a la vida de los y las usuarias sobre quienes trabajarían y de los que ahora debían tomar nota en función de lograr una atención integral. ${ }^{121}$

Por su parte, en el segmento que abordaba la higiene mental, la primera unidad estaba dedicada a "la necesidad de la higiene mental y su relación con la psiquiatría y criminología”. En este sentido, la materia era pensada como parte de la cruzada educativa iniciada por los médicos vinculados a la tradición eugenésica, considerando que su abordaje se encargaría de prevenir la "desadaptación psíquica en la sociedad actual" como planteaba el Dr. Arturo Ameghino en 1935. ${ }^{122}$ Esta materia se fue modificando en sus contenidos, pero se mantiene en la actualidad solo como psicología. La materia Servicio Social también será dictada en 2do año, al igual que lo estipulado en el programa de estudios de 1938, pero será ampliada y dictada también durante el tercer año de formación. Se agregaron nuevos contenidos a la misma teniendo mayor centralidad las definiciones de los fundamentos sociológicos del SS y sus diferencias con otros modos de intervención como los de la Iglesia y la caridad. De algún modo, en el programa se plasmaban los intereses que estaban presentes en las políticas sociales del gobierno peronista con la ampliación de la asistencia y la centralidad desde el Estado.

Algunos saberes que estaban mencionados en el programa de 1938 son nuevamente considerados pero en la materia Servicio Social II, que correspondía al tercer año de la carrera. Allí se destacaba la definición de los métodos a utilizar en las intervenciones. El SS de los casos individuales y las encuestas que resultaban de una trayectoria previa a la profesionalización siguieron vigentes en el plan de estudios, pero se agregaron nuevas unidades dedicadas a tratamientos colectivos y a la readaptación social. ${ }^{123}$ Excede a los objetivos de esta tesis, pero resta indagar las vinculaciones entre el supuesto de trabajo para la resolución de casos colectivos y las propuestas de abordaje a la comunidad que serán posteriormente planteadas en la década de 1960 con el movimiento de reconceptualización. ${ }^{124}$

\footnotetext{
${ }^{121}$ Universidad Nacional de La Plata, Facultad de Ciencias Médicas. Escuela de Visitadoras de Higiene Social. Programas de Segundo año. La Plata, 1948. pp. 17-21.

$122 \mathrm{pp} 134$.

${ }^{123}$ Universidad Nacional de La Plata, Facultad de Ciencias Médicas. Escuela de Visitadoras de Higiene Social. Programas de Tercer año. La Plata, 1948. pp. 12-14.

${ }^{124} \mathrm{La}$ reconceptualización en Trabajo Social es un fenómeno producido a nivel latinoamericano entre las décadas de 1960 y 1970. Es producto de una mayor modernización de la práctica profesional y el diálogo con la teoría marxista que cuestiona las prácticas tradicionales precedentes, y apunta a una formación política ideológica que favorezca un mayor compromiso político de las trabajadoras sociales con las comunidades. Ver: Rozas Pagaza, M. (2001), La intervención profesional en relación con la cuestión social. Buenos Aires: Editorial espacio.
} 
La polivalencia se tradujo en una mayor formación para la intervención en las instituciones sociosanitarias como auxiliares médicos y educadoras sanitarias, como vimos que estipulaba el programa de 1938. Con la ampliación de la intervención del Estado durante la década de 1940 se dio un proceso de mayor planificación que guiaría la acción pública. Si bien con antelación había planificación para la intervención sociosanitaria, lo que se modifica a partir de la creación de la Secretaría de Salud Pública es que deja de ser excepcional o para atender una epidemia en particular. Desde 1947 pasa a ser parte de la política del Estado tal como se plasmó en el Plan Analítico de Salud Pública (Ramacciotti, 2010).

Además, se debía modernizar la estructura administrativa, producir bienes y servicios sanitarios específicos para el control del accionar profesional (Ramacciotti, 2010, pp. 183-184). En este marco de mayor burocratización es que las visitadoras polivalentes eran formadas en dos materias que les servirían en su actuación profesional, a saber: Administración Sanitaria y Sociología y Legislación Social.

La primera de ellas atendía una amplia gama de cuestiones referidas al funcionamiento burocrático de la sanidad. En las dos primeras unidades se presentaba la historia de las instituciones de sanidad de Argentina, su organización y evolución desde el Departamento Nacional de Higiene. En la unidad dedicada exclusivamente a la administración sanitaria se destacaban algunos conocimientos que debían tener las visitadoras en relación al personal que trabajase en las instituciones. Así se mencionaban "reclutamiento, instrucción, material de trabajo, derechos, deberes, retribución y disciplina". ${ }^{125}$ Cabe preguntarse si estos saberes eran aplicados en función de controlar a otros trabajadores de la administración sanitaria o eran conocimientos con los que cualquier otro trabajador del área tuviera que contar. Este interrogante nos haría explayar temporalmente más allá de los límites de esta tesis, así que lo mantendremos en suspenso.

La materia Sociología y Legislación Social resultaba más extensa que la anterior. En ella se detallaban definiciones acerca de la sociología como los hechos sociales, las agrupaciones humanas y la historia de la propia disciplina. Estos contenidos ocupaban solo siete unidades de las veintiséis que componían la materia, las restantes estaban dedicadas a: legislación social, políticas sociales, legislación del trabajo, entre otras. También se mencionaban las particularidades de trabajadores del campo, trabajadoras mujeres, los derechos adquiridos por cada grupo, las particularidades de las leyes

${ }^{125}$ Universidad Nacional de La Plata, Facultad de Ciencias Médicas. Escuela de Visitadoras de Higiene Social. Programas de Tercer año. La Plata, 1948. pp. 7-8. 
emitidas para cada grupo, las indemnizaciones, las funciones de los tribunales de trabajo, las jubilaciones y los seguros de trabajo. Resulta interesante que aquí se hace evidente el acrecentamiento de tareas y funciones que tendrían las visitadoras en relación a una mayor ampliación de políticas sociales destinadas a los y las nuevas trabajadoras.

Por último, otra materia que se sumaba al nuevo programa fue Elementos de Nutrición, en la cual se destacaban las diferencias entre alimentos, las calorías necesarias en cada momento de la vida y las distintas composiciones químicas de la comida, etc. La aparición de esta materia en particular, ya no como parte de la economía doméstica y el servicio social, o de la materia puericultura como aparecía en el Plan de Estudios de 1938, se debe al gran interés que cobró la nutrición durante la década de 1930, hecho que incluso se consolidó en el campo de las ciencias auxiliares de la medicina a través de la creación de la Escuela de Dietistas en 1935. ${ }^{126}$ Por otro lado, había un claro interés desde el gobierno por ampliar las políticas de consumo y el acceso a bienes para la totalidad de la población, en particular para la alimentación, hecho que se vio reflejado no solo en las políticas salariales para la participación en el mercado interno, sino también en la promoción y difusión de estos saberes de los que serían parte las visitadoras de higiene social, y del que también formaban parte programas radiales que alentaban al consumo saludable de productos nacionales. Ejemplo de ello es la actuación que tuvo la famosa ecónoma doméstica y cocinera Doña Petrona de Gandulfo, quien desde Radio el Mundo se ocupaba de promover la compra de los recortes de carne que no eran absorbidos por el mercado extranjero o incluso, cuando era necesario, alejaba a sus oyentes del consumo de carne y trigo en los momentos en que resultaba más requerido por el mercado externo (Pite, 2016, pp. 113-118).

A partir de esta reforma del plan de estudios encontramos elementos comunes en la extensión de las tareas que realizarán las visitadoras, pero también se hace evidente el carácter político de su función dado que el nuevo gobierno necesitará tecnificar aun más sus funciones. Es decir, con el cambio en la política de intervención por parte del Estado, las visitadoras tuvieron que cubrir una mayor cantidad de problemáticas que se desprendían de una nueva concepción de la asistencia social que pretendía una mayor

\footnotetext{
${ }^{126}$ Para mayor información acerca de los alcances y objetivos presentes en la creación de la Escuela de Dietistas se sugiere la lectura de Buschini, J. (2016) "Surgimiento y desarrollo temprano de la ocupación de dietistas en Argentina", Avances del Cesor, XIII (15), 135-156. Recuperado de: http://web2.rosarioconicet.gov.ar/ojs/index.php/AvancesCesor/index
} 
integración de los sectores sociales largamente abandonados, del mismo modo en que necesitaba controlar a los grupos que podían generar algún desorden social.

\subsection{El currículo oculto de la EVHS}

"Se abstenga de concurrir a clases y trabajos prácticos hasta tanto las autoridades correspondientes tomando la resolución pertinente en salvaguarda de la indiscutible ejecutoria moral que debe ostentar la visitadora de higiene social egresada de esta universidad"

Dr. Orestes Adorni

El Decano de la Facultad de Medicina, Dr. Orestes Adorni, escribió así su preocupación acerca del porvenir de las estudiantes de la EVHS en 1939. En el mes de septiembre, la estudiante María Isabel Gómez tomó renombre en la escena universitaria ayudada por los medios locales que se hicieron eco de sus acciones en el ámbito de su vida personal. Esta joven que se encontraba cursando el segundo año de formación para visitadora de higiene "pretendió atacar a balazos a su novio presa de un ataque de nervios"127, según titulaba el diario. Por los relatos que se recogían en los matutinos, este "hecho de sangre" era producto de una discusión incidental. Como dice el Diario "El Argentino" en su edición del 9 de septiembre de 1939:

\footnotetext{
María Isabel Gómez sostenía desde hace tiempo relaciones amorosas con Luis Alonso, dos años menor que ella, pero igual a ella en lo que respecta a la fuerza de los sentimientos afectivos que los unía en los primeros tiempos de sus amores. Después por causas comunes en esta clase de relaciones era a las que ella le diera inusitada trascendencia, se enfriaron las relaciones [...] se renovó la vieja cuestión y Maria Isabel corrió al interior de su casa y se armó de un revólver con el que regresó dispuesta a dispararlo contra Alonso.
}

En el relato se describe una licenciosa relación amorosa por parte de Gómez y su amante, que de algún modo justificaría el desenlace agresivo de la relación. El hecho culminó con la madre de María Isabel herida por intentar intervenir y sacarle el arma a su hija, junto a la denuncia de los vecinos frente a la Asistencia Pública y la posterior detención policial de Gómez, quien "se lamentaba amargamente de las consecuencias de su incontrolada actitud". Lo cierto es que no sabemos de sus razones para disparar, aunque solo se cite un ataque de nervios.

\footnotetext{
${ }^{127}$ Diario El Día No 2016, 26 de setiembre de 1939.
} 
Este hecho generó temor en las autoridades de la Facultad de Ciencias Médicas que pidieron el pronto desplazamiento de la estudiante que formaba parte de la UNLP a fin de que no propague estos hábitos confrontativos al poder patriarcal. De alguna manera, la institución educativa debía facilitar la reproducción ideológica de la diferencia sexual junto con el rol subalterno de la mujer en la sociedad, pero también como profesional del ámbito sanitario, y acorde a estos fines, decidió expulsar a quien contradecía tal estructura de poder.

Es innegable que la moral de las estudiantes formó parte de un currículo oculto de la EVHS. Mediante la expulsión de Gómez se trataba de ejemplificar cómo debía ser la ejecutoría moral de las estudiantes, más allá de que entre los requisitos para ingresar estuviera un certificado de buena conducta, junto con otras exigencias para la entrada como eran: la cédula de identidad, tener más de dieciocho años de edad y presentar un certificado de buena salud y sus vacunas. ${ }^{128}$ De acuerdo a lo planteado por Fernández y Hernández (2014), la moral operó a principios del siglo XX en Argentina como un modo de imponer la alteridad y organizar los límites de la nación a través del establecimiento de una cultura urbana y civilizada. Para estos autores el "otro" no era el extranjero en sí mismo, sino un extranjero moral, o sea, aquel que no acataba las sutiles intervenciones del Estado y la opinión pública respecto de cómo vestirse, actuar, caminar, hablar, etc. (pp. 133-134).

Las estudiantes no sólo debían cumplir con las certificaciones institucionales, cada especialidad requería de una instrucción previa particular, como ya hemos mencionado con antelación. Dezeo (1938) consideró que estas auxiliares sanitarias debían formarse con "técnicas para el estudio y solución de la realidad social a fin de acrecentar la eficacia del esfuerzo, no malgastando energías en soluciones intuitivas, incompletas" (p. 3). Lo que se esperaba de la acción de las visitadoras era que fueran insistentes, fuertes, constantes como una ola que no detiene su marcha para el saneamiento de conflictos sociales y sanitarios; pero a su vez, que sean suaves y angelicales a fin de lograr su objetivo. Tal representación evidencia el uso de la fuerza de trabajo de las mujeres de una manera en que no se distingue el tiempo de la acción y su función es tomada al extremo, como un tiempo de insistencia que no se detiene hasta lograr la modificación de una roca, dando cuenta del carácter infravalorado de las acciones de las mujeres, a quienes se les solicitaba "ignorad las horas para hacer el bien".

Estos objetivos se plasmaron de distintas maneras en el Plan de Estudios y la Ordenanza de Creación de la EVHS en 1938, donde también se explicitaron las funciones que se

\footnotetext{
${ }^{128}$ Ordenanza de creación para la Escuela de Visitadoras de Higiene Social, año1938.
} 
asignarían a las graduadas y las estrategias que permitirían garantizar el carácter feminizado e infravalorado de la profesión y a su vez, difundir estereotipos de género hegemónicos al interior del espacio doméstico.

La expulsión de Gómez resultó un ejemplo de las expectativas sobre las mujeres a principios de siglo, como así tambien de las visitadoras de higiene. Sin embargo, el orden moral de las relaciones sexo afectivas privadas apareció como parte del currículo oculto.

Este caso no fue el único en el que se sancionaba a las estudiantes. Otro ejemplo interesante lo constituye la negativa expresada desde la Dirección del Colegio de Señoritas Liceo Víctor Mercante, donde funcionaba la EVHS, para la realización de eventos culturales y festivos propuestos por el incipiente Centro de Estudiantes de Visitadoras de Higiene. ${ }^{129}$ Las estudiantes mediante una carta de puño y letra solicitaban el salón del Colegio Liceo Víctor Mercante para desarrollar allí un evento festivo, pero la respuesta fue rotundamente negativa aduciendo que no tenían noticia de la existencia del centro, a pesar de que en la misma nota reconoce haberse reunido con quien se identifica como la presidenta. En otra nota de puño y letra, la secretaria del Colegio expresa su posición diciendo "no se les permite efectuar reuniones en el local del Colegio [...] este solo queda circunscrito al desarrollo de las clases". Propone en su lugar que se reunieran durante las horas de clase en los laboratorios, o que pidieran a los docentes y el Director de la EVHS que diera noticias de la existencia de este centro de estudiantes. Hecho que no pudo constatarse en las fuentes puesto que esas cartas eran parte del archivo del Liceo y no de la Escuela.

Si bien desde el diseño curricular y el dictado de clases ambos curriculums operaron en función de mantener el control y disciplinamiento de las estudiantes, no resultó tarea sencilla que las visitadoras fueran ángeles de piedad, incluso en los pocos registros escritos que poseemos de estas mujeres podemos encontrar algunos intentos por desafiar la estructura de poder establecida en las profesiones médicas.

En el próximo y último capítulo ahondaremos en las posibilidades de resistencia y agenciamiento frente al poder galeno que establecieron las estudiantes y graduadas a través del estudio de sus funciones como radioconferencistas.

\footnotetext{
${ }^{129}$ Carta del Centro de Visitadoras de Higiene Social dirigida a la Vicedirectora del Colegio de Señoritas, 8/8/1939, y Carta de respuesta a la nota enviada por el Centro de Visitadoras de Higiene Social firmada por la vicedirectora.
} 


\section{PARTE III: Las visitadoras de higiene social: entre el conservadurismo de la teoría y el reformismo de la práctica}

\section{Capítulo 4: Acciones de solidaridad, complicidad y agenciamiento}

A lo largo de los capítulos anteriores abordé la necesidad de los hombres que instrumentaron la medicina preventiva y el higienismo en Argentina - puntualmente en la ciudad de La Plata- por expandir la educación sanitaria del pueblo, con el fin de lograr la modificación de hábitos y conductas que resultaran peligrosos para el control social de los sectores populares y trabajadores, poniendo especial atención en las mujeres. La intimidad y la dedicación que exigía la modificación de hábitos y costumbres parecían exceder el ámbito exclusivamente sanitario, por lo cual los médicos buscaron formar un agente exclusivo capaz de conjugar saberes técnico instrumentales junto con dotes amorosos, morales y de abnegación que, sin exigir estipendio alguno y menos aún tener la osadía de desafiar al poder galeno, se formaran como agentes del servicio social y sanitario.

El carácter feminizado y subyugado a la ciencia médica varonil con el que se pretendía formar a las visitadoras de higiene social no fue analizado críticamente desde los estudios que abordan la historia del Trabajo Social. En gran parte de trabajos nacionales realizados por trabajadores sociales se destaca la creación de la EVHS como un hito transicional en la institucionalización de la carrera, entendiendo que la misma fue fundada para atender a las necesidades de la medicina preventiva (Alayon, 1978; Parra, 1999; Rozas Pagaza, 2001; Carballeda, 2006). El inicio de la carrera también fue interpretado como respuesta ante posibles conflictos sociales generados por la organización colectiva de quienes no podían garantizar su reproducción cotidiana (Oliva, 2007). Si bien esta propuesta se alinea con la perspectiva teórico crítica y evidencia las vinculaciones de las antecesoras de las visitadoras de higiene con las demandas colectivas por mejorar las condiciones de subsistencia (como inspectoras municipales, monjas, damas de caridad, entre otras), no problematiza el carácter feminizado de la profesión. Un aporte sustancial en este sentido fue realizado por la antropóloga Estela Grassi (1989), quien asumió el desafío de comprender las funciones de las mujeres en la historia de la asistencia social, aunque de manera similar a los autores anteriores su estudio estuvo centrado en la capital nacional. En los últimos años 
otras historiadoras y trabajadoras sociales dieron cuenta del desarrollo histórico de la profesión enalteciendo la participación de las mujeres, sus modos de intervención regional (Di Liscia y Billorou, 2005), rescatando a su vez a las principales figuras del servicio social anglófono como Mary Ellen Richmond, Gordon Hamilton y Helen Harris Perlman (Travi, 2006).

Estos trabajos -ya mencionados en la introducción- que iluminan y dialogan con esta tesis aportan elementos para pensar cómo la profesión fue asociada a supuestas características amorosas, disciplinantes y moralizantes, y el modo en que sus labores de prevención y profilaxis cumplieron con lo establecido por los médicos. Sin embargo, estas investigaciones hacen caso omiso de otras acciones disruptivas, creativas y de agenciamiento propias del quehacer profesional de estas mujeres, como también de su compromiso con las personas con quienes trabajaron. Esto establece otro problema ya expresado en la introducción, como es el hecho de considerar exclusivamente el carácter conservador al momento inicial de la profesionalización y obturar con ese presupuesto una reflexión de mayor alcance que evidencie las disputas ideológicas de los diversos equipos docentes que formaron las EVHS. Pero sobre todo niega la experiencia de las propias profesionales en la definición de los contornos de la disciplina. Considero que estas interpretaciones producen una visión homogénea del proceso y borran otras experiencias de intervención profesional comprometidas con proyectos político sociales con antelación al período de la reconceptualización teórica de la profesión.

Por ello, en este último capítulo pretendo desestabilizar los supuestos con que se aborda este período de la profesión e indagar sobre las diferentes disrupciones al discurso disciplinante y feminizante sobre las visitadoras. Con esta operación pretendo modular un relato que potencie las acciones de resistencia y prácticas de agenciamiento frente a las expectativas médicas esperables en su desempeño laboral. Es decir, articular lo que Michael Foucault (2008) consideró un modo arqueológico de abordaje que permita incluir y comprender aquellos elementos excluidos de los grandes relatos, como interrupciones, errores y contrariedades para poner en suspenso el carácter dominante de los discursos médicos producidos por varones desde una voluntad de verdad que solapó los propios discursos y representaciones producidas por las visitadoras de higiene social. En este capítulo las voces que ocuparán el centro de la escena no son las de los médicos, sino la voz de las propias visitadoras de higiene, quienes mediante la escritura de radioconferencias dan cuenta de su propio desempeño profesional, los modos en que comprendieron su intervención, cómo percibían a los sujetos beneficiarios de las políticas sociales, entre otras cuestiones. Especialmente, veremos los intentos de 
interrumpir las propuestas de los médicos que pretendían la formación de agentes “dóciles" y conservadoras.

Para este reconocimiento serán fuente de análisis las voces de las profesionales en su desempeño como radioconferencistas en las dos principales radios de la ciudad de La Plata y con gran alcance en la región: Radio Provincia LS 11 y Radio Universidad LR 11, donde tuvieron la posibilidad de disertar sobre su práctica laboral y ensayar discursos que alentaron a la complicidad con otras mujeres de la región. También abordaré informes técnicos realizados por las visitadoras dentro del Club de Madres, institución vinculada al Partido Socialista y a la militancia por la reforma universitaria. Las pretensiones de este apartado no se limitan a revalorizar las acciones de las primeras visitadoras de higiene social, sino que se procura, desde los aportes de los estudios de género, revisar las relaciones de poder establecidas en el ámbito sanitario, y analizar cómo las discursividades formuladas por las propias visitadoras sirven para cuestionar los intentos de regulación del género femenino en el proceso de profesionalización. Mediante la producción de saberes que generaban estas mujeres resultaron nuevos espacios de producción y reproducción de conocimientos que tensionaron la pretendida masculinización del campo médico y dieron lugar a prácticas de agenciamiento. En este sentido, Thomas Lynn (2016) considera el agenciamiento como una clave para comprender las prácticas y experiencias que posibilitan pensar las acciones de mediación, resignificación y resistencia de los sujetos autónomos dentro de las situaciones y status de los espacios que ocupan. Con ello, la agencia no sería entonces un argumento concluyente y totalizante, sino un elemento de análisis que posibilita la emergencia de acciones ignoradas.

\subsection{El paisaje sonoro local}

Las labores educativas de las visitadoras no se limitaron a la acción pedagógica en los hogares, en las escuelas y en los centro de atención sociosanitario. Las visitadoras también fueron parte de la difusión educativa mediante la radiofonía. La difusión radial se presentó como un fenómeno de masificación de la información que colaboró en la homogeneización cultural desde la década de 1920 y para los años '40 ya tenía una amplia presencia en las viviendas urbanas. Entre los medios de comunicación masivos ocupó un lugar de privilegio puesto que su alcance llegaba incluso a quienes no tenían intenciones o posibilidades de informarse a través de la lectura, por lo que colaboró en el proceso de integración nacional al comunicar a los habitantes del campo y la ciudad. En 
1920 se había realizado la primera transmisión experimental del país que colocó a Argentina entre los países de avanzada en la radiodifusión mundial. Años más tarde, con la inclusión del parlante las trasmisiones alcanzaron a una mayor audiencia, así dos décadas después la radio pasó a ser un artefacto familiar en los hogares, e incluso se estima que había una radio cada diez habitantes, indicando que la llegada de estas trasmisiones tenía un alto alcance (Torre y Pastoriza, 2002, pp. 269-270). Las mismas colaboraron en la difusión de prácticas, costumbres e imaginarios que no estaban tan difundidos en las áreas más alejadas de las urbes, lo que convocaba a la identificación con una cultura nacional común.

La radio, junto con el cine y la música, fueron parte de un proceso de ampliación del consumo y de la cultura de masas que durante las décadas de 1920 y 1930 pusieron a circular posibilidades de conformismo como también fantasías de ascenso social. Más allá de cualquier carácter intencional o inocente, allí se desplegaron versiones de la identidad nacional que reproducían e intensificaban una cultura de clase. Tal como sostiene Mattew Karush (2013), las radios divulgaban canciones de jazz traídas de Estados Unidos, y en el cine se difundían gran parte de las películas de Hollywood, sin embargo, los productores culturales argentinos intentaron competir con un nacionalismo defensivo y una nostalgia localista, que promoviera e incitara al consumo, emulando los estándares técnicos y estilísticos norteamericanos (pp.19-26).

En la búsqueda por fomentar una cultura de masas nacional, Karush sostiene que las únicas practicas culturales que podían ser rediseñadas como exclusivamente argentinas eran las de los pobres por contraposición a los ricos que representarían una cultura transnacionalizada. No obstante, como veremos más adelante, este proceso por implantar una cultura común no resultó homogéneo presentando incluso mensajes contradictorios, tal como sucedió con las radioconferencias de las visitadoras.

La radio, en particular, facilitó el ingreso incuestionable en los hogares puesto que, sin necesidad de solicitar una visita o ingresar por algún control sanitario, las voces se mezclaban en el paisaje sonoro doméstico. En la ciudad de La Plata, distinguida desde su fundación por el carácter moderno de sus instituciones, se construyeron dos radios de amplio alcance nacional que, a diferencia de las otras radios del país mayormente dedicadas a la transmisión de publicidades y entretenimientos, tenían por objetivo la difusión política y científica.

En el año 1924 se creó la Radio Universidad LR11, dependiente de la Universidad Nacional de La Plata y reconocida por ser la primera radio universitaria del mundo y la segunda radio del país. Acorde al proyecto reformista de los y las estudiantes que 
componían la casa de estudios, su principal tarea era convertirse en un elemento de extensión para la enseñanza, la investigación y la divulgación científica y cultural, hecho que la distinguió como una promotora del conocimiento científico a través de la voz de los propios actores de la sociedad científica que tendieron puentes con la comunidad, y también entre docentes y alumnos (Antonucci, Beneitez, Gabay y Turconi, 2009, p.19).

Si bien comenzó con una pequeña antena que operaba de manera experimental y como herramienta de educación popular, era considerada una oportunidad para devolver al medio social lo que hacía para sostenerla. En principio funcionaba de manera experimental en su circuito de transmisión moderado entre las facultades de la UNLP, difundiendo solamente las conferencias realizadas en la universidad. Este alcance fue ampliado en 1933 por el entonces presidente de la UNLP, Ricardo Levene, quien creó la Comisión de Transmisiones por Radiotelefonía a fin de ponerla al servicio de un plan orgánico que facilitara la tarea de difusión $\mathrm{y}$, un año después, inició un plan de inversiones para modernizar el aparato transmisor. Aun así, durante los primeros años la radio funcionó ocasionalmente, incluso durante algunos años se transmitió una sola conferencia al año. En el año 1944 fue cerrada por decisión del gobierno nacional de Edelmiro Farell y vuelta a su frecuencia habitual en el año 1948, momento en que comienza a emitir dos horas diarias de radio.

La radio universidad no fue la única de la región. En el año 1937, el gobernador conservador Manuel Fresco fundó Radio Provincia LS11 con el objetivo de establecer una herramienta de gestión. Hasta el momento no existía una radio oficial a nivel nacional, pero con la intervención del Ministro de Gobierno Roberto Noble (quien luego fundó el diario Clarín) se organizó en forma definitiva el servicio oficial de Radiodifusión por el decreto provincial № 51 en marzo de 1937, que constituyó a la Radio Provincia como el primer broadcasting oficial del Estado Argentino con dependencia de la Dirección de Correos y Telégrafos de la Nación. ${ }^{130}$

A través de la radiodifusión, el gobierno de Fresco realizó propaganda partidaria, reemitió programas de difusión nazi, e incluso discursos del mismo Adolf Hitler con el objetivo de utilizar los artilugios de la comunicación moderna y con ello colocar en un rol protagónico del paisaje sonoro sus lemas de disciplinamiento social y la defensa de Dios, la Patria y el Hogar. Además de las pretensiones de la radiodifusión oficial, se

\footnotetext{
130 Jara, Juan Carlos; Bosaro, Leopoldo (1997) LS 11 Radio Provincia. 60 años. La Plata. pp. 3. Vale aclarar que en el mes de julio del mismo año, el Presidente Agustín P. Justo funda la Radio del Estado, actualmente Radio Nacional. Ver: Ulanovsky, Carlos (2004) Días de radio. Buenos Aires. Espasa Calpe.
} 
buscaba generar el contacto con todos los habitantes de la provincia para informarles de la gestión administrativa, contribuir al desarrollo de la cultura y brindar esparcimiento con un elevado criterio artístico que se alejaba del lenguaje chabacano y arrabalero, que incluso podía ser censurado (Jara y Bossaro, 1997, pp.6-8). Esta radio, al igual que la dependiente de la UNLP, tampoco contaba con financiamiento comercial y por dicha razón durante largos períodos no contrataba profesionales para su programación, lo que limitó su programación a la transmisión de música clásica para la cual contaba con una amplia discoteca reconocida a nivel sudamericano.

Estas dos radios de amplio alcance en la región tenían propuestas claramente diferenciadas. La Radio Universidad apuntó a la difusión de la cultura y el conocimiento universitario, y la otra, funcionó como herramienta de gestión de gobierno. Resta indagar sobre la relación entre la creación de Radio Provincia como parte de la oposición que existía entre Fresco y la universidad, a la que consideraba un foco de subversión comunista plagado de indiferencia patriótica. Aun así, y dejando esta inquietud para otro análisis, cabe destacar que ambas emisoras se ocuparon de difundir conferencias realizadas por agentes del ámbito sanitario, donde participaron tanto médicos de la EVHS como estudiantes y graduadas con el fin de difundir algunos preceptos básicos de higiene.

\subsubsection{Voces femeninas en el paisaje sonoro}

Durante los primeros años de radiodifusión en Argentina, las mujeres tuvieron una participación que podríamos considerar desafiante. En principio, porque el hecho de participar en el paisaje sonoro, en el universo auditivo particular situado espacial y temporalmente, implicó la emergencia de una tonalidad que no predominaba en el ámbito público, un sonido disonante que con antelación no contaba con semejante audibilidad. Es decir, las voces que eran más oídas en el espacio público eran las de los hombres, quienes tenían la potestad y garantía cívica para la participación pública y política.

Christine Ehrick (2015) señala que la participación de las mujeres en las radios de Argentina y Uruguay permitió trastocar los espacios tradicionales de género y las demarcaciones entre los espacios público y privado, colaborando en un proceso de reformulación y renegociación de las relaciones entre los géneros, y además otorgó un lugar de encuentro entre las que hablaban y eran oídas. De esta manera, la autora destaca que a través de la radio las mujeres podían combinar sus quehaceres domésticos 
y combatir el aislamiento característico de la época, invitando a las féminas a una comunidad más amplia de vida moderna y esfera pública (pp. 2- 4).

El hecho de intervenir el éter radial invitó a reconfigurar la relación entre lo público y lo privado, especialmente en un momento de expansión del Estado y de crecimiento del movimiento feminista en Argentina, donde las mujeres interrumpieron la univocidad del paisaje sonoro masculino (Ehrick, 2015, pp. 13-15). Algunas visitadoras se valieron de su lugar de difusoras de la educación sanitaria y trabajadoras de la prevención para irrumpir en el silencio de las mujeres a través de la enseñanza de conceptos de higiene así como también de los conocimientos producidos por sus experiencias profesionales con el objetivo de acercar a las mujeres a una comunidad científica favorable a su vida cotidiana, e incluso alertarlas acerca de las mejores condiciones de vida que podían exigir. Este hecho resulta más destacado aún puesto que a medida que avanzaba la década de 1930 y las actividades de la radio se profesionalizaban, la participación de las mujeres en clave política o intelectual resultaba fuertemente cuestionada por los varones, quienes se presentaban como los difusores de dicha información (Ehrick, 2010, pp. 75$83)$.

El peso de la división sexual del trabajo en el ámbito sanitario, junto con las prerrogativas por hacer de las visitadoras ángeles de piedad, se conjugaba con el interés de los médicos higienistas para que las visitadoras dedicaran todos sus esfuerzos en modificar los hábitos de los sectores populares, sobre todo mediante la educación de las madres. No obstante, desde esa atribución laboral las visitadoras pudieron configurar un lenguaje particular para mediar las representaciones e intenciones del mundo profesional médico con la situación particular de las mujeres que las oían. Estas mujeres pudieron valerse de su lugar como intermediarias sanitarias para negociar los postulados coercitivos de la ciencia médica con un lenguaje ameno y estimulante que, si bien podía acordar con las prescripciones médicas, también invitaba a las oyentes a acercarse a una comunidad ampliada de beneficios sociales y políticos, como veremos a continuación.

Es interesante indagar en la acción de las visitadoras como intermediarias sanitarias puesto que rompe la lógica verticalista y unidireccional con que suelen considerarse las tareas de estas profesionales. La noción de intermediaria sanitaria construida por Gudiño Cejudo (2015) alude al espacio de autonomía y creatividad que tienen las profesiones auxiliares del ámbito sanitario, resultado de un carácter intermedio por el lugar ambiguo producto de una ubicación particular entre el grupo de los dominadores, en tanto profesionales sanitarias, $\mathrm{y}$, como partícipe del mundo de los dominados, en tanto mujer desprovista de derechos políticos y salarios equitativos a los hombres. En su función 
como agentes de circulación podían ser tanto guardianas de las ideologías dominantes como voceras de revueltas entre los sectores populares a los que "instruían" y con los que tenían contacto, e incluso de los que podían ser parte.

Mediante el estudio de las acciones de difusión radial de las visitadoras podemos encontrarnos con la enunciación de estas profesionales que, en primera persona, exponen su acción profesional. El acceso a estas radioconferencias fue posible por dos motivos distintos: en el caso de las radioconferencias de la Radio Universidad, fue posible la conservación de las mismas por la política de publicación y divulgación científica de la UNLP que se encargó de editar un año completo de las conferencias del programa "Educación Sanitaria Popular y Propaganda higiénica", e incluso aquellas que no fueron emitidas eran publicadas en la Revista de la Facultad de Ciencias Médicas y Centro de Estudiantes de Medicina, órgano de difusión estudiantil y de graduados, donde tuvo gran importancia el Dr. Alberto Zambosco. Estas radioconferencias se habían iniciado en el año 1937, y Pilades Dezeo fue uno de los principales propulsores de esta estrategia comunicativa siendo la radio un medio esencial para la extensión universitaria. ${ }^{131} \mathrm{Si}$ bien en los inicios de las radioconferencias nos encontramos con la participación de estudiantes de 5to y 6to año de la carrera de medicina, hay una mujer que es estudiante de la carrera, Alfina Copani, quien luego también se formará como visitadora de higiene social. Las radiconferencias que aquí analizaremos se destacan por formar parte del mismo ciclo aunque con la presencia de las visitadoras y otros médicos vinculados con los aspectos legales del área. El objetivo de este espacio radial era aproximar la cultura universitaria a los sectores populares, considerados por el ámbito científico como “ignorantes" y, por ello mismo, peligrosos, y sobre todo pretendía abocarse a los problemas de "madres e hijos, débiles y desvalidos"(Zambosco, 1942, p.6). A diferencia del espacio radial dedicado a la educación sanitaria de la Radio Provincia LS11, cuya única preocupación versaba sobre la prevención y lucha contra la tuberculosis, éste estaba dedicado a una serie de problemáticas, a saber: I. Problemas de maternidad e infancia, II. Asistencia social, III. Medicina preventiva, IV. Higiene y medicina social, V. Enfermedades trasmisibles, VI. Industrialismo y VII. Aspectos médico-legales. Hubo tres áreas de conferencias donde solo disertaron hombres: industrialismo, aspectos médicos legales y medicina preventiva. No es casual tal exclusión, como dijimos anteriormente, esto es parte de cómo se tradujo la división sexual del trabajo en las áreas

\footnotetext{
${ }^{131}$ Revista de la Facultad de Ciencias Médicas y el Centro de Estudiantes de Medicina. Julio, 1937. No 5. pp.109-110.
} 
auxiliares de la medicina, donde las mujeres debían abocarse a tareas que las contactaran entre ellas.

El objetivo de estas radioconferencias no sólo era difundir y traducir la palabra médica a fin de desarraigar conocimientos no científicos y sumarse a la cruzada por centralizar el poder legítimo en el discurso médico, otra de las pretensiones era clasificar aquellos saberes y prácticas que resultaban científicos y los que no. Por ello, mediante la lucha por la prevención de enfermedades sociales se daban a conocer las instituciones sanitarias disponibles para cada problemática específica, con el propósito de restarle fuerza a otros cuidados vinculados al curanderismo.

El otro ciclo radial aquí analizado se diferencia del anterior no solo por los objetivos que tenía cada radio, sino porque estaba organizado por la Comisión de Propaganda Higiénica y Educación Sanitaria Popular de la Liga Popular contra la Tuberculosis de la Provincia de Buenos Aires (LPTPBA), también a cargo del ex referente reformista, el Dr. Alberto Zambosco. Respecto a la conservación de estas radioconferencias no es claro si fueron transcriptas y conservadas por la LPTPBA como parte de una política archivística, o pudieron ser guardadas producto de haber sido objeto de control y censura dentro de la Radio Provincia.

Este ciclo radial surgido en 1939 pretendía difundir las estrategias de lucha contra la tuberculosis por medio de disertaciones sobre la prevención y tratamiento de esta enfermedad. La tuberculosis estaba cargada de significados que excedían lo patológico y la acercaban a una "plaga social", vista por los sectores gobernantes como el origen de la supuesta decadencia material y espiritual de la sociedad (Armus, 2007, p.16). Esta enfermedad pulmonar propagada por el bacilo de Koch circula en todos los ambientes, especialmente en aquellos poco ventilados, con insuficiente iluminación y húmedos, que permiten al bacilo reproducirse con mayor facilidad. Los espacios más frecuentes eran instituciones de encierro, cárceles, fábricas e incluso las viviendas familiares, viéndose afectadas principalmente las casas de sectores populares y trabajadores, dado el hacinamiento en el que vivían por sus condiciones precarias de subsistencia. Desde fines del siglo XIX, se sabía que esta enfermedad era transmisible y no hereditaria, por lo tanto el Estado y otras organizaciones sociales no gubernamentales como la LPTPBA buscaron difundir información acerca de cómo evitar su transmisión y lograr espacios más higiénicos. Por ello, no es casual que este ciclo de conferencias se trasmitiera en la Radio Provincia LS11 que, como anteriormente presentamos, tenía por objetivo difundir las acciones del gobierno como también desterrar las supuestas costumbres perniciosas 
y, en especial, disciplinar a los sectores más renuentes a aceptar la consigna de "orden, disciplina, jerarquía” del gobernador Manuel Fresco (Reitano, 2005, pp. 30-32).

En las radioconferencias de este ciclo participaban médicos, personajes de la política local, referentes del periodismo de la ciudad de La Plata, estudiantes y graduadas de la EVHS que trabajaban sobre la problemática de la tuberculosis en preventorios y en escuelas. Así, las visitadoras llevaban adelante su principal función, a saber: realizar propaganda sanitaria y educación popular en materia de higiene y medicina preventiva con el objetivo de difundir hábitos higiénicos y atraer al individuo y a sus familias a los preventorios de atención contra a tuberculosis. Para obtener éxito en su desempeño se valían de un lenguaje lo más ameno posible, que vulgarizara el conocimiento científico y, a su vez, persuadiera al público de acercarse al dispensario sanitario. Esta última característica era compartida con la estrategia que asumían los estudiantes reformistas de la Facultad de Ciencias Médicas de la UNLP, enfatizando el carácter de la conferencia: "se hablará preponderantemente de etiología y profilaxis, prestándoles atención a la sintomatología funcional que pueda ser conocida por el público, empleando siempre una terminología sencilla y popular". ${ }^{132}$

En sintonía con el proyecto de los estudiantes reformistas y también con el de los médicos higienistas por vulgarizar el conocimiento científico, las visitadoras irrumpieron en el espacio radial para dar cuenta de su quehacer como educadoras sanitarias y de prevención, pero también para desestabilizar el orden de género que las pretendía como ejecutoras de una moralidad dominante y ensayar acciones de persuasión, complicidad y solidaridad con otras mujeres en un contexto donde carecían de derechos políticos. En este sentido, la radio les facilitó presentar algunas contradicciones entre las condiciones sociales y políticas en que vivían, y las posibilidades de reformar y trastocar situaciones individuales y colectivas.

\subsection{La persuasión del público como estrategia de intervención}

Delia Gordon, visitadora de higiene escolar egresada de la EVHS- UNLP, tituló su disertación del día 19/1/1940 en la Radio Provincia del siguiente modo: "La tuberculosis es una enfermedad curable y evitable". Su exposición formaba parte de las políticas de difusión llevadas adelante por la Comisión de Propaganda Higiénica y Educación Sanitaria Popular de la LPTPBA.

\footnotetext{
${ }^{132}$ Revista de la Facultad de Ciencias Médicas y Centro de Estudiantes de Medicina, julio, 1937, nº.
} 
La insistencia en que la tuberculosis era una enfermedad evitable y curable fue uno de los enunciados desde el que se posicionaron las visitadoras para desterrar los temores de herencia de la enfermedad, lograr la atención de sus oyentes y alertar sobre la necesidad de iniciar acciones cotidianas y cambios de hábitos para cuidar al conjunto de la población. Especialmente, apuntaron a los sectores populares. Por ejemplo, la visitadora Elida Sciani en su conferencia "Concepto general de lucha antituberculosa. Recursos económicos y profilaxis antituberculosa", sostuvo: "Que por ignorancia, dejadez o miseria la más de las veces, es donde el mal encuentra el cultivo, razón por la cual se debe provocar la intervención de los poderes públicos en la lucha contra la tuberculosis" (Sciani, 1940, Conferencia no 46 26/2/1940, p. 460).

La idea de asociar la ignorancia a los sectores populares se trasladó a los oyentes, a quienes, en cada una de las disertaciones, se volvía a explicar la historia de la tuberculosis y cómo repercutía en su salud. Por ese motivo, en su disertación "La tuberculosis es una enfermedad evitable y curable", Delia Gordon detalló: "El mi- crobio: micro que quiere decir pequeño, bio: que quiere decir vida. Tan pequeño que su tamaño es de dos o tres milésimas, no obstante para ser tan pequeñito sabe seleccionar sus víctimas" (Gordon, 1940, Conferencia no 45 19/ 02/1940. p. 354).

Sus discursos tuvieron un carácter propedéutico, cargados de explicaciones minuciosas que intentaban concientizar a los y las oyentes acerca del contagio de la enfermedad. Existió una pretensión de persuadir al público a través de los detalles con que argumentaron las problemáticas presentadas, que de alguna manera intentaban generar temor respecto de este microbio "tan pequeñito".

Desde su rol educativo como conferencistas las visitadoras se ocuparon de persuadir al público a través de dos mecanismos. En principio, como ya hemos dicho, con la explicación reiterada y pormenorizada de la enfermedad que se presentaba como un peligro inminente pero evitable en cada conferencia, y, por otro lado, a través de la descripción exhaustiva del trabajo que realizaban ellas y los médicos dentro de los dispensarios para mostrar la conveniencia de acercarse y evitar "males mayores". Así relató Nélida Tebaldi en la radio su experiencia como visitadora honoraria del Dispensario Central "Susana Araoz Alfaro", en la conferencia titulada "Cómo trabaja un dispensario de lucha antituberculosa":

Si se trata de un adulto que por primera vez concurre al Dispensario pasa al Consultorio de Adultos donde es recibido por la Visitadora quien inicia su función por un interrogatorio. Este interrogatorio le permitirá llenar una ficha llamada Primer Examen de Adulto: que consta de varias preguntas que se refieren a los datos de identidad personal: nombre, apellido, 
nacionalidad, profesión, etc, [...] Luego le interroga sobre los antecedentes familiares (Tebaldi, Conferencia No 50, 25/03/1940 p. 395-396) ) $^{133}$

Con este interrogatorio querían saber si había personas posiblemente infectadas en la familia o allegados, de modo que las preguntas sanitarias se extendían sobre aquellas personas con las que tenían vida íntima, sobre todo en los inquilinatos y las pensiones. A través de esta presentación detallada, Tebaldi intentó generar cierta confianza persuadiendo al público acerca de la "simplicidad" que suponía acercarse al dispensario. Es interesante que la labor de las visitadoras en tanto conferencistas y propagadoras de nuevos hábitos higiénicos (por ejemplo, se mencionan los modos en que debe trapearse el suelo para evitar que se levante polvillo y con él los bacilos de koch, o cómo debe hervirse la leche para evitar el contagio de tisis por la vía intestinal) no se limitó a persuadir sobre la inminencia de modificar sus costumbres, sino que también intentó promover la confesión de las prácticas cotidianas (si escupe, cómo lo hace, cuántas veces tose, si abre la ventana por la mañana, con quiénes vive, entre otras) a través del acercamiento al Dispensario y en los domicilios particulares, donde se relevaban datos sobre el nivel educacional del enfermo, la conducta moral, condiciones higiénicas de la casa y sus recursos económicos por medio de la Encuesta Social. En la detallada y extensa exposición de Tebaldi en la conferencia ya citada, explicitó cuál era uno de los objetivos de las visitas domiciliarias: "La visitadora debe tratar entonces de que concurran al Dispensario no solo el sospechoso, sino todas las personas que habitan la casa; venciendo las resistencias que se le opongan por medio de la persuasión" (Tebaldi, Conferencia $\mathrm{N}^{\mathrm{o}} 50,25 / 03 / 1940$ ).

La estrategia persuasiva apareció constantemente en las exposiciones de las visitadoras para convencer y familiarizar a la población sobre la importancia de acercarse al Dispensario dada la simplicidad del tratamiento y conveniencia colectiva de hacerlo. Es destacable el hecho de que las visitadoras hayan reconocido la persuasión como un modo de intervención en las visitas domiciliarias que les posibilitó lograr con éxito su labor. Esto nos permite considerar que las acciones de estas mujeres no se basaron exclusivamente en un vínculo afectivo y amoroso, sino que eran conscientes de su capacidad argumental y racional para convencer a la población de seguir sus propuestas de cuidados sociosanitarios.

133 En Comisión de propaganda higiénica y educación sanitaria popular, Liga Popular Contra la Tuberculosis de la Provincia de Buenos Aires, La Plata, 1940. 
Las visitadoras sabían que sus acciones médicas profilácticas no bastaban para el mejoramiento de las condiciones de vida de la población, por lo tanto, la radio operó como una tribuna desde la cual llamar la atención de quienes en principio no eran el público destinatario. La visitadora Elida Sciaini en su disertación "Concepto general de la lucha antituberculosa. Recursos económicos y profilaxis”, destacó:

Para preservar la infancia se debe procurar la buena alimentación general y la vivienda higiénica para todos, no solo debemos completar y ampliar la obra social de protección a la madre y al niño [...] deben generarse espacios de profilaxis indirecta, como leyes de trabajo, maternidades, cantinas maternales, casas aireadas, escuelas con inspección médica permanente, educación física adecuada, escuelas al aire libre (Sciani, 1940, Conferencia $\mathrm{n}^{\circ} 46$ 26/2/1940, p. 365).

Reparemos entonces, ¿con quién dialoga Sciaini en su conferencia? ¿Es al público "ignorante" de los sectores populares a quien exige ampliar la obra social, dar leyes de trabajo y garantizar escuelas al aire libre? Evidentemente no. Parece que haciendo uso del privilegio de tomar la voz en público y durante los minutos que duró su conferencia se permitió alentar a la reflexión de los hombres de política y de leyes que tuvieran a su alcance estas modificaciones de orden sanitario y habitacional.

Desde las radioconferencias las visitadoras se colocaron en un umbral que trastocó el espacio público y privado, reconfiguraron su posición "privada" y auxiliar a través de la interrupción en un paisaje que era mudo para las mujeres. Expresión de ello es la disertación "La tuberculosis, cómo se adquiere y cómo se evita" de Sofía Ricci, quien encendió el espacio radial de este modo:

Cada media hora muere un tuberculoso. Esta verdad debe preocuparnos a todos, al pueblo y a sus dirigentes [...] el problema no puede ser exclusivamente médico, que es en gran parte una cuestión social. Es por ello que el día que se procure a las masas humanas una buena alimentación, una mejor vivienda y el conocimiento de una serie de medidas higiénicas se habrá dado un gran paso hacia el exterminio de este terrible mal (Ricci, Conferencia $n^{\circ} 8021$ / 10/1940, p. 638-639). ${ }^{134}$

Este llamamiento a los dirigentes del país generó otra disonancia en el paisaje sonoro. Era una mujer exigiendo respuestas y soluciones para una enfermedad cuya solución no se limitaba a la intervención del médico, ni a las acciones que pudiesen tomar

134 En Comisión de propaganda higiénica y educación sanitaria popular, Liga Popular Contra la Tuberculosis de la Provincia de Buenos Aires, La Plata, 1940. 
individualmente las familias de los sectores populares, ni a los cuidados que pusieran las mujeres. Ricci extendió sus demandas a la clase dirigente, y con ello intentó acortar las distancias entre el espacio político masculinizado y el espacio de cuidados en el que se ubicaba a las féminas.

Las voces de las visitadoras de higiene invadieron el espacio radial con la autoridad de la experiencia como agentes del servicio social, con conocimientos sobre los tratamientos que se realizaban sobre las personas infectadas, sobre la alimentación de los niños, sobre las causas sociales de las enfermedades e incluso sobre cómo operaba cada instancia del Dispensario. Con la descripción de sus acciones pretendían persuadir a los distintos públicos a los que indicaron insistentemente la necesidad de realizar modificaciones en sus conductas, e incluso en sus estrategias políticas. En la enunciación de sus conocimientos y experiencias laborales podemos encontrar una búsqueda de la legitimación social de la nueva profesión que, más allá del rol auxiliar de los médicos, pudieron delinear saberes y prácticas específicas por lo que exigían audibilidad y atención. ${ }^{135}$ La estudiante Hortensia Moretti en su conferencia titulada "Ahorrar a costa de la salud es comprometer el porvenir biológico", lo planteó del siguiente modo:

Yo, como todas mis compañeras, puestas al servicio de la Nación para salvaguardar las vidas de nuestros semejantes, pedimos se escuchen y valoren todo lo que se dice y hace en vuestro favor, para ver coronados nuestros esfuerzos de ser útiles y de conseguir así, un pueblo sano y hacer una Nación floreciente (Moretti, Conferencia n ${ }^{\circ} 64$ 1/7/1940, p. 505). ${ }^{136}$

La joven estudiante irrumpió en la sonoridad radial para aclarar que sus acciones debían ser valoradas, requerían de un respeto e importancia por la población puesto que sus intervenciones y consejos hacían a la nación misma. El pedido de escucha demuestra que el acto de hablar en la radio no garantizaba ser oídas, como evidentemente podía suceder en sus visitas domiciliarias o en otras conferencias, pero se atrevió a exigirlo desde la radio mediante la justificación de su utilidad para el bienestar de la comunidad.

La intención de persuadir a la población para que se acercaran al tratamiento desde alguna institución sanitaria alcanzó a otro conjunto de preocupaciones más allá de la tuberculosis. Una de ellas era el bienestar materno e infantil, del que ya he mencionado

\footnotetext{
${ }^{135}$ Carlos Montaño (1998) indica que existen dos posturas diferentes acerca de la legitimidad en el trabajo social, una de orden funcional, caracterizada por la demanda que ejerce el Estado en consonancia con las necesidades de los sectores hegemónicos por garantizar su dominio; y otra de carácter social, que proviene del vínculo establecido entre la trabajadora social y el sujeto usuario al que se dirigen sus prácticas. Ver: Montaño, Carlos (1998) La naturaleza del Servicio Social. Un ensayo sobre su génesis, su especificidad, su reproducción, Cortez Editora, San Pablo.

${ }^{136}$ En Comisión de propaganda higiénica y educación sanitaria popular, Liga Popular Contra la Tuberculosis de la Provincia de Buenos Aires, La Plata, 1940, p. 505.
} 
su centralidad durante la primera mitad del siglo XX. En el primer grupo de conferencias trascriptas por la Radio Universidad, "Problemas de maternidad e infancia", nos encontramos nuevamente con Nélida Tebaldi quien, dos años después de las conferencias brindadas desde la LPTPBA, ocupó el cargo de jefa de clases prácticas de la materia Servicio Social en la EVHS. En esta ocasión, manifestó su preocupación acerca de las mujeres embarazadas que morían por su "incapacidad para sobrellevar la tremenda responsabilidad que su nuevo estado significa" (1942). ${ }^{137}$ Esta reflexión se vinculó con la preocupación por el binomio madre-hijo y el cuidado sobre las madres como parte de una cruzada por el futuro de la "raza" y, con ello, del progreso material y social de la Nación (Biernat y Ramacciotti, 2013). ${ }^{138}$ En esta conferencia desarrolló un análisis procesual acerca del tratamiento que debía tener una mujer embarazada, inicialmente con el seguimiento eugenésico de los padres previo a la gestación, luego con la descripción de los estudios generales en los consultorios obstétricos para, finalmente, luego del parto, presentar las utilidades de las maternidades con el fin de persuadir a las futuras madres sobre los beneficiosos de acercarse al centro de atención socio sanitario para un mayor cuidado e instrucción.

Las visitadoras en Radio Universidad disertaron como conocedoras de las problemáticas sobre las madres e hijos $\mathrm{y}$, con esta posición de autoridad desde el saber de su experiencia, generaron una operación por la cual nuevamente una vivencia de orden privado (como el cuidado de los hijos) era presentada al espacio público como una problemática general y no individual desde la que trazaron posibles confabulaciones con la audiencia femenina Así, la visitadora Nélida Tebaldi incluso cuestionó la problemática de los hijos ilegítimos y la responsabilidad de los padres y del Estado por asistir a esas madres, e incluso se atrevió a exigir que se modifique la legislación que calificaba a los hijos como ilegítimos sin intervenir sobre las responsabilidades paternas, en ese sentido sentenció "que se reconozca por la ley la maternidad de hecho y se disponga de una investigación de la paternidad" (1942). ${ }^{139}$

Al considerar la maternidad e infancia como problemas sociales y no como situaciones individuales y de orden exclusivamente doméstico, que concernían a las mujeres en general pero también a las autoridades sanitarias, las visitadoras ampliaron sus propuestas a distintos sectores sociales a través de la radio. En este sentido, Alfina

\footnotetext{
${ }^{137}$ Tebaldi, Nélida, "El amparo de la mujer en su condición de madre o de futura madre". En Educación Sanitaria y propaganda higiénica. Conferencias radiotelefónicas. Facultad de Ciencias Médicas. Cátedra de Higiene Médica y Preventiva, UNLP, La Plata, 1942, pp. 23- 32.

${ }^{138}$ Biernat, Carolina y Ramacciotti, Karina (2013) Crecer y Multiplicarse. La política sanitaria materno infantil. Argentina, 1900-1960, Buenos Aires, Biblos. p. 103.

139 Tebaldi, Nélida, "El amparo de la mujer...", Op. Cit., p. 29.
} 
Copani, visitadora de higiene social y secretaria de la EVHS, planteaba hipotéticas soluciones a la mortalidad materna en su disertación "La mortalidad materna y su profilaxis", como la siguiente:

Es necesario para ello crear una organización de asistencia y previsión médico-social que beneficie a todas las madres de la República, y abogar por la implantación de medidas de mejoramiento de nivel económico, educativo, higiénico y moral de la población (1942). ${ }^{140}$

Nuevamente, las visitadoras dialogaron no solo con el público "ignorante", sino también con el conjunto de universitarios que eran parte del auditorio de la Radio UNLP. Tal vez por ello, a diferencia de las conferencias en Radio Provincia, en esta emisora la estrategia persuasiva se valió de argumentos del discurso sanitario, jurídico y sociológico, e incluso estuvo cargado de estadísticas nacionales sobre los niveles de mortalidad, referencias a leyes y ordenanzas para la protección del binomio madre-hijo, como las ya citadas: Ley $\mathrm{N}^{\mathrm{o}} 11.933$ del año 1934 que prohibía el trabajo de las mujeres un mes antes y 45 días después del alumbramiento, la ordenanza $\mathrm{N}^{\mathrm{0}} 7.915$ del año 1936 por la que los servicios de maternidades de los hospitales municipales se elevaron a la categoría de Institutos de Maternidad y Asistencia Social, también la ley No 12.331 de profilaxis antivenérea como parte del aspecto preventivo y eugenésico para el mejoramiento de la salud maternal, y, por supuesto, la ley $\mathrm{N}^{\circ} 12.341$ de Protección a la Maternidad e Infancia.

Las visitadoras se presentaron así en el paisaje sonoro universitario como profesionales de la problemática, capacitadas para debatir, presentar informes e incluso proponer soluciones. Su voz en el éter hizo audible y visibilizó una problemática muy sensible entre la comunidad científica.

Las experiencias como agentes del servicio social habilitaron la voz de las visitadoras como expertas en sus áreas de intervención específicas. En el ciclo destinado a la Asistencia Social, María Haydee Aguilar, visitadora egresada de la EVHS- UNLP y visitadora del Instituto de Maternidad y Asistencia Social del Hospital Parmenio Piñero en Capital Federal, compartió la preocupación por dos de los problemas desprendidos de su intervención en las maternidades: la ilegitimidad y las carencias económicas de las madres. Para dar cuenta de esta situación sustentó su análisis con la presentación detallada de estadísticas realizadas por ella en Capital Federal y sobre el final de su exposición titulada "Importancia del servicio social en la maternidad", Aguilar destacó:

\footnotetext{
140 Copani, Alfina (1942) "La mortalidad materna y su profilaxis" En Educación Sanitaria y propaganda higiénica. Conferencias radiotelefónicas. Facultad de Ciencias Médicas. Cátedra de Higiene Médica y Preventiva. UNLP, La Plata, pp. 41-50.
} 
al hacer estos enunciados, queremos dejar bien aclarados que, con ellos, no pretendemos realizar, en las salas de Maternidad, la obra integral que requiere la solución de sus múltiples problemas, por cuanto una obra educativa es imposible de realizar durante el breve tiempo que estas mujeres permanecen internadas en dichos servicios, lo que solo podrá realizarse en Hogares Refugio (Aguilar, 1942, pp.125-126).

¿A quién le hablaba Aguilar con estas palabras? ¿Se expidió de no poder resolver el malestar económico y el abandono de las mujeres que se acercaban a las maternidades o, en realidad, hizo un llamamiento a los sectores gobernantes para que intervinieran y complejizaran la atención sobre las mujeres madres? Claramente extendió una exigencia a los sectores gobernantes que tenían la posibilidad de ejecutar una obra integral para el bienestar de las mujeres madres. Esta posición en defensa de los intereses de la maternidad junto con la exigencia de nuevos servicios interrumpió el silencio de las mujeres. Con este modo de intervención las visitadoras alientan de algún modo a romper con la individualidad y el aislamiento de las mujeres

\subsection{Interrupciones al discurso higienista: entre consejos domésticos e interpelaciones públicas}

La estudiante de la EVHS de la UNLP, Elba Dolly Villanueva, cerraba su radioconferencia "La protección de la infancia contra la tuberculosis" del día 29 de julio de 1940 presentándose como una agente confiable del servicio sanitario con quien podían contar las familias para explicitar los problemas de salud de la unidad doméstica. Específicamente, Villanueva se refería a la problemática de la tuberculosis puesto que disertaba en el ciclo de conferencias organizado por la Comisión de Propaganda Higiénica y Educación Sanitaria Popular de la Liga Popular contra la Tuberculosis de la Provincia de Buenos Aires (LPTPBA).

Las palabras de las visitadoras en este ciclo radial parecen entrar en contacto directo con las madres puesto que, como ya hemos dicho, aparecían como responsables del mantenimiento del núcleo doméstico, convirtiéndose en las primeras a convocar. En la radioconferencia anteriormente citada, Villanueva expuso una serie de razones respecto de cómo se debían cuidar a los niños dentro del ámbito doméstico a fin de evitar el contagio de la tuberculosis, haciendo hincapié en brindar una buena alimentación y garantizar un espacio higiénico. 
Si bien la principal interlocutora de las visitadoras fueron las madres, en ocasiones han sabido hacer algunos llamamientos que iban dirigidos a los varones. Ese es el caso de Hortensia Moretti, alumna de la EVHS de la UNLP, quien realizó una disertación acerca del malestar sanitario que se producía en las familias de bajos recursos que no sabían utilizar "racionalmente" sus ingresos económicos. Moretti inició su disertación cuestionando aquellas teorías antiguas o tradicionales que perjudicaban la salud y la moral familiar. En su disertación "Ahorrar a costa de la salud es comprometer el porvenir biológico", del día 1 de julio de 1940, afirmó lo siguiente:

\footnotetext{
Más de una vez habrán oído comentar al jefe de una familia numerosa de qué manera ahorra para realizar lo que él llama su gran idea de "la casita propia". Si bien es cierto que esto es necesario para poder defenderse de un salario que; para ganarlo, pide todas sus fuerzas y le da como recompensa lo escaso para poder vivir modestamente, más necesario aun es la conservación de la vida en perfectas condiciones de salud, ya que sin ella todo esfuerzo es vano (Moretti, 1940, p. 501).
}

Moretti cuestionó la toma de decisiones de los jefes de las familias y con ello expuso cuáles eran las relaciones de poder dentro de la economía familiar patriarcal donde los varones podrían detentar una mayor autoridad para decidir qué hacer con los recursos financieros, ya que podían acceder a salarios más abultados por su condición de género, mientras que las mujeres trabajadoras llevaban a su casa un salario "complementario". Sin embargo, aún con menores ingresos o incluso sin realizar aportes monetarios a la economía doméstica, las mujeres eran quienes se ocupaban habitualmente de la organización de los recursos cotidianos, e incluso hubo programas radiales emitidos desde la ciudad de Buenos Aires que promovían el ahorro doméstico y fomentaban el desarrollo de nuevas habilidades, tal como lo hacía la ecónoma doméstica y cocinera Doña Petrona de Gandulfo por Radio Prieto durante la década de 1930 y principios del 40 (Pite, 2016, p. 80). En esa radioconferencia la visitadora no se opone a que las unidades domésticas realicen el ahorro, sino que alienta a las mujeres a que decidan sobre las utilidades del mismo. Si bien con la reforma del Código Civil de 1926 las mujeres casadas conseguían el derecho a administrar sus bienes, profesionalizarse y comerciar, por los dichos de las visitadoras parece que el espacio de la intimidad requería una negociación constante. Es sumamente interesante ver esta estrategia discursiva de Hortensia Moretti en la que, a pesar de no mencionar a las madres, se trasluce en sus palabras cierto llamado de atención y alerta para incitarlas a que tomaran decisiones sobre el dinero familiar. 
La estudiante de la EVHS no dudó en deslizar un lábil cuestionamiento a la autoridad patriarcal con la que seguramente muchas otras oyentes, inhabilitadas para decidir los cauces de su salario, se habrían identificado. A lo largo de su alocución parece haber mayores cuestionamientos al orden económico en que vivían las mujeres y los trabajadores, no obstante declinó de poner en palabras propias dicha cuestión, tanto es así que Moretti cerró su disertación mediante la relectura de una cita del militante socialista y reformista, y desde 1940 Rector de la UNLP, el Dr. Alfredo Palacios:

Hay que llevar a los hogares de todos los argentinos el pan nuestro de cada día que no ha podido ser garantizado por el libre juego de las fuerzas económicas. De otra manera estaremos, del punto de vista de la salud del pueblo y del porvenir del país, en la misma situación del campesino que sabe lo que vale la vaca pero ignora lo que valen su mujer y sus hijos (Moretti, 1940, p. 506).

Moretti decidió dar un final a su disertación ubicando en el paisaje sonoro local la figura de Alfredo Palacios, destacado abogado, profesor y referente del movimiento estudiantil reformista, más conocido por su labor como diputado socialista y promotor de leyes en favor de la protección a las mujeres obreras. Su mención en el escenario radial del broadcasting provincial podía resultar disonante a sabiendas que allí solo se difundían las palabras del gobierno conservador y que, además, todas las conferencias debían someterse, previo a su emisión, a un proceso de lectura y censura (Jara y Bosaro, 1997). Desconocemos las estrategias llevadas adelante por esta joven para que su discurso pudiera ser emitido, pero tenemos registro que, escudada en su condición "amigable" de visitadora, presentó esta pequeña reflexión del referente socialista y con ello facilitó el ingreso de una crítica estructural sobre las condiciones del mercado de trabajo en que se insertaban los sectores populares. Es interesante esa suerte de invitación a la reflexión respecto de cómo suplir aquellas necesidades disociadas del salario, es decir, cómo compensar aquellas carestías que no podrían saldarse mediante la remuneración salarial de las patronales.

Si las visitadoras debían educar en prevención sanitaria para abaratar los costos de reproducción social mediante la instrucción de las mujeres madres que en su condición de "amas del hogar" disciplinarían al grupo doméstico, entonces, ¿qué sentido tenía alertar acerca de los actos descuidados e ignorantes de los hombres que ponían en peligro el bienestar de la familia $y$, sumar a ello, las palabras del referente latinoamericano del socialismo? Considero que, de algún modo, Moretti -al igual que otras estudiantes y graduadas de la EVHS- invitaban a las mujeres a pensarse como partícipes de una comunidad ampliada más allá del individualismo de los límites de su 
casa, incitando así a identificarse con la crítica al orden económico familiar, pero a su vez acordando con referentes del Partido Socialista acerca de la importancia de priorizar el bienestar familiar sobre el lucro. Más adelante veremos otros acercamientos de las visitadoras de higiene social con grupos cercanos a los socialistas y reformistas de la ciudad de La Plata.

Otras visitadoras también habían enunciado en el mismo ciclo de Radio Provincia algunas reflexiones y críticas respecto de las condiciones materiales en que se encontraban las personas susceptibles de contraer tuberculosis. Zélika Daneri y Hornos, graduada de la EVHS UNLP, en su radioconferencia "Más vale prevenir que curar", sostenía lo siguiente:

El reajuste que necesariamente debe introducirse en la estructura jurídica, económica y política del país a fin de obtener una mayor justicia social, encuentran en la sordidez y el egoísmo el obstáculo más serio que se opone a su realización. Hay que detener este muro de incomprensión que detiene las conquistas de la solidaridad humana. Los que ocupan un lugar de privilegio o en el banquete de la vida no deben olvidar que la tuberculosis no es solo patrimonio del tugurio; también entra en el palacio (Daneri y Hornos, 1940, p. 611).

Si los "ángeles de piedad" debían educar a las mujeres para que asumieran su rol maternal y modificaran hábitos cotidianos dentro de la esfera doméstica a fin de evitar mayores conflictos sociales, en el caso de la visitadora de higiene social Daneri y Hornos parece haber una actitud que trasciende el espacio privado y las soluciones que allí podían esgrimir de manera solitaria las mujeres. En cambio, la visitadora ubicó en el espacio público y político las falencias estructurales que impedían avanzar en la readaptación de los y las infectadas por el flagelo social de la tuberculosis y cuestionó el orden jurídico, económico y político dominante que impedía avanzar en vínculos solidarios entre los más y los menos privilegiados.

Aún privadas de participar en esferas políticas para la definición de políticas sociales, las mujeres se ocupaban de trabajar y gestionar el desenvolvimiento cotidiano de los espacios dedicados a la asistencia social, por lo que esos saberes y experiencias las respaldaban en sus críticas. Así lo demostraba Sofía Ricci en su radioconferencia "La tuberculosis, cómo se adquiere y cómo se evita“:

Cada media hora muere un tuberculoso. Esta verdad debe preocuparnos a todos, al pueblo y a sus dirigentes que la lucha contra la tuberculosis no se puede reducir a la lucha contra un factor microbiano, que el problema no puede ser exclusivamente médico, que es en gran parte una cuestión social. Es por ello que el día que se procure a las masas humanas una buena alimentación, 
una mejor vivienda y el conocimiento de una serie de medidas higiénicas se habrá dado un gran paso hacia el exterminio de este terrible mal (Ricci, 1940, p. 639).

Sofía Ricci, quien esgrimió estos argumentos, es una de las pocas visitadoras de higiene social de la cual tenemos mayores referencias respecto de su destacado desempeño laboral, en tanto fue una de las principales colaboradoras del Dr. Noel Sbarra ${ }^{141}$, tuvo a su cargo la subcomisión técnica del Club de Madres -hablaremos más adelante de esta experiencia -, además fue una de las pocas que en su época publicó artículos sobre su experiencia profesional en las maternidades de la ciudad de La Plata e incluso fue docente de la materia Servicio Social en la EVHS de la UNLP durante la década de 1940. Más allá de estos datos biográficos, esta visitadora provocó una disonancia en el espacio sonoro al ubicar como problema político y económico a la tuberculosis, ya no reducible a un asunto microbiano que solo podría resolverse en el ámbito médico, sino que exigía mayores modificaciones como alimentación y viviendas para todos. Con su discurso, Ricci acercó dos instancias: por una parte, el espacio privado, individual y de cuidados de las féminas para combatir y prevenir la enfermedad, hecho que le era exigido por su formación para el desempeño profesional; y por el otro, un espacio masculino de decisión política, que aun estaba vedado para las mujeres en Argentina, pero al que ella no temía exigirle modificaciones.

Con la presentación de estas acciones de cuestionamiento al orden económico de la esfera familiar, planteado por Moretti mediante el llamado de atención sobre las condiciones estructurales existentes en el país para principios de la década de 1940, tanto como las radioconferencias de Daneri y Ricci, las visitadoras mostraron a la audiencia otra faceta de su potencial profesional que no se condecía exclusivamente con la pretensión médica de ejercer una intervención "altruista y amorosa"; sino que intentaban acercarse a posiciones críticas sobre el estado en que se encontraba el sistema sanitario, político y económico del país. Con sus traducciones de las palabras científicas y universitarias pusieron en evidencia un entramado de negociaciones y resistencias al discurso médico higienista.

La necesidad de difundir los preceptos de higiene para economizar la intervención sanitaria sobre las consecuencias de enfermedades y embarazos que no se desarrollaran saludablemente, permitió a las visitadoras irrumpir en el espacio radial científico académico con una serie de conocimientos específicos que se desprendieron de su

${ }^{141}$ Reconocido médico sanitarista y tambien médico rural. Estuvo a cargo de la Casa Cuna de la ciudad de La Plata, donde creó el espacio específico para el Servicio Social. Interesado por las problemáticas de los niños y la necesidad de dar debates científicos, editó la Revista Hoja Médica de la Casa Cuna durante el año 1944. Este médico también fue parte del plantel docente de la EVHS. 
práctica profesional como también del avance en sus estudios. Tal es el caso de la estudiante de la EVHS, Orfilia Aprá, quien narró algunas reflexiones respecto a la importancia de los factores ambientales para el desarrollo de los niños. En su exposición no aparece la madre como único sujeto responsable de la crianza, por el contrario, el padre es mencionado como parte integral del proceso. En la radioconferencia titulada "Importancia de los factores hereditarios y ambientales", Orfilia Aprá sostuvo lo siguiente:

Si queremos lograr un nivel más alto de mentalidad en nuestros ciudadanos de hoy y de mañana, debemos crear padres con una buena visión del problema, padres y madres que se hayan unido no solamente para cambiarse mutuas satisfacciones o para criar uno o dos hijos, sino padres y madres que comprendan que el oficio que les toca puede volverse más exigente (Aprá, 1942, p. 55).

El binomio madre-hijo consagrado a partir de la década de 1920 como destinatario de múltiples políticas sanitarias para garantizar el crecimiento de la población (Biernat y Ramacciotti, 2013, p. 25), como ya hemos mencionado, hizo que la principal responsable del cumplimiento de las mismas fueran las mujeres, y serían las visitadoras quienes las educarían en esas tareas. No obstante, en esta radioconferencia la futura visitadora de higiene social ubica a los padres como partícipes del proceso educativo y garantes del bienestar del niño a quien también le cabían responsabilidades y, por lo tanto, debían ser educados en pos del mejoramiento colectivo. Si bien parte del trabajo de las visitadoras era promover la consumación de matrimonios eugenésicos que garantizaran una reproducción sana, también pretendían evitar la propagación de los hijos ilegítimos así como de la infancia abandonada, en la operación discursiva realizada por Aprá hay una intención de colocar en el espacio público y audible una problemática que seguramente vivían muchas mujeres, algunas con mayor suerte sufrirían el reparto desigual de tareas domésticas, pero otras quizás debían enfrentar la crianza de sus hijos material y afectivamente de manera individual. Decirlo, mencionarlo, insistir con las tareas correspondientes a la actividad paterna, permitía darle existencia y carnadura a una problemática que no se abordaba en los medios de comunicación desde el cuestionamiento al poder patriarcal.

La joven estudiante no fue la única encargada de ampliar el marco de complicidades con las mujeres madres. Nélida López, estudiante de la EVHS y presidenta del Centro de Estudiantes de la misma institución, brindó una detallada radioconferencia donde hizo mención al proceso evolutivo del niño y los compromisos de la madre para brindarle un ambiente saludable. El proceso presentado de acuerdo a la mirada eugenésica como individual y solitario donde solo la fémina sería la garante de ese bienestar, parece 
abrirse a una comunidad de mayor alcance. Así lo planteó López en su radioconferencia "El amparo de la mujer en su condición de madre o de futura madre":

Junto con el conocimiento del niño, se ha desarrollado un intenso movimiento mundial a favor de la protección de la infancia. Se han creado instituciones, se han reunido congresos nacionales e internacionales, se han fundado revistas, publicado libros, dictado leyes y se han formulado declaraciones de derecho (López, 1942, p. 65).

Luego de esta presentación, la futura visitadora detalló el decálogo de derechos acordado por el Instituto Internacional Americano de Protección a la Infancia de la ciudad de Montevideo en Uruguay ${ }^{142}$, que resultaba sumamente alentador en términos de alivianar la reproducción cotidiana de los niños a través de la creación de espacios recreativos, kindergarten y el otorgamiento de garantías económicas desde el Estado, entre otros. De esta manera, la futura visitadora abrió el juego a más de un actor involucrado en el desarrollo de los niños, es decir, la madre -con un partenaire o no- ya no estaría sola en su preocupación respecto de la crianza del niño sino que distintas leyes y declaraciones de derechos alivianarían la responsabilidad individual, junto con un colectivo científico académico que se estaban ocupando del tema. Es decir, habría garantías para que sus hijos pudieran acceder a distintos beneficios que debería otorgar el Estado mediante la ley $\mathrm{N}^{\mathrm{o}} 12.341$-que ya hemos presentado- y no serían preocupación exclusiva e individual de ella.

En este sentido, es importante recordar que si bien la radio facilitó la representación y la reproducción de normativas de género, por ejemplo, mediante los famosos radioteatros, al mismo tiempo posibilitó reformularlos mediante la presentación de nuevos imaginarios, tal como sostiene Christine Ehrick (2015). Incluso, mediante la radiofonía las visitadoras podían difundir avances legales, científicos y políticos a los que quizás las mujeres no tenían acceso por falta de contacto con los espacios donde circulaban esas novedades. Por eso, a través de un medio de comunicación masivo como lo era la radio en las décadas de 1920 y 1940, las mujeres podían acceder a esta comunidad de información ampliada que resquebrajaba la individualidad de su hogar (Gavrila, 2016). Además, a través de la radio, las visitadoras podían generar lazos de complicidad, una suerte de pacto de escucha ${ }^{143}$ por el cual el contenido a transmitir por las profesionales

${ }^{142}$ La Oficina Americana de Protección a la Infancia fue creada en el año 1922, luego del Tercer Congreso Americano del Niño celebrado ese mismo año en Río de Janeiro, Brasil. Dos años después se decidió fundar el Instituto de Internacional Americano de Protección a la Infancia, fijando su sede en la ciudad de Montevideo en Uruguay. A partir de ese momento fundacional se sumaron Argentina, Bolivia, Chile, Brasil, Estados Unidos, Perú y Venezuela. En el año 1949 se integró a la Organización de Estados Americanos (OEA) como organismo especializado en materia de niñez y adolescencia. Ver: www.iin.oea.org

${ }^{143}$ El pacto de escucha funciona como una paráfrasis del "pacto de lectura" propuesto por Eliseo Verón 
apelara a lugares comunes de las mujeres, a sus necesidades, debilidades y fortalezas. En los casos expuestos de visitadoras conferencistas podemos encontrar una interpelación a las madres como actoras con poder de decisión sobre la crianza de sus hijos, en un contexto en que no eran poseedoras de la patria potestad de los mismos. Podemos entender esta complicidad como una práctica específica de agenciamiento donde las visitadoras flanqueaban los límites impuestos a su desempeño profesional.

Otra de las visitadoras que buscó alentar a las complicidades entre mujeres fue Alfina Copani. Realizó la ya citada conferencia titulada "La mortalidad materna y su profilaxis", en la que presentó un pormenorizado desarrollo de las razones biológicas que entorpecían el desarrollo saludable del niño y también, con el mismo carácter propedéutico, señaló cada una de las condiciones sociales que ponían en riesgo la vida de las mujeres gestantes. En esta descripción sobre las condiciones económicas, sociales y familiares en que la mujer podía desarrollar una maternidad armoniosa, Copani ponía en escena toda una serie de elementos provenientes del discurso eugenésico que resultaban necesarios para el buen desarrollo de la mujer gestante y destacaba un conjunto de indicadores como la cercanía a la atención sanitaria, el estado económico del hogar, la cantidad de hijos, la edad de la madre gestante, las horas de trabajo y la conformación de la estructura familiar; variables en función de la cual se establecían las principales diferencias materiales que ponían en riesgo el desarrollo del binomio madrehijo (Copani, 1942, pp. 41-43). Luego de la presentación de estos elementos donde probablemente muchas de las radioescuchas podían identificarse, Copani ubicó la mayor atención en destacar la importancia de que fuera el Estado quien impulsara las principales campañas de educación sanitaria y se ocupara efectivamente de cuidar a las mujeres madres.

Como parte de sus acciones persuasivas, la visitadora Copani presentó los porcentajes de niños ilegítimos nacidos durante el año 1935 que alcanzaban casi un veinticinco por cierto del total de los nacidos durante 1942, año de la emisión de la radioconferencia a su cargo. Los nacimientos ilegítimos formaban parte de una seria problemática para el desarrollo de la nación, ya que eran considerados como causantes de la corrupción de la familia y del tejido primario que construía las bases de la sociedad. Sumado a ello, el peso moral de no ser reconocido por el progenitor no sólo era vergonzante para los

para estudiar el vínculo establecido entre quien locuta un discurso y el o la destinataria del mismo. Para ello se ejercerán diferentes estrategias con el fin de otorgar un lugar prefigurado e ideal que otorgue sentido a quien recibe el mensaje. En las modalidades del decir es donde se encuentran los elementos que unifican este pacto o aíslan a las partes. Ver: Verón, Eliseo (1985) El análisis del "Contrato de Lectura", un nuevo método para los estudios de posicionamiento de los soportes de los media, en "Les Medias: Experiences, recherches actuelles, aplications", París, IREP. 
niños y las madres, sino que además dificultaba el sostenimiento económico que recaía exclusivamente en la progenitora. La visitadora, a sabiendas de cuán difícil era la vida cotidiana de estas mujeres y niños, se oponía al aislamiento y castigo que debían soportar, por ese motivo, Copani hizo audible un reclamo en su ya mencionada radioconferencia:

La sociedad debe ofrecer amparo a toda mujer y colocarla en las condiciones materiales y morales que necesita para dar a luz y atender la lactancia de su hijo. Debe propenderse a la creación de maternidades especiales para madres solteras. Una legislación conveniente debe proteger a los derechos de la madre y el hijo frente al padre ilegítimo (Copani, 1942, p. 43).

Si hasta el momento las madres solteras resultaban un problema no solo en términos morales, sino también en términos eugenésicos, en su relato la visitadora decidió colocarse en defensa y empatía con la mujer que tendría sola a su hijo/hija. Esta solidaridad y pacto de escucha con las féminas que, por voluntad -o no-, no se ajustaban a los moldes de la familia heteronormativa, les posibilitaba a la visitadora exponer una problemática de índole individual, privada, oculta y "vergonzante" en un lugar de audibilidad y, por ende, de existencia.

En su preocupación respecto a la mortalidad materna, Copani hizo caso de los preceptos médicos por educar a estas mujeres en que aceptaran su condición sin restricciones, pero además deslizó algunas sugerencias sobre quiénes debían ocuparse del asunto y de qué modo. Así lo dijo esta visitadora en su radioconferencia:

La lucha debe encarar el problema en forma integral, es decir, mejorando las condiciones actuales de asistencia y protección maternal, técnicas, institucionales, sociales, educativas, económico- morales, jurídicas, etc.; solo desarrollando una acción de conjunto y contemplando los múltiples y variados aspectos que integran el vasto y complejo problema será permitido alcanzar en el porvenir el llamado "irreductible mínimo" de mortalidad materna (Copani, 1942, p. 44).

Copani convocó a la sociedad para garantizar las condiciones materiales de desarrollo y contención de las madres, mencionó entrelíneas a legistas y a políticos que tenían la posibilidad de establecer maternidades especiales, promover leyes protectoras y garantizar el cumplimiento de las mismas. Es interesante considerar que, a través de este tipo de discursos, las visitadoras producían interrupciones en el rol esperable para su profesión, que si bien debía facilitar el ingreso del Estado en la casa de las personas por medio de un lenguaje amoroso que favoreciera el disciplinamiento de los sectores 
populares, en el caso de las radioconferencias, las visitadoras tomaron las problemáticas domésticas individuales y las colocaron en la escena pública, sugiriendo soluciones que debían encarnar los hombres de la política, ámbito que aun les estaba vedado a las féminas. Copani fue insistente en este punto:

El cuidado y la vigilancia pre natal tiene por objetivo evitar todos los accidentes de la gestación y proteger al niño contra la mortinatalidad, y esto lo lograremos solamente si el Estado y las organizaciones privadas, con una visión clara del futuro, hacen posible el examen sistemático de todas las mujeres gestantes desde el 3 o 4 mes hasta dar a luz. En nuestro país nunca se ha hecho tan necesario como ahora emprender una labor de esta índole que constituye una necesidad pública nacional (Copani, 1942, pp. 48-49).

Con estas palabras la visitadora se acercó a las críticas estructurales que esgrimía el reformismo universitario platense años antes respecto de la necesidad de expandir los conocimientos sobre higiene al pueblo a fin de elevar su conciencia y alentar a mejores condiciones de vida. Valiéndose de las críticas fundamentadas al sistema político local y nacional desde la trinchera radial universitaria, podía corroer su posición subalterna y colocarse como una voz de referencia en materia de las problemáticas sanitarias.

\subsection{Entre tareas moralizadoras y reivindicaciones de demandas colectivas. La experiencia del Club de Madres}

Alfina Copani no fue la única que presentó denuncias en la radio, y con ello complicidades y solidaridades con mujeres, madres y trabajadoras. Otra de las visitadoras que se alió a la propuesta reformista por involucrarse y difundir proyectos tendientes al afianzamiento de lazos de solidaridad con los sectores populares para el desarrollo del país fue la estudiante de la EVHS, Ivone Baroude, quien contó la experiencia del Club de Madres (CM) del que era partícipe, seguramente como parte de las prácticas profesionales que llevaban adelante las estudiantes.

Vale mencionar la experiencia de este Club. El mismo fue creado en el año 1942 por la Comisión de Mujeres y Niños de la Universidad Popular Alejandro Korn (UPAK). Esta institución había sido formada cinco años antes por jóvenes estudiantes y graduados de la Universidad Nacional de La Plata ligados a la Reforma Universitaria y al Partido Socialista, ambos afrontaban disputas al interior de la Universidad y en la arena de la política nacional. El propósito de esta institución no era saldar el déficit académico de la 
formación en la Universidad Nacional de La Plata, sino promover la difusión de conocimientos en "solidaridad" con la lucha de los sectores obreros (Graciano, 2008).

Casi treinta años antes de la creación del CM en la UPAK, existió otro Club de Madres en la ciudad de Buenos Aires comandado por mujeres universitarias. Mediante esta asociación buscaron suplir las necesidades de las madres y niños con una estrategia educativa y de control sanitario (Coni, 1918, p.100). El desenvolvimiento de esta asociación llegó hasta finales de la década de 1930, y se desconoce a través de las fuentes escritas si existieron vínculos entre ambos $\mathrm{CM}$ a pesar de las cercanías temáticas.

Desde su creación, la UPAK se había vinculado íntimamente con los estudiantes de medicina, quienes encontraban en esta experiencia la consumación del ideal reformista, por ello, dedicaron varias páginas de su revista $\left(1938\right.$, año $\left.2, \mathrm{~N}^{\circ} 8\right)$ para enaltecer su obra y difundir el Estatuto con el que había sido formada la institución; destacaron entre ellos: la amplia labor de cultura dirigida a obreros, empleados y estudiantes para afianzar su "responsabilidad social" (p. 63), la promoción de la investigación de problemas sociales y argentinos, el deseo por "estructurar" la educación para las mujeres como también por fomentar el arte popular y la cultura física.

Puesto que el CM funcionaba como parte de un proyecto político social más amplio que pretendía afianzar los lazos de solidaridad, aunque también de disciplinamiento, con los sectores trabajadores su estrategia buscaba garantizar mejores condiciones de manera colectiva para el desarrollo del recién nacido y de los niños pequeños, sin perder de vista la instrucción de las mujeres madres. Respecto al rol central de las mujeres madres y la importancia de su educación, la estrategia de las mujeres del CM tuvo puntos de contacto con la lucha iniciada desde fines del siglo XIX por las socialistas feministas, quienes en su derrotero político apuntaban a denunciar la opresión sexual a partir de la defensa de la diferencia sexual y la consideración de la maternidad como núcleo estructurante de la feminidad (Becerra, 2009, p.63; Lavrin, 2005, p. 35-39). Si bien la propuesta no cuestionaba el orden heterosexual dominante, pretendía privilegiar a las mujeres madres considerándolas responsables de la producción de los futuros ciudadanos. Con esta operación se diferenciaban de las posiciones conservadoras que entendían la reproducción biológica como una "función social" y no como posición política de enunciación desde la cual construir una tribuna de denuncia para el reclamo de derechos civiles y políticos (Nari 2000, p. 204) Así, desde la defensa de la maternidad afirmaban su derecho para el ingreso en la vida pública y política. 
Si bien las socialistas disputaron desde el partido un nuevo estatuto de ciudadanía (Valobra, 2008), también trazaron otros espacios desprendidos de su organización que apuntaron a la formación de las mujeres madres trabajadoras. Desde este interés, durante el año 1902, crearon el Centro Socialista Femenino donde confluían mujeres con distintos intereses agrupados en actividades educativas, gremiales y políticas referidas no solo a la conquista del voto y a reformas legislativas que favorecieran a la mujer trabajadora y a sus hijos, sino que también promovieran la difusión de conocimientos para elevar la condición intelectual y moral de las féminas con el objetivo de optimizar las condiciones de vida de las mujeres y de sus familias. Prueba de ello fueron las conferencias sobre: higiene infantil, divorcio, condición política de la mujer, entre otras (Raiter, 2004).

La lucha entablada por las socialistas y feministas durante las décadas de 1910 y 1920 , plasmada en el Primer Congreso Femenino Internacional y en los dos simulacros de voto en la década de 1920, mostraban un crecimiento en la lucha por la adquisición de derechos políticos de las mujeres. Sin embargo, esta situación favorable a las mujeres socialistas y feministas tuvo que enfrentar nuevos desafíos durante la década de 1930. Con la avanzada fascista a nivel internacional y el conservadurismo reinante en la región, las socialistas argentinas tomaron la estrategia de reforzar las asociaciones de mujeres, replegarse al interior del partido y dejar de lado la primacía del discurso feminista por una militancia a favor de cuestiones universales vinculadas a la democracia, la libertad y sobre todo contra el fascismo (Barrancos, 2007, p. 174).

Aun así, las socialistas continuaron en la trinchera política educativa mediante la instrucción de las mujeres madres y de los niños. Este interés las impulsó a organizarse para ampliar las propuestas educativas generadas desde el Estado y efectivizar otras que alcanzaran a los sectores trabajadores. La preocupación por el trabajo infantil y las mujeres madres trabajadoras organizó a las militantes socialistas feministas no solo en la lucha por reformas legislativas ${ }^{144}$, también en la creación y promoción de espacios alternativos institucionales donde mujeres madres, niños y niñas tuvieran un lugar de recreación, aprendizaje y contacto con la cultura socialista (Tripaldi, 2002, pp. 83-85). De algún modo, esta experiencia se inscribió como parte de una demanda desde la

144 Entre las reformas legislativas alcanzadas por las y los socialistas podemos mencionar: Ley $\mathrm{N}^{\mathrm{o}} 4.661$ Descanso dominical (1905); Ley No 5.291 Reglamentación del trabajo de Mujeres y Niños (1908); Ley N ${ }^{\circ}$ 8.999 Organización del Departamento Nacional del Trabajo (1912); Ley No 11.178 Salario mínimo para empleados y obreros de Estado (1921); Ley No 11.337 Pago de Salarios en moneda nacional (1926); Ley $\mathrm{N}^{\mathrm{o}}$ 11.640 Sábado Inglés (1932); Ley No 11.729 Vacaciones pagas, indemnizaciones por enfermedad y despido (1934); Ley No 11.838 Ayuda al niño (1934); Ley $\mathrm{N}^{\circ} 11.896$ Junta nacional para combatir la desocupación (1934); Ley No 11.933 Protección a la madre obrera (1934; Ley No 12.205 Ley de Silla (1935); Ley No 12.341 Creación de la Dirección de Maternidad e Infancia (1936). 
sociedad civil que articuló una pre política social para dar respuesta a necesidades colectivas (Guy, 2011).

El interés por el desarrollo saludable de los niños era parte de las políticas llevadas adelante por el PS desde su fundación, y también de la UPAK. Delia Etcheverry supo combinar las estrategias de ambos espacios con su interés feminista por la politización de la educación y la elevación de las mujeres en la cultura política. Esta doctora en Letras tuvo una destacada influencia en proyectos vinculados a la reforma universitaria desde las actividades de enseñanza y de extensión educativa, trayectoria que seguramente la impulsó a crear en el año 1942 el Club de Madres. ${ }^{145}$

El CM estaba integrado por mujeres agrupadas en distintas actividades, a saber: taller, la subcomisión de recreación y educación popular, y por último, la subcomisión técnica a cargo de Sofía Ricci, visitadora de higiene social a quien ya hemos presentado con antelación. Estos tres espacios actuaban de manera mancomunada. Una de las actividades a partir de la cual se articulaban sus acciones era el "canastillo circulante", que era una suerte de ajuar del recién nacido que se entregaba a las madres que lo solicitaban y en menor medida también se prestaba este servicio a otras instituciones que trabajaran con madres. ${ }^{146} \mathrm{El}$ canastillo incluía colchón, mosquitero, sábanas, frazadas, un ajuar compuesto por más de cincuenta prendas, entre otros elementos. Una vez que la madre ya no lo necesitaba lo devolvía al club y era puesto en circulación nuevamente por las agentes encargadas de acercarse a las madres (Baroude, 1942, p. 146).

Acorde a las innovaciones en materia de intervención sobre la cuestión social, para que este canastillo iniciara su recorrido las visitadoras de higiene se encargaban no solo de inspeccionar y relevar información acerca de las condiciones de vida de los sectores populares, haciendo uso de los dispositivos de la profesión, sino que también se ocupaban de prolongar la educación universitaria en materia de higiene sobre estos sectores a fin de evitar la propagación de enfermedades como la tuberculosis, y enseñar

\footnotetext{
145 En el año 1922, Delia Etcheverry realizó una propuesta pedagógica para el Colegio de Señorita Liceo Víctor Mercante, dependiente de la UNLP. En ella proponía una reforma curricular que preparara a las estudiantes para el ingreso en la universidad y no se inclinaran directamente al ejercicio del magisterio. La experiencia se desarrolló durante breve tiempo, y en 1923 fue suprimida por decisión de las autoridades de la universidad. Ver Graciano, Osvaldo (2008) Entre la torre de marfil y el compromiso político, p. 68.

${ }^{146}$ Durante el año 1942 entregaron 200 canastillos, 196 de ellos fueron solicitados por mujeres próximas al alumbramiento y otros 6 por instituciones, entre ellas, el Servicio Social de la Casa Cuna de La Plata, el Hogar Policlínico de la Sección 3ra con la Maternidad de La Plata, con el Instituto Autárquico de vacunación y con distintas escuelas de la provincia (Memoria un año de labor del Club de Madres. UPAK, 1944).
} 
hábitos saludables y cotidianos que abarataran los costos de reproducción social de las familias, tal como ya habíamos mencionado.

Para que las mujeres accedieran al canastillo eran "prolijamente atendidas" y se les realizaba la encuesta para definir un diagnóstico social. Es interesante que ellas propusieran no el análisis de caso individual y aislado, sino el análisis grupal que les permitía dar cuenta del carácter social de las problemáticas sanitarias, y el caso particular de estos ajuares colectivos. En palabras de Sofía Ricci:

En esta forma se ha procurado siempre asistir al más necesitado -necesidad económica o moralteniendo en cuenta que nuestra acción no se limita a la ayuda paliativa que significa un canastillo sino que lleva su finalidad efectuar una protección integral del niño y una asistencia constructiva del grupo familiar (Informe anual Club de Madres, 1945).

Lo que aquí sugiere Ricci es que el diagnóstico social realizado a los beneficiarios y las beneficiarias de los servicios del CM ayudaría no solo a las madres y su prole, sino que su pretensión era abarcar al conjunto familiar en función de conocer las condiciones y necesidades de cada grupo. A fin de cumplir con dicha estrategia, una vez que las visitadoras entregaban los canastillos tenían las puertas abiertas para iniciar su labor de educación popular, asegurar un diagnóstico precoz y efectuar la profilaxis para el tratamiento necesario. También cabe pensar que una vez entregado el canastillo se establecía una relación de dependencia entre la familia beneficiaria y el CM que acercaría al grupo a las políticas del PS.

Ahora bien, para que estos canastillos pudieran ser compartidos entre distintas familias necesitaban ser puestos en condiciones. En primera instancia debían ser desinfectados por la Comisión de Higiene de la ciudad, luego, una vez devueltos al CM existía un grupo de mujeres que conformaban la Subcomisión Taller. En ella las socias se encargaban de tejer, rearmar, lavar y desinfectar los canastillos que llegaban, como también de reforzar los colchones e intercalar las prendas nuevas con las viejas. Estas prendas nuevas eran realizadas en los talleres de corte y confección que brindaba la UPAK a las mujeres, de manera que el vínculo entre estos espacios se consolidaba entre varias instancias de trabajo compartido entre mujeres para alivianar el costo individual de la sostenibilidad del grupo familiar.

Además de estas acciones de reparación y acondicionamiento, también se encargaban de reordenar las donaciones recibidas de algunas tiendas platenses y de señoras de familias socialistas. Es sabido que estas funciones de cuidado y de acondicionamiento para el recién nacido son generalmente asignadas al ámbito privado y femenino, sin embargo, 
mediante la intervención del taller del CM, convirtieron una acción individual y privada en una acción colectiva, enmarcada en un proyecto político de mayor aliento que se articula en la solidaridad entre mujeres y con los sectores trabajadores.

Si bien la práctica de redistribución de donaciones también era realizada por las instituciones de caridad y beneficencia, como hemos citado en el capítulo II, Ivone Baroude, estudiante de la EVHS de la UNLP y radioconferencista, marcaba una diferencia entre ambas prácticas. En su radioconferencia titulada "El Club de Madres", así lo definía:

Nuestro país está lleno de instituciones de beneficencia y de caridad que no son precisamente la solución científica y feliz, sino momentánea y falsa, de los problemas sociales; nuestro país necesita instituciones que, como el CM, practica la beneficencia como un medio y nada más que como un medio para llegar a un fin que es la educación del pueblo y en especial de las madres para subsanar y evitar, sobre todo evitar, los problemas sanitarios morales, productos de la mala educación (p.150)

El interés por realizar un abordaje científico de la cuestión social se hace indudable a través de las funciones que cumplen las visitadoras de higiene, que a diferencia de otras visitadoras o inspectoras formadas en instituciones religiosas o municipales, eran capacitadas dentro del ámbito de la universidad desde la medicina higienista y, por lo tanto, representaban una suerte de voz autorizada para la intervención. Es evidente que la disputa política que enfrentaban los socialistas y los reformistas en el plano nacional, sobre todo en el final de la década infame, también se tradujo en las diferencias entre las mujeres que realizaban acción social y su participación política ${ }^{147}$, donde las participantes del Club de Madres parecen más cercanas a las posiciones que defendían las socialistas en referencia a la necesidad de instruir y elevar intelectualmente a las mujeres para evitar problemas sanitarios, pero también podría pensarse que desde esta estrategia disputan el estatuto de ciudadanía.

Si bien algunas posiciones minoritarias dentro del partido socialista bregaban por una modificación de la familia como organización acorde a su proyecto de reforma social (Marpons, 1949, p. 20), las mujeres del CM trataron de mejorar las condiciones de desarrollo de la familia, sin cuestionar el ordenamiento heterocentrado de la misma, sino

147 Vale destacar que en el mismo año en que las mujeres de la UPAK dan surgimiento al CM, la delegación de moralidad de la Asociación de Mujeres de la Acción Católica de la ciudad de La Plata inicia un proceso de reclutamiento de mujeres cristianas a fin de difundir educación católica y luchar contra las publicaciones y "malas lecturas que se ofrecen a los niños en numerosas revistas". Diario El Argentino, 15 de junio de 1942. 
que apuntaron a reformas para alivianar la reproducción cotidiana, no solo mediante el canastillo, también existió otra acción concreta que fue la creación de espacios recreativos para niños, similar a lo que hacían las mujeres del PS en la ciudad de Buenos Aires. Es así que el CM creó un jardín de infantes experimental, en el Parque San Martín de la ciudad de La Plata, situado en la calle 23, entre 51 y 53. Allí las niñas y los niños además de integrar un espacio recreativo y disciplinante con pares de su rango etario establecido entre los tres y seis años, eran partícipes de una educación que apuntaba a la adquisición de hábitos higiénicos y de convivencia, como también de enseñanzas de carácter "moral, manual y sensorial" de la cual se esperaba que favoreciera el desarrollo de personalidades fuertes. Dentro de este espacio recreativo y educativo también se motorizaban festejos a fin de vincular a las familias de las y los infantes con el club. ${ }^{148}$

Para el funcionamiento de este jardín la UPAK donó muebles y distintos materiales didácticos, a su vez se encargó del dictado de un "cursillo para maestras de Jardín de Infantes". ${ }^{149}$ Éstas eran las encargadas del desarrollo del jardín y del Recreo Infantil de la UPAK, donde entregaban desde una merienda hasta cepillos de dientes para los niños y niñas. Con estas acciones se aliaban tanto a las estrategias médicas por el desarrollo fuerte de los niños, como así también alivianaban las responsabilidades por la reproducción familiar que competían, acorde a los preceptos de la época, exclusivamente a las mujeres.

Puesto que el jardín de infantes se alineaba en el interés del CM por instruir a las familias, las visitadoras desplegaban aquí su acción del mismo modo que con el canastillo circulante. Con el levantamiento de la ficha social, pretendían obtener información sobre la alimentación, la vivienda, el nivel económico y cultural de la familia, las enfermedades padecidas y vacunas, entre otros elementos, que permitieran a la CM extender una "provechosa acción social de verdadera trascendencia". ${ }^{150}$

Lo interesante de la experiencia del jardín de infantes del $\mathrm{CM}$ es que se mantenía de manera autónoma del financiamiento estatal, favoreciendo lazos de solidaridad entre la comunidad (el CM dejaba alcancías en distintas instituciones para conseguir donaciones) como con la UPAK que realizaba donaciones materiales para el desarrollo de sus actividades. En este sentido, es interesante poder pensar las acciones del CM

\footnotetext{
148 Memoria de 2 años de labor (1945) Asamblea bianual de julio de 1945. UPAK. Departamento de la Mujer y el niño.

${ }^{149}$ Memoria de un año de labor. UPAK. Departamento de la Mujer y el niño. p.16.

${ }^{150}$ Memoria de 2 años de labor (1945) Asamblea bianual de julio de 1945. UPAK. Departamento de la Mujer y el niño. p. 13.
} 
como parte de acciones establecidas por la UPAK y el PS durante las décadas de 1930 y 1940, puesto que durante esas décadas el partido vivió una serie de cambios y debates en su interior respecto a cuál era el rol de los trabajadores y del partido en relación a la posibilidad de ser partícipes activos del "capitalismo organizado", es decir, un capitalismo económico planeado y dirigido desde la intervención estatal donde se hacía indispensable la presencia de la clase obrera en pos de una revolución democratizante (Torti, 2009).

El sentido de la ampliación y democratización de los debates políticos que promovía el socialismo al igual que el reformismo era también practicado desde el CM. Entre las conferencias que se realizaban allí se encontraron "Principios sencillos de alimentación familiar", "Los peligros de la tuberculosis" y una sobre los problemas de conducta infantil que enfrentan las madres, expresados en la disertación sobre los "diez si y diez no", basado en los principios que sustentaba la Dra. Telma Reca, también afiliada al PS. $\mathrm{Si}$ bien estas conferencias no afrontaron debates políticos de orden partidario y legislativo como los que realizaban décadas anteriores el Centro Socialista Femenino, mantuvieron la propuesta reformista de poner al servicio de los sectores trabajadores los conocimientos producidos en la universidad.

La unión entre el CM y la propuesta del grupo reformista de la UPAK era que ambos se identificaban estrictamente con un proyecto de sociedad y de ciencia que respaldaba sus acciones. Ivonne Baroude, en su disertación radiofónica llamada "El Club de Madres", destacó:

El Club de Madres prepara, con gran éxito campañas periódicas de educación pre-natal, de seguridad infantil, pro higiene; a favor de la educación pre-escolar; semana de la alimentación; semana del nene, etc.; todas tendientes a preparar a la madre para criar hijos siguiendo las últimas normas que marca la ciencia tanto en lo que se refiere a la higiene como a la salud y a la alimentación, hábitos, etc. [...] La educación sanitaria se realiza con la colaboración de médicos generales y especializados y con la ayuda de las Visitadoras de Higiene Social, ocupándose el Club de Madres de demostrar al público el peligro del curanderismo y la necesidad de consultar al médico cuantas veces sea necesario (Baroude, 1942, p. 146).

La educación sanitaria de las mujeres madres las inscribiría en una línea de conocimientos que la alejan del curanderismo y otros saberes no científicos. Se buscaba maximizar los esfuerzos de la crianza dentro del ámbito doméstico y producir mejoras de la higiene y de la alimentación de los niños, saberes que ya formaban parte de la vida doméstica de las mujeres pero que con estas acciones "científicas" pretendían optimizarse. Si bien resta indagar los vínculos entre feministas platenses y la UPAK, podemos suponer que a través de las acciones del $\mathrm{CM}$ de algún modo se materializaron 
parte de los intereses que feministas y socialistas compartían por la instrucción de las mujeres madres, puesto que legitimadas por su "función" de dar vida podrían reclamar derechos civiles. Partían del presupuesto de que la responsabilidad de la maternidad les permitiría obtener derechos para intervenir en la esfera pública y política, sobre todo valiéndose de la idea en boga acerca de su imprescindible rol para la producción de varones "sanos", futuros ciudadanos, como una tarea intransferible que debían realizar las mujeres madres (Becerra, 2009). Siguiendo esta idea, es probable que a través de los cursos del CM y de esta radioconferencia en particular, se buscara aproximar a las mujeres no solo para darles una ayuda paliativa, sino también para acercarlas al espacio político de la UPAK y el Partido Socialista.

Al igual que Copani, Baroude utilizó el espacio radial para criticar las políticas estatales, pero además proponer un modelo alternativo de reparto de los cuidados familiares. Así lo explicitó la joven en la radioconferencia "El Club de Madres":

en la alta labor que se han impuesto [en referencia a las profesionales que forman parte del CM] no han olvidado ningún problema cuya solución pueda ser útil para la sociedad; por el contrario, han reparado en algunos que descuidan el Estado y la familia, por ejemplo, el de la educación pre-escolar, tan imprescindible, porque abarca un período del niño en que, si se lo dirige correctamente, se puede lograr que rinda al máximo de sus posibilidades (Baroude, 1942, p. 147).

En sintonía con las propuestas del entonces presidente de la UNLP, Dr. Alfredo Palacios, por construir respuestas políticas colectivas y solidarias frente a las problemáticas sociales, la visitadora sugiere que las soluciones pueden ser otorgadas desde un proyecto reformista y socialista que apunte al desarrollo científico donde el ideal educativo se "realiza a través de obras de beneficencia siempre que sea preciso pero, que no tiene el carácter de institución de caridad" (Baroude, 1942, p. 150). Así, se refuerza la defensa de una respuesta científica para la intervención profesional que les permitiera actuar "no por mera intuición, sino por preparación científica", como planteó en el mismo ciclo radial la visitadora de higiene Sofía Ricci (1942, p. 133).

La difusión de saberes entre las mujeres que integraban el CM, según las palabras de Baroude, se justificaban como parte decisiva para el progreso de un pueblo, interés que compartía con los médicos higienistas. Más allá de que si estas mujeres que participaron en el CM eran militantes o no del Partido Socialista, es seguro que desde su lugar como profesionales del ámbito sociosanitario y conferencistas radiales realizaron una difusión afín a las ideas propuestas por el partido para consolidar los lazos de solidaridad con las 
mujeres de sectores trabajadores. El hecho que se mencionara en la radio implicó ubicar en un lugar de mayor difusión y conocimiento una experiencia de orden militante al que podían acceder quienes estuvieran organizados políticamente o cercanos a los sectores del PS, sin embargo, dado el alcance de las antenas podían sentirse convocadas otras mujeres de lugares más alejados.

En las palabras de las visitadoras había una ponderación del rol social de las mujeres madres, que en tanto educadoras de sus hijos podrían evitar males morales y sanitarios. Si bien la educación de sus hijos aparece como una responsabilidad individual y privada de las mujeres madres, las visitadoras pusieron en evidencia que era el Estado quien debía prestar apoyo material para el cuidado del vínculo entre madre e hijo.

En el paisaje sonoro las visitadoras no solo resultaban la irrupción en la voz médico sanitaria que era mayormente difundida por varones, también eran las educadoras de los avances legales, educativos y de servicios sanitarios que se establecían progresivamente en el país y en la ciudad. Dada su posición como mujeres profesionales y auxiliares de la salud, supieron aprovechar los intersticios de sus lugares de trabajo para deslizar cuestionamientos, más o menos velados, al sistema que las empleaba.

\subsection{Acciones de agenciamiento y experiencias profesionales: persuasión, solidaridad y complicidad}

A lo largo de los tres apartados que componen este capítulo presenté el modo en que las visitadoras pudieron establecer diferentes formas de contacto y acercamiento con las y los usuarios con quienes trabajaban. Mediante las radioconferencias e informes de las gestiones realizadas en el Club de Madres nos acercamos a una serie de acciones donde las visitadoras tensionaron los roles de género establecidos por la ciencia médica para estas profesionales y dejaron en suspenso el carácter de entrega absoluta con el que los médicos intentaron teñir sus acciones.

La presentación de estas experiencias profesionales de las visitadoras no pretende destacar a este grupo auxiliar de la medicina preventiva de una manera unívoca, traslúcida y universal a todo el cuerpo profesional, por el contrario, presentar este conjunto de experiencias de disertación e intervención de las visitadoras posibilita enunciar las relaciones de poder y negociación donde se tensó y construyó el carácter feminizado de la profesión. Desde un carácter epistemológico, el concepto de experiencia tiene un valor crítico que radica en postular formas de conocimiento parciales, relativas a la ubicación in situ de una construcción local de sujeto y de 
práctica que desmiente la posición universalista y generalista masculina (Richards, 1996, p.739), posición de poder y autoridad que también se expresa en el ámbito médico sanitario.

A partir de estas experiencias podemos dimensionar los procesos de actuación que dotaron a las visitadoras de posibilidades para movilizar sentidos respecto de una profesión feminizada, e incluso alentar la politización de la maternidad a una comunidad más ampliada, a un colectivo que se identificara con esa práctica velada en el sistema representacional del patriarcado moderno.

Reparar en estas "pequeñas" acciones posibilita quebrar las significaciones con las que se piensa a una profesión feminizada, e incluso con las que se reactualizan las posiciones conservadoras de las profesionales del trabajo social. Comprender ese pasaje entre el carácter normativo que se imprimen a los cuerpos de la mujeres y la transparencia con que la ideología dominante pretende presentar lo femenino como propio del sexo, supone creer estos significados como fijados por única vez.

Sin embargo, podemos encontrar en las acciones de las visitadoras una negociación individual que alienta al colectivo de féminas a cuestionar el orden situado en que se encontraban durante las década de 1940. De esta acción, a mi entender, se desprende el carácter político de su intervención en tanto enuncian, visibilizan y construyen problemáticas supuestamente individuales como problemas colectivos. Ubicar en el “aire radial” las problemáticas "íntimas" no era una acción unidireccional, mediante la alocución de las reflexiones sobre las falencias del sistema sanitario, económico, jurídico y político, podían ingresar mediante la radio cuestionamientos extradomésticos al ámbito familiar que hacían a la vida cotidiana, como las críticas a los bajos salarios, a la falta de maternidades, etc. De este modo, y aún privadas de derechos de ciudadanía política, las visitadoras aquí presentadas se exhibieron en el espacio radial como partícipes activas de la comunidad de la que eran parte ellas y sus oyentes.

Si bien con esto no niego las acciones de disciplinamiento y control social que ejecutaron muchas visitadoras y otras agentes del servicio social, considero importante rescatar otras acciones como la persuasion, la solidaridad y la complicidad, a partir de las cuales ensayaron modos de trastocar los límites de su condición de género al interior del campo profesional de la salud.

Mediante esas acciones de persuasión, solidaridad y complicidad, a través de pactos de escucha e intervenciones como intermediarias sanitarias, estas mujeres pudieron desestabilizar, o al menos sospechar acerca del orden prescrito a su género, y producir prácticas de agenciamiento. Su preocupación e interés por otros proyectos políticos, 
como el del Club de Madres de la Universidad Popular Alejandro Korn, evidencia que no todas las profesionales aceptaron ser agentes al servicio de la ideología conservadora, por el contrario, podían valerse de su lugar público como profesionales de la asistencia social para convocar a otras mujeres a cuestionar el orden político económico, a modificar sus condiciones cotidianas de existencia desde la individualidad de su hogar o a través de la participación en proyectos colectivos dentro de los límites que imponía el sistema imperante y su lugar dentro de la estructura sanitaria.

En sus acciones de compromiso político con otros proyectos sociales, en las críticas que deslizaron al sistema sanitario, en la persuasión al público en general por modificar hábitos y costumbres, en el establecimiento de un pacto de escucha con otras mujeres estructurado en una complicidad que las identificaba, podemos encontrar fisuras al relato médico hegemónico que ellas debían replicar. En sus traducciones entre el discurso científico y estrategias de vulgarización del conocimiento para los sectores populares, las visitadoras no dejaron de cumplir con su misión educativa de difusión sanitaria y eugenésica, no obstante, con sus acciones de agenciamiento establecieron prácticas de resignificación y mediación dentro de las situaciones y espacios que ocupaban, por eso creo importante destacarlas a fin de alentar la reflexión sobre el carácter político de la intervención feminizada. 


\section{Conclusiones}

En el año 2013, la trabajadora social del Patronato de Liberados de la provincia de Buenos Aires, Laura Iglesias, fue encontrada muerta y atada a un árbol con marcas de haber sido violada de forma reiterada y asesinada cruelmente. Este suceso ocurrió mientras ella estaba en su horario de trabajo, horario de trabajo no reconocido como tal en términos formales. Al igual que sus otras colegas del área, la tarea consistía en acompañar a tutelados del patronato de la provincia de Buenos Aires en su reinserción luego de la privación de su libertad, para ello viajaba sola en su auto diariamente a visitarlos y acompañarlos. Laura tenía mucha información sobre los "tutelados" y su relación con la policía local, y su interés junto con otras colegas era favorecer proyectos de incorporación al mercado de trabajo para estas personas con las que trabajaba a destajo para, de esta manera, efectivizar material y económicamente la utopía de la reincersión.

Las condiciones de trabajo de Laura y sus colegas era denunciada desde la Asociación de Trabajadores del Estado (ATE) puesto que cada asistente debe tutelar a casi ciento cincuenta liberados, cuando técnicamente no podría hacerlo con más de treinta. Este hecho indica el carácter de sobreexplotación que viven parte de las trabajadoras sociales, que parecen mantener correlatos con la historia de la profesión y su función "economizante" dentro de las instituciones del Estado. La precarización y desvalorización en que desarrollan sus intervenciones profesionales las trabajadoras sociales, donde la polivalencia funcional que cumplen no es considerada parte del trabajo, pone en evidencia el entramado de disputas en que se insertan las trabajadoras y el peso del rol auxiliar y secundario con que fue construida la disciplina.

El caso de Laura resulta la máxima expresión de la desidia, subestimación e infravaloración de los trabajos profesionalizados de asistencia y de cuidados, del mismo modo en que hace visible el castigo para aquellas que cuestionan el ordenamiento estatal y sus instituciones de control, como la policía, entre otras instituciones que en algunos casos también las emplea. Esta historia no es la única, muchas otras trabajadoras y asistentes sociales que viven y manifiestan la tensión entre la exigencia estatal y sus acciones concretas de intervención revelan el malestar respecto a las condiciones precarias de trabajo en que deben desarrollar sus labores, donde todavía parece primar la noción de vocación en detrimento de los derechos del colectivo profesional. 
Esta tesis es, en parte, una indagación por estas problemáticas del presente hacia el pasado, por eso con esta escritura se pretende articular un relato sobre cómo estas tensiones entre el carácter afectivo, científico y normado por las prescripciones de género facilitaron la infravaloración de la profesión en tanto se buscaba la formación de féminas que, convocadas por sus cualidades amorosas para que cumplieran con multiplicidad de tareas educativas, de contención, seguimiento, inspección y vigilancia sobre los sectores populares, también fueran las encargadas de recavar información que sería de interés y utilidad para médicos higienistas e instituciones de atención sociosanitaria.

El proceso de formación profesional y el establecimiento de la institucionalización de la asistencia social mediante la visita de higiene tiene un claro carácter feminizante, que sirvió a estudiantes y graduadas de la EVHS UNLP como espacio profesional para la realización de otras acciones que facilitaran la educación de las mujeres madres, tal como lo exigían los médicos a cargo de la escuela y de las instituciones que las empleaban, pero también les permitía el involucramiento con proyectos colectivos por la elevación cultural de las mujeres, como el caso del Club de Madres de la UPAK, del mismo modo en que mediante la participación en los ciclos radiofónicos podían figurar una comunidad de mujeres, sus radioescuchas, a quienes presentar problemáticas, avances legislativos, beneficios para la crianza de sus hijos e hijas, e incluso ensayar afinidades y compartir desde su voz cuestionamientos políticos al ordenamiento socioeconómico. Es decir, realizaban acciones tendientes a democratizar conocimientos, tal como lo proponían los estudiantes y graduados reformistas, pero también, mediante esa operación, alentaban a la elevación cultural de las mujeres y de las propias visitadoras, que de algún modo se iban construyendo en una voz autorizada y audible para la generación de propuestas interventivas, cuestión que no sabemos si era deseada por los estudiantes reformistas y que queda pendiente para otros estudios dedicados a vislumbrar el rol de las mujeres en este movimiento universitario.

Fueron estas acciones las que delinearon posibles puntos de disidencias, cuestionamientos, del mismo modo que solidaridades, empatías e involucramiento en proyectos colectivos que han realizado las profesionales del trabajo social desde la institucionalización universitaria a través de la creación de la Escuela para Visitadoras de Higiene Social, específicamente en la ciudad de La Plata.

Ponderar y hacer emerger relatos nuevos sobre el inicio de la Escuela para Visitadoras de Higiene Social UNLP implicó el desafío de iniciar una pesquisa de intenso aliento donde dar cuenta del entramado de relaciones profesionales de los médicos y graduados 
reformistas de la universidad local, junto con una historia de las mujeres en relación a la asistencia social con antelación a la creación de una formación específica. El mayor problema para abordar este estudio fue la carencia de otros trabajos que indagaran sobre las modalidades de atención sanitaria y social de los sectores que no podían garantizar su reproducción cotidiana, como también de los informes y dispositivos de intervención con los que contaban las mujeres que llevaron adelante dichas tareas en la ciudad de La Plata.

La construcción de un archivo de estas labores, de sus modos de intervención y de organización en las asociaciones que trataron de paliar las necesidades insatisfechas fue posible gracias a distintas mujeres, que no casualmente trabajan como bibliotecarias, $\mathrm{y}$ que colaboraron en el trabajo demiurgo de encontrar a las féminas durante la primera mitad del siglo XX para trazar una primera cartografía de sus espacios y proyectos para la intervención en la vida cotidiana. Dicha cartografía dialogó con otro circuito de ideas provenientes de los documentos producidos por la burocracia universitaria, me refiero a las actas en que se trató la necesidad de creación de la EVHS como también de los debates, proyectos, ordenanzas y propuestas para la creación de la misma. En este punto quisiera aclarar que si bien el Archivo Histórico de la Biblioteca de la Facultad de Trabajo Social resulta un rico acervo documental para conocer la EVHS y tiene parte de los materiales que hacen a esta tesis, e incluso las compañeras que allí trabajan diariamente practican búsquedas constantes por reconstruir y encontrar documentos, hay un mayor cúmulo de documentación luego de la reforma de 1948. Sin embargo, fue posible hallar los mismos, en parte, en otras dependencias de la Universidad donde había funcionado la escuela. Esta desarticulación no es casual, sino que a mi entender resulta de dos elementos, por una parte, del carácter infravalorado con el que fue pensada esta profesión auxiliar que pareciera no tener la jerarquía suficiente como para poseer un archivo propio, o incluso ser parte de los anales de la Facultad de Ciencias Médicas, y por el otro, el carácter androcéntrico con que fueron seleccionados los documentos válidos y por tanto merecedores de archivos, y los referentes a cuestiones de práctica profesional de las mujeres, que con suerte se conservan en depósitos. Esta invisibilidad de las mujeres en los archivos es compartida también con otrxs sujetxs gays, lesbianas, trans, travestis e intersexuales, que al no identificarse con el varón blanco, burgués y heterosexual, máximo referente de los relatos históricos, hizo que quedaran silenciados e incluso fuera castigadxs.

Este descuido que se traduce en la no conservación documental del desarrollo de la primera etapa, implicó un desafío no solo en cuestiones de armado y rescate de los 
depósitos en que se encontraban parte de los documentos sin catalogar, sino también, en función de lograr la democratización de los mismos, es decir, que sean de acceso público para otras y otros deseosos de investigar estas cuestiones.

Resulta innegable el peso que ha tenido la palabra médica en la definición y establecimiento de contornos de la profesión, la incidencia de la eugenesia y los discursos maternalistas heterosexualizantes. La voluntad política de control y disciplinamiento de la ciencia médica hicieron que junto con las tareas que se exigía para el desempeño profesional donde versaban acciones de vigilancia, control, confesión, existiera una fuerte insistencia en validar y legitimar las acciones profesionales en función de la reproducción de las normativas de género para las mujeres. Así, mediante el análisis del proyecto de creación y la ordenanza para el funcionamiento de la EVHS, intenté demostrar el ideal de mujer profesional que pretendía la ciencia médica y que se emparentó con algunas profesiones dedicadas al cuidado y la atención, como las terapistas ocupacionales, dietistas y enfermeras. Mediante el análisis de los planes de estudio resulta evidente cómo mediante la parcialización del conocimiento se intentó reforzar el lugar auxiliar y dependiente de la autoridad médico masculina. De la misma manera, y mediante el encuentro con documentos no catalogados, como cartas del Centro de Estudiantes de Visitadoras de Higiene con la Secretaría del Liceo Víctor Mercante, o través de intercambios epistolares entre autoridades de la Facultad de Ciencias Médicas y la EVHS, pude presentar otro sustrato de la trayectoria educativa de las visitadoras de higiene social donde el peso de la moral y el disciplinamiento ejemplar formó parte de un currículo oculto de la profesión.

Más allá de la voluntad médica, mediante otros documentos fue posible reconsiderar el carácter subyugado de las profesionales a la autoridad médica. A través de la presentación de las radioconferencias y los informes técnicos de las visitadoras, podemos encontrar algunas cuestiones que dejan en suspenso, al menos momentáneamente, el poder de la autoridad galena. Desde la participación radial es posible es evidente cómo algunas de estas profesionales franquearon los límites impuestos a la soledad y abnegación esperable para su profesión, y en cambio supieron utilizar el espacio educativo radial para alentar a las mujeres al conocimiento de los beneficios que podían obtener en materia de protección a la maternidad y atención socio sanitaria para ellas y sus hijos. Además de cumplir con esas tareas prescriptas por los médicos, las visitadoras utilizaron su lugar como intermediarias sanitarias para presentar críticas al sistema sanitario de atención a las mujeres, como también para cuestionar la 
autoridad paterna y el ordenamiento familiar. Incluso, mediante discursos de orden persuasivo las visitadoras pudieron establecer una serie de críticas direccionadas a médicos y hombres de política, donde figuraron desde sus discursos, comunidades más ampliadas de reclamo para las mujeres que las oían en la individualidad de su casa y que se encontraban aun en un contexto en que la participación en la política institucional aun estaba vedada a las mujeres.

El carácter político de la participación de algunas de estas visitadoras, comprometidas con el proyecto reformista abre una línea de investigación en sí misma respecto al vínculo que tuvieron las mujeres en relación al proceso reformista y los vínculos existentes en estos grupos. Hasta el momento conocemos a pocas referentes mujeres del período, siendo Delia Echeverry la más emblemática.

Mediante este trabajo quise ponderar cómo en el proceso de institucionalización del trabajo social mediante la Escuela de Visitadoras de Higiene Social, además de llevarse adelante el interés disciplinante, de control, educación y modificación de hábitos de los sectores más desprotegidos de la sociedad, las mujeres también tuvieron la posibilidad de ser partícipes de una mayor comunidad científica y política. Estos relatos no tienen pretensiones totalizantes, ni pretenden disputar una posición de verdad respecto de si las visitadoras eran conservadoras del orden o promotoras de revueltas populares, este relato pretende poner en palabras pequeñas acciones que configuran una historia desde la cual ver el proceso de institucionalización cargado de mensajes contradictorios, acciones de agencia, compromisos políticos, intensiones persuasivas y no amorosas, que sospechan del carácter unívoco de reproducción ideológica que cumplirían las agentes del servicio social. Así, esta tesis, vigilar y hermosear enuncia las disposiciones y prescripciones médicas para el control y disciplinamiento de los sectores subalternos, como también de las mujeres profesionales en la visita de higiene, y de las mujeres madres que recibían su asistencia. Vigilar y hermosear son acciones que implicaron hacer gala de los saberes científicos, convocatoria que supuso la habilidad de mediar la posibilidad de hermosear sus acciones de cuidado y negociar los modelos de asistencia fundamentados en la construcción hegemónica del carácter feminizado de la atención y en el abaratamiento de la intervención sanitaria. Fue también la posibilidad de "hermosear su propia existencia" desde acciones quizás pequeñas para los relatos totalizantes, pero disruptivas y de agencia. 


\section{Bibliografía}

\section{Fuentes documentales:}

Revistas y periodicos:

Hoja Medica de la Casa Cuna

Revista Viva Cien Años

Revista de la Facultad de Ciencias Médicas y el Centro de Estudiantes de Medicina.

Diario El Día

Diario el Argentino

Diario La Vanguardia.

Correspondencias:

Carta de Orestes Adorni al Dr. Pilades Dezeo.

Carta de Pilades Dezeo, Director de la EVHS a Orestes Adorni, Decano de la Facultad de Ciencias Médicas UNLP. 1939.

Carta del Centro de Visitadoras de Higiene Social dirigida a la Vicedirectora del Colegio de Señoritas, 8/8/1939.

Carta de respuesta a la nota enviada por el Centro de Visitadoras de Higiene Social firmada por la vicedirectora. (Borrador de puño y letra)

Leyes y resoluciones:

Ley provincial No 2338 (1890) creación de la Asistencia Pública.

Ley $N^{\circ} 5.291$ (1908) de Reglamentación del trabajo de mujeres y niños Ley No 11357 (1926) Derechos civiles de la mujer.

Ley $\mathrm{N}^{\circ} 11933$ (1934) Protección a la madre obrera

Ley $\mathrm{N}^{\circ} 12.111$ (1934) de Licencia a empleadas y obreras antes y después del parto

Ley N 12.341 (1936) Creación de la Dirección de Maternidad e Infancia

Decreto No 12.311 (1943) Creación de la Dirección Nacional de Salud Publica y

Asistencia Social.

Ley No 13.341 (1949) Creación de la Dirección Nacional de Asistencia Social dependiente de la Secretaría de Trabajo y Previsión. 
Ley provincial $\mathrm{N}^{\circ} 4.377$ (1936) de Profilaxis de la tuberculosis

Ley Nº 4.547 (1937) Creación de la Dirección General de la Protección a la infancia

\section{Bibliografía, memorias y actas}

Actas I Conferencia Nacional de Asistencia Social (1933). Buenos Aires. Tomo I y Tomo II.

Actas de las Sesiones Consejo Académico UNLP 1937.

Aprá, O. (1942) Importancia de los factores hereditarios y ambientales. (51- 57)En

Educación Sanitaria y propaganda higiénica. Conferencias radiotelefónicas. La Plata:

Facultad de Ciencias Médicas, Cátedra de Higiene Médica y Preventiva, UNLP.

Araoz Alfaro, G. (1929) El libro de las madres. Buenos Aires: - CABAUT y CIA .

Baroude, I.(1942). El Club de Madres. (145-151)En Educación Sanitaria y propaganda

higiénica. Conferencias radiotelefónicas. La Plata: Facultad de Ciencias Médicas,

Cátedra de Higiene Médica y Preventiva, UNLP.

Betinotti, S. (1922). Situación actual de la Visitadora de Higiene en Argentina. en

Revista de la Sociedad de Higiene y Microbiología

Carbonell, M. (1924), Proyecto de creación del curso para Visitadoras de Higiene Social.

Carbonell, M. (1928) Instituto de Higiene. Organización, enseñanza, trabajos. Buenos Aires: FCM UBA.

Carbonell, M. (1929) Higiene. Epidemiología y profilaxis. Higiene Social. Buenos Aires: El Ateneo.

Carbonell, M. (1925) Función social de la visitadora de higiene. Palabras en el acto de la entrega de los certificados de estudio a las visitadoras de higiene social.. Buenos Aires: imprenta de la Universidad.

Censo de la ciudad de La Plata. Año 1910. La Plata: Talleres Gráficos.

Copani, Alfina (1942) La mortalidad materna y su profilaxis (41-50) En Educación

Sanitaria y propaganda higiénica. Conferencias radiotelefónicas. Facultad de Ciencias Médicas. Cátedra de Higiene Médica y Preventiva. UNLP, La Plata.

Daneri y Hornos, Z. (1940). Mas vale prevenir que curar. (607-614) Comisión de propaganda higiénica y educación sanitaria popular. La Plata: Liga Popular Contra la Tuberculosis de la Provincia de Buenos Aires.

Dezeo, P. (1927) Tesis sobre educación sanitaria popular. Buenos Aires: editada por el círculo médico argentino y el Centro de Estudiantes de Medicina. 
Dezeo, P. (1937) Educación Sanitaria Popular. Importancia de la extensión universitaria. La Plata: Centro de Estudiantes de Ciencias Medicas. UNLP. Dezeo, P. O. (1938) Conferencia Inaugural de los cursos de la Escuela para Visitadoras de Higiene Social. En Anales de la Facultad de Ciencias Médicas de La Plata. Estatutos de la Sociedad Protectora de la Infancia. 1905. La Plata. Talleres "La Popular”. La Plata.

Fundamentos del Proyecto de Creación de la Escuela para Visitadoras de Higiene. 1937. Universidad Nacional de La Plata. Mesa de entrada. Expte CM No 90.

Grau, C. (1954) La sanidad en las ciudades y pueblos de la provincia de Buenos Aires. Buenos Aires: Archivo histórico.

Labor comunal. Libro de cesiones del año 1937. Honorable Cámara de Diputados de Provincia de Buenos Aires.

Lopez, N. (1942) El patrimonio biológico del niño. En Conferencias radiotelefónicas. La Plata: Facultad de Ciencias Médicas, Cátedra de Higiene Médica y Preventiva. UNLP. pp. 59- 67.

Loza Colomer, J. (1966) En "Homenaje de la Cátedra de Medicina Social e Higiene al Dr Pilades Orestes Dezeo. En el 25 aniversario de su fallecimiento”. Departamento Audiovisual de la Facultad de Ciencias Médicas.

Manual del Socio de San Vicente de Paul para las Visitas a Domicilio. (1888) Buenos Aires: Imprenta de "La voz de la iglesia".

Memoria anual de la Asistencia Pública 1937 (1938). La Plata: Taller de impresiones oficiales.

Memoria anual de la Asistencia Pública. (1939)Taller de impresiones oficiales. La Plata. Taller de impresiones oficiales.

Memoria presentada a la asamblea anual por la comisión directiva respecto a la Labor Comunal realizada desde el 1 de octubre de 1936 al 31 de diciembre de 1937. Memoria. 1938- 1939. La Plata. Taller imprenta municipal. 1940.

Memoria de la administración municipal. 1936. Ciudad de La Plata. Memoria del accionar de la EVHS durante el año 1939 presentada por su director, el Dr. Pilades Dezeo, al Decano de la Facultad de Ciencias Médicas Dr Orestes Adorni. Memoria de la Sociedad Francesa de Beneficencia. 1922. La Plata: Talleres Gráficos Alfredo Crespo.

Memoria correspondiente al año 1921- 1923 de la Liga Popular contra la Tuberculosis de la Provincia de Buenos Aires. (1923). La Plata. 
Memoria de un año de labor del Club de Madres. 1944. UPAK. Departamento de la Mujer y el niño.

Memoria de 2 años de labor del Club de Madres. . Asamblea bianual de julio de 1945.

UPAK. Departamento de la Mujer y el niño.

Memoria presentada a la Honorable Legislatura por el Ministro de Obras Públicas de la provincia de Buenos Aires Dr Edgardo J. Miguez, Tomo I, 1932.

Moreau de Justo, A. (1921) Conferencia en el Tercer Congreso de Profilaxis

Antituberculosa. Revista del Centro de Estudiantes de Medicina. La Plata. No1. pp. 4446.

Moretti, H. (1940). Ahorrar a costa de la salud es comprometer el porvenir biológico.

En Comisión de propaganda higiénica y educación sanitaria popular (500-506). La

Plata: Liga Popular Contra la Tuberculosis de la Provincia de Buenos Aires.

Ordenanza de Creación de la Escuela para Visitadoras de Higiene Social. 1938.

Facultad de Ciencias Médicas . Universidad Nacional de La Plata.

Programas de Estudios de la Escuela para Visitadoras de Higiene Social. 1938. Facultad de Ciencias Médicas . Universidad Nacional de La Plata.

Programa de Estudios de la Escuela para Visitadoras de Higiene Social. 1948.

Reglamentación y programa para el examen de ingreso a la Escuela para Visitadoras de Higiene Social. 1938. Facultad de Ciencias Médicas . Universidad Nacional de La Plata. Reglamentación de la Escuela para Visitadoras de Higiene Social. 1948. Facultad de Ciencias Médicas. Universidad Nacional de La Plata.

Reglamento de la Sociedad de Beneficencia de la Plata- Año 1892. La Plata: Talleres de Publicaciones del Museo.

Reglamento del Hospital de niños, aprobado por la Sociedad de Beneficencia (1890). La Plata: Imprenta Americana de Manuel Cerdeña

Ricci, S. (1940)La tuberculosis, como se adquiere y cómo se evita. (Conferencia $n^{\circ} 80$ 21/10/1940) en Comisión de propaganda higiénica y educación sanitaria popular, Liga Popular Contra la Tuberculosis de la Provincia de Buenos Aires, La Plata.

Ricci, S (1942) Los agentes del servicio social. ( 133-140) )En Educación Sanitaria y propaganda higiénica. Conferencias radiotelefónicas. La Plata: Facultad de Ciencias Médicas, Cátedra de Higiene Médica y Preventiva, UNLP.

Ricci, S. (1945) Instituciones de protección materna infantil de la Ciudad de La Plata. En Hoja Médica de la Casa Cuna (Sociedad de Beneficencia de La Plata) Número 3. Marzo de La Plata.

Rodríguez, G. La organización higiénica de la Republica. Diario La Prensa. 31/03/1927. 
Rodríguez, G. (1952) La encuesta Social, en Principios Generales de Asistencia Social.

Editorial Universitaria. Buenos Aires. Cap. VIII, pp. 165-185.

Ruiz Moreno, Guido, Ruiz Ventue, Maria Luisa y Adam, Karma Elena (1948) “La

Visitadora de Higiene como asistente médico social”. En La revista de Medicina y

Ciencias Afines. Año X, No 8. Buenos Aires.

Sempe, M. (1969) Algo para recordar. Años 1882- 1969. La Plata

Sociedad de Beneficencia de La Plata. (1894) Relación Documentada de la traslación

del Hospital Misericordia a su nuevo Local cedido por la municipalidad. La Plata: El mercurio.

Sociedad de Beneficencia de La Plata (1924) Antecedentes y gestiones.

Sociedad de Damas de la Providencia (1927) Informe presentado por su asesor

Monseñor Federico J. Rasore en ocasión del XXV Aniversario de la fundación de la

Sociedad. La Plata

Sbarra, N.H.; Ricci, S. (1946) El Servicio Social de la Casa Cuna, en Revista de la Sociedad de Pediatría de La Plata, Año X.

Sciaini, E. (1940) Concepto general de lucha antituberculosa. Recursos económicos y profilaxis antituberculosa. (Conferencia $n^{\circ} 46$ 26/2/1940) en Comisión de propaganda higiénica y educación sanitaria popular, Liga Popular Contra la Tuberculosis de la Provincia de Buenos Aires, La Plata.

Tebaldi, N. (1940) Cómo trabaja un dispensario de lucha antituberculosa" (Conferencia $\mathrm{N}^{\mathrm{o}}$ 50, 25/03/1940), en Comisión de propaganda higiénica y educación sanitaria popular, Liga Popular Contra la Tuberculosis de la Provincia de Buenos Aires, La Plata.

Tebaldi, N, (1942) El amparo de la mujer en su condición de madre o de futura madre. En Educación Sanitaria y propaganda higiénica. Conferencias radiotelefónicas.

Facultad de Ciencias Médicas. Cátedra de Higiene Médica y Preventiva, UNLP, La Plata, pp. 23- 32.

Tonina, T. A. (1938) Elementos de higiene. Buenos Aires, El Ateneo.

Universidad Nacional de La Plata, Facultad de Ciencias Médicas. Escuela de Visitadoras de Higiene Social. Programas de Primer año. La Plata, 1948. Universidad Nacional de La Plata, Facultad de Ciencias Médicas. Escuela de Visitadoras de Higiene Social. Programas de Segundo año. La Plata, 1948. Universidad Nacional de La Plata, Facultad de Ciencias Médicas. Escuela de Visitadoras de Higiene Social. Programas de Tercer año. La Plata, 1948 
Zambosco, A. (1942). Introducción. En Conferencias radiotelefónicas. La Plata:

Facultad de Ciencias Médicas, Cátedra de Higiene Médica y Preventiva. UNLP. Zwanck, A. (1921) "La visitadora de higiene en la escuela", en El Monitor de la Educación Común. Buenos Aires: Consejo Nacional de Educación.

\section{Bibliografía:}

Adamovsky, E. 2012, Historia de las clases populares en la Argentina. Desde 1880 hasta 2003, Buenos Aires: Sudamericana.

Aguilar, P.L. (2014). El hogar como problema y como solución. Una mirada genealógica de la domesticidad a través de las políticas sociales. Argentina 18901940. Buenos Aires: Ediciones CCC.

Altable, R. (1993). El Curriculum oculto: La Coeducación sentimental. En: Educación y Género. Una propuesta pedagógica. Santiago de Chile: Ediciones La Morada.

Altamirano, C.(2013) Intelectuales. Notas de investigación de una tribu inquieta. Buenos Aires: Siglo XXI.

Antonucci, S., Beneitez, M.E.,Gabay, S., yTurconi, O. E. (2009).Radio UNLP. 85 años. 1924- 2009. La Plata: Edulp.

Armus, D (2000). El descubrimiento de la enfermedad como problema social. En Lobato, M. Nueva Historia Argentina, Tomo V. Buenos Aires: Sudamericana

Armus, D. (2007). La ciudad impura. Salud, tuberculosis y cultura en Buenos Aires, 1870-1950. Buenos Aires: EDHASA.

Arrúa, N. (2016) Modernización, comunidad y política. La historia de la carrera de Trabajo Social en instituciones de gestión pública de la ciudad de La Plata entre 1957 a 1975. Tesis de maestría. Disponible en: http://sedici.unlp.edu.ar/handle/10915/52560

Balán, J. (1991). Cuéntame tu vida. Una biografia colectiva del psicoanálisis argentino. Buenos Aires: Planeta.

Barrancos, D. (1996) La escena iluminada. Buenos Aires: Plus Ultra.

Barrancos, D. (2002). Inclusión/ Exclusión. Historia con mujeres. Buenos Aires: FCE.

Barrancos, D. (2007). Mujeres en la Sociedad Argentina. Una historia de cinco siglos. Buenos Aires: Sudamericana. 
Becerra, M. (2009).Marxismo y feminismo en el primer socialismo argentino. Enrique del Valle Iberlucea. Rosario: Prohistoria Ediciones.

Belmartino, S. (1996). Las obras sociales: continuidad o ruptura en la Argentina de los años 40. en Lobato, M. (ed.) Política, médicos y enfermedades. Lecturas de historia de la salud en la Argentina. (pp. 211-246) Buenos Aires: Biblos.

Belmartino, S. (2005) La atención medica argentina en el siglo XX. Instituciones y procesos. Buenos Aires: Siglo XXI.

Biagini, H, (comp.)(2001) La universidad de la Plata y el movimiento estudiantil. Desde sus orígenes hasta 1930. La Plata: Edulp.

Biernat, C. (2015). El proceso de centralización del Departamento Nacional de Higiene (1880-1944) En Biernat, C., Ramacciotti, K. y Cerdá, J.M.(Ed.), La salud pública y la enfermería en la Argentina. (pp.47- 83) Bernal: Universidad Nacional de Quilmes editorial.

Biernat, C. y Ramacciotti, K (2013) Crecer y Multiplicarse. La política sanitaria materno infantil. Argentina, 1900-1960. Buenos Aires: Biblos.

Bourdieu, P. (2002). "Campo intelectual y proyecto creador", en Bourdieu, P. (2002), Campo de poder, campo intelectual. Buenos Aires: Montressor/Jungla simbólica. P. 950 .

Bourdieu, P. (2005)."La ilusión biográfica" en Archipiélago (69), pp. 87-93.

Bourdieu, P. (2007) Intelectuales, politica y poder. Buenos Aires: Eudeba.

Bravo, C. y Landaburu, A. (2000) Maternidad, cuestión social y perspectiva católica. Tucumán, fines del siglo XIX, en Gil Lozano, F. et al., Historia de las mujeres en Argentina, Buenos Aires: Taurus.

Buchbinder, P. (2005) Historia de las universidades argentinas. Buenos Aires: Sudamericana.

Buschini, J. (2016). Surgimiento y desarrollo temprano de la ocupación de dietistas en Argentina, Avances del Cesor, XIII (15),135-156. Recuperado de: http://web2.rosarioconicet.gov.ar/ojs/index.php/AvancesCesor/index

Camarotta, A. (2016) Saberes médicos y medicalización en el ámbito escolar (19201940). Revista Pilquen. 19 (3), 33-51. Recuperado de: http://curza.net/revistapilquen/index.php/Sociales/article/view/153 
Campione, D. (2007). Los orígenes estatales del peronismo. Buenos Aires: Miño y Davila editores.

Carballeda, A. (2006). El trabajo social desde una mirada histórica centrada en la intervención. Buenos Aires: Espacio Editorial.

Castel, R. (2008), La inseguridad social. ¿Qué es estar protegido?, Buenos Aires: Manantial.

Castiñeiras, J. (1938) Historia de la Universidad Nacional de La Plata. La Plata: UNLP.

Cerdá, JM. (2015) Política social y salud.(2015). En Biernat, C., Ramacciotti, K. y Cerdá, J.M.(Ed.), La salud pública y la enfermería en la Argentina. (pp.19-46) Bernal: Universidad Nacional de Quilmes editorial.

Ciafardo, O. (1990) Caridad y control social: Las sociedades de beneficencia en la ciudad de Buenos Aires (1880-1930. Tesis de maestría. FLACSO.

Cisne, M. (2012) Cisne, Mirla (2012): Gênero, divisão sexual do trabalho e Serviço Social. São Paulo: Editora Outras Expressoes.

Colángelo, MA. (2001) Un abordaje del abandono infantil. El hospital zonal especializaco "Dr. Noel H. Sbarra” de La Plata. La Plata: Ediciones Casa Cuna.

Colectivo Precarias a la Deriva (2004). A la deriva por los circuitos de la precariedad femenina. Madrid: Traficantes de Sueños.

Federici, S. y Cox, N. (1975) Contraatacando desde la cocina. En Federici, S. (2013) Revolución en punto cero. Trabajo doméstico, reproducción y lucha feminista. (pp. 5170) Madrid: Traficantes de sueños.

Ferrari, M. (2008). Los políticos en la república radical: prácticas políticas y construcción de poder (1916-1930). Buenos Aires: Siglo XXI Editores

De Alba, A. (1998) Currículo: crisis, mito y perspectivas. Buenos Aires: Miño y Dávila editores SRL.

$\square$ De Luque, S. y Scaltritti, M. (2006) Una década de transición: el estado y la sociedad argentinos durante los años '30”, en Pasados presentes (pp.117-158). Buenos Aires: Dialektik.

Di Liscia, M.S. (2014). Renovación de la historia sobre instituciones, profesionales y salud. En Biernat, C. y Ramacciotti, K. (Ed.) Historia de la salud y la enfermedad. Bajo la lupa de las ciencias sociales (pp117-129). Buenos Aires: Biblos.

Di Liscia M. S. y Billorou, M.J. (2005) Cuadernos de las visitadoras de higiene. 
Fuentes para una historia regional de género. Santa Rosa: Instituto Interdisciplinario de Estudios de la Mujer, Edulpam, Cuadernos del Instituto, $n^{\circ} 2$.

Dorlin, E. (2009) Sexo, género y sexualidades. Introducción a la teoría feminista. Buenos Aires: Nueva Visión.

Eraso, Y. (2009). Mujeres y asistencia social en Latinoamérica, siglos XIX y XX. Argentina, Colombia, México, Perú y Uruguay. Córdoba: Alción.

Ehrenreich, B y English, D. (1973) Brujas, parteras y enfermeras. Una historia de sanadoras. Barcelona: La sal.

Ehrick, C. (2010). "Savage Dissonances": Gender, Voice and Woman's Radio Speech in Argenina, 1930- 1945. En Suisman, D. y Strasser, S. (Ed.) Sound in the age of mechanical reproduction, (pp. 69-93).Philadelphia: University of Pensylvania Press.

Ehrick, C. (2015) .Radio and gendered soundscape. Women and broadcasting in Argentina and Uruguay, 1930- 1950. Cambridge: Cambridge University Press.

Fernandez J. y Hernandez, D. (2014) La devolucion de las cacerolas: repreentaciones sobre la mujer en la construcción de la Nación Argentina. En Barrancos, D., Guy, D y Valobra, A. Moralidades y comportamientos sexuales. Argentina 1880- 2011. pp. 131154. Buenos Aires: Biblos.

Foucault, M. (2008). La arqueología del saber. Buenos Aires: Siglo XXI.

Frederic, S; Graciano, O. y Soprano G. (comp.) (2010). El Estado argentino y las profesiones liberales, académicas y armadas. Rosario: Prohistoria.

Freidson, E. (1978). La profesión médica. Un estudio de sociología del conocimiento aplicado. Barcelona: Ed. Península.

Gavrila, C. (2014) Algunas consideraciones sobre las implicancias del trabajo femenino en la génesis y legitimación del trabajo social (1924-1938) (En línea). Trabajo presentado en VIII Jornadas de Sociología de la UNLP, 3 al 5 de diciembre de 2014, Ensenada, Argentina. Disponible en: http://www.memoria.fahce.unlp.edu.ar/trab eventos/ev.4773/ev.4773.pdf Gavrila, C. (2016) "División sexual del trabajo, régimen político de la heterosexualidad y género. Multiplicando las categorías útiles para el análisis histórico de las mujeres". En Arias, AC y López, MD (Editores) (2016) Indisciplinas. Reflexiones sobre la práctica metodológica en Ciencias Sociales. Diálogos entre investigadores/as en formación de la UNLP, EDULP- FILOSURFER, La Plata. 
Gavrila, C. (2016) Prevenir y persuadir. La radio y las visitadoras de higiene en las décadas de 1930 y 1940 en la ciudad de La Plata. Avances del Cesor, XIII (15), 93-111. Recuperado de: http://web2.rosarioconicet.gov.ar/ojs/index.php/AvancesCesor/article/view/v13n15a05

Gavrila, C. (agosto, 2017) La "exclaustración" del conocimiento científico sobre las problemáticas de hijos y madres. El caso de las Visitadoras de Higiene conferencistas de la Universidad Nacional de La Plata (1940-1950). Trabajo presentado en XVI Jornadas Interescuelas Mar del Plata Departamento de historia. Universidad Nacional de Mar del Plata. Recuperado de:

https://interescuelasmardelplata.files.wordpress.com/2017/09/31

Gimeno Sacristán, J. (2012). “QQué significa el curriculum?”. En Gimeno Sacristán, J., Feito Alonso, R., Perremoud, P. \& Clemente Linuesa, M. Diseño, desarrollo e innovación del curriculum. Madrid: Morata.

González Leandri, R. (1998). Curar, persuadir, gobernar. La construcción histórica de la profesión médica en Buenos Aires, 1852-1886. Madrid: Consejo Superior de Investigaciones Científicas.

González Leandri, R. (2005) Madurez y poder. Médicos e instituciones sanitarias en la Argentina a fines del siglo XIX. Entrepasados. No 27, 133- 150.

González Moya, M. (ed.) (2010). Historias del Trabajo Social en Chile 1925- 2008 contribución para nuevos relatos. Santiago de Chile: Ediciones Técnicas de Educación Superior.

Graciano, O. (1999). Entre cultura y política: La Universidad Popular Alejandro Korn. 1937- 1950. Trabajos y Comunicaciones, 2da época, 71-119. n²5. La Plata.

Graciano, O. (2008). Entre la torre de marfil y el compromiso político. Bernal: Universidad Nacional de Quilmes editorial.

Grassi, E. (1989). La mujer y la profesión de asistente social: el control de la vida cotidiana. Buenos Aires: Humanitas.

Guillaumin, C. (2005) Práctica del poder e idea de Naturaleza. En Curiel, O. y Falquet, F (comp.) El patriarcado al desnudo. Tres feministas materialistas, (pp. 19-56). Buenos Aires: Brecha Lésbica.

Gudiño Cejudo, M.R. (2016). Educación Higiénica y cine de salud en México, 1925 1960. México: Colegio de México.

Guy, D. (2011). Las mujeres y la construcción del Estado de Bienestar. Caridad y 
creación de derechos en Argentina. Buenos Aires: Prometeo.

Haraway, D. (1995) . Ciencia. cyborgs y mujeres. La reinvención de la naturaleza. Barcelona: Cátedra.

Hirata, H. y Kergoat, D. (1997). La división sexual del trabajo. Permanencia y cambio. Buenos Aires. Editado por Asociación trabajo y sociedad.

Jara, J. C. y Bosaro, L. (1997). LS 11 Radio Provincia. 60 años. La Plata. Gobierno de la Provincia de Buenos Aires, Secretaria de Comunicación Social.

Karush, M. (2013). Cultura de clase. Radio y cine en la creación de una Argentina dividida (1920-1946). Buenos Aires: Ariel.

Karsz, S. (2007). Problematizar el trabajo social. Definición, figuras, clínica. Barcelona: Gedisa Editorial.

Krmpotic, C. (2002) La conferencia nacional de asistencia social. los debates en torno al progreso, a la pobreza y la intervención estatal. Buenos Aires: Espacio.

Krmpotic, C. (comp.) (2008), Cuidados, terapias y creencias en la atención de la salud, Buenos Aires: Espacio.

Lavrin, A. (2005). Mujeres, feminismo y cambio social en Argentina, Chile y Uruguay(1890-1940). Santiago de Chile: Centro de Investigaciones Diego Barros Arana.

Ledesma Prieto, N.M.F. (2016). "La revolución sexual de nuestro tiempo” El discurso médico anarquista sobre el control de la natalidad, la maternidad y el placer sexual. Argentina 1931- 1951. Buenos Aires: Biblos.

Linares, L. (2016). Matrimonios y algo más. Discurso eugénico en torno al proceso de selección de pareja. El caso de la revista Viva Cien Años. 1935-1947. Avances del Cesor, V. XIII, No 14, Primer semestre 2016, pp. 89-109. ISSN 1514-3899/ISSN 24226580. Recuperado de: http://web2.rosarioconicet.gov.ar/ojs/index.php/AvancesCesor/index

Lobato, M. (2001). La vida en la fábrica. Trabajo, protesta y política en una comunidad obrera, Berisso (1904-1970.) Buenos Aires: Prometeo.

Lobato, M. (2002) Entre la protección y la exclusión: Discurso maternal y protección de la mujer obrera, argentina 1890- 1934. en Suriano, J. La cuestión social en la Argentina 1870-1943. Buenos Aires: La Colmena. 
Lobato, M. ( 2007). Historia de las trabajadoras en la Argentina (1869-1960). Buenos Aires: Edhasa.

Lorenzo, M. F. (2016). "Que sepa coser, que sepa bordar, que sepa abrir la puerta para ir a la universidad" Las académicas de la Universidad de Buenos Aires en la primera mitad del siglo XX. Buenos Aires: Eudeba.

Lynn, T. (2016) Historicing Agency. Gender \& History. 28 ( 2), 324- 339. Recuperado de: https://onlinelibrary.wiley.com/doi/pdf/10.1111/1468-0424.12210

Mateos, R. (2008). Recordar el pasado para afirmar el porvenir. Hospital Zonal Especializado "Dr Noel Sbarra”. La Plata: Ediciones Pro Infantia.

Martín, A.L. (2015). Mujeres y enfermería. Un asociación temprana y estable, 18861940. En Biernat, C., Cerdá, J. M. y Ramacciotti, K. (Ed.), La salud pública y la enfermería en Argentina (257- 286). Bernal: Universidad Nacional de Quilmes.

Miranda, M. y Vallejo, G. (2005.) Darwinismo social y eugenesia en el mundo latino. Buenos Aires.: Siglo veintiuno.

Montaño, C.(1998) La naturaleza del Servicio Social. Un ensayo sobre su génesis, su especificidad, su reproducción, San Pablo: Cortez Editor.

Moreno, JL. (2009) Éramos tan pobres... De la caridad colonial a la Fundación Eva Perón. Buenos Aires: Sudamericana.

Nari, M (2002) El feminismo frente a la cuestión de la mujer en las primeras décadas del siglo XX. En Suriano, J. La cuestión social en la Argentina 1870-1943. pp. 277300. Buenos Aires: La Colmena.

Nari, M (2000) Maternidad política y feminismo. En Gil Lozano, F. ; Pita, V. e Ini, M.G. Historia de las mujeres en Argentina. Siglo XX. Buenos Aires: Taurus.

Nari, M. (2004). Políticas de Maternidad y Maternalismo Político. Buenos Aires: Biblos.

Oliva, A. (2007). Trabajo social y lucha de clases. Buenos Aires: Imago mundi.

Páez, O.; Villarreal, M.; Gianna, S. (comps.) (2012) Estado, formación profesional y proyectos societarios: claves para comprender el surgimiento y desarrollo del Trabajo Social en Córdoba (1930-1971). Córdoba: Espartaco.

Parra, G. (2007). Antimodernidad y Trabajo Social. Orígenes y expansión del Trabajo Social Argentino. Buenos Aires: Espacio Editorial. 
Pascucci, S. (2007) Costureras, montas y anarquistas. trabajo femeninos, Iglesia y lucha de clases en la industria del vestido (Bs. As. 1890- 1940). Buenos Aires: Ediciones R y R.

Pateman, C. (1995). El contrato sexual. México: Antrhopos/UAM.

Perez Martinez, J. E., Mujeres en la radio española (1924-1989) ARENAL, 23:1;, 35-58. Recuperado de: http://revistaseug.ugr.es/index.php/arenal/article/view/4996

Pérez Orozco, A. (2014) Subversión feminista de la economía. Aportes para un debate sobre el conflicto capital-vida. Madrid: Traficantes de sueños.

Pite, R. (2016) La mesa está servida. Doña Petrona C. de Gandulfo y la domesticidad en la Argentina del siglo XX. Buenos Aires: Edhasa.

Portantiero, JC (1978) Estudiantes y política en América Latina. 1918- 1938 el procesod e la reforma universitaria. Buenos Aires: Siglo XXI.

Pozzio, M. (2012) Análisis de género y estudios sobre profesiones: propuestas y desafíos de una diálogo posible -y alentador-. Programa Interuniversitario de historia politica.

Queirolo, G. (2010). Las mujeres y los niños en el mercado de trabajo urbano (Buenos Aires, 1890-1940). En: Recalde, H. E. Señoras, Universitarias y Mujeres (1910-2010). La Cuestión Femenina entre el Centenario y el Bicentenario de la Revolución de Mayo. Granada: Grupo Editor Universitario.

Raiter, B. (2004) Historia de una militancia de izquierda. Las socialistas argentinas a comienzos de siglo XX, cuaderno $\mathrm{n}^{\circ}$ 49, Buenos Aires: Centro Cultural de la Cooperación.

Ramacciotti, K. (2004) El Museo Social Argentino y el Primer Congreso de Población de 1940. en Sociohistórica. Cuadernos del Centro de Investigaciones Sociohistórica, La Plata, No 13 y 14.

Ramacciotti, K. (2009). La política sanitaria del peronismo. Buenos Aires: Biblos.

Ramacciotti, K. (2010) Administración sanitaria. Reformas y resultados obtenidos. 1946-1955. En Bohoslavsky, E. y Soprano, G. Un Estado con rostro humano. Funcionarios e instituciones estatales en Argentina (1880 a la actualidad) Buenos Aires: UNGS - Prometeo.

Ramacciotti, K. y Valobra, A. (2011) Modernas esculapios: acción política e inserción profesional. En Lizette, J. y Scarzanella, E. (Ed.). Género y Ciencia en América 
Latina: mujeres en la academia y en la clínica. (23-51).Madrid: Editorial Iberoamericana.

Ramacciotti, K. y Valobra, A (2015) Feminización y profesionalización de la enfermería. En Biernat, C. y Ramacciotti, K. (Ed.), Historia de la salud y la enfermedad. Bajo la lupa de las ciencias sociales ( pp. 287-313). Buenos Aires: Biblos.

Razavi, S. (2007) The Political and Social Economy of Care in a Development Context: Conceptual Issues, Research Questions and Policy Options. Ginebra: Instituto de Investigaciones de las Naciones Unidas para el Desarrollo Social.

Recalde, H. (1988). La higiene y el trabajo. Tomo I y Tomo II. Buenos Aires. CEAL.

Reitano, E. (2005) Manuel Fresco. Entre la renovación y el fraude. La Plata: ICP.

Rodríguez Enriquez, C. (2015) Economía feminista y economía del cuidado. aportes conceptuales para el estudio de la desigualdad. Revista Nueva Sociedad. no 256. 30-44. marzo abril.

Rozas Pagaza, M. (2001). La intervención profesional en relación con la cuestión social. Buenos Aires: Editorial espacio.

Rubinzal, M. (2014) Historia de la Escuela de Servicio Social de Santa Fe (1943 2013). Santa Fe, Universidad Nacional del Litoral.

Salessi, J (1995). Médicos maleantes y maricas. Higiene, criminología y homosexualidad en la construcción de la nación argentina (Buenos Aires 1871-1914). Rosario: Beatriz Viterbo Editora, Biblioteca Estudios Culturales.

Salinas Fernández, D. (1997). "Curriculum, racionalidad y discurso didáctico”. En Poggi, M. (Comp.), Apuntes y aportes para la gestión curricular. Buenos Aires: Kapelusz.

Soprano, G. (2014). Agencias estatales y procesos de configuración profesional. En Biernat, C. y Ramacciotti, K. (Ed.), Historia de la salud y la enfermedad. Bajo la lupa de las ciencias sociales (pp. 131-146). Buenos Aires: Biblos.

Scelsio, J. (2016). Reseña para la presentación de los Libros de Actas que contienen archivos históricos de los antecedentes y orígenes de la Facultad de Trabajo Social en la Universidad Nacional de La Plata. Disponible: http://sedici.unlp.edu.ar/handle/10915/53725

Scott, J. ([1986] 1996) El género. Una categoría útil para el análisis histórico. Lamas, M. (Comp), El género: la construcción cultural de la diferencia sexual. México: PUEG. 
Scott, J. (1993). La mujer trabajadora en el siglo XX. En Duby, G. y Perrot, M. Historia de las mujeres. V. IX. El siglo XIX. ( pp. 427-461) Madrid: Editorial Taurus.

Scott, J. (2001) “Experiencia”. En Revista La ventana, No.13. pp. 42-73.

Scott, J. (2011). Género: ¿Todavía una categoría útil para el análisis? en: La manzana de la discordia, Enero-Junio, vol. 6, № 1: 95-101.

Suriano, J. (2002). La cuestión social en la Argentina 1870-1943. Buenos Aires: La Colmena.

Tabet, P. (2005). Las manos, los instrumentos y las armas. En Curiel, O. y Falquet, J. (comp) El patriarcado al desnudo. Tres feministas materialistas. (57- 129) Buenos Aires: Brecha Lésbica.

Talak, A. (2005) Eugenesia e higiene mental: usos de la psicología en Argentina (19001940). En Miranda, M. y Vallejo, G. (2005.) Darwinismo social y eugenesia en el mundo latino. pp. 563- 600. Buenos Aires: Siglo veintiuno.

Terán, O. (1987). Positivismo y nación en la Argentina. Buenos Aires: Punto Sur.

Testa, D. (2012) ¡SOS Vacunas! Tensiones entre Estado y sociedad civil (1957-

1971) en Carolina Biernat y Karina Ramacciotti (editoras), Políticas Sociales.

Entre Demandas y Resistencias, Argentina, 1930-1970, Buenos Aires, Biblos.

Torre, J. C. y Pastoriza, E. (2002). La democracia del bienestar. En TORRE, J. C. Los años peronistas 1943- 1955 (pp. 257- 311). Buenos Aires: Sudamericana.

Travi, B. (2006) La dimensión técnico instrumental en Trabajo Social. Reflexiones y propuestas acerca de la entrevista, la observación y el informe social. Buenos Aires: Espacio Editorial.

Tripaldi, N. (2002) Las mujeres de la política, los niños de la calle y las bibliotecas: apostillas bibliotecológicas sobre el tema de la asociación de bibliotecas y recreos infantiles. Inf. cult. soc. n.7 Ciudad Autónoma de Buenos Aires jul./dic. 2002.

Vallejo, G. (2007). Escenarios de la cultura científica argentina. Ciudad y Universidad (1882-1955). Madrid: CSIC.

Vallejo, G (2015) Proyecto urbano y sectores populares en la génesis de La Plata. Rosario: Prehistoria.

Veron, E. (1985). El análisis del "Contrato de Lectura", un nuevo método para los estudios de posicionamiento de los soportes de los media. En Les Medias: Experiences, recherches actuelles, aplication (pp. 203-230) París: IREP.

Wittig, M. (2006) El pensamiento heterosexual y otros ensayos. Madrid: Egales. 
Zimmerman, E. (1995). Los liberales reformistas. La cuestión social en la Argentina (1890-1916), Buenos Aires: Editorial Sudamericana. 